\title{
BRITISH PLANTS THEIR BIOLOGY AND ECOLOGY
}

\section{J.F. BEVIS AND H.J JEFFERY}




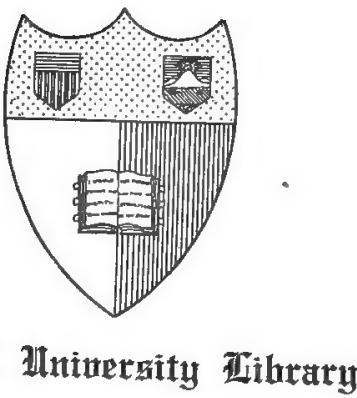
ITthara, Nour 留nek

\section{Crarnell Unturergty Tithrary}

BOUGHT WITH THE INCOME OF THE

SAGE ENDOWMENT FUND

THE GIFT OF

\section{HENRY W. SAGE}

1891

\section{RETURN TO}

\section{ALBERT R. MANN LIBRARY}

ITHACA, N. Y. 


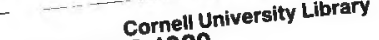
QK 47.858 1920

Drits their biology and ecology .

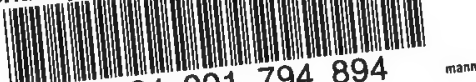

31924001794894 


\section{Cornell University Library}

The original of this book is in the Cornell University Library.

There are no known copyright restrictions in the United States on the use of the text.

http://www.archive.org/details/cu31924001794894 


\section{BRITISH PLANTS}

\section{THEIR BIOLOGY AND ECOLOGY}





\title{
BRITISH PLANTS
}

\section{THEIR BIOLOGY AND ECOLOGY}

\author{
BY \\ J. F. BEVIS, B.A., B.Sc. \\ LECTURER IN HOTANY AT THE WOOLWICK POLYTHCHNIC \\ AND \\ H. J. JEFFERY, A.R.C.Sc., F.L.S. \\ LATELY LECTURER WN BOTANY TO THE PHARMACEUTICAL SOCIETY OF \\ GREAT BRITALN
}

WITH II5 ILLUSTRATIONS

SECOND EDITION, REVISED AND ENLARGED

METHUEN \& CO. LTD. 36 ESSEX STREET W.C. LONDON 




Originally Published by Messrs. Alston Rivers, Ltd., in 1911 Second Edition, Revised and Enlarged (Methuen and Co., Ltd.), 1920 


\section{PRE F A C E}

THE object of the present volume is to fill a gap which appears to the authors to exist in the literature of elementary botany, and, however imperfectly this object has been attained, it is their hope that a sufficiently clear indication has been given to teachers and students alike of the lines upon which the interaction between the vital element on the one hand and the forces of Nature on the other may be read into the hard facts of morphology, and thus the "dry bones" of descriptive botany be " clothed with living flesh." The association of form with function, of fact with environment, and of effect with cause, provides undeniably the most efficient method of securing a real knowledge of any branch of Natural History, the study of which by this means becomes one of the highest educational value.

Botany is the most accessible of the Natural Sciences. Flowers are everywhere. They appeal to the wonder of the child, and for older folk their study and cultivation form an unrivalled hobby. To many, however, botany appears a science of hard names and still harder factsat least at the outset. The knowledge derived from the text-book is too often overburdened with detail and is therefore soon forgotten. Too much of it is concerned with the bodies, and too little with the lives, of the plants so minutely described. This should not be. There is romance and tragedy in the struggle of vegetable forms and races as among animal. Plants as well as animals constitute an aggregate of living things, the component races of which compete for mastery one against the other; plants no less than animals have a history past 'and present-a history of strife with the elements, of invasions, of colonization, of the formation of communities and associations. In the course of time they change: some perish; others give origin to new forms destined one day to displace them and, through their 
superior qualities, to win a habitation which they themselves could not retain.

The book is divided into three parts. The first part deals with fundamental ecological considerations-the factors of the physical environment-water, temperature, light, air, and soil. The second part comprises a general description of British plants examined in the light of these factors and considered as an outcome and expression of them. The third part is an attempt to present in an elementary manner the physiognomy of the British flora in its most conspicuous associations, to explain its origin and development, and to analyze its present distribution.

The matter dealt with in the third part covers a wide field, and in the present state of our knowledge only a broad survey can be attempted. This department of the science is quite a recent one; but the principles of ecological botany are now fairly well known. It only remains for the student to apply them to the interpretation of the facts of the flora of his own neighbourhood.

The book is designed as a companion to the elementary text-book and the field flora. To aid the reader, the subject-matter has been treated wherever possible in a suggestive manner, so that interest may be awakened and inquiry stimulated. With this end in view, we have been sparing of technical terms, and care has been taken to explain their meaning and to give their derivation where necessity or convenience has compelled their use.

In this new edition a rather large number of alterations and additions have been made in order to keop pace with the onward march of the subject. Some of these, it is hoped, may be of considerable interest to the reader in view of the present tendencies of economic botany and agriculture; others, on the ecological side, are due to the authors' desire to incorporate in their book some of the most important features of the work which has been done in various parts of the world since the publication of the first edition.

August, 1920. 


\title{
C O N T E N T S
}

\author{
PART I
}

THE ENVIRONMENT AND ITS INFLUENCE UPON VEGETATION

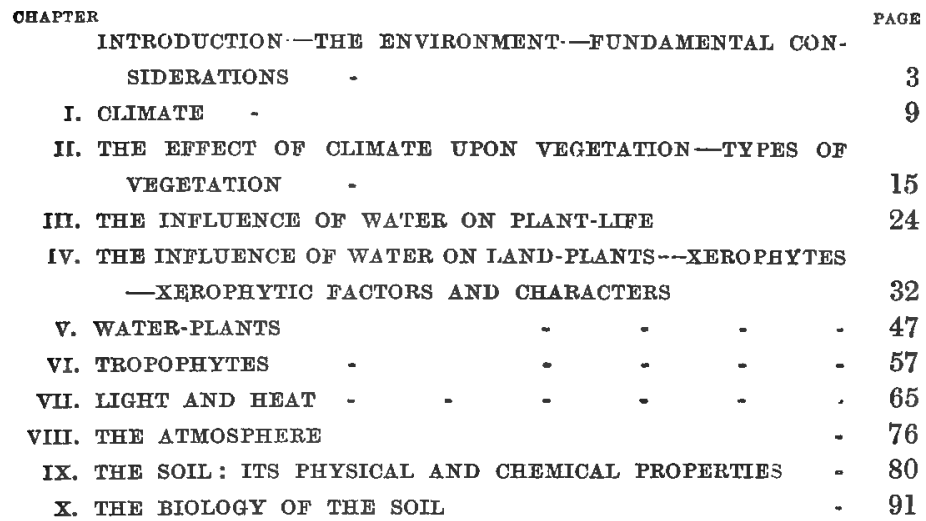

\section{PART II}

THE LIFE OF THE INDIVIDUAL PLANT-PLANT

\section{BIOLOGY}

INTRODUCTION-PLANT BIOLOGY

XI. DIVISION OF TERRESTRIAL PLANTS ACCORDING TO THEIR LONGEVITY AND FREQUENCY OF SEEDING

XII. CLASSIFICATION OF PLANTS ACCORDING TO THEIR MODF OF GROWTH

XII. OLASSIFICATION OF PLANTS ACCORDING TO THEIR MODE OH NUTRITION 
CHAPTRP

XIV. THE DEFWNSIVE EQUIPMENT OF PLANTS - 135

XV. THE STORAGE OF FOOD-RESERVES-FCONOMIC BOTANY - 145

XVI. REPRODUCTION - MODES OF VEGETATIVE REPRODUCTION 153

XVII. REPRODUCTION BY SEED-POLLINATION 162

XVII. FRUTS AND SEFDS $\quad$ - $\quad . \quad \ldots \quad \ldots$

\section{PART III}

THE BRITISH FLORA: ITS EVOLUTION AND PRESENT DISTRIBUTION

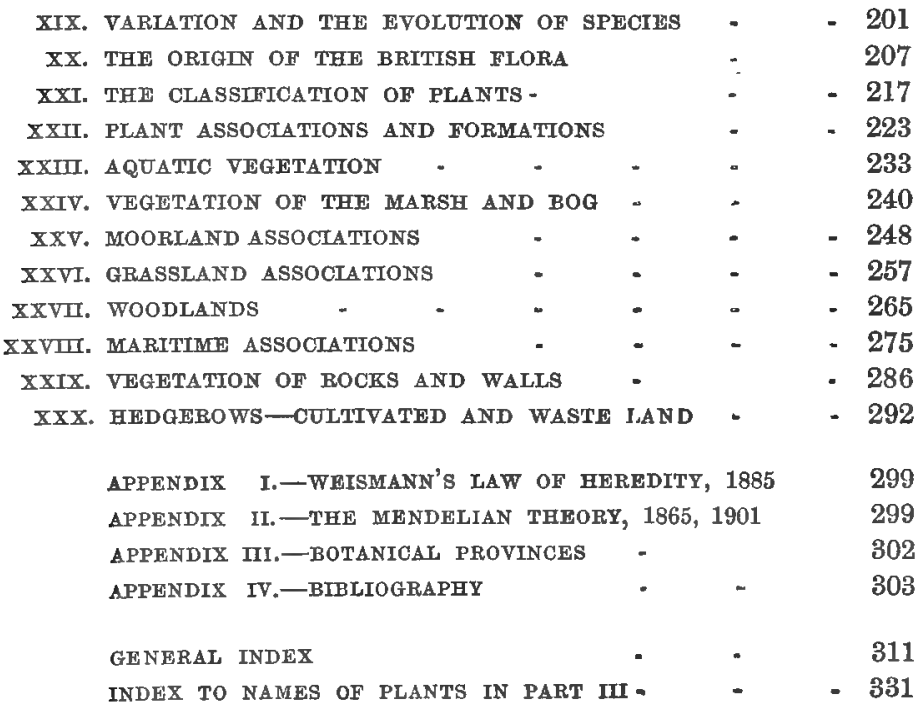




\section{LIST OF ILLUSTRATIONS}

Fia.

1. Seedling of Mustard, showing Root-Hairs - - - 25

2 Longitudinal Section of Part of a Root-Tip, showing Outer Tissues of Root and Root-Hairs, surrounded by SoilParticles - - - 25

3. Epidermis, with Stomata, from the Under Side of a Leaf $\quad$ - 20

4. Vertical Section of Part of a Leaf cut through a Stoma - 27

5. London-Pride, showing Rosette-Habit - 37

6. Cypress, showing Concrescent Type of Leaf - $\quad$ - $\quad$ - 39

7. Stonecrop (Sedum acre), showing Crowded Succulent Leaves - $\quad 39$

8. Section of Part of a Pine-Leaf, with deeply-sunk Stoma $\quad$ - 40

9. Transverse Section of Rolled Leaf of Erica cinerea - - 41

10. Salicornia herbacta (Glasswort), showing Succulent Stems and Minute Adpressed Leaves - - 42

11. Transverse Section of Rolled Leaf of the Marram-Grass (Psamma arenaria) - - $\quad 43$

12. Erica Tetralix, showing Heath Type of Leaf - 43

13. Seedling of Acacia melanoxylon, showing Transition from Ordinary Petiole to Phyllode - - 44

14. Cytisus scoparius (Common Broom) - - - - 45

15. Ruscus aculeatus (Butcher's-Broom), showing Cladodes arising in Axils of Leaves and Each bearing a Flower

10. Lycopodium clavatum (Common Clubmoss), with Small, Crowded Leaves

17. Transverse Section of Submerged Stem of Water-Violet (Hottonia palustris)

18. Formation of Brood-Bud in Potamogeton crispus

19. Hydrocharis Morsus-ranoe (Frogbit), showing Broad Floating Leaves

20. Climbing Shoot of Ivy, showing Leaf-Mosaic Sides of Stem

22. Erect Shoot of Maple, with Leaves standing out on all Sides of Stem

23. Horizontal Shont of Maple, with Leaves arranged in One Plano 
24. Leaf of Wood-Sorrel -

25. Transverse Section of Sun-Leaf of Whortleberry (Vaccinium Myrtillus) - . - - - 72

26. Transverse Section of Shude-Leaf of Whortleberry - - 73

27. Bird's-Foot Trefoil (Lotus corniculatus), showing RootNodules

28. Underground Rhizome of Couch-Grass _ - - $\quad 110$

29. Underground Rbizome of Mint - - - - $\quad$ - 110

30. Basal Part of Potato Plant - - - - - $\quad$ - 111

31. Swede, showing Tuberous Hypocotyl - $\quad$ - $\quad$ - 112

32. Kohlrabi, showing Tuberous Stem bearing Leaf-Scars $\quad$ - 112

33. False Oat-Grass (Arrhenatherum avenaceum) - 113

34. Convolvulus (Bindweed), twining Counter-Clookwise - 117

35. Hop, twining Clockwise - - - 117

36. Passion-Flower $\quad$ - $\quad$ - $\quad$ - $\quad 118$

37. Stem-Tendrils of Ampelopsis Veitchii, showing Suckers 119

38. Everlasting Pea, with Leaf-Tendrils and Winged Stem $\quad$ - 120

39. Apex of a Root invested with a Mycorhiza - 124

40. Corallorhiza innata (Coral-Root Orchid) - $\quad 125$

41. Lathrcea squamaria (Toothwort), showing Underground Shoot bearing Scale-Leaves, attached to the Roots of Hazel by Absorbing Suckers

42. Cuscuta (Dodder) growing on Hop $\quad$ - 128

43. Mistletoe attached by Haustoria to Branch of a Tree, Both seen in Section . $\quad$ - $\quad$ - $\quad$ - $\quad 129$

44. Drosera longifolia (Sundew) - - $\quad$ - 130

45. Pinguicula vulgaris (Butterwort) - - 131

46. Utricularia vulgaris (Bladderwort), showing Bladders on Submerged dissected Leaves and absence of Roots - 132

47. Acorn with Hard Cupule - 137

48. Edible Chestnut, with Three Nuts enclosed in Spiny Cupule - 137

49. Stem of Barberry with Leaf-Spines 141

50. False Acacia (Robinia Pseudacacia) with Spiny Stipules 141

51. Stinging Hair of Nettle - 141

52. Longitudinal Section of Albuminous Seed of Onion - $\quad 146$

53. Four-Seeded Drupe of Holly - $\quad 147$

54. Longitudinal Section of Albuminous Seed of Poppy 147

55. Longitudinal Section of Fruit of Garden Nasturtium, showing $\begin{array}{llll}\text { Exalbuminous Seed } \quad \text { - } & \text { - } & \text { - } & 147\end{array}$

56. Runner of the Strawberry - - - $\quad$ - $\quad$ - 155

57. Sucker of Elm $\quad$ - $\quad$ - $\quad$ - $\quad$ - 155

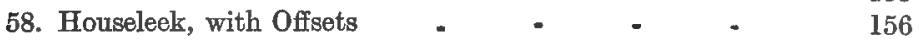



60. Narcissus Bulb cut longitudinally - $\quad-\quad \quad-\quad$ - 157

61. Crocus Corm in Resting Condition, with Enveloping Scale-

Leaves removed to show Solid Stem $\quad$ - $\quad$ - $\quad 158$ 
FIG.

62. Longitudinal Section of the Bud shown in Fig. $61 \quad-\quad-158$

63. Young Croous Corm, with Thick, Fleshy, Contractile Root - 159

64. Radical Leaf of Cuckoo-Flower (Cardamine pratensis), showing Formation of New Plantlet on Terminal Leaflet 160

65. Poa alpina, showing Replacement of Flowers by Viviparous Plantlets

66. Diagram of Flower at Time of Fertilization

67. Convolvulus sepium : Longitudinal Section of Flower $\quad$ - 169

68. Flower of Geranium, with Sepals and Petals removed to show Honey-Glands

69. Petal of Buttercup with Nectary at Base - $\quad$ - 170

70. Fennel : Longitudinal Section of Flower - - $\quad-170$

71. Monk's-Hood : Longitudinal Section of Flower - $\quad 171$

72. Christmas Rose (Helleborus) - $\quad$ - 172

73. Inflorescence of Cuckoo-Pint (Arum maculatum) $\quad 175$

74. Longitudinal Section of Unfertilized Flower of Aristolochia - 176

75. Diagram of Raceme - - - $\quad 179$

76. Diagram of Corymb - . $\quad$ - $\quad$ - $\quad$ - $\quad 179$

77. Diagram of Spike $\quad 180$

78. Willowherb: Longitudinal Section of Flower, showing Long, Stalk-like Inferior Ovary - $\quad$ - 180

79. Diagram of Cyme - $\quad$ - $\quad$ - 181

80. Diagram of Head (Capitulum) $\quad$ - $\quad$ - 181

81. Diagram of Compound Umbel - - $\quad$ - 182

82. Achene (Cypsela) of Dandelion - - - $\quad$ - 186

83. Samara of Ash - . $\quad$ - $\quad$ - $\quad$ - 187

84. Nut (Acorn) of Oak-Tree - . - - $\quad$ - $\quad-187$

85. Fruit of Edible Chestnut - $\quad$ - $\quad$ - $\quad$ - $\quad-187$

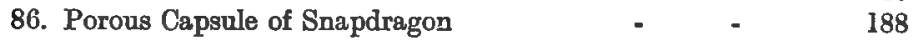

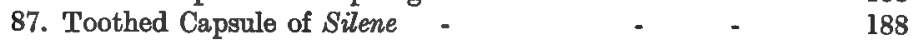

88. Capsule of Scarlet Pimpernel, splitting transversely - 188

89. Capsule of Iris, splitting longitudinally - $\quad-189$

90. Legume of Orobus, split down both Seams - $\quad$ - $\quad 189$

91. Lomentum of Sainfoin $\quad$ - $\quad 189$

92. Group of Three Follicles of Monk's-Hood, split down One Seam only

93. Siliqua of Mustard, showing the Two Valves split away from Central Partition $\quad$ - $\quad$ - $\quad$ - $\quad$ - $\quad 190$

94. Double Samara of Sycamore 191

95. Schizocarp of Stork's-Bill (Erodium), showing Mericarps splitting away from Central Pillar 191

96. Schizocarp (Cremocarp) of Fennel, showing the Two Mericarps split apart - $\quad * \quad+\quad * \quad-192$

97. Schizocarp of Mallow - - - 192

98. Drupe of Peach cut longitudinally - - - - $\quad$ - 192

99. Fruit of Gooseberry $\quad$ - $\quad$ - $\quad$ - 193 
100. "Pseudocarp" of Strawberry _ _ _ _ _ - 193

101. Multiple Fruit of Mulberry - _ _ _ _ $\quad$ - 193

102. Fruit of Fig - - - $\quad$ - $\quad-194$

103. Achene (Cypsela) of Thistle - - - $\quad$ - $\quad-195$

10.4. Achene of Clematis with Feathery Style - - - $\quad$ - 195

105. Debisced Capsule of Violet $\quad-\quad-197$

106. Achene of Avens (Geum), with Hooked Style $\quad-\quad-197$

107. Achene (Cypsela) of Bur-Marigold (Bidens) $\quad 197$

108. Section of Soil in a Wood, showing Stratification of Plants 228

109. Hydrocharis Morsus-ranae (Frogbit) - 238

110. Isoëtes lacustris (Quillwort) $\quad 239$

111. Map of a Wood, showing Distribution of Trees 266

112. The same Wood as in Fig. 111, showing Distribution of Bracken $\quad$ - - $\quad 267$

113. Salicornia herbacea (Annual Glasswort). - 278

11. Carex arenaria, with Rhizome near Surface of Sand - $\quad$ - 280

115. Tuberous Stem of False Oat-Grass - _ - - $\quad 297$ 


\section{PART I}

THE ENVIRONMENT AND ITS INFLUENCE UPON VEGETATION 



\section{BRITISH PLANTS :}

\section{THEIR BIOLOGY AND ECOLOGY}

\section{INTRODUCTION}

THE ENVIRONMENT-FUNDAMENTAL CONSIDERATIONS

THE study of plants in relation to their natural surroundings or environment is known as Plant Ecology (Gr. oikos, a home).

Every plant which lives and succeeds in reproducing itself may be regarded, on the one hand, as an efficient machine, satisfactorily performing its various physiological functions; and, on the other, as an organism adapted to, or in equilibrium with, its environment. Otherwise it would perish and leave no descendants behind. Again, when we examine any association of plants living together under much the same conditions, a wonderful diversity of form, habit, and growth meets our eyes; and, seeing that each plant in this association is a successful unit in the battle of life, we are driven to the conclusion that not only is it adapted to its environment, but that this adaptation is reached in many and various ways.

These three considerations-namely,

(1) That a successful plant is an efficient machine ;

(2) That it is in equilibrium with its environment;

(3) That this adaptation is reached in many different ways

- lie at the root of Plant Ecology, and form the basis upon which our knowledge of the vegetable population of the globe has been founded. 
In dealing with environment we have three things to consider :

1. The items or factors of the environment which affect vegetation (Part I.).

2. The effect of these factors upon

(a) The vegetative,

(b) The reproductive parts of plants (Part II.).

3. The results of competition among plants, for the satisfaction of their needs, as also between plants and animals in the general struggle for existence. The results are expressed in the flora just as we find it anywhere to-day (Part III.).

As the first part of the book is devoted to those factors of the environment which influence vegetation, we will survey them briefly first, leaving details to future chapters.

\section{A. SOLAR ENERGY.}

The sun is the ultimate source of all terrestrial energy; its rays illumine as well as warm. We have therefore to consider the solar energy which is poured upon the earth, under what appears to us its two manifestationslight and heat. To the plant, however, these two manifestations are one-it is simply energy.

\section{Light.}

The world of green plants owes its existence to light. In the presence of light, the green cell combines the carbonic acid gas which it receives from the air with the elements of water derived from the soil to form substances like starch and sugar. The process is known as photosynthesis (Gr. photos, light; synthesis, a putting together), or carbon-assimilation. The term assimilation bas rather a wide meaning in plant physiology; but it always implies making or building up. In its wide sense it embraces not only all those processes which, as a result of vital activity, lead to the construction of food, but also those less known and even more wonderful processes by which, step by step, food itself is trensformed into 
living flesh. In botany, however, assimilation is generally used in a more restricted sense, being limited to those processes which result in the production of nutriment only. Starches and sugars belong to a group of bodies called carbohydrates, the simplest and most widely distributed of the food-stuffs. In plants they form the starting-point of all the other kinds of food. When we recognize that the vegetation is the ultimate source of food for the whole of the animal kingdom, and that the starting-point of food-production in plants is carbohydrate, we begin to realize the importance of that kindly light without which this earth would be a dead and uninhabited world.

Classification of the Primary Food-Stuffs.-The constituents of food are divided into three classes:

1. Carbohydrates (e.g., starches and sugars).-These are organic compounds of rather simple chemical composition, containing the elements carbon, hydrogen, and oxygen. They owe their existence to the green cell of the plant, which is the ultimate source of all the carbohydrates in nature.

2. Proteins.-These are substances of complex chemical composition, and, in addition to carbon, hydrogen, and oxygen, they contain nitrogen and sulphur, and, in some cases, phosphorus. The source of the carbon is a carbohydrate, while the nitrogen, sulphur, and phosphorus are derived from mineral salts present in the soil and absorbed by the roots in solution in water. The construction of proteins is carried on chiefly in the leaf and at the points of growth, and is not directly dependent upon light. They are utilized in growth, and form the raw material out of which the living protoplasm is made. Proteins occur in all plant and animal tissues-e.g., as albumin in white of egg, gluten in flour, casein in milk and cheese; lean meat is a mixture of proteins.

3. Fats and Oils.-These contain carbon, hydrogen, and oxygen, but the proportion of oxygen present is less than in carbohydrates. They occur in plants chiefly as food-reserves in fruits and seeds, and are very rarely rroduced as the result of photosynthesis.

Unlike plants, animals can make no food; all that they receive they obtain directly or indirectly from the vegetable world. Green plants which absorb solar energy are 
known as autotrophic, or self-nourishing; plants which are not green, and all animals, except a few of the very lowest, are heterotrophic - that is, they derive their food from without. These external sources of food may be either living or dead. Organisms living on rotting organic matter-e.g., animal or plant remains-are called saprophytes; those which prey upon living bodies, parasites. In either case the ultimate source of food is the green plant.

\section{Heat.}

Life is impossible without a certain degree of warmth. Within certain limits, the activity of all the vital or physiological functions exhibited by plants-viz., assimilation, respiration, absorption, transpiration, growthincreases with a rise of temperature and decreases with a fall. It is therefore through the variation in the activity of these functions that we observe the effects of heat and cold upon plants (Chapter VII.). The general character of the vegetation everywhere is largely determined by the climate; heat is one of the fundamental factors of climate (Chapter I.).

\section{B. THE ATMOSPHERE.}

The air is the second great factor of the environment. Land-plants are immersed in it; it dissolves in water, and so reaches water-plants. In dealing with the relations between plants and the atmosphere we have to deal with

1. The chemical effects of air upon plants.

2. The physical effects of air upon plants.

\section{The Chemical Effects of Air.}

The air is a mixture practically of three gases-oxygen $(20.8$ per cent.), nitrogen $(79 \cdot 10$ per cent.), and carbonio acid gas $(0.035$ per cent.) -all of which are, directly or indirectly, of vital importance to plants. A varying amount of water-vapour is always present, as well as dust and impurities and traces of rare gases.

(a) Water-Vapour.-The other constituents of the air remain very nearly constant, but the amount of water- 
vapour present varies considerably at different times and in different places. Atmospheric moisture plays an important rôle in climate (Chapter I.).

(b) Carbonic Acid Gas.-This is a compound of carbon and oxygen $\left(\mathrm{CO}_{2}\right)$. The amount of the gas present in the air is small, but the importance of this quantity is manifest when we consider that it forms the ultimate source not only of all food, but also, perhaps, of every other organic compound in nature. We have already referred to the rôle played by carbonic acid gas in photosynthesis. In this process, carbonic acid gas is withdrawn from the air, its oxygen is liberated as a gas, and its carbon fixed in the starch which is produced. The energy required to carry out the process is obtained from sunlight. In spite of the fact that carbonic acid gas is continually being withdrawn during photosynthesis, the quantity present in the air remains constant. This is because the atmospheric supplies are always being replenished from other sources-e.g., respiration (Chapter VIII.).

(c) Oxygen.-All living things breathe, plants and animals alike. During respiration oxygen is taken in, food is destroyed, and carbonic acid gas given out. The nutritive body most commonly destroyed in this way is starch, and in this case the process is the reverse of photosynthesis. Energy is imprisoned in food. When food is broken down by respiration, energy is liberated, and becomes available for the performance of physiological work. The part played by oxygen in the process is chemical; it attacks nutritive substances and breaks them down into simpler bodies, one of which is always carbonic acid gas. Oxygen, therefore, plays the part of an energy-liberator, and, with rare exceptions, energy in living bodies is liberated in no other way.

(d) Nitrogen.-Atmospheric nitrogen is of no direct use to ordinary plants, which derive their nitrogenous supplies from mineral salts present in the soil. But all the nitrogen fixed in the soil has been ultimately derived from the atmosphere. This interesting problem of nitrogenous circulation is considered in Chapter $\mathbf{X}$. 


\section{The Physical Effects of Air.}

Of these the most important in relation to plants are: (a) The effects of air in motion-i.e., wind (Chapter VIII.), and-

(b) Its rate of diffusion through perforated membranes, such as exist in plants in the form of surfaces pierced with small holes or stomata.

\section{THE SOIL.}

The earth, or edaphic factor, is the third great factor of the environment. The soil is the medium in which the great majority of plants are fixed, and from which they draw all the materials necessary for nutrition, excepting only the carbonic acid gas required for photosynthesis and oxygen for respiration.

The soil is considered under the following heads :

(a) The physical and chemical properties of the soil (Chapter IX.).

(b) The relations of soil to water (Chapter IX.).

(c) The decaying organic matter in the soil-humus (Chapter X.).

(d) The biology of the soil (Chapter X.).

of all the factors in the environment water is the most important. It leaves a stamp upon the vegetation that no other factor does. A large portion of Part I. is concerned with the relations between plants and water.

Such, briefly summarized, are the five ecological factorg of the environment-light, heat, water, air, and soil. Each is treated in detail in the chapters following. 


\section{CHAPTER I}

\section{CLIMATE}

USED in a wide sense, the term vegetation may be applied to the general appearance of an aggregate of plants as it is viewed in a natural scene. Thus conceived, the vegetation forms a constituent feature of the landscape. Most of us have derived from pictures some idea of the great differences that exist in the vegetation in different parts of the world, and it is not difficult to associate these differences with the climate. Thus the prairies are great plains covered with grass, but the prairie is - A-dry region upon which trees cannot grow. A large part of Mexico is a semi-desert, the stony soil of which is sparsely studded with queer-looking fleshy plants, called cacti. The plains of the Amazon and the Congo are covered with great tropical forests, in which the vegetation is most luxuriantly developed, but these regions are very hot and among the rainiest in the world. From these and similar examples, it is easy to infer that a close relation exists between the vegetation of a district and the climate. We will consider how close this relation is, after we have examined the various external factors which influence and determine climate.

\section{CLIMATIC FACTORS.}

These may all, on analysis, be expressed in terms of two factors of the environment:

I. Heat.

II. Humidity.

\section{Heat.}

The only heat received by the earth which has any effect upon climate is that which is derived from the sun. 
The effect of solar heat upon climate may be considered in two relations :

1. Latitude.-As we recede from the Equator to the Poles, the sun's rays reach the earth in an increasingly slanting direction. In consequence of this, the heat received from the sun gradually diminishes in effect, owing to the spherical shape of the earth's surface, and the losses sustained by the rays having to pass through increasing thicknesses of air. The Tropics occupy a belt about the Equator, and within this belt the sun is directly overhead twice every year. Here, therefore, there is no alternation of seasons corresponding to our idea of summer and winter, and consequently there is no such break in the period of vegetative activity as that which is so familiar to us-when flowers are nowhere to be seen, when seeds lie dormant, and trees have discarded their summer foliage.

In the Tropios the "winter "temperature is but a few degrees lower than the "summer" temperature, and the vegetation is always green. There may, however, be another kind of seasonal alternation, depending, not, as summer and winter, upon the variations of heat received from the sun, but upon the supply of water received in the form of rain-that is, wet and dry seasons may alternate. In some parts of the Tropics this alternation occurs with great regularity, and if the dry season is long and very pronounced, a break in the vegetation may be produced, which is very similar in its effects to that which occurs in winter in northern latitudes-e.g., in the Caatinga forests of the Brazilian plateaux. In the Tropics, therefore, dearth of water has the same effect in arresting the activity of the vegetation as cold in northern winters.

In regions outside the Tropics, a regular alternation of seasons occurs, and, in consequence, that break in the vegetation known as the winter-rest. In proportion as we recede from the Tropies, the winters increase in duration at the expense of summer, and not only do the summers become shorter, but the sun's power during the daytime becomes less effective, the only compensation for this being the increasing length of the individual day as we approach the northern limits of vegetation. 
2. Altitude.-The temperature falls as we rise above the sea-level just as it falls as we recede from the Tropics. In consequence of this, the succession of vegetation up a mountain is much the same as that which we observe as we proceed along the earth's surface from the Equator to the Poles.

\section{Humidity.}

Water has a high capacity for heat; in other words, it takes a relatively large amount of heat to raise its temperature one degree; it is slow to get warm and slow to cool. This fact has an important bearing upon climate, for where there is a great deal of water-vapour present in the air, the variations and extremes of temperature are not so marked as in the case of a dry atmosphere. The climate is more equable, the summers being cooler and the winters milder than in drier countries; nor does the night-temperature differ so greatly from the day.

1. Rainfall.- This is by far the most important factor in climate, and as we are here concerned with the effects of rain on vegetation, the following considerations with respect to the rainfall become very important :

(a) The actual number of inches of rain falling in a year. The effect of this varies with the temperature. In a hot country a much larger rainfall is necessary to serve the needs of the vegetation than in a cold country ; for example, the minimum amount of rain necessary to maintain forest will not be the same in all latitudes. In dealing with climatic effects, heat and moisture must always be considered together.

(b) The frequency of rainy days. This is more important than the actual quantity of rain which falls in a year. Occasional torrents, however heavy, influence climate, and therefore vegetation, far less than precipitations, which, though less in quantity, are more evenly distributed throughout the season.

(c) The season of greatest rainfall. Rain falling during the season of vegetative inactivity is largely lost to vegetation. Most rain should fall when the vegetation needs it most-that is, in summer.

2. Proximity to the Sea.-Countries near the sea generally enjoy a mild and moist climate, especially when the winds that reach them come laden with moisture 
picked up in their journey over a wide stretch of sea. This oceanic type of climate prevails over western Europe and the British Isles. Owing to the humidity of the atmosphere, the winters in these regions are mild and the summers cool. Regions remote from the sea have a continental type of climate, in which the dryness of the atmosphere leads to extremes of temperature, the summers being very hot and the winters very cold: such is the climate of Russia and the interior of Canada.

3. Proximity to Highlands and Mountain Ranges.Highland masses cool the air-currents, and much of their contained moisture is consequently condensed to liquid water, and falls as rain. There is a "wet" and a "dry" side to mountain chains; the side facing the direction of the prevailing winds is wet, for the aircurrents, following the rising gradients of the ground, become cooled and gradually damper, the excess of moisture falling as rain ; as the currents descend on the other side, they become warmer and drier. Places situated on the "lee" or dry side are said to lie in the rain-shadow of the mountains. A good example of this is Bray, a watering-place near Dublin, which lies in the rain-shadow of the Wicklow Hills. Though on the seacoast, it is one of the driest spots in Ireland. In the same way, the desert of Atacama is a rainless region lying along the coast of Chili in the rain-shadow of the Andes.

Elevated plains, especially when they are very extensive, as in Spain and India, are usually very dry, and subject to wide extremes of temperature. The winds that blow over them lose most of their moisture while they are ascending the flanks. The latter, being exposed to the falling rain, are richly clothed with vegetation, whilst the plateaux themselves are grassy plains or semi-deserts.

4. Direction of the Prevailing Winds.-If these have passed over a broad expanse of water, they will be moist; if, on the other hand, they have travelled over a great land-surface, they will be dry. Again, winds blowing from the north are cold and dry, while those which come from the south are warm and moist. North winds blowing southwards must gradually become warmer, and, if at the same time they are travelling over a wide-land- 
surface, they must also become drier. We perceive this well enough in the case of our own east winds.

5. Ocean-Currents.-These have a marked influence on climate. The Gulf Stream spreads as a drift over the surface of the North Atlantic Ocean, moving in a northeasterly direction towards the shores of Western Europe, to which it brings the stores of heat and moisture which it has drawn from tropical seas. The climatic effect of the Gulf Stream is, however, mainly attributable to the winds that accompany it in its long journey from the Tropics. Owing to the presence of these winds, the fiords of Norway are free from ice all the winter, even up to the Arctic Circle, while on the other side of the Scandinavian Mountains, the Baltic Sea, exposed to the dry cold winds of Northern Russia, is frozen over for several months in the year.

6. Presence of Clouds and Fogs.-Where these constitute a characteristic feature of the climate, the weather is raw and cold. Clouds and fogs form an effective barrier to the sun's rays, and the soil, thus screened, loses much of the warmth that otherwise would reach it. Scotland is, for the most part, such a country. Holland, too, is cold and foggy. In Tierra del Fuego, in certain oceanic islands like the Falklands, and in the lonely island of Kerguelen in the Indian Ocean, the sun is rarely visible through the clouds.

7. The Destruction of Forests.-Even in nature, forests may occasionally be destroyed by fire, but in most cases their disappearance is due to their deliberate removal by man. As a result, the atmosphere in these localities has become drier; on sloping ground the rain runs off instead of soaking in; the soil gets washed away; and the fertility of the land is destroyed. On the other hand, afforestation tends to increase humidity and restore fertility to the whole district. Thus, between 1863 and 1878 , trees were planted on 19,500 acres of barren land on the stony slopes of Ventoux, in Provence, France. These forests yielded $£ 2,800$ a year in 1911 , a sum which was expected to increase to $£ 3,600$ in five years' time. But far more important than this is the accompanying statement that "springs have reappeared, the lower lands have increased in value, and the village proprietors have found themselves suddenly enriched." 
8. The Nature of the Soil.-From a purely climatic point of view, the soil is not important, but ecologically it is important because it forms the abode of the vegetation. Climate may determine in broad outlines the geographical aspects of the vegetation, but the diversity of the flora in particular areas is the result, not of differences in the climate, but of differences of interaction between soil and climate. What these interactions are will be made plain when we have considered the properties of the soil, and the relations of the various kinds of soils to the available supply of heat and moisture (Chapter IX.). 


\section{CHAPTER II}

THE EFFECT OF CLIMATE UPON VEGETATION-TYPES OF VEAETATION

THE two most important factors in the plant's environment are climate and soil. In the preceding chapter we considered one of these-climate-and we showed that the type of climate anywhere prevailing may be expressed in terms of two external agencies, variously combined-heat and moisture.

Types of climate operate over wide areas, and if it is true that the character of the vegetation varies with the climate, it should be possible, in some rough way at least, to distinguish broad types of vegetation, just as it is possible to distinguish broad types of climate. Let us see how this may be done.

If one were able to survey the vegetation of a country as a whole, viewing it from a distance, so as to see its broad outlines without being disturbed by details, what are the types which would stand out most conspicuously? It would not require great powers of observation to give an answer. One person might say woodland, grassland, desert. To these another might add marshes, and another heath.

These are types of vegetation regarded as aspects of scenery, but how far is it possible to associate them with definite conditions of climate? A marsh is wet, woodlands are generally damp, and grasslands dry; heath is very dry, and deserts are almost rainless. But there are two types of grassland-one, meadow-land, which is wet; and the other, pasture or prairie, which is dry. The term "woodland " is still more vague, since it includes several types easily distinguishable from each other. For example, there are evergreen woods and deciduous 
woods, and of evergreen woods there are several types, each characterized by a special kind of climate. Thus we have the evergreen rain-forests of the Tropics, with a climate exceedingly hot and moist; the coniferous evergreen forests of Northern Russia, where the climate is cold and dry ; and the evergreen dry-woods of Southern Europe, where the climate is dry and warm.

We seo from this that the physiognomic groups into which we have divided the vegetation (woodland, grassland, heath, etc.) are only in part associated with definite types of climate. A nearer approach to a clin atic grouping is obtained if we split up the physiognon ic groups into subdivisions founded upon climatic differences, thus :

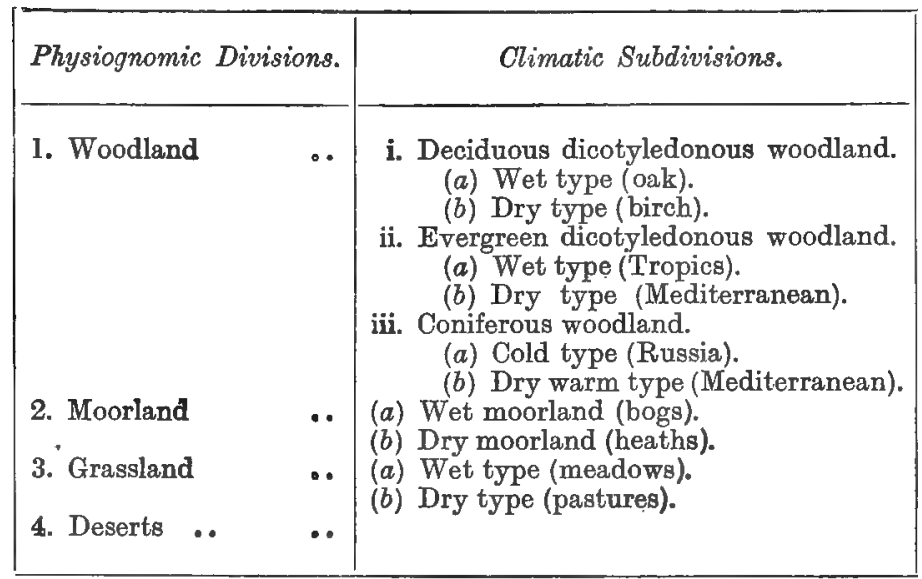

In this country the only natural deserts we have are sea-beaches and sand-dunes. The desert is an open type of habitat, containing many bare spots where plants are practically free from competition. Artificial open habitats are produced in cultivated fields and waste places frequently disturbed by man. When the ground is fully occupied by plants, the habitat is said to be closed, and where this has happened, a stable community of plants or associations of plants is established.

The number of physiognomic divisions into which vegetation may be divided is, of course. a matiter of 
choice ; the same is true of the climatic divisions. Neither of the divisions, however, is very satisfactory from an ecological point of view. A proper ecological grouping must be based on something more than climate. It should take into consideration not one factor of the environment, however important, but all the factors, both of soil and climate, which influence vegetation, and lead to the establishment of plant-communities in definite habitats.

There is no sharp line dividing one type of vegetation from another, any more than there is a sudden change from one climate to another. Woodland, for example, gradually merges into heath, moor, or grassland, while the transition from the grassland to the desert is almost imperceptible.

In temperate regions like our own, some 25 to 30 inches of rain are required annually for the maintenance of permanent natural forest, and as we approach the Tropics the amount increases. When this minimum amount is not reached-i.e., when the soil is too dry for foresttree-growth becomes diminished, and gradually gives way to grass. Park-land or savannah is grassland, interrupted with trees and woods, the latter occurring generally in the wetter parts, and frequently marking the line of the watercourses.

With the increasing dryness of the soil, stunted and thorny bushes make their appearance, constituting in some regions (Australia, South Africa) definite communities of scrub or bush; tussocks of hard, wiry grasses imperfectly clothe the soil, and as the moisture further diminishes, the vegetation gradually disappears, the bare places increase, until in the "desert" only a few specially equipped plants are able to eke out a precarious existence, and break the uniformity of the bare earth.

Again, when we ascend the mountains of Scotland or Wales, the trees vanish from every exposed spot, and the great shoulders of the uplands are covered with dreary stretches of bog, moor, and heath. The rainfall is heavy, but the soil is cold; covering the rock-surfaces are vast accumulations of peat, which has its own characteristic vegetation, giving a definite stamp to the scenery.

These illustrations give us some idea of the influence of climate upon the vegetation. The most important 
factor is the water-supply, the next is the temperature. The amount of water available to a plant affects its nutrition, the temperature affects its vital activities. The two things together constitute the climatic surroundings of the plant.

At this stage, and especially as we are chiefly concerned with our own country, it is advisable to draw attention to the influence of man upon the vegetation of the land upon which he has settled. Experience has taught him from the earliest times the importance of water upon the fertility of the soil, and by regulating and controlling the water-supply-- that is to say, by drainage and irrigation-he has modified the face of the land to meet his requirements. Bogs have been drained, moor and heath reclaimed; forests have fallen beneath his axe, and vast tracts of country, previously incapable of yielding crops, have been brought into profitable cultivation. Man, however, modifies the vegetation only through the soil-factors. By removing or planting forests, he may modify the humidity of the atmosphere (p. 13), but otherwise he has no control over the climate.

\section{The Cultivation of Food-Produets in the British Isles.}

This is an interesting and instructive subject, and we touch upon it briefly because it is an excellent illustration of the work of man in regulating and modifying the vegetation.

The land of Great Britain may for the present purpose be divided into three main regions :

1. Uncultivated Land, including alpine regions, moors, heaths, lowland-swamps, and natural pastures.

2. Woodland.

3. Cultivated Land :

(a) Arable Land-(i.) In which wheat can be grown.

(ii.) In which wheat cannot be

(b) Pasturesgrown.

(i.) Permanent pastures.

(ii.) Pastures under clover and grasses in rotation.

Most of the cultivated land was at one time covered by forest. Forest-soil, if properly drained, is naturally 
fertile, because of the relatively large amount of humusi.e., rotting plant and animal remains-present in it. Some cultivated land has, however, been reclaimed from moorland and fen, and some even from the sea.

Arable land is, as the name implies, land under the plough, and is utilized for the raising of crops. The nature of the crops raised depends, in the first place, upon the climate; secondly, upon the soil ; and, lastly, upon the conventional needs of the resident community or the demands of neighbouring or distant profitable markets.

By cultivation, man so modifies the soil-factors that the soil itself plays a part vastly inferior to that of climate in deciding the most suitable crop for a locality. Indeed, under the methods of modern agriculture, the nature of the soil is quite a minor matter, granted, of course, a certain minimum of fertility. For this reason the great cereal crops like wheat, maize, and oats grow on all kinds of soil within limits which are climatically determined. The water-supply dominates all other factors in cultivated soils.

\section{Agriculture and Farming in the British Isles.}

1. Wheat.-In this country wheat can only be grown with profit-at least, under present agricultural methods -where the mean summer temperature during the ripening of the ear is greater than $56^{\circ} \mathrm{F} .\left(13^{\circ} \mathrm{C}\right.$. $)$, and the rainfall is less than 30 inches annually. These limiting factors readily determine the range of wheatcultivation in the British Isles. They exclude most of the upland slopes over 500 feet, large parts of the West of England, all Wales, and most of Scotland and Ireland. In countries like ours, where the winter is not severe enough to destroy the seedlings, wheat is usually sown in the autumn. In Canada, on the other hand, where the ground is frozen hard for several months, it is sown in the spring, as soon as the snow has disappeared and the ground is sufficiently thawed to be broken by the plough.

Wheat flourishes best in a dry, sunny region, and the winter conditions determine whether the sowing should be before or after the frost. The great wheat-districts of the world are thius the grasslands-e.g., the steppes of 
Russia, the puzstas of Hungary, the prairies of America, and the pampas of Argentina. In the British Isles the culture of wheat is limited to certain well-defined areas: in England to the Eastern and South-Eastern counties, certain central counties, and the plains east of the Pennine Chain; in Scotland to the lowlands of the Clyde and Forth, and the coastal ledges from Berwick to the Firth of Tay; in Ireland wheat is now confined to the driest and sunniest spots, such as occur in the rain-shadow of the mountains in the south-eastern parts of the island.

In recent years the fall in prices, due to the importation of wheat from abroad, has contracted the limits of its cultivation at home. Much of the land has been converted into pastures and market-gardens, and the culture of wheat is gradually becoming restricted to the heavy clay-lands of Essex and the Wash.

Barley has a much wider range than wheat. It is grown throughout the wheat-area and considerably beyond it. Much of it is converted into beer and spirits.

Oats are, of all the cereal grasses, the most indifferent to climate. They are grown all over Ireland and in the damp valleys of Scotland, where they form a staple food for man and beast.

2. Pastures.-These may be natural or artificial. The former occur in elevated regions (e.g., downs), and are used mainly for grazing sheep. Artificial pastures are of two kinds :

(a) Permanent Pastures, which have been reclaimed from moor or bog. They were ploughed once and sown with grass. One crop of hay is perhaps taken off them each year, after which they are abandoned to grazing. Hill-pastures are used as sheep-runs.

(b) Pastures sown with Clover and Rotation-Grasses.These occur on the richer, moister soils of the lowlands, and require periodical manuring and ploughing. They may be used either as meadows cut for hay, yielding on damp soils two crops a year, or for the grazing of cattle in the milk-districts. The dairies of England are chiefly in the west, where the rainfall is abundant and the grasses tall and succulent.

3. The Conversion of Vegetation into Meat.-The feeding of stock upon pastures results in the conversion 
of vegetation into milk, butter, cheese, or meat. Cattle need to be pastured on rich and succulent grasses to yield good and abundant milk. Dairy-farming is thus most successful in the moister parts of oceanic regions (e.g., Brittany, Denmark, Holland, West of England, Ireland). Where cattle are reared for meat and hides only, and not for milk, a relatively poor grass will suffice, and such are the conditions on the great ranches of America.

The large amount of food required by stock leads, on the one hand, to the utilization of large areas of pasturage, as in the case of nomadic pastoral tribes ; or, on the other hand, to the necessity for a certain amount of artificial feeding, at least during a portion of the year, when the natural herbage fails. For this reason, fodder and rootcrops are raised in dairy-districts almost entirely as food for cattle.

\section{Climate and Vegetation in Europe.}

.1. Tundras.--These are a type of treeless moorland occupying the Arctic parts of Europe. In winter they are icy. wastes, in summer, morasses. The growing season is cold and very short. The vegetation is poor and dwarfed, consisting chiefly of mosses and lichens. Mosses such as Polytrichum occupy the wet peaty parts, while lichens like Cladonia rangiferina, the reindeer moss, flourish on the higher, drier ground. The tundras, however, are not devoid of other vegetation, especially towards their southern limits, where, among the carpets of moss and lichen, occur lycopodiums, sedges, reeds, grasses (Nardus stricta, Aira flexuosa), dwarf shrubs (Vaccinium, Calluna), and even a few stunted trees (Arctic birches and willows), but these are rarely more than a few inches high. A similar moss and lichen-flora is found on high mountains just below the snow-line.

2. Coniferous Forests.-These form a broad belt on the glacial soils south of the Tundra. The winters are cold and long and the summers short, but tall tree-growth is made possible by the absence of violent wind in winter. The forests are composed almost entirely of conifers with very small evergreen leaves (pines, firs), a single species of which often monopolizes large areas. Two deciduous trees, however, the larch and the birch, accompany these evergreens to the limits of tree-growth and even extend 
beyond them. In the vertical direction this type of vegetation characterizes the higher altitudes in mountainous regions everywhere in Europe. The perticular kind of tree dominant anywhere naturally varies. The Scots Pine, Pinus sylvestris, likes room and sun, the Norway Spruce, Picea excelsa, prefers shade. The Silver Fir, Abies pectinata, forms vast and stately forests in the ancient highlands of Southern Germany; while the Mountain Pine, Pinus montana, inhabits the high barren slopes of the Pyrenees and French Alps. The Stone Pine, Pinus Pinea, is common in the Mediterranean, where it suppresses the holm-oak, Quercus Ilex, on high, moderately weathered slopes. The leaves of conifers contain resin and rot with difficulty. This combined with a cold soil, in which there is a deficiency of nitrifying bacteria, makes it ill-suited for cultivation. The region is sparsely populated.

3. Deciduous Forests (e.g., oak, beech, birch, ash, etc.).These trees lose their leaves in winter. They require more moisture and warmth than conifers, and therefore have their greatest extension in Western Europe. The leaves decay quickly and as they all fall every year a deep fertile soil is gradually formed which can be efficiently cultivated when the trees are cleared away. The greater part of the lowlands of Germany, France, and Great Britain was once covered with deciduous forests. In Germany much of these still remains, but in England only fragments of the original forests survive. With the growth of settled populations these forests have fallen a sacrifice to the needs of civilization, providing timber for the builder, fuel for the smelter of iron, and ground for the tiller of the soil.

4. Grassland.-This is characteristic of the continental type of climate with wide extremes of temperature. The rainfall, though too scanty for trees, is fairly uniform, most falling in spring and early summer, that is, in the growing season when the vegetation needs it most. The largest grasslands in Europe are found in Russia and Hungary. The Ukrainian Steppes lie between Poland and the Black Sea. These are covered with a fine sandy humus-laden soil, called loess, an air-borne deposit which owes its origin to the Ice Age. Upon the ice-sheets, which at this period covered Northern Europe, lay a 
great mass of cold, heavy air, and from these was liberated an outward-blowing wind which carried over the Southern plains the finer particles of soil and vegetable fragments that had accumulated on the surface of the ice. These steppes are amazingly fertile. The soil is black with humus, and cultivation can be carried on year after year with little or no manuring. Clover in some places grows to a height of 15 feet and hemp to 20 . Such a soil is very retentive of moisture, and this is important in a region where the rainfall is so scanty. Towards the South and the East the fibrous black earth dies away and the steppes pass into dry barren pastures.

5. The Mediterranean Region.-This has a subtropical climate characterized by wet cool winters and dry warm summers. In summer cultivation is limited by drought and in many places is possible only if the soil is irrigated. The winters are so mild that there is no break in the vegetation, and most of the crops that we grow in summer can be grown there in winter. Trees are not abundant. Most of the forests have been cut down and are now represented only by their undergrowth of shrubs, the maqui, and there is much grass. Deciduous trees are rare except in damp spots, while the chestnut is restricted to mountainous tracts, where, of course, the climate is different. The characteristic vegetation is evergreen, e.g., the olive, orange, oleander, evergreen oak, arbutus, bay-tree, yew, cypress, stone-pine, and myrtle. Aromatic plants are common. One palm, Chamoerops humilis, reaches Europe, where it occurs on the Riviera. The flora of the Mediterranean has changed within historical times. When the Greeks landed in Southern Italy, forests of oak and beech were common; now they are rare, the beech being confined to the highest mountains. This is largely owing to the gradual dessication of the whole Mediterranean region, which has been going on for ages. But man has accelerated Nature by replacing the deciduous trees which he cut down by evergreens, most of which are derived from Asia and suit the climate better. The orange was brought from the East during the Middle Ages, and since the discovery of America, the magnolia, agave, and Indian fig have been introduced from the New World. This shows how important human control is in considering present-day floras. 


\section{CHAPTER III}

\section{THE INFLUENCE OF WATER ON PLANT-LIFE}

Water is the most important factor in ecology. In conjunction with heat, it determines climate. It plays a dominant part in the life and well-being of every individual plant, and decides the form and character of the vegetation everywhere. Where water fails, there is no vegetation; where it is most abundant, there the vegetation is most luxuriant and varied.

\section{The Rôle of Water in Plants.}

1. Water is the medium which conveys to all parts of the plant-body the materials required for its nutrition and growth. These must be in solution, for solid particles cannot pass through the tissues of plants. These substances are, for the green plant:

(a) Mineral salts, absorbed by the roots from the. soil, and destined to be employed in the elaboration of food; and

(b) The food itself (carbohydrates, proteins, etc.), conveyed in a watery sap to every living part of the plant - to the points of growth, to the centres of work, or to the seats of storage.

2. The body of the plant is nearly all water. In a living cell which has reached its full size, the living substance, or protoplasm, is little more than a thin skin lining the wall. The rest is sap, a watery liquid containing nutriment and other substances in solution.

3. Moreover, the living cell can only keep in health and perform its functions successfully while it is turgid, or stretched with water. As soon as the cells lose their turgidity, the leaves and shoots become limp and droop, 
and if this condition is prolonged the plant dries up and dies.

4. The materials derived from the soil and absorbed by the roots are conveyed in a current of water which passes up the stem to the leaves. This ascending stream of sap is called the transpiration-current, and the maintenance of its flow is necessary to the healthy life of the plant, for, like the stream of blood in animal bodies, it conveys a cargo of materials by the utilization of which

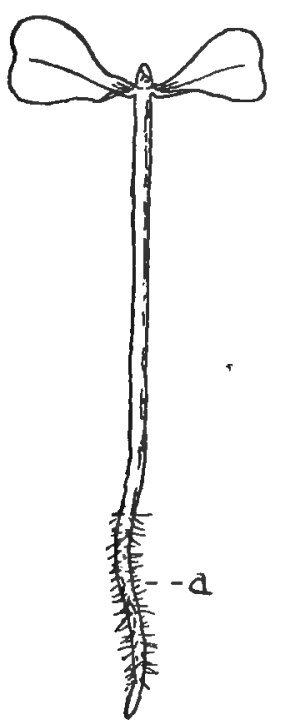

FTa. 1.-SEeditna of MUSTARD, SHOWING ROOT.HAIRS (a). (Natural Size.) the plant is enabled to live. The path of the water is through the woody tissues which constitute the greater part of the vascular system



Frg. 2.-Longitudinal Section of Part of a ROOT-TIP, SHOWING OUTER TISSUES OF ROOT (a) AND ROOT-HAIRS (b), SURROUNDED BY Soll-Particless (c). (Blghly Magnified.)

in roots and stems. From the stems great trunk-veins are given off to the leaves, where they break up into a network of capillaries. Here the water is yielded up to the living cells, and with it the nutrient material contained in it.

Root-Absorption.--Most of the higher plants live rooted in the ground. Water enters the plant by the roots. The actual entrance is effected through the root-hairstiny, hair-like cells which are found clothing the roots near their tips (Figs. 1 and 2). The water passes through the walls of these root-hairs by a physical process known as liquid-diffusion, or osmosis (see p. 91). 
Transpiration.-The transpiration-current starts in the roots and ends in the leaves. So long as the roots absorb, this stream is fed and kept in motion. What happens, then, to the water at the end of its journey? The leaves must get rid of the water which the plant does not require, otherwise the current would stop, and the plant would become surcharged with water and suffocated. The nutritive substances which the current carries are left in the cells, and the excess of water is evaporated away. The doors of exit are the stomata (Gr. stoma, a mouth; plural, stomata), small pores or openings which are found in enormous number on the surface of the leaves

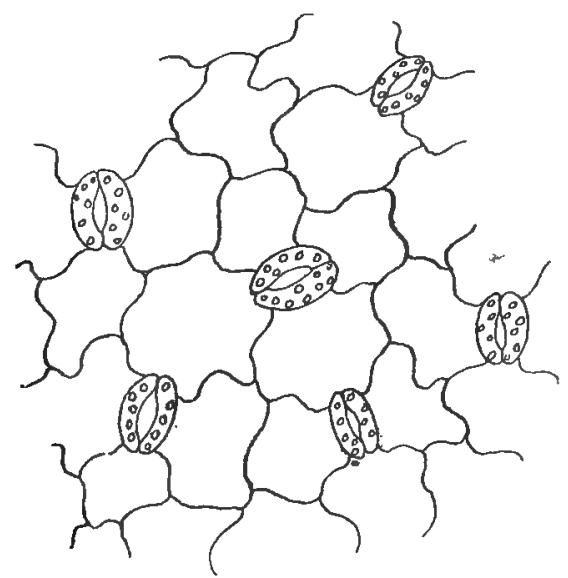

Frg. 3.-Epiderms, with Stomata, from the Under Sidz of a Leaf. (HighLX MagNIFIHD.)

(Fig. 3). The water escapes in the form of vapour, and not as liquid drops. In the leaf the cells are not packed closely together, but are loosely arranged, with the cavities between them filled with air. All these cavities communicate with one another, and ultimately focus on to the large air-spaces which occur below the stomata. The plant has the power of varying the size of these openings according to the amuunt of moisture in the atmosphere.

The aperture of the stoma is bounded by two modified epidermal cells called guard-cells (Fig. 4). When these are turgid, the stoma is wide open; when, through excessive loss of water, they lose their turgidity, they fall together 
and close the opening. This controlled or regulated diffusion of water-vapour through the stomata is called transpiration.

In a few cases water is actually expelled in liquid drops from the leaves. These emergency-exits are special openings (hydathodes; Gr. hydatos, water; hodos, way, channel), usually in the form of large stomata, always open.

Plants which grow in an atmosphere constantly moist, such as exists in a tropical rain-forest, and to a lesser degree in damp lowland valleys in this country, must get

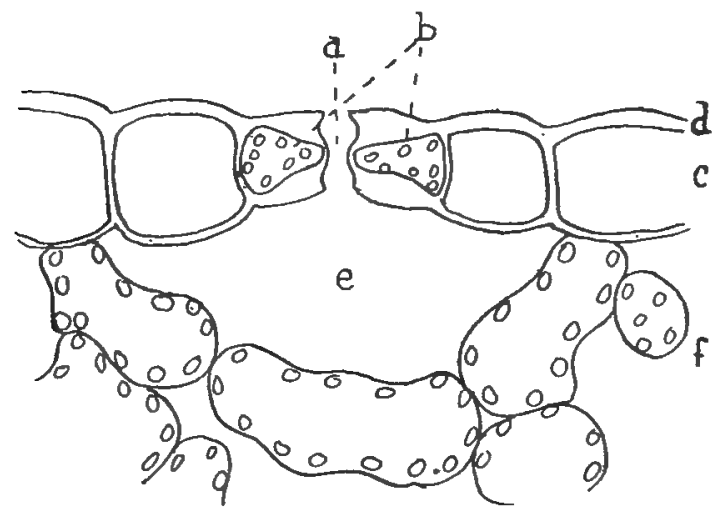

Fia. 4. - Vertical Section of Part of a Leaf cut throtah a Stoma. (HTGHLY MAGNIFTED.)

$a$, stoms ; $b$, guard-cells ; $c$, epidermis ; $d$, cuticle ; $e$, air-cavity ; $f$, chlorophyll-tissue.

rid of their surplus water in this way, for the amount transpired is very small. The young leaves of most rapidly-growing herbaceous perennials also possess hydathodes. In these cases large quantities of water must be absorbed in order to supply adequate nourishment, but, at the same time, the surface through which water can be transpired is small. The only method by which the whole of the excess can be got rid of is by excreting it in a liquid form. The small white spots on the teeth of such leaves indicate the position of these hydathodes, and if they are examined in the early morning of a moist spring day, drops of water can be seen hanging from 
the tips of the teeth or in the grasses balanced upon the apex of the leaf-e.g., hogweed, garden-nasturtium, creeping buttercup, etc.

The Supply of Water in the Soil.-This depends upon :

(a) The rainfall- that is, upon the water which enters the soil from above ; and, as we have shown in Chapter I., this has to be considered in relation to (1) its amount, (2) its frequency, and (3) the season of maximum fall.

(b) The nature of the soil which receives the rain. This is described in detail in Chapter IX.

(c) The water which enters the surface-soil from below. This depends upon the existence and availability of ground-water. The ultimate source of all the water in the soil is rain; but rain, sinking through the ground, sooner or later reaches a layer of clay or hard rock, through which it cannot penetrate. Upon this impermeable bed it settles, and forms a supply of underground, or telluric (Lat. tellus, the ground), water. The presence or absence of this underground water, its depth below the surface, the power of the soil above it to suck it up, and its availability to the surface-vegetation, constitute a factor of such ecological importance that we shall deal with it at length in a later chapter (Chapter IX.).

So important is water, that plants may be divided into two groups, according to whether they live in water or upon land:

1. Aquatics (Lat. aqua, water), or Water-Plants, adapted to life in water. Their vegetative parts are partly or entirely surrounded by liquid water (Chapter V.).

2. Terrestrial, or Land-Plants, adapted to existence on land. Their vegetative organs are surrounded by air (Chapters IV. and VI.).

The division between the two groups is not well marked. On the border lie plants which can live either in water or air. Many marsh-plants are amphibious in this way -e.g., Polygonum amphibium, Nasturtium amphibium, and Pilularia. The land-form, however, differs more or less from the water-form, the latter generally havir.s weaker stems and narrower leaves. Polygonum amphibium in water has floating leaves; on muddy soil the stems creep at the base, and its leaves are often downy.

Land-plants are usually divided into three classes, according to the nature of their water environment: 
1. Hygrophytes (Gr. hygros, moist; phyte, plant), plants adapted to very moist conditions.

2. Xerophytes (Gr. xeros, dry), plants adapted to live in a dry soil or under conditions unfavourable to their development, at least during a part of the year. The conditions may all be ultimately referred to the quantity, availability, and usefulness of the water-supply (Chapter IV.). A wet soil is $d r y$ if the plant can absorb none of the water.

3. Mesophytes (Gr. mesos, middle, intermediate), plants occupying an intermediate position with regard to water.

\section{Hygrophytes.}

True hygrophytes are plants which live in places always moist, and which, during the whole year and the whole of their lives, exhibit characters adapted to moist conditions. The extreme hygrophyte lives in an atmosphere saturated with moisture. It cannot transpire, but the transpiration-current is kept going by the elimination of water in liquid drops through hydathodes (p. 27). Moreover, such plants can only live in regions where no unfavourable season intervenes to disturb their development. Winter-cold means drought even for a hygrophyte (p. 64). For this reason they are only found in the wet parts of the Tropics, where there is no dry season and no winter. They are evergreen, and live in the shade of trees or dripping rocks. Outside the Tropies they are only found in very damp, shady places where frost is unknown. In the British Isles the nearest approach to these conditions is found in the extreme south-west of Ireland, and the plants which, in their characters, most nearly resemble true hygrophytes are the Filmy Ferns. The Killarney fern, for example, is a plant with delicate evergreen leaves, and lives in wet, sheltered crannies in the rocks near the Lakes of Killarney. Elsewhere in this country they can only be reared in glass cases, which are shaded from the sun, and in which the air is kept constantly saturated with moisture.

The leaves of many of our marsh and wet-meadow plants exhibit hygrophilous (Gr. hygros, moist; phileo, I love) characters in summer; but as they perish at the 
approach of winter, and are renewed in the spring, the plants to which they belong cannot be regarded as true hygrophytes (see Tropophytes, p. 57).

\section{Xerophytes.}

Most plants have to face a deficiency of water sometimes, and if there were no peculiarity of habit or structure to prevent them from suffering during these periods, their existence would be threatened, and the continuance of the race endangered. Every peculiarity of habit and every peculiarity of structure or mode of growth which enables a plant to get through a period when water is lacking either in quantity or quality is known as a xerophytic character, and these characters may be few or many, slight or pronounced, permanent or temporary, according to the conditions which obtain in the normal surroundings of the plant.

Just as the true hygrophyte exhibits adaptations of a permanent character towards moist conditions, so a true xerophyte shows adaptations of a permanent character towards dry. The unfavourable conditions may only come once a year, and if the plant meets this by some permanent modification in its structure it is a true xerophyte. Thus the holly is common in moist woods in the West of England. Its leaf is evergreen, thick, and shiny-characters associated with deficiency of water (p. 39). The deficiency, however, only occurs in winter, when, through the coldness of the soil, the roots become inactive and lose, more or less completely, their power of absorption. The holly therefore exhibits during the summer characters which are only really useful in winter. In other cases, unfavourable conditions occur all the year round; during summer they may be of one kind, during winter of another. When this is so, we should naturally expect the plants to be equipped with permanent xerophytic characters. All true xerophytes are evergreen-e.g., yew, heath, pine, ling, box, laurel, many succulents, etc. Plants which assume xerophytic characters only at the approach of winter are tropophytes (see p. 57). 


\section{Mesophytes.}

Some plants are pronounced hygrophytes, others pronounced xerophytes. Hygrophytes lie, in their relation to water, at one end of a series which is terminated at the other extremity by the highly specialized xerophytes. Between the two lie a vast host of plants, generally known as mesophytes, which possess no marked characters either way. Such plants live in conditions which are fairly favourable to the plant all the year round. The true mesophyte is an evergreen, and lives only in the Tropics or in regions not far removed from them. Any winter-break would entail the assumption of some more or less marked xerophytic characters. We have no true mesophytes in Great Britain because the interruption of winter is too pronounced. The nearest plants we have to them are certain marsh-plants like the iris. If the winter is mild, the leaves of the iris persist to the spring. The leaves are long, band-shaped, and erect. The latter is a xerophytic character (p. 46). Amid a host of hygrophytic characters, the iris, therefore, has at least one xerophytic character-it avoids the light by turning its leaves edgewise to it. If, however, the winter is severe, the leaves all perish, and the plant dies down to an underground stem, and behaves as a pronounced xerophyte.

Tropophytes (Gr. tropos, change).-The great majority of our plants are tropophytes. Unlike evergreens, they exhibit one set of characters in summer and another during winter. They provide against drought by changing their mode of life at the approach of winter (see Chapter VI.). 


\section{CHAPTER IV}

THE INFLUENCE OF WATER ON LAND-PLANTS-XERO.

PHYTES-XEROPHYTIC FACTORS AND CHARACTERS

WE considered in the last chapter the transpiration- or water-current, and we pointed out how impcrtant it is that this current should be maintained in sufficient motion and strength to satisfy the needs of the plant during the various phases of its existence. The needs of the plant, of course, vary with the seasons. In spring the demand upon the water-current is greatest, because growth is then most vigorous; in winter the demand sinks to a minimum, and the transpiration-current becomes almost stationary. This stream of water starts at the roots, where it is absorbed, and after dividing into countless tributaries, ends at the leaf-surfaces, where it is transpired. It is clear, therefore, that anything which tends either to diminish the amount of water absorbed by the roots or to increase the quantity of water transpired through the stomata, must weaken the strength and flow of the transpiration-current, and in either case the plant may suffer through lack of water. In the summer this is serious, for if the deficiency becomes too pronounced, the plant may dry up and perish. Even when means are present, whereby the loss by transpiration is so regulated that it does not exceed the absorption, the current runs slow, and as the materials necessary in the construction of food are contained in this current, growth is checked, and the plant suffers from lack of nutrition. To a small extent, however, every plant has control over its transpiration. The guard-cells of the stomata are self-regulating, and they adapt the width of the apertures to the state of the weather. This is manifestly advantageous to the plant. During the day 
the stomata are generally open, but if the weather is very dry and hot, as it often is at midday, the guard-cells lose their turgidity and close. This safeguards the plant against the risks of excessive transpiration during the heat of the day, but it is at the expense of assimilation, for when the pores are closed, no carbonic acid gas can enter the leaf. The stomata also close at night, probably owing to the withdrawal of light, but this, again, serves the plant well, for the ground cools at night, and the roots then absorb less water.

The amount of water retained in the plant may be reduced in two ways :

(a) By those causes which diminish the absorption of water by the roots.

(b) By those causes which increase transpiration.

\section{Causes which reduce Absorption.}

1. Cold.-Just as a rise in temperature increases the activity of all the vital functions, so a fall in temperature decreases it. For this reason, the power of the roots to absorb water declines as the soil becomes cold, and this happens, even though the actual amount of water present may increase. As freezing-point is approached, the roots become extremely inactive, and when the ground is frozen no water is absorbed at all.

2. A Sour or Salt Soil produces a similar effect. The water absorbed by roots is really a very dilute solution of mineral salts, the amount of solids dissolved in the water rarely reaching 1 per cent. As this proportion of solids is exceeded, the activity of the roots declines, and when the amount reaches 3 to 5 per cent., the roots cease absorbing altogether ; in fact, a very strong solution presented to the root-hairs will actually withdraw water from the plant, and the cells will collapse. Salt water is therefore as good as no water at all, for none is absorbed. Just as with The Ancient Mariner, there may be

"Water, water everywhere,
Nor any drop to drink."

We conclude from this that, as far as plants are concerned, there are several conditions which produce a state of dryness besides drought. Plenty of water may 
be present, but if it is not of the right, sort it is not absorbed. This kind of dryness is called physiological dryness, and, in ecology, when we speak of dryness in external conditions, we mean not only physical dryness, but this physiological dryness as well.

\section{Causes which tend to increase Transpiration.}

These are, with one exception, the same as promote evaporation from the surface of any moist body exposed to the air :

1. A Dry Air, which promotes evaporation from all the water-surfaces in contact with it. When the air is very dry, evaporation is very rapid; as the amount of water-vapour in the air increases, the rate of evaporation decreases, and when the air is saturated, it ceases altogether.

2. A High Temperature, which increases evaporation by increasing the amount of water-vapour the air can hold.

3. Wind.-The faster the air in contact with the evaporating surfaces is renewed, the more quickly the water is evaporated. Wet clothes dry more quickly in a wind than in a calm.

4. Rarefaction of the Atmosphere-Evaporation of water increases with the diminution of the air-pressure on its surface. On a high plateau, water exposed in a bowl will disappear more quickly, other things being equal, than on a lowland plain.

5. Light. - Intense illumination does not increase evaporation if the temperature is unaltered, but it does increase transpiration. The phenomenon is clearly a vital or physiological one, for light only promotes loss of water from a living plant, not a dead one.

The rate at which a body loses water by evaporation depends also upon the Extent of Surface exposed to the Air. Half a pint of water spread out over a table will soon dry up, but if enclosed in a jug, with only a small evaporating surface exposed, it will take a long time to disappear, even in dry weather. It is the same with a leaf. A small, thick leaf may contain as much tissue and as much water as a large, thin leaf, but the latter will lose water more quickly than the former, because the amount of exposed surface is greater. 


\section{Summary of Xerophytic Factors.}

I. Causes which reduce Abscrption, and so set up a state of physical or physiological dryness :

1. A physically dry soil.

2. A cold soil.

3. A salt soil.

4. A sour soil.

II. Causes which increase Transpiration, and so set up a condition in which the loss of water tends to outrun the supply:

(a) Physical factors :

1. A dry atmosphere.

2. A high temperature.

3. Wind.

4. Rarefaction of the atmosphere.

(b) Physiological factor :

1. Intense illumination.

\section{Natural Regions where Physical or Physiological Dryness jrevails.}

1. Deserts (lack of water, dry air, intense illumination).

2. Steppes and prairies (soil dry and hot in summer, air dry, intense illumination, intense heat, especially at noon).

3. Rocks and stones (lack of water).

4. Sandy and gravelly soils (lack of water).

5. Chalk-downs (exposed to wind-chalk is porous, and therefore apt to become very dry).

6. Bark of trees (lack of water).

7. Salty seaside - soils, salt swamps and marshes (presence of salt).

8. Peat-bogs (presence of souring acids).

9. Polar regions (cold).

10. Alpine regions (cold soil, wind, intense illumination, rarefied air).

11. Wind-swept, exposed situations (drying winds, intense illumination). 


\section{Xerophytic Characters exhibited by Plants living under Physiologically Dry Conditions.}

The difficulty with xerophytes is to retain within the tissues sufficient water for their needs. If, from any cause, little is absorbed, then little must be lost. To secure this, the organs on which are found the exits for the escape of water are modified.

Thus leaves and shoots are modified in form and structure, curious and characteristic habits of growth are assumed, and the display of the leaves to the light is not the same as in ordinary plants.

Whatever the means adopted, the end is always the same-to keep down transpiration to a minimum, in order that as much water as possible may be retained within the body of the plant.

1. Stunted Growth of Stems.--This is brought about by lack of nourishment, a condition experienced by all xerophytes whose water-supply is limited. Trees become stunted and dwarfed, assuming the low bush-form in regions where the xerophytic conditions become pronounced-e.g., in semi-deserts, on dry, windy plateaux, in cold alpine regions, and near the limits of tree-growth towards the Pole. Under extreme conditions, the trees may be only a few inches high, and the annual output of leaves not more than two or three. On the crests of Snowdon, the common juniper forms a great branching mat, lying prostrate on the rocks. The soil is thin, and the plants are exposed to violent desiccating winds, great heat at noon, severe cold at night, and intense illumination when the sky is clear. The internodes are short and the development of buds is feeble and irregular. The mat-like growth serves to keep the plant just out of reach of the most violent wind, and at the same time keeps the soil underneath it shady and moist.

This form of stunted growth is not, however, permanent, because under more genial conditions many stunted alpines will develop tall stems, while, on the other hand, plants which are several feet high on the plains shrink to a few inches on high alps and wind-swept downs (see p. 77).

Although light has some effect in dwarfing plants by promoting transpiration, it has a direct effect upon growth, which is far more important. Shoots and leaves 
exposed to the sun are always smaller than those which develop in partial shade, and the dwarfing of plants in exposed situations is due, in part at least, to this effect.

Another kind of stunted growth is the rosette-form, characteristic of many plants living in regions either permanently or periodically dry or cold. The rosetteform, however, is permanent; it is inherited, and therefore independent of circumstances. In a rosette-plante.g., London-pride (Fig. 5), the stem, through the suppression of the internodes, does not elongate, but bears

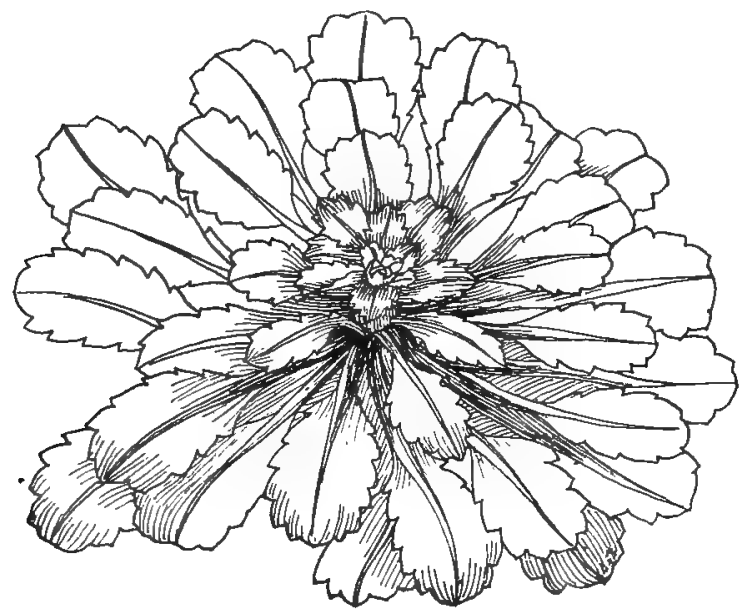

Fig. 5.-London-Pride, Showing Rosette-Habit. (Natdral Size.)

a number of closely-set radiating leaves close to the ground. These leaves provide a deep shade under which no other plants can grow, and in this way the plant frees itself from competitors. The soil, being shaded, tends to remain moist beneath the leaves, and, as the stomata are found on the under surface, transpiration takes place in moist shade, and is therefore not excessive.

Rosette-plants are common, not only in alpine regions, but in all grassy places where the herbage is low, and tall weeds are in danger of desiccation by violent winds. The presence of rosette-plants (e.g., dandelion, daisy, plantain) in a damp meadow might appear to conflict 
with this statement, but such plants are exposed to the same danger in the physiologically-dry winter. Rosetteplants have often long tap-roots which are perennial, and the stunted stems are known as root-stocks.

A third form of stunted growth is the cushion-growth, a habit assumed by many plants growing in alpine situations. The stems do not elongate, but they branch freely close to the ground, forming dense cushions (Silene acaulis, Saxifraga hypnoides).

2. Leaf-Modifications. - The leaf, because of its stomata, is the chief transpiring organ of the plant. Any reduction of the leaf-surface entails a diminution in the number of the stomata, and consequently a reduction in the amount of water transpired. On the other hand, the green leaf is conspicuously the seat of food-construction, and therefore any diminution in the loss of water can only be effected at the expense of assimilation. If the leaves are small, less food is made, growth is checked, and the whole plant suffers. Reduced assimilation, however, is the lesser of two evils, and most small-leaved xerophytes show manifest signs of impaired nutrition; in fact, the diminution in the size of the leares is evidence in itself that the plant is imperfectly nourished.

The effect of a xerophytic environment is expressed in the size, form, characters, and display of the leaves more than upon any other vegetative organ. The leaf is essentially an expression of its environment. Where moisture is abundant, and there is no danger of desiccation, the leaf is generally large and thin. As the environment becomes physiologically drier, the leaf tends to exhibit one or more of the characters enumerated below. This does not mean that the removal of any particular plant to drier surroundings will result in any corresponding modification of its leaves. The size, form, and characters of leaves are, within narrow limits, fixed for every species. What is really meant is that those plants whose leaves display xerophytic characters, do so because they are best adapted for dry situations, and such plants will consequently be found there to the exclusion of all other plants not so well equipped to contend with the perils of drought.

The various forms and characters associated with the leaves of xerophytes may be looked upon as the outcome 
of a gradual evolution along certain lines or tendencies, the purpose of which is to protect the plant against physical or physiological dryness.

\section{External Xerophytic Tendencies.}

1. Diminution of the Transpiring Surfaces-e.g., cypress (Fig. 6).

2. Increase in Bulk compared with surface-e.g., fleshy-leaved plants, as stonecrop (Fig. 7).

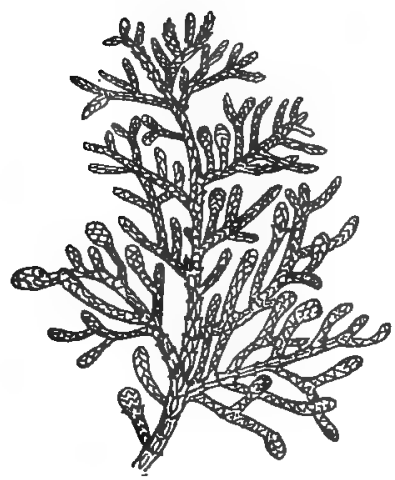

Frg. 6.-Cypress, SHOWING CONCRESCENT TYPe OF LEAF. (Natural Size.)

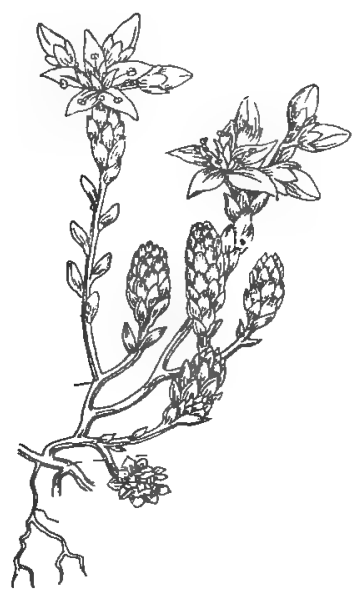

FTg. 7.-STonecrop (Sedum acre), show ING CROWDED SUCCULENT Leavers. (Natural Size. After Sowerby.)

3. Increase in Longevity.--In this country land-plants which retain their leaves in winter are almost invariably evergreen xerophytes-e.g., holly, ivy, heath, laurel, box, pine. By increasing the longevity of their leaves, plants are spared the necessity of making a complete set each year. This economy is imposed on most xerophytes because they are poorly nourished, and possess none too much nutriment.

4. Development of Sereening Structures, such as hairs, scales, etc., which prevent the wind from removing moist air from the neighbourhood of the stomata-e.g., mullein, cudweed. 


\section{Internal Xerophytic Tendencies.}

1. Thickening of the Cuticle.-The cuticle is a layer or membrane formed by the external walls of the epidermal cells (Fig. 8). In xerophytes this becomes thickened and strongly cuticularized. The latter condition is brought about by the deposition in the walls of a waxy substance called cutin, a body closely allied to cork, which renders the membrane impermeable to water.

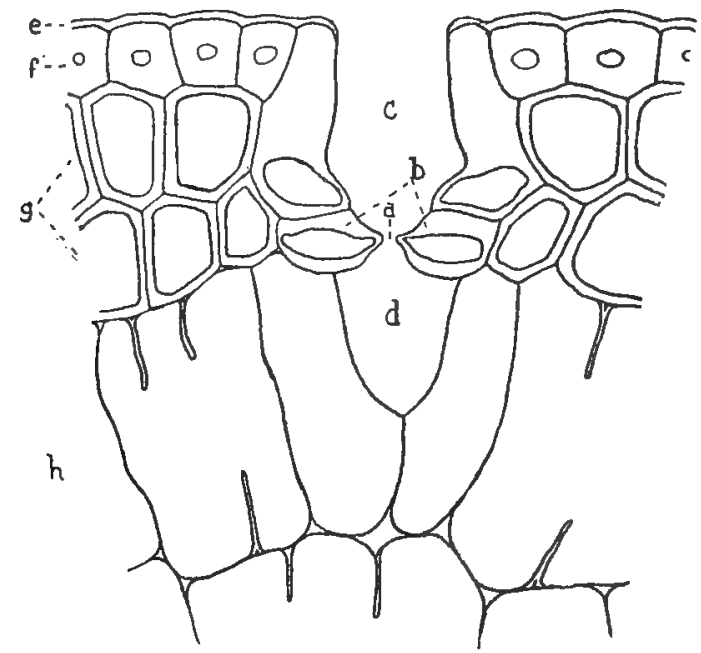

Fig. 8.-Section of Part of a Prne-Leaf, with Defely-sunk Stoma (a). (HighLy Magnified.)

$b$, guard-cells; $c$, stomatal pit; $d$, air-cavity ; $e$, cuticle; $f$, epidermis; $g$, thick-walled hypodermis (sclerenchyma); $h$, chlorophyll-tissue.

2. Diminution in the Volume of the Intercellular AirSpaces.-The cells of the leaf are packed closely together, thereby impeding transpiration.

3. The Stomata are reduced in Number and placed in sheltered positions in pits and grooves, the entrance to which is often closed by hairs - e.g., heaths (Fig. 9), marram-grass (Fig. 11). The stomata thus come to be in moist chambers. In most plants, however, each stoma is sunk in its own pit-e.g., pine (Fig. 8). 
4. The Leaf is thickened either by the increase of the palisade-tissue, or by the development of special waterstoring cells. The former is strongly developed in sunleaves (Fig. 22), the latter tissue is found in succulents. The storage of water in fleshy or succulent organs is very common in desert and strand plants (see p. 277). All parts of the plant exposed to the air may become succulent -e.g., the leavos in stonecrop (Fig. 7), the stems in glasswort (Fig. 10). The water is stored in a special tissue, the cells of which are large and devoid of chlorophyll; the cell-sap is abundant, clear, but somewhat slimy through the presence of mucilage. The presence of mucilage in

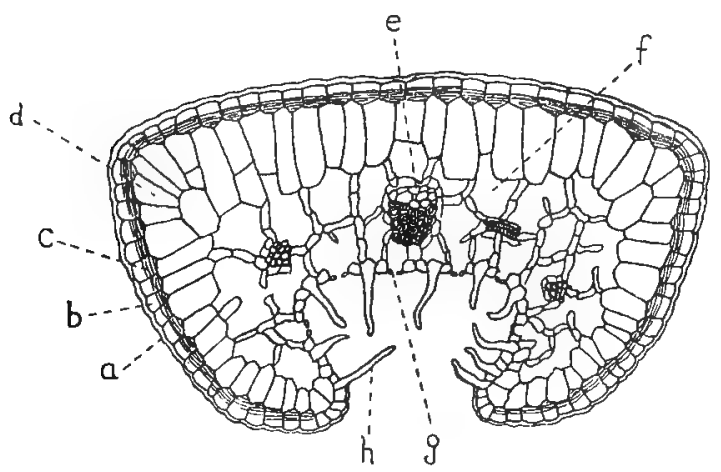

Fia. 9.-Transterse Section of Rolled lafaf of Erica cinerea. (Highly Magnified.)

$\boldsymbol{a}$, cuticle ; $\boldsymbol{b}$, epidermis ; $c$, mucilage in the cells ; $d$, chlorophyll-tissue; $e$, vascular bundle; $f$, air-space; $g$, stoma ; $h$, hair.

water makes its evaporation difficult, and this difficulty is increased by the scarcity of air-spaces. Lignified tissue in succulents is also poorly developed, and there is little cork, the retention of water within the plant being secured by other means.

5. The Augmentation of Lignified and Corky Tissues. - This serves in leaves the same end as succulencenamely, the retention of water within the plant. No large reserves of water are here stored away for future use ; in fact, the actual water-containing and waterconducting tissue is small; but what there is, is protected by masses of sclerenchyma-elongated cells with thick, 
lignified walls, non-living, and containing only air. The cells are cemented together in sheets and columns, and form very effective screens between the living cells filled with water and the external air (Fig. 11). A covering of cork on stems and shoots serves a similar purpose. The presence of sclerenchyma in large and long-lived



FIG. I0.-Salicornia herbacea (GLassWORT), SHOWINa SUCCULENT STEMS AND Mrvote AdPRESSEd Leaves. (Slightily Reduoted. After SOWERBY.) 2. The Concrescent Type, as in many cypresses and junipers (Fig. 6). The leaves are thick and evergreen, very small, erect, and fused with the stem along nearly their whole length. There is very little internal airspace, the cuticle is thick, and the surface smooth and polished. leaves gives them mechanical support, and keeps them from being easily torn and injured-e.g., New Zealand flax (Phormium tenax), Aspidistra.

6. Some xerophytes contain oil in their tissues, especially in the leaves. Where present, it undoubtedly serves to check evaporation. Many strand and semi-desert plants are quite remarkable for their fragrance-e.g., rosemary, bay-laurel, sage, wormwood, etc.

\section{Xerophytic Forms of Leaf and Shoot.}

The most important are : 1. The Needle -Type, as in the pine. The leaf is evergreen, thick and tough, with a much reduced surpacked closely together, the cuticle is thick, and the stomata are reduced in face; the internal cells are 
3. The Heath or Ericoid $\mathbf{T}_{y}$ pe (Fig. 12), characteristic of many heath-plants-e.g., Erica, Empetrum, Calluna. The leaves are small and their edges are rolled under and nearly touch, forming a chamber the entrance to which is almost closed by hairs (see Fig. 9).

4. In the Myrtle-Type the leaves are thick, leathery, and evergreen, sometimes large, as in the Rhododendron, sometimes small, as in the box.

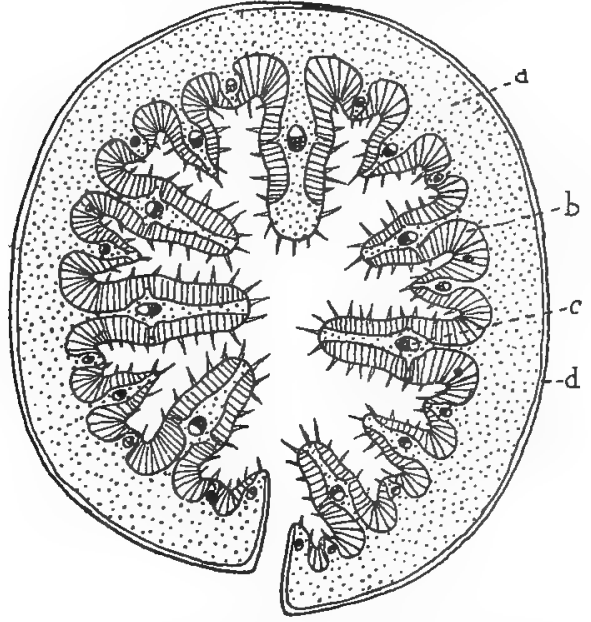

Fia. 11.-Transtersi Section of Rolled Leaf of THE Marram-Grass (Pramma arenaria). (MAGNIFIED.)

$a$, sclerenchyma ; $b$, chlorophyll-tissue ; $c$, vascular bundle; $d$, epidermis.

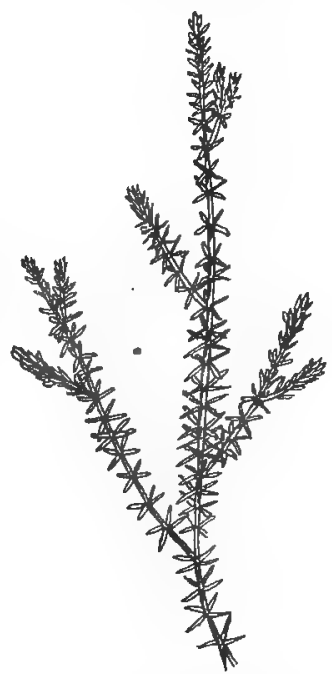

FIf. 12. - Erica Tetralix, sHowny HEATH TYPE OF Leat. (Slightur REDUCHD.)

5. The Reed or Juncoid Leaf is long, smooth, and circular. The transpiring surface is small, and as the leaves are erect, the effect of the sun's rays upon their surface is much reduced.

6. The reduction of the leaf-surface may be carried so far that modifications are rendered necessary in other parts of the plant. When the leaf-system is too small to accomplish the necessary assimilation, this work has to be carried on elsewhere, either by the leaf-stalks, which flatten out and become green and leaf-like (the phyllodes 
of acacia, Fig. 13), or by shoots which function as leaves. These shoots are of two kinds :

(a) The leaves are small and green or reduced to scales, and all the stcms take over the functions performed by

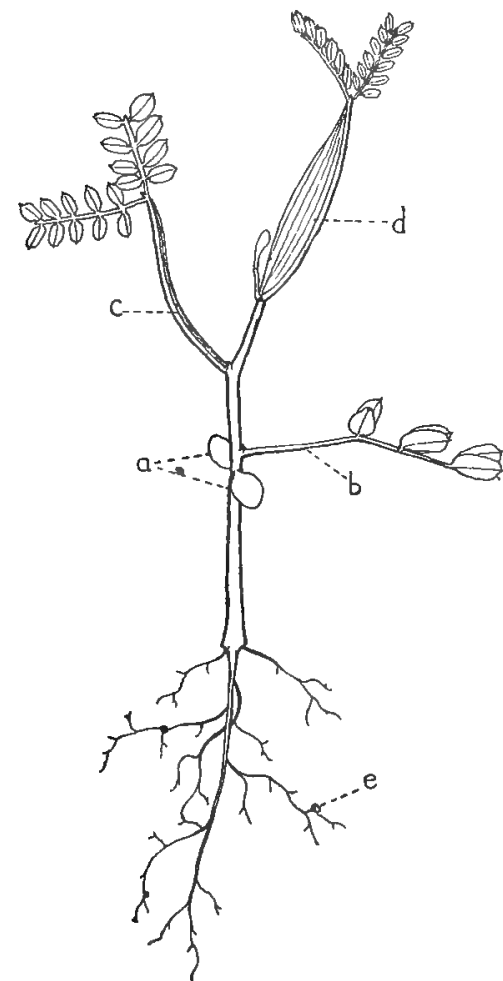

Fig. 13.-Segding of Acacia melanoxylon, SHOWING TRANSITION FROM Ordinary Petiole (b) to Phyllode $(d)$. (Abodt Halt Natural Size.)

In $c$ the petiole is slightly winged. $a$, cotyledons; $e$, root-nodules. lcaves, as in switchplants-e.g., horsetail, broom (Fig. 14).

(b) The leaves are again reduced to scales, but most of the branches are flattened, and resemble ordinary foliage - leaves - e.g., butcher's - broom (Fig. 15). Theșe flat branches, known as cladodes or phylloclades, are at once distinguished from true leaves by their position in the axils of the scales, and because they themselves often bear scales, and even flowers, on their upper surface or along their edges. Cladodes are distinguished from phyllodes in the same way, for, after all, the latter are only parts of leaves, while cladodes are shoots.

7. Lack of nutrition sometimes reduces shoots to thorns, and leaves partially or entirely to spines. Thorny plants are pronounced xerophytes, and form a considerable part of the bush and scrub vegetation of semideserts. In England, gorse is characteristic of dry heaths. Some plants even have two forms; Ononis arvensis (rest-harrow) growing on the seashore usually develops 
thorns; in less xerophytic situations the thorns are absent.

Certain peculiarities in the arrangement and display of the leaves are also to be recognized as xerophytic

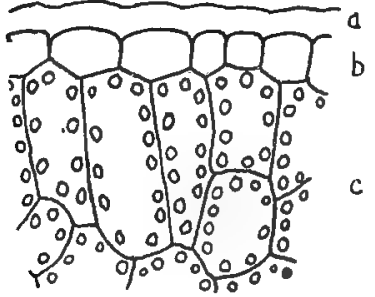

2.

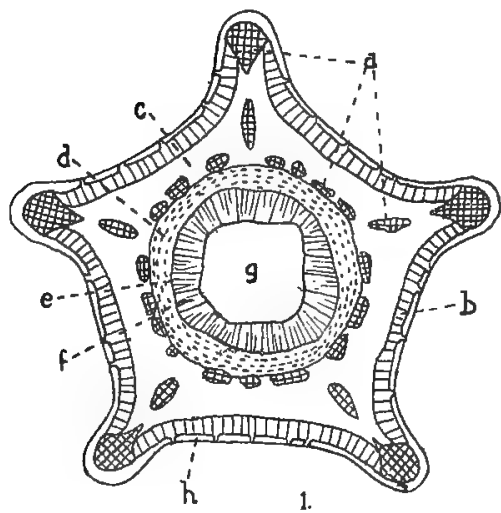

Fic. 14.-Cytisus scoparius (Common Broom). (Slightuy Magnified.)

1. Transverse section of green assimilating stem. $a$, sclerenchyma; $b$, chlorophyll - tissue ; $c$, cortex; $d$, phloem; $e$, cambium ; $f$, xylem; $g$, pith; $h$, epidermis possessing stomata at intervals.

2. Portion of outer tissues, magnified more highly to show thick cuticle (a), epidermis (b), and ohlorophylltissue (c).

leaf-mosaic, p. 68). The leaves of xerophytes, on the other hand, are not displayed in this way.

Direct sunlight promotes transpiration, and as this is adaptations. The hygrophytic type of leaf spreads out its surface to catch as much light as possible, and the leaves are so arranged.

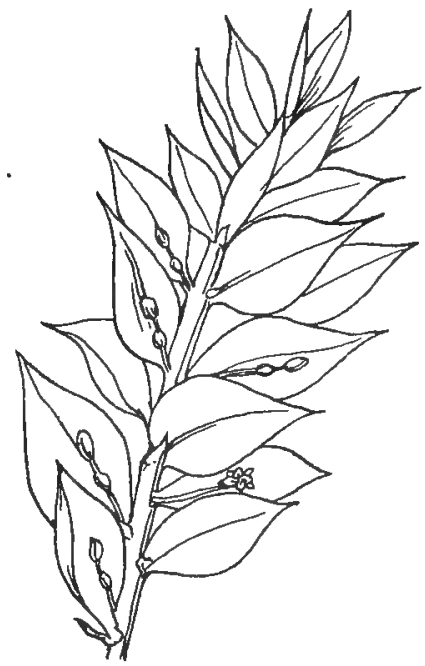

Fig. 15. - Ruscus aculeatus (BUTCHER's-BrooM), SHOWING Cladodes arising in Axils of Leaves aND Each Bearing a Flower. (NaTural Size. AFTER KERNER.)

- with respect to each other, that every available portion of space upon which light falls is occupied by a leaf (see
es of xerophyres, on the 
a source of danger to xerophytes, their leaves are arranged to avoid the effects of full illumination. This is accomplished in several ways :

1. The Leaves are arranged in Close Ranks or Filfs on the stems, so that they overlap and shade one anothe $r$ - e.g., clubmosses (Fig. 16), the evergreen Veronicas grown in gardens.

2. The Leaves turn their Edges instead of their Surfaces to the Light.-The Eucalyptus is a xerophyte. During the early years of its life, when the plant is more or less screened by the trees around, the stem produces horizontal, unstalked leaves. Later on it bears long, narrow, sickle-

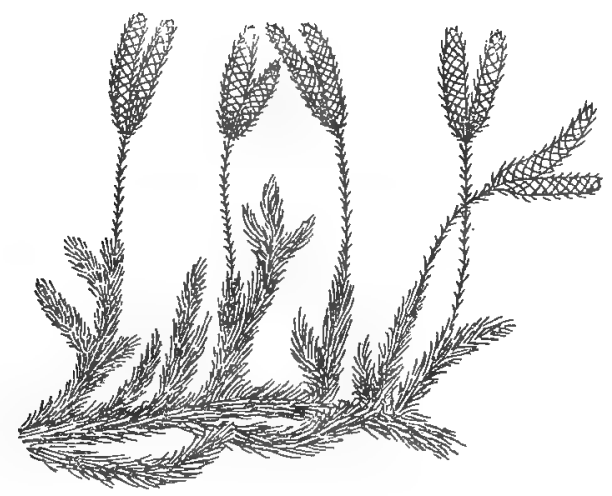

Fra. 16. - Lycopodium clavatum (Common CldoBmoss), with Smatu, Crowded Leaves. (Slightly Reduced.)

shaped, stalked leaves, which hang pendant, with their edges turned towards the sky. Cladodes and phyllodes also are generally vertical.

The same light-avoiding habit is met with even among marsh-plants. The iris, for example, has long, upright, strap-shaped leaves. Many reeds and sedges have circular leaves which are erect. Thus plants which in other respects appear to be hygrophytes, may, if their leaves are long-lived, exhibit some xerophytic adaptations for winter conditions.

We reserve the consideration of the xerophytic characters associated with hibernating organs (seeds, buds, bulbs, rhizomes, etc.) for Chapter VI. 


\section{CHAPTER V}

$W \mathcal{A} T E-P L A N T S$

AT the end of Chapter III. we pointed out that the vegetation can be divided into two great series: (1) Those which live in water, and (2) those which live on land. The water-plant lives either within or upon liquid water, and the conditions by which it is surrounded are conditions that operate in water. The land-plant, on the other hand, has its leaves and stems in the air; it is therefore exposed to the conditions that operate in air. The distinction is fundamental. The submerged aquatic differs from the land-plant in nearly all its vital relations with the outside world. Light reaches it through the water ; air comes to it from the water ; it cannot transpire. The land-plant, as we have seen in the case of xerophytes, is equipped for the perils of the land; the water-plant has to provide against the dangers that threaten it through the water-dangers arising from its mode of life in water. How it meets them we shall see when we have compared the characters exhibited by waterplants with those exhibited by land-plants.

Aquatics, or hydrophytes (Gr. hudor, water), may be free-floating or anchored in the mud, and their leaves and shoots may be floating or submerged.

\section{The Characters of Aquatic Plants compared with those of Terrestrial Piants.}

1. Aquatics show an enormous increase in the amount of internal air-space (Fig. 17). So abundant is this in some organs, that the tissue is almost limited to the thin partition-walls which separate the air-chambers. The large air-spaces in the leaves are continuous with the air- 
passages of the leaf-stalks, stems, and roots, and so a free circulation of air, and therefore of oxygen, is possible throughout all parts of the plant. In xerophytes the great danger threatening the plants is lack of water; in aquatics a danger equally serious threatens-scarcity of air. The aquatic might experience a difficulty in obtaining sufficient oxygen for respiration after the cessation of photosynthesis if all that formed during

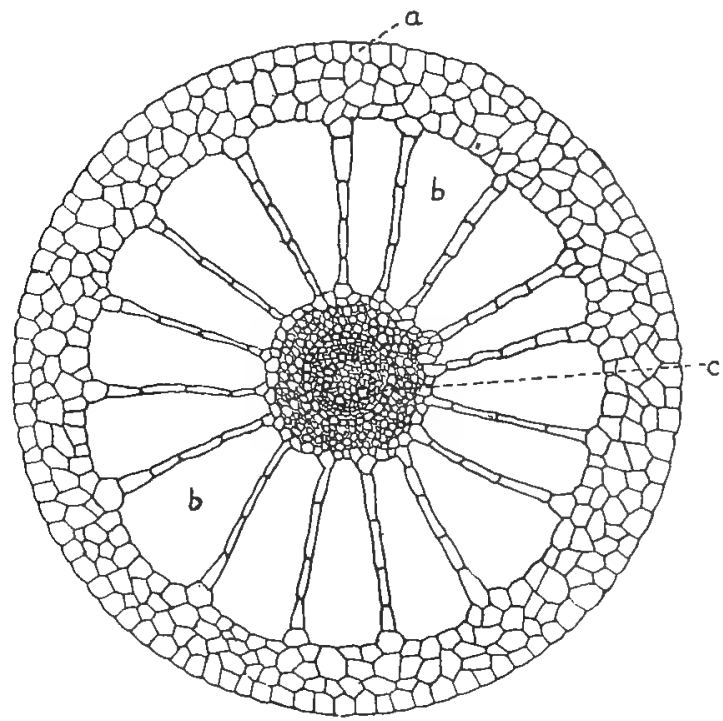

Fra. 17.-Transverse Section of Submerged Stem of Water-Violet (Hottonia palustris). (HIGHey Magnified.)

$a$, epidermis, without cuticle; $b$, air-space; $c$, woody part (xylem) of vascular system.

the latter process were allowed to escape. Much of it does escape into the water, but sufficient is always retained in the air-spaces to insure efficient aeration. The presence of air in the tissues may also be useful in another way. It serves to keep the assimilating organs at or near the surface of the water, where oxygen and light are most abundant.

2. The cuticle in aquatics is thin and devoid of wax, Water can therefore be absorbed over the whole surface. 
and the presence of stomata is rendered unnecessary. For this reason, stomata are either absent on the submerged parts, or, if present, they do not open and close. In floating leaves-e.g., water-lilies-normal self-regulating stomata occur on the upper surfaces which are in contact with the air.

3. In submerged aquatios the leaves are thin, and the epidermal cells contain chlorophyll, and so take part in the work of assimilation. This is correlated with the weak light that reaches them under water. By catching it in the outermost cells, the leaves are able to utilize the light at its strongest, before it suffers further loss by penetrating tissues which do not assimilate.

4. Diminution of the Vascular System.-Since water can be absorbed over almost the whole surface, the presence of a vascular system conveying water from the roots to the leaves is not required, and, like all useless structures, it tends to disappear. The part of the vascular system which conducts water is the wood, or xylem, and it consists of vessels or tubes whose walls have become lignified, or woody. In the oldest aquatics the wood has disappeared entirely, but the phloem-that part of the vascular system which is set apart for the conduction of food-material made in the leaves-remains as it was. The need for the distribution of water throughout the plant has disappeared, but not the need for the distribution of food. Plants growing in flowing water, however, need woody tissue in the stems to enable them to withstand the strain to which they are subjected.

5. Roots are also superfluous in aquatics, and tend to disappear. The British plants Wolffia (a duckweed), Utricularia (the bladderwort, Fig. 46), and Ceratophyllum - (the hornwort), have no roots. In other cases roots are present, but they do not act as absorbing organs; they bear no root-hairs, and merely serve to anchor the plants in the mud. In Lemna (duckweed) they still persist, although the plant is free-floating, but the chief purpose they seem to serve is to keep the plant right side up on the surface of the water.

In dealing with xerophytes, we showed that the leaf is that part of the plant which expresses in the most striking manner the nature of the environment. The same is true in aquaties. 


\section{Leaf-Types in Aquatic Plants.}

\section{Submerged Leaves.}

1. The Dissected Type - e.g., water-buttercup (Ranunculus aquatilis), water-dropwort (GEnanthe Phellandrium), water-violet (Hottonia palustris), bladderwort (Utricularia, Fig. 46). In these plants the submerged leaves are so extensively divided that the ultimate segments are almost filamentous. Three reasons have been offered in explanation of this dissection-namely :

(1) That such a finely-divided leaf offers less resistance to moving or disturbed water than an entire leaf, and so runs less risk of being damaged by tearing.

(2) That it offers increased surface for the intake of the carbonic acid gas dissolved in water, and required by the plant for assimilation; and

(3) That it offers increased surface for the absorption of oxygen required in respiration. The second explanation is founded on the fact that, although there is more carbonic acid gas in water than in air, it is not so available. Diffusion is so rapid in air, that as soon as one particle of the gas is removed by the plant, another at once takes its place; in water, however, the rate of diffusion is much slower, and the particles removed are not so quickly replaced by others as in air. The first explanation is founded upon an obvious danger in moving water, the third upon a still more serious peril in stagnant water.

2. The Ribbon-Type.-In this the leaf is long, undivided, and band-shaped. It tends to set itself in the same direction as the current, and as it offers no resistance to it, it is not likely to be damaged-e.g., water-plantain (Alisma Plantago), Vallisneria, Zostera, Potamogeton crispus (Fig. 18).

3. The Awl-Shaped Type, seen in the water-lobelia (Lobelia Dortmanna), the shoreweed (Littorella), in the spore-bearing cryptogam, Isoïtes lacustris (Fig. 110), and the water-fern, Pilularia (the pillwort). These leaves are short, smooth, thick, and tapering, and contain enormous air-spaces. 


\section{Floating Leaves.}

1. The Circular or Orbicular Type.-Leaves of this kind float on the surface of the water-e.g., water-lilies, frogbit (Hydrocharis Morsus-rano, Fig. 19), the floating leaves of the water-buttercup (Ranunculus aquatilis). In some cases the leaf has an upturned margin, which diminishes the risk of capsizing (the great Amazon waterlily, Victoria regia). The petioles of these leaves are
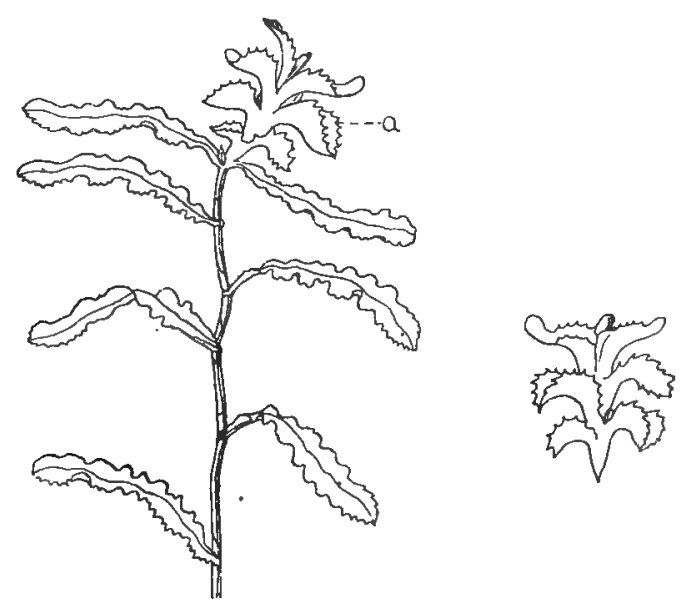

Frg. 18.-Formation of Brood-Bud in Potamogeton crispus. (ABodt Half Natural Size. After Kierner.)

To the left a bud still attached to plant, to the right the separate bud.

usually elastic and very flexible, so that they can, by coiling or uncoiling, adjust themselves to variations in the depth of the water.

2. The Long Floating Ribbon-Type.-This differs in no respect from that previously described, except that it is not submerged. It is found in Sparganium natans, and in the floating manna-grass (Glyceria fuitans).

Heterophylly (Gr. heteros, different; phyllon, leaf).Some plants exhibit two types of leaves, one floating and the other submerged, and the two appear together on the same plant. Thus the water-buttercup has finely-dissected submerged leaves, and broadly- 
orbicular floating leaves; the arrowhead (Sagittaria sagittifolia) has long ribbon-leaves under water, and arrow-shaped leaves standing out above it; the yellow water-lily (Nuphar luteum) in deep water forms long ribbon-shaped leaves instead of the ordinary orbicular floating ones.

\section{Dangers to which Aquatics are exposed.}

Most of the dangers to which xerophytes are exposed. may be summed up in two words-physiological drought. Aquatics live in a medium which is all water, but, like xerophytes, aquatics have their physiological troubles too, though of quite a different kind :

1. Difficulty of Transpiration.-Being surrounded by water, the submerged aquatic is able to absorb water through the whole of its surface, but it cannot transpire. The cells, however, can get rid of superfluous water by allowing it to escape into the large air-cavities that abound in the tissues. But if these happen to be filled with water instead of air, the aeration of the plant is rendered difficult, physiological disturbances of all kinds are set up, and growth ceases. The aquatic whose aircavities are waterlogged soon dies. In the case of floating aquatics, the upper surfaces of the leaves, in contact with the air, bear stomata. Interchange of gases can, therefore, take place directly . between the atmosphere and the plant, but transpiration is still difficult, because the air immediately above the water is always moist.

2. Scarcity of Air.-Land-plants are never troubled with lack of oxygen for respiration; it is all round them. With water-plants it is different. Running water is well aerated, and aquatics living in it never suffer from lack of air to breathe. The danger of suffocation, however, is a real one in the case of plants growing in stagnant water which is strongly charged with carbonic acid gas, but contains little or no dissolved oxygen. There is a good deal of rotting material in stagnant water, and what oxygen is absorbed is at once utilized for the decomposition of this dead matter, and little is left for the living.

3. Light.-Light is considerably altered in its passage through water. A great deal is lost by reflection upon 
the water-surface, especially when it is disturbed, and that which enters is still further enfeebled by absorption. Beyond a certain depth no light penetrates, and vegetation is impossible. The quality of the light is also altered. The red and yellow rays are gradually absorbed, and the light, as it descends, turns from white to green, then to blue, and, before it fades out altogether, to a pale ultramarine. The deeper vegetation of the sea consists chiefly of coloured algæ, and since the rays that are lost are just those which are most concerned in assimilation, it follows that these algæ must be profoundly modified in order that adequate use may be made of the changed and weakened light which they receive. The difficulty is overcome by the adoption of colour-adaptations. The pigments found in the brown and red seaweeds do not, however, replace chlorophyll ; they merely mask it, acting as a screen to absorb the rays which chlorophyll alone cannot utilize. The marine algæ are roughly zoned out in depth, according to their colour. Near the surface, where light is abundant, the green seaweeds flourish. At a lower depth their place is taken by the brown algæ, and lowest of all grow the red seaweeds, in liquid regions where only a pale blue light reigns. The coloration of seaweeds is a striking illustration of adaptation to environment.

All submerged aquatics suffer more or less from diminished light. If the surface is disturbed, only a fraction of the light that reaches the water passes into it; the rest is scattered by the broken surface and lost. Beneath this liquid screen the aquatics live in partial shade, and show, in consequence, many of the characters of shade-loving plants. For example, they have long, thin, weak stems with distant nodes, and chlorophyll is present in the epidermal cells.

\section{Propagation in Aquatics.}

In this country water-plants experience, like landplants, the vicissitudes of the seasons, but life in water is more uniform than on land, and winter to the aquatic is not the same thing as it is to the terrestrial plant. With the exception of some of the algæ, summer is the season of vegetative activity, and 
winter a period of rest. During winter most aquatics experience a break in their vegetative development, and in many cases they pass into specialized resting forms. In a few cases the plant merely sinks to the bottom of the pond, and there it remains till spring comes, when it rises to the surface again, and goes on growing-e.g., the water-starwort (Callitriche), the hornwort (Ceratophyllum). In other plants, special resting or broodbuds, surrounded by closely-packed leaves, are formed. These drop off and sink into the mud, where they remain

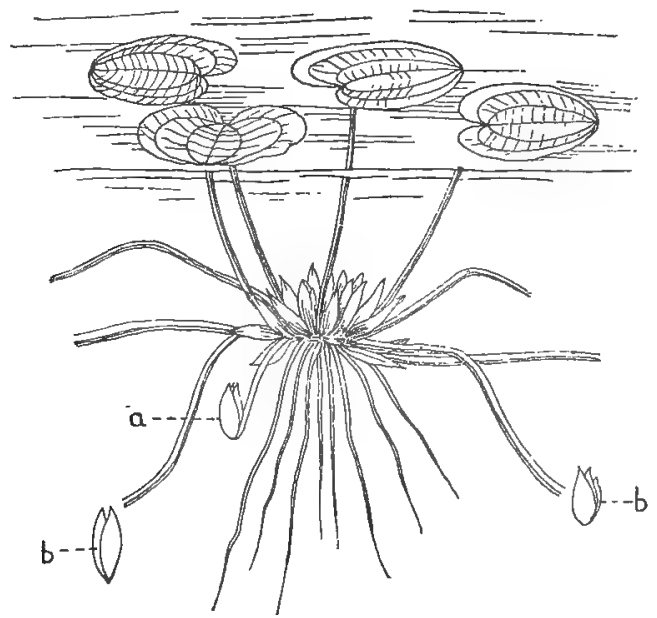

Fig. 19.-Hydrocharis Morsus-rance (Frog bit), SHowing Broad Floating Leaves. (SLIGHTly Reduced. AFTer Kerner.)

$a$, brood-bud attached to shoot ; $b$, same detached and descending to bottom of pond.

quiescent till the spring-e.g., Myriophyllum, bladderwort (Utricularia), frogbit (Hydrocharis, Fig. 19), the waterviolet (Hottonia), and the pondweed (Potamogeton crispus, Fig. 18). In the arrowhead (Sagittaria), solid corm-like buds are formed. Water-lilies die down to rhizomes cmbedded in the mud.

Seeding among perennial aquatics is casual, and in many forms rare. Annuals must produce seed to carry on the race, and in aquatics annuals are very rare. This is not surprising when we consider how freely most aquatics 
multiply by vegetative means, and how difficult and uncertain seed-formation is with them. Again, the annual, represented in winter by seed only, is clearly more suited to life on land than in water, for it is here that winter conditions are more pronounced. Among the alleged aquatic annuals found in Great Britain may be mentioned the duckweeds (Lemna), Zannichellia, and awlwort (Subularia).

\section{The Origin of Aquatics.}

It is generally assumed that the first forms of life originated in water, and that the earliest plants on the globe were aquatics. By a gradual process of modification some forms became fitted to live on land, and these, emerging from the water, gradually established themselves on dry soil, and became the forerunners of all subsequent land-plants. That was a long time ago, when the world was still young, and the first stratified rocks were being laid down under water. But from that day to this, through the countless ages of geologic time, plants have been changing and modifying, the better equipped races ever driving the weaker ones out of the fair and pleasant places on the soil. The flowering seed-plant is a late arrival on the scene, the highest and the most successful expression of natural adaptation in the long line of descent of land-forms. Certainly no plant could have evolved the seed-habit while it was submerged in water; the flower is a useful structure only in the air. From this we conclude that every seed-bearing plant that lives in the water to-day is not a primitive aquatic, but has been derived from ancestors that once lived on the land. In the struggle for existence, certain plants were bound to be driven off their habitats by stronger and better equipped competitors. Those among them that were able to adapt themselves to the conditions of other environments, lived on; some took to the water, others to the hills, where competition was less keen. These were preserved from extinction; those which could not so adapt themselves perished. Our modern flowering aquatics therefore are, in every case, the descendants of plants which were thus worsted in the struggle for existence 
on land, but which afterwards succeeded in making the water a place of abode. In the course of time they have become, by gradual modification, better adapted to a watery existence, but traces of their terrestrial origin always remain. The oldest aquatics are, naturally, most changed (Lemna, Elodea, Ceratophyllum), while the latest emigrants from the land differ little in organization from ordinary land-plants-e.g., water-buttercup and waterviolet. Thus, when we find an aquatic whose vascular tissue has lost all trace of lignification (e.g., Ceratophyllum), which has no stomata or no roots (bladderwort), we know that we are dealing with a very ancient race which has lost most of its land-characters through its long sojourn in the water. Probably the oldest aquatics are the duckweeds (Lemna), which seem to have lost all the characters of land-plants except their method of flowering. Of all organs the flower is the most conservative, and, except in a few cases, all water-plants still send their flowering shoots into the air, where the flowers are pollinated by the same means as their relatives on land. Some aquatics, indeed, possess large and quite showy flowers-e.g., water-lobelia, water-violet, bladderwort_-all of which are pollinated by insects.

Some of the very recent inhabitants of the water live equally well on land-e.g., Polygonum amphibium. These are amphibious plants (p. 28), and it is from among the amphibious plants which throng the edges of water everywhere that the aquatic vegetation is continually being recruited. 


\section{CHAPTER VI}

\section{TROPOPHYTES}

WE live in a country subject to changing seasons. Winter follows summer, but in neither case are the conditions extreme. During the summer any interruption caused by drought is only partial and transitory. The fields may become parched and the grass brown, but little else suffers. In other countries where the summer is very dry, the break begins at the onset of the greatest heat.

Our winters, too, are mild, frosts being intermittent and seldom lasting long. For this reason we are never utterly without flowers. A few hardy stragglers, surviving in sheltered places, bloom in November (purple deadnettle, Euphorbia Peplis, Stachys arvensis), while the first pioneers of spring bloom soon after Christmas (Christmas-rose, snowdrop, winter-aconite). The gorse is found in bloom nearly all the year ; it starts flowering after Christmas, and goes on till the middle of summer ; it flowers again in the autumn. Apart from this, however, the frequently low temperature and the prevalence of strong winds, often from the east, make the winterbreak, even in England, serious for the greater part of the vegetation. For four to five months there is a marked period of rest, during which most of the vegetation is in a hibernating condition.

Now, there are two ways by which plants may meet the winter :

1. They may possess permanent adaptations providing against the physiological drought of winter. These are evergreen xerophytes, bearing throughout the summer an equipment which is most useful only in winter (see p. 30).

2. They may discard all or part of their summer characters at the close of the vegetative season, assuming a 
xerophytic form which will suffice to carry them safely through the winter. These are tropophytes (p. 31), a type of plants well suited to a country like ours, and prevalent in all regions outside the Tropics.

The least that any tropophyte can discard are its summer leaves; shoots may also fall, and the destruction of summer organs may be carried so far that all the vegetative parts above ground may perish, and only specialized underground organs survive (pp. 62, 110). The perennial parts of tropophytes are always xerophytic.

In summer, tropophytes, like other plants, are variously circumstanced with regard to water. Some live in moist habitats, others in dry. If water is abundant at all times, the summer characters are hygrophytic; if water is deficient, xerophytic characters dominate. Between the two extremes lie a host of mesophytic forms with no marked features either way; the water-supply is adequate, and the drought is seldom sufficiently prolonged or intense to cause them much damage.

According to the nature of the summer environment, tropophytes are divided into three groups:

1. Hygrophilous Tropophytes, which, during summer, are surrounded by constantly moist conditions; the annually-renewed foliage and shoots exhibit only hygrophytic characters-e.g., marsh-plants.

2. Mesophilous Tropophytes.-The great majority of tropophytes are included in this group-e.g., deciduous trees and bushes, herbaceous perennials, and most annuals and biennials.

3. Xerophilous Tropophytes.-These are tropophytes which during the vegetative season live in physically or physiologically dry places-e.g., sand-dunes, sea-beaches. They show one kind of xerophytic characters in "summer" and another kind during "winter." But, however bad the summer conditions may be, the winter conditions are worse, for then cold is added to the other factors reducing absorption. If the xerophytic characters present during summer are not sufficiently pronounced to secure safety to the plant in winter, they must be discarded, and a more suitable habit adopted. The most important representatives of this group are :

1. Succulent seaside-annuals - e.g., glasswort (Salicornia herbacea), sea-blite (Sueda maritima), etc. 
2. A few prickly, succulent, or woolly-leaved deciduous perennials-e.g., sea-samphire (Crithmum maritimum), seaholly (Eryngium maritimum, sometimes an annual), etc.

In nature, of course, these groups are not sharply separated. The divisions, being based upon the watersupply available during summer, must merge insensibly one into the other. Almost any actual plant will, owing to a mixture of characters, occupy a position between the divisions. As the environment becomes drier, the xerophytic characters of the plants become more pronounced, while if the conditions become moister, hygrophytic characters will begin to dominate.

Annuals. - We have here regarded the annual as a tropophyte, although at the end of summer the whole plant dies, leaving only the living seeds to carry on the race during the winter. Biologically, they are tropophytes, for it is the race that matters, not the individual. The seed is, of all resting forms, the most xerophytic. It can endure, without injury, a greater degree of drought or cold than any other hibernating structure. In an annual the summer plant is only one phase ; the young plantlet embedded in the seed during the winter is the other. The nature of the water-supply determines the characters of the adult, as it does those of all tropophytes.

1. Hygrophytic Annuals.-These are few, most plants living in moist conditions being perennial. The following marsh-plants are annuals: The celery-leaved buttercup (Ranunculus sceleratus), marsh louse-wort (Pedicularis palustris), the bur-marigolds (Bidens cernua and $B$. tripartita), and the toad-rush (Juncus bufonius).

2. Xerophytic Annuals.-A large number of annuals exhibit characters which are more or less xerophytic. This is not surprising when we remember that annuals are most common in dry, waste places.

(a) Seaside-Annuals, generally succulent: glasswort (Salicornia herbacea), sea-rocket (Cakile maritima), saltwort (Salsola Kali), and sea-blite (Sueda maritima).

On sand-dunes the summer is the most unfavourable season. Many of the annuals that live there germinate in the autumn, form a small rosette for the winter, and flower early the next year. When the hottest part of the summer is reached, and the sand is scorched by the sun, the plants die, leaving only their seeds to meet the hardships of 
the physiological winter-e.g, Cerastium semidecandrum, Trifolium arvense, Aira procox, Bromus mollis, Phleum arenarium, Jasione montana, and Draba verna (see p. 107).

(b) Weeds of Cultivation in dry fields and waste places - e.g., cudweed (woolly), Lepidium ruderale (leaves small, plant shrubby), corn-spurrey (fleshy), Saxifraga tridactylites (rosette-form), etc.

3. Mesophytic Annuals - e.g., corn-buttercup, corncockle, herb-Robert, black medick, fool's-parsley, cleavers (a climber), yellow rattle, Poa annua, etc.

Biennials.--Most biennials at the end of the first season die down to tuberous underground structures (p. 111). These often carry a rosette of radical leaves close to the ground (see rosette-type, p. 37)-e.g., foxglove, carrot, burdock, ox-tongue, etc.

Deciduous Trees and Shrubs.-At the approach of winter, these plants lose their leaves. They are not destroyed by cold or stripped off by the wind, but are discarded, as it were, by an act of the tree itself. The deciduous leaf is essentially a summer leaf, typically large, thin, horizontally placed, exposed freely to the light and the wind, and richly provided with stomata on its under surface. Although these characters favour transpiration, there is little danger of excessive transpiration in summer, because the soil is warm and the supply of water is adequate. In winter, however, the possession of these leaves would be injurious, and in most cases fatal to the plant. The soil is cold, and very little water is absorbed by the roots. If, under these circumstances, transpiration could not be controlled, the plant would lose more water than it could get, and death would follow from drought. To meet this peril, the tree forms a layer of cork across the base of the leaves in autumn. The leaves, thus cut off from their water-supplies, dry up and die, and, a layer of cells just outside the cork splitting, they easily become detached and fall to the ground. And so the tree, which during the summer stood up, with its thousands of expanded leaves - a typical mesophyte - becomes now a leafless xerophyte, with bare cork-covered twigs, and the buds which will renew its foliage in the spring protected from desiccation in many and wonderful ways.

Buds and Bud-Protection.-In perennial plants, the assimilating organs are formed in buds, which are situated 
laterally in the axil of the leaves or terminally at the end of the branches. Each bud consists of a condensed shoot-axis bearing leaves. On herbaceous shoots the buds develop immediately into leafy shoots or flowers until exhaustion puts an end to growth. The leaf-buds of trees are formed in autumn and develop in the following spring. They have therefore to endure the winter. To equip them for this, various xerophytic characters and habits are assumed. The bud is primarily protected against excessive transpiration by the fact that a number of leaves are closely packed together in a small space. In addition, they are usually surrounded by corky scales, which allow no water or water-vapour to pass either in or out. The escape of water from within would lead to the desiccation of the bud; the entrance of liquid water from without would cause it to rot, or at least make it more susceptible to injury during frost. Additional security against drought is provided, in some cases, by the young foliage-leaves within the bud being covered with cottony hairs, and the scales being closed and sealed by a secretion of gum. Bud-scales, cork, cotton, and gum are, without doubt, all adaptations primarily directed against drought, but they benefit the buds in other ways too. They preserve the tender parts within against rapid changes of temperature, from the ravages of injurious insects, and from the attacks of disease-spreading bacteria and fungi. A certain amount of protection is also afforded to buds while they are immature and developing. This is secured by their position in the leaf-axils, where they are, to a greater or less extent, covered by the leaf-bases. In the plane, the leaf-base envelops the whole bud, so that it is not seen until the leaf falls; in the willows and roses the stipules are so placed as to ward off the wind; in the elder and currant (Ribes) the sheathing leaf-bases act in the same way.

The morphology of the bud-scales varies; they are always leaves or parts of leaves. In the honeysuckle, privet, lilac, and holly they are complete leaves and green, but somewhat modified from the ordinary foliage-leaves. In the horse-chestnut, cherry, elder, maple, ash, and plum they are leaf-bases only. In the sweet-chestnut, lime, rose, pear, elm, blackberry, birch, oak, hazel, apple, beech, poplar, willow, and hawthorn they are modified stipules. 
In the spring, when the buds open, the bud-scales fall off, leaving scars on the shoots. The shoot does not elongate in the region of these scars, and if we examine an old twig we can, by noting the places where these scars are close together in a series of rings, determine how old the twig is, and how much it has grown each year.

Geophilous Plants.-This term, which means earthloving (Gr. ge, earth; phileo, I love), is applied to those herbaceous perennials which, after flowering, die down to the ground. During winter either nothing at all shows above ground or a rosette of closely-packed radical leaves lie just on the surface of the soil. The important part is underground. The tulip hibernates in a bulb (p. 156), the crocus in a corm (p. 158), the meadow-saxifrage in bulbils (p. 160), the potato in tubers (p.111). The fern dies down to a short, thick, unbranched, erect rhizome, or "root-stock" (p. 110); the dog's-mercury, coltsfoot, and couch-grass to long branching rhizomes (p. 110). All these perennating* organs are stem-structures, well stored with food, from whose buds arise the shoots which appear above ground the following spring. These aerial leafy shoots are hygrophytic, mesophytic, or xerophytic, according to the water-conditions which prevail during the summer :

1. Many marsh-plants are hygrophilous geophytes, dying down in the winter to rhizomes which hibernate in the mud-e.g., reeds, sedges, horsetails, reed-mace (Typha), common reed (Phragmites), etc. Plants living in moist shade like wood-sorrel and the moschatel (Adoxa) may be regarded as less pronounced hygrophilous geophytes.

2. The majority of our herbaceous perennials show no decided summer habit, and are therefore mesophilous geophytes: white deadnettle, toadflax, mint, chervil, tulip, crocus, etc.

3. A few are even xerophytic in the summer-e.g., Sedum Rhodiola, a large-leaved alpine stonecrop, and Psamma, the sand-dune grass, etc.

Bulbs.-As an example of a pronounced geophyte, we will take a bulbous plant. If a narcissus or tulip be dug up in September, it will be seen that a new leafy shoot is packed away in the bulb in the form of a large bud

$$
\text { * Latin, perennis = lasting. }
$$


(Figs. 59, 60). The flower is also there, and so far developed that all its different parts may be quite easily recognized and separated. In this bud-like condition the plant hibernates out of harm's way, protected from wind and weather. "As soon as the frost is gone, and the first warm days of spring arrive, the little shoots break from their bulbous cradles and grow into the air. In a short space of time-about two months - the plant has flowered, set its seeds, and died down again to the ground.

To what conditions of climate is such a life as this adapted? Clearly to one where the unfavourable season is long and the vegetative season very short. Some of our bulbous plants, both native (snowdrop) and alien (hyacinth), are the first flowers of spring. Plants which depend upon seed for their renewal require a warmer temperature for germination than buds require for growth. They must therefore wait a little longer, till the spring is more advanced. This delay is immaterial when the vegetative season is long, but when it is short it is important that the plant should start on its career as soon as possible, and, like the snowdrop, take advantage of the first warm days of spring.

Most of the bulbs and corms which are cultivated come from the dry and sunny parts of the world. The narcissus is a native of the Mediterranean region, lilies come from Asia Minor, tulips from Siberia, and the gladiolus from South Africa. In these countries the middle of summer, besides being dry, is very hot, and where this is followed by a long, hard winter, as in Siberia, the vegetative season is reduced to the spring. When the drought of summer comes, most of the ground-flora perishes, and among its earliest victims is the bulbous plant.

Marsh-Plants.-These plants live in a soil which is always saturated with water, but the greater part of their leaves and stems is in the air. Since water is always abundant, they naturally show many of the characters of water-plants (e.g., large internal air-spaces), and most of them may be submerged for a long time without injury. On the other hand, they agree with land-plants in possessing a good vascular and mechanical system, for they draw their water from the ground, and their assimilating organs are exposed to the air. The air over the marsh is sometimes dry, especially when the wind is blowing. 
This does not matter in summer, when the soil is warm, for there is plenty of water, and the roots are active. In winter, however, the water is cold, and there is danger of excessive transpiration. For this reason most marshplants are tropophytes, and die down in winter. Those that remain evergreen show xerophytic characters (p. 31). When the water becomes sour, the marsh passes over into the bog, and the number of xerophytic forms increases. The same thing happens as it becomes salt, the salt-marsh vegetation becoming markedly xerophytic.

Biological Classification of Plants in Relation to Water.

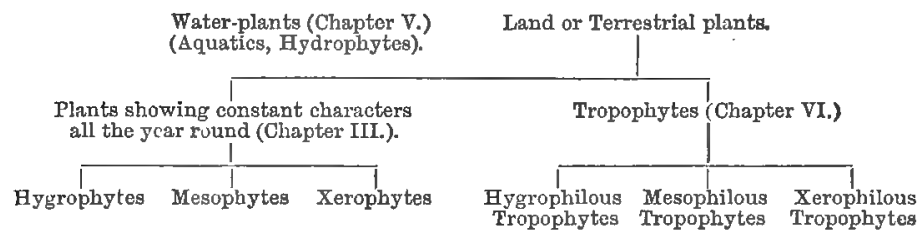




\section{CHAPTER VII}

\section{LIGHT AND HEAT}

THE ancients worshipped the sun as the source and giver of all good things. And so it is, for without its creating and sustaining energy this world would be a dead and tenantless globe, without sunshine and shower or any green and living thing. The energy of the sun's rays is manifested to us under two forms :

\section{Light. \\ 2. Heat.}

The sun is always pouring into space streams of energy. These are transmitted as movements or undulations of the ether, a medium which is supposed to fill all space and penetrate all matter. The vibrations or undulations set up by the sun in the ether travel with incredible speed186,000 miles per second-and in less than nine minutes .traverse the vast distance (over 90,000,000 miles) which separates the sun and the earth. Light itself is invisible ; it is a sensation or form of consciousness produced in the brain by certain rays when they strike upon the sensitive nerves of the eye. Heat, on the other hand, is produced whenever the rays falling upon a material body are absorbed. What is really absorbed in this case is energy, and the rise in temperature is due to the increase of energy thus received. Since light, then, is a mode of consciousness, sunshine is only light to those that see. Plants cannot see. So far as they are concerned, the world is always in darkness, and what, in the daytime, is streaming upon the vegetation is not light, but energy. 


\section{Light.}

An ordinary beam of white light is a bundle of manycoloured rays ; mixed together and falling all at the same moment upon the retina, they produce upon the brain an effect which is manifested in the consciousness as white light. A beam of light may be resolved into its constituent coloured rays by passing it through a triangular prism of glass. Not only are the rays bent or refracted in passing through the prism, but each coloured ray is bent to a different extent, so that, if the emerging beam is caught on a screen, a multicoloured band of light is produced which is known as the solar spectrum. This spectrum contains all the colours of the rainbow, one colour fading into the next imperceptibly. Nevertheless, seven primary colours may be recognized following each other in order : red, orange, yellow, green, blue, indigo, and violet. The red rays are the least refracted by the prism, the violet rays the most. This luminous spectrum, however, does not contain all the rays which pass through the prism. The band is continued at either end by rays which, though invisible, produce other effects. The dark rays beyond the red end of the visible spectrum, falling upon a body, raise its temperature (dark heat-rays); those beyond the violet end do not perceptibly warm, but they act powerfully upon a photographic plate, and so are chemically very active (ultra-violet or actinic rays).

Now, these variously coloured rays are of different value in their influence upon plants. The manufacture of starch in the green leaf is possible only in the presence. of light, and it is easy to find out which rays are the most useful by growing plants under coloured screens. Under a red or yellow screen a plant will be found to be as active in making starch as if it were living in ordinary white light; in a blue or violet light little or no starch will be formed. We conclude from this that the red and yellow rays of the solar spectrum are the most effective in photosynthesis, and that the green chlorophyll present in the assimilating cells absorbs these colours from the beams, and utilizes them in the construction of carbohydrates. This selection of rays accounts also for the colour of green plants; the green pigment absorbs the red and yellow rays, but rejects the green; the rejected 
rays meet the eye, and the plant appears green. Regarded thus, even the colour of the vegetation is an expression of its needs.

Now, in dealing with sunshine and its effect upon vegetation we have to consider two things:

\section{Its intensity.}

2. Its duration.

The intensity of the sunlight is measured by the amount of energy falling upon any space. It varies with the latitude, diminishing from the Equator to the Poles. During the day it increases from dawn to noon, and decreases from noon to sunset. The value of a beam of light, so far as its energy is concerned, is proportional to the angle at which it strikes the earth. When the sun is vertically overhead, as it is twice every year within the Tropics, its effect is the greatest; when it is on the horizon its effect is least. This fact is well appreciated in photography. The chemical salts present in the photographic film are affected chiefly by the actinic rays which lie beyond the violet end of the visible spectrum. In July the lightvalue for exposure at noon is six times as great as at. 7 p.m., while in the latitude of London the lightvalue at noon in January is only one-third of that in July.

The duration of light varies with the seasons. At the equinoxes, when the sun crosses the Equator (March 21 and September 22), day and night are equal throughout the world-that is, each is twelve hours long. When the sun is overhead at the Tropic of Cancer, on June 24 (Midsummer Day), we have the longest day (about sixteen and a half hours in the latitude of London), and consequently the shortest night. The sun is, at that time, more nearly overhead in the North Temperate Zone than at any other, and so has its greatest effect. After midsummer daylight decreases, both in intensity and duration, until midwinter, when the days are less than eight hours in length.

This accounts for the great contrast between tropical and polar climate. Within the Polar Circle the sun is never far from the horizon, while in the Tropics it is always nearly overhead. Again, the polar regions in winter revolve in continuous shade, and there is no day; 
in summer they revolve in the full light of the sun, and there is no night. The long duration of the summer days in Northern regions compensates, in some measure, for the shortness of the summer and the low intensity of solar radiation. In Norway, for example, cereals ripen in a much shorter time than in England. In the Tropics there is no alternation of summer and winter, because the sun is never far from the zenith at noon; the vegetation is therefore always green, and, provided sufficient water is present, does not display the seasonal changes of activity and rest so familiar to us.

Heliotropism.-The growing parts of plants are affected by certain physical forces in the environment, with the result that the different organs tend to turn towards a position of advantage and away from a position of disadvantage. Curvatures of this kind are known as tropisms. Perhaps the most obvious of these tropisms is that which is brought about by oblique illumination. Stems grow towards the light, and the leaves bend so as to receive as much of it as possible. The heliotropism (Gr. helios, sun; tropos, turning) of stems and leaves is easily observed in plants grown before a window in a dwelling-house. The same thing happens outside. Plants growing in shady situations bend towards the direction in which they can catch the greatest amount of light. The stems curve towards a position of advantage, and here the position of advantage is that best suited for assimilation.

Leaf - Mosaic.-Closely associated with heliotropism is the phenomenon of leaf-mosaic. If the leaves of a horsechestnut be viewed from above, it will be found that they are so arranged in regard to size and position that each leaf gets its full share of the light without let or hindrance from its fellows. On looking down upon the leaf-surface of a shoot there is little or no overlapping, and each portion of its area is occupied by a leaf. This arrangement is brought about by the bending of the leaf-stalks under heliotropic influences, and by variation in the length of the petioles and the size of the leaves-e.g., climbing plants like ivy (Figs. 20 and 21). prostrate stems like ground-ivy, rosette-plants like dandelion, and bushes with oblique or horizontal stems like the box, yew, and maple (Figs. 22 and 23). 
The Fixed Light-Position of Leaves.-Every leaf takes up a fixed position with regard to the light, and this position is that in which it receives the maximum average


Fit. 21.-Flowering Shoot of Ivy with Lleaves standing out on all Sides of Stem.

amount of light. This, of course, is only true of those herbaceous forms of leaves which spread out horizontally to catch as much light as possible. In xerophytes the 
tendency is to avoid the direction of strongest light (p. 46).

Sleep-Movements in Leaves '(nyctitropism). - In some plants leaves change their position periodically in relation to light. The trifoliate leaves of the wood-sorrel close together at night (Fig. 24). The three leaflets droop into a vertical position round the petiole, forming a kind of moist chamber with the lower surfaces of the leaves facing inwards. In the clover the two basal leaves rotate



Jig. 22.-Erhct Shoot of Mapti, with Leaves standing oUt on alt. Sides of Sthm. (Reduchd. Afrer Kernhr.)

so as to bring their under surfaces together in a vertical plane, while the terminal leaflet comes down over the top, closing the chamber thus formed. The position assumed at night is one which tends to diminish the loss of water from the lower surfaces of the leaves. On a clear night the eanth quickly cools, and with it the plant. Absorption is therefore diminished, but this is counteracted by the night-position assumed by the leaves. The day-position is of no service to a plant at night, and so they move into 
a position which tends to check transpiration. The stimulus causing the leaflets to move is the withdrawal of light. The vertical position is also a protection against excessive radiation and possible injury by frost. Radiation is greater from a horizontal than a vertical surface;

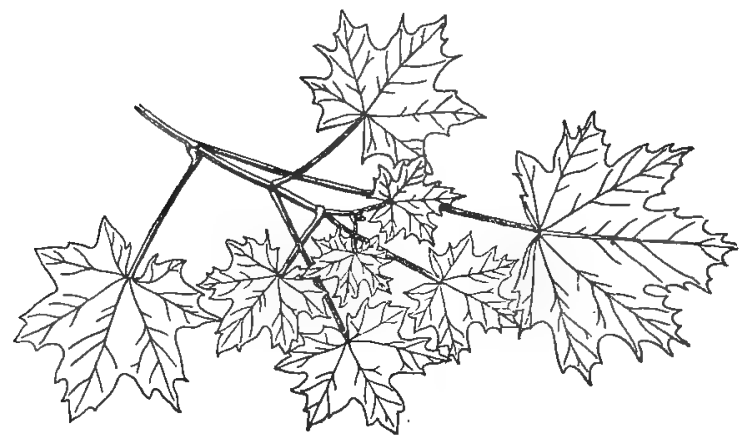

Fia. 23.-Horizontal Shoot of Maple, with Leaves arrakged in One Plane. (Reduchd. After Kerwer.)

there is therefore less risk of excessive cooling when the leaves are in the night-position than if they remained spread out as they are during the day.

Similar movements take place in flowers. The flowerheads of many Compositæ close at night, and only open during certain hours of the day, when the weather is fine


Fig. 24.-LEaF OF WOOD-Sorrel.

1, night-position ; 2, day-position of leaflets.

and warm and the pollinating insects are about. In dull, cold weather they remain closed. By this means pollen and honey are protected from the rain, as well as from marauding insects not engaged in pollination.

The Effect of Light upon Growth.-If potatoes are allowed to sprout in darkness, not only is chlorophyll 
absent, but the internodes become very long and thin, and the leaves produced are small. The diminution in size of the leaves is brought about by defective nutrition, but the abnormal lengthening of the internodes is directly due to the withdrawal of light. Lilies and grasses, under similar conditions, produce elongated leaves. On the other hand, intense illumination has a retarding effect upon growth. It is partly for this reason, and partly also from malnutrition, that arctic and alpine plants are dwarfed in stature. In the shade of hedges and woods

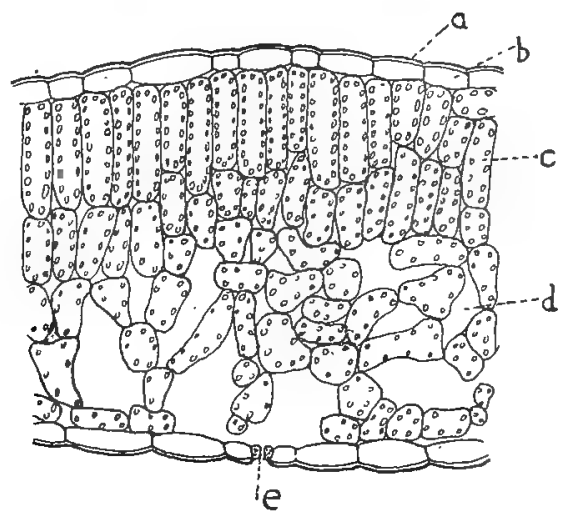

Fig. 25.-Transvirse Section of Sun-Leaf of Whortleberry (Vaccinium. Myrtillus). (HroHLY Magnified.

$a$, cuticle ; $b$, epidermis ; $c$, chlorophyll-tissue ; $d$, air-space ; $e$, stoma.

there is enough light to keep the plants green, but it is sufficiently weak to produce long internodes. Such plants have a long, weedy appearance, approximating to that observed in plants grown in darkness (p. 119). In sunplants the leaves are generally small and thick, with many layers of chlorophyll-containing tissue. In the shade, on the other hand, the leaves are thinner, because the light is too weak to penetrate more than one or two layers (Figs. 25 and 26). To some extent, however, this diminution in thickness is compensated by the larger size of the shade-leaf. In many trees and bushes there is a marked difference in size between the leaves on the sunny side and those on the shady. The latter are much larger than the former. 
The Colour of Young Leaves and Shoots.-In some cases young leaves are, for some time after emerging from the bud, reddish in colour. As the leaves grow older, this pigmentation gradually passes away, and the natural green colour is assumed. The pigment is contained in the sap, and is protective. The phenomenon is chiefly observed among plants in the Tropics, where the light is very strong. Certain rays of the spectrum-chiefly the blue and the actinic, which are very abundant in strong light-act injuriously upon the chlorophyll, especially in young leaves. The red sap, by absorbing these rays,

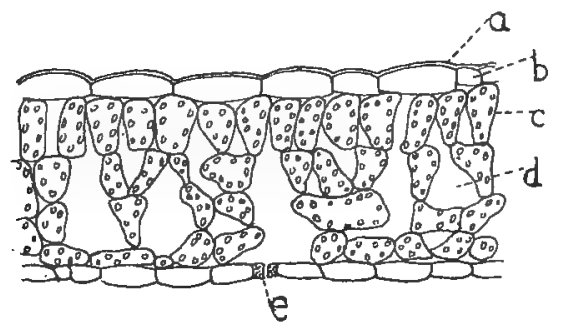

Fig. 26.-Transtirse Section of SHade-Leaf of Whortleberry.

$a$, cuticle; $b$, epidermis ; $c$, chlorophyll-tissue ; $d$, air-space ; $e$, stoma.

screens the chlorophyll from damage, at the same time allowing the red rays, to which it is transparent, to pass into the assimilating cells.

\section{Heat and Cold.}

But for the heating effect of solar radiation, the world would be so cold that life of any kind would be impos. sible on its surface. In the neighbourhood of freezingpoint most of the vital activities manifested by plants sink to zero. A further increase in cold becomes dangerous, and in most cases a point is soon reached when the aerial organs are killed. Some plants, however, can withstand a great deal of cold. In one case, recorded from Siberia, a plant was suddenly caught in the grip of winter while in full flower; the sap froze hard, and animation was suspended for many months. When the frost broke, the plant thawed and renewed its activity at the point where it left off, just as if nothing had occurred. 
For every plant there is a certain limit of temperature below which it cannot live, and for some hibernating structures like dry seeds the temperature which they can survive is very low indeed. Of all living things, the seed is able to resist the greatest cold, and for this reason it is looked upon as the most pronounced xerophytic structure in Nature ( $p .59)$. Geophytic structures such as bulbs, rhizomes, etc., also survive refrigeration. Herbaceous organs, on the other hand, suffer severely at low temperatures, and in some cases, especially when they contain a great deal of water, they are killed off at the first frost.

Heat and cold, as such, seem to evoke little or no protective adaptations in plants. They act indirectly through the water-factor, and cannot be disassociated from it. Cold, for example, diminishes absorption by the roots, and therefore necessitates a control of transpiration ; cold regions are therefore regions of physiological drought, and their vegetation is xerophytic. Heat, on the other hand, increases the activity of all the functions, absorption and transpiration alike; but as the area which absorbs is generally very much less than the area of the surfaces which transpire, and as a rise in temperature increases all the factors favouring transpiration, a high temperature tends to make the loss by transpiration excessive and dangerous. Hence hot regions, unless they are constantly moist, are regions of physiological drought, and the vegetation is xerophytic. Thus, extreme heat and extreme cold both lead to xerophytic adaptationthe latter always, and the former when the water-supply becomes insufficient for the increased demands. Apart from this, however, it is pretty clear that some plants are constitutionally better able to stand cold than others; those are most delicate whose tissues contain much water : plants accustomed to alpine surroundings must naturally be better able to stand cold than the inhabitants of warmer regions. There are some common plants, also, which flourish during winter without showing in their structure any particular marks of protective adaptation. The chickweed, for example, lives throughout the winter, survives frosts, and yet shows no special adaptations by which we can explain its immunity; even its buds are not protected. It must therefore be constitutionally hardy. 
Its protoplasm must be made of sterner stuff than most plants.

Although little is known as to the physiological causes which enable some plants to withstand low temperatures, it is probable that the density and nature of the sap play an important part. It has been demonstrated that the most hardy of the magnolias possess the densest sap. Again, it has been shown in the case of some plants which resist severe frosts that the insoluble starch in the leaves becomes replaced by soluble sugar during the winter, whilst seedlings and leaves which have been fed with a sugar solution can withstand a lower temperature than they normally do. The reason that has been suggested for this is that, in the ordinary course, when the sap begins to freeze, water is withdrawn and the sap becomes more concentrated, with the result that the proteins in solution in the sap and protoplasm separate out, but that if sugar is present this "salting out " process takes place at a much lower temperature.

Acclimatization of Plants.-Southern races habituated to warm conditions are very susceptible to cold, and not easily cultivated in cold countries, except in warm greenhouses. Some plants, however, may, if suitable measures be taken, be gradually acclimatized. During the winter they are kept in the greenhouse; in the spring they are not put out in the open at once, but are first transferred to a cooler house or frame till they are hardened off. In this way they are gradually inured to colder conditions before being bedded out. 


\section{CHAPTER VIII}

\section{THE ATMOSPHERE}

Is the Introduction we pointed out that the air was a mixture of gases, and we referred briefly to the part played by these gases in the life of plants. This was dealing with the atmosphere from the chemical side. It remains now to say something of the physical effects of air upon plants-that is to say, of air in motion-wind.

Wind.-The effect of wind upon vegetation is twofold : (I) It promotes evaporation, and therefore increases transpiration; and (2) it lowers the temperature of the bodies over which it blows. The second effect is really a consequence of the first; for a body which is losing water by evaporation is at the same time losing heat and becoming cooler. Heat is required to change any liquid into vapour ; where the heat is not imparted from without, the body from which the water is evaporating provides it, and its temperature falls. Common experience testifies in a very simple way to the truth of this. A person, exerting himself greatly, becomes hot and perspires. If he takes off his hat, a pleasant coolness accompanies the disappearance of the perspiration from his head. Again, if ether is poured upon the hand, it evaporates away in a few seconds, but heat for the purpose is drawn from the hand, which therefore experiences a sensation of cold.

Wind promotes evaporation by constantly and rapidly renewing the air in contact with the evaporating surfaces. Wet clothes dry quicker when a breeze is blowing than in a calm. Plants suffer in the same way, and when the wind is strong, they are in danger of losing more water than they can afford. This danger is increased by the drying and the cooling of the soil, and the decrease in 
absorption resulting from it. Plants which grow in windy situations therefore exhibit xerophytic characters, or they soon perish, and where the wind is incessant and frequently violent, tall growth fails altogether, giving place to a low or dwarfed vegetation. This is well seen on wind-swept downs by the sea. On Beachy Head, for example, trees are absent, and the ground is covered with short, thick grass ; what bushes there are are low, stunted, and dense, while the herbaceous weeds scarcely rise above the level of the herbage. It is curious to observe how plants which in the sheltered hollows and dips grow to their natural size of several feet, sink on the exposed downs to an inch or two, bearing a few leaves, and perhaps a single flower. But the flower is not reduced in any way; if anything, its colours are brighter than usual.

Where trees occur in windy places, they are bent away from the wind, and the branches and foliage develop entirely on the sheltered side. This is because the buds on the exposed side do not develop, or, if they do, the young shoots arising from them are killed by the drying action of the wind. Sometimes a curious phenomenon is witnessed. Springing from a broad crown of foliage rises a miniature forest of short, erect, dead twigs. These were shoots which, in their upward growth, just touched a zone where the wind was stronger than their powers of endurance; they ceased to grow, dried up, and perished.

Atmospheric Equilibrium.-Before leaving the subject of the air, we will refer to a phenomenon which at first sight is not altogether easy of explanation. The world is teeming with life, animal and vegetable. Gases are continually being withdrawn from the air and discharged into it, and yet it is a matter of common knowledge that the constitution of the atmosphere remains practically constant at all times and in all places. How is this equilibrium brought about and maintained? We will endeavour to answer the question by preparing a balancesheet of the losses and gains of the atmosphere: 


\section{Oxygen.}

Loss to the Air.

Gain to the Air.

Oxygen is withdrawn from the Oxygen is restored to the air air, and chemically fixed in other by:

substances in various ways. The Photosynthesis. Green plants process is called combustion, or oxi- in the presence of light withdraw dation, the chief modes of which carbonic acid gas from the air, are:

1. Burning, as by fre (rapid retain the carbon, which they build combustion).

2. The oxidation or rusting of up into carbohydrate, and restore again to the air the oxygen not metals (slow combustion).

3. Respiration, or breathing, both in animals and plants (physiological combustion).

4. Putrefaction and decompos:tion, entailing the absorption of oxygen (organic combustion).

\section{required.}

The gain balances the loss.

\section{Carbonic Acid Gas.}

Loss to the Air.

Carbonic acid gas is extracted from the air in photosynthesis.
Gain to the Air.

It is added to the air during the destruction of organic material. All organic substances are compounds of carbon. They are destroyed by combining with oxygen, being broken into simpler bodies, one of which is always carbonic acid gas :

1. Destruction by slow com. bustion, as in decomposition or decay.

2. Destruction by rapid combustion, as in the burning of wood and coal.

3. Destruction by physiological combustion, as in the respiration of plants and animals.

The gain balances the loss. 


\section{Nitrogen (see p. 99).}

The Interdependence of Plant and Animal Life.-In the preceding section we have drawn attention to the influence of the life and death of organic material upon the constitution of the atmosphere. A large part of organic matter is used as food. Food is eaten by animals for two purposes :

1. By its further elaboration it is made into new tissue, which either replaces the waste of the old or adds to growth.

2. By its destruction during the processes of respiration it maintains the heat of the body, and supplies to every organ the energy necessary for it to perform its functions.

Animals all their lives consume food, but the food which they eat they do not make. The real maker of food, and the only maker, is the green plant, which manufactures from two bodies present everywhere-carbonic acid gas and water-the primary food-stuff out of which all others are-elaborated. Animals all their lives are putting carbonic acid gas back into the air, and from this body food is again made by the vegetation. And so the cycle ever goes on, food being continually re-formed out of the elements of its destruction. Without the green plants there could be no animals, because food would not exist. If animals alone existed, their respiration would, in the course of time, make the air unbreathable, because its oxygen could not be replenished. Without the foodconsuming animals the supply of carbonic acid gas would sooner or later be used up, and the green plant would vanish. The interdependence of plants and animals is complete. 


\section{CHAPTER IX}

\section{THE SOIL : ITS PHYSICAL AND CHEMICAL PROPERTIES}

THE green plant derives its carbon, in the form of carbonic acid gas, from the air. All the other materials required for growth are obtained from the soil. If we burn a plant, the organic matter is burnt off, and an ash is left the materials of which were obtained by the plant, during life, from the soil.

The soil, in which the plant is fixed, and from which it draws its inorganic food, is derived in situ from the breaking up, or "weathering," of the rock-masses upon which it rests ; in other cases the soil has been deposited in its present position by the sea (marine deposits), by lakes (lacustrine deposits), rivers (fluviatile deposits, alluvium), or glaciers (till, boulder-clay), or it may have been blown there by the wind, as in the case of dunes. Mingled with the rock-particles forming the soil are the rotting remains of animals and plants, which form a constituent part of all soils supporting vegetation.

\section{Agents of Denudation.}

The most important natural agencies which bring about the fragmentation of rocks into soil are :

1. Water, which acts in two ways:

(a) Chemically.-The water which falls on and penetrates into the rocks is not chemically pure, but contains gases in solution. The most important of these gasescarbonic acid-dissolves out certain of the mineral constituents, thereby causing the rest of the rock to crumble. Clay is formed in this way from granite. Granite is a rock composed principally of three minerals-quartz, felspar, and mica. Quartz is quite insoluble in water. 
Felspar, chemically, is a double silicate of alumina and potash or lime. Silicate of alumina is insoluble in water, but the silicates of potash and lime are soluble. Felspar, therefore, is the weak point in granite, and in the presence of water it gradually breaks down, owing to the loss of the other constituents which the water dissolves out. Just as the strength of every chain is the strength of its weakest link, so the durability of granite is measured by the durability of its felspar. The disintegration of the felspar causes the whole rock to crumble, the insoluble silicate of alumina being washed away as clay, and the quartz and mica as sand. The mica undergoes a similar series of changes as the felspar, but so much more slowly that it plays very little part in the disintegration of the rock. Water charged with carbonic acid gas also attacks limestone and chalk, dissolving out the carbonate of lime. It is for this reason that limestone hills are often honeycombed with caves and caverns, whose collapse has formed some of the most beautiful gorges in Englande.g., the Cheddar Gorge in the Mendip Hills of Somersetshire.

(b) Physically.-Moving water carries with it solid particles. If the current is swift, heavy stones are rolled along which grind against one another and the rocks of the river-bed. The destruction of sea-cliffs by the waves is partly due to the water undermining the rock chemically, and partly to their bombardment by sand and stones, especially during storms.

2. Frost causes the water which has soaked into the rocks to freeze. When the water turns into ice it expands, and its expansion cracks and breaks the rocks in all directions.

3. Glaciers grind out the beds in which they move. This is not done by the ice itself, but by the angular stones and rock-fragments embedded in it.

4. Changes of Temperature.-In the daytime rocks are heated by the sun, and expand; at night they cool and contract. The effect of these movements, if great, is to shatter the rocks into fragments. The sands of the Sahara Desert have been formed in this way. 


\section{Rocks and Soils.}

The rocks from which soil is derived are either igneous or aqueous in origin. Igneous rocks are those which have been erupted from volcanoes (lavas), or which have cooled down within the earth from a molten condition (granites). Aqueous rocks, as the name implies (Lat. aqua, water), have been deposited under water, in seas and lakes, or upon the beds of rivers. Most soils are derived from rocks of aqueous or sedimentary origin, the chief of which are clays, shales, and slates, which give rise to clay soils; sands and sandstones, from which sandy soils are derived; and chalk and limestone, which form calcareous soils.

The physical characters of a soil depend mainly on the size of its particles and to some extent on the presence or absence of humus (see p. 83). In describing the soilparticles it is usual to fix a more or less arbitrary limit to the size. Those which range in diameter from $1 \mathrm{~mm}$. to $0.05 \mathrm{~mm}$. are designated "sand," those from $0.05 \mathrm{~mm}$. to $0.005 \mathrm{~mm}$. "silt," and those below $0.005 \mathrm{~mm}$. "clay." In a heavy clay soil, the small particles greatly predominate, two-fifths, perhaps, being clay, one-third silt, and less than one-tenth sand. A coarse sandy soil, on the other hand, may contain as much as four-fifths of sand, only about 5 per cent. of silt, and under 2 per cent. of clay. The rest of the soil will consist mainly of humus with a certain amount of chalk and moisture. Soils intermediate in character between the heavy clay and coarse sand are termed loams; when sand predominates the soil is a sandy loam; when clay and silt, a clayey loam. A clayey loam containing chalk is called marl; if the amount of chalk exceeds 20 per cent. it is a calcareous marl.

Clay consists mainly of kaolin (hydrated silicate of alumina), which is derived from the felspar of igneous rocks by the action of weathering. China clay is practically pure kaolin; but in most clays small quantities of quartz, mica, and other minerals are also present. When wet, the particles of clay stick together, forming a wet mass, greasy to the touch, very difficult to dry, and almost impermeable to water. In drying, clay cracks into hard consolidated masses, which the roots of plants cannot penetrate. 
Silt consists of fragments of quartz, felspar, mica, zircon, iron-oxides and other minerals which have resisted weathering action.

Sand consists mainly of quartz, but the other minerals found in silt are also present to some extent. A fundamental character of sand is that it falls to powder when dry and is not plastic like clay.

Chalk is an amorphous form of carbonate of lime; when crystalline, it is limestone. Soils derived from chalk or limestone are naturally alkaline and rich in lime. They usually contain some sand, derived either from the siliceous skeletons of organisms from which the rocks are built up, or from overlying deposits which have been removed by denudation.

Humus.- This is one of the most important constituents of fertile soil ; when it is absent, the ground is sterile and unproductive. More or less of it is present in every soil which supports vegetation, and sometimes the soil consists of little or nothing else. Where plants grow, humus accumulates. The conversion of dead vegetation or animal remains into humus is brought about by germs (bacteria) and fungi living in the soil. Where air is abundant and the ground not too cold, the organic matter in the soil is completely destroyed, the final products of its decomposition being carbonic acid gas, water, and mineral salts-substances valuable to plants as sources of food. When, through any cause, decomposition is checked, dark-coloured "earth"-acids are formed, which have a souring effect upon the soil. If lime, however, is present, it combines with these acids, rendering the humus mild and alkaline, and consequently fertile (p. 94). Enormous masses of humus in the form of peat have accumulated upon the rock-surfaces of the land, where, through lack of air, abundance of water, or extreme cold, decomposition has been arrested. In the form of coal, we dig up and burn as fuel the compacted and mineralized humus of past ages; in the form of manure, the agriculturalist renews the fertility of the fields with "artificial" humus. At the present day peaty matter is constantly being formed on wet, cold moors, on dry, cold heaths, in mossy bogs, whilst in forests large quantities of mild humus are formed from rotting leaves and wood. 


\section{The Relations between Soil and Climate.}

In Chapter I. we considered the factors determining climate, and we learned that differences in the vegetation are associated with differences in climate. But climatic conditions are the same over wide areas, and yet marked and profound differences may be found in the flora. We cannot go far from our doors without seeing this. In some localities we may, in a few hours' walk, pass by cultivated fields, wet meadows, rough fields, dry pastures, reedy swamps, and several kinds of woods and thickets. The climate is the same for all ; it could hardly vary in the course of a short walk. The same is true when we examine the vegetation in an upward direction. Hills of the same height may carry very different kinds of plants. One may be covered with reedy bogs, another with gorse and heather, and another with grassy pastures. Wood differs from wood, and field from field. Even in the same field, when we come to details, many differences are apparent; the vegetation on the dry rising knolls is not the same as in the damper hollows, and disturbed patches can be detected by their distinctive plants, even from a distance. What is the cause of all this variation within the limits of practically the same climatic conditions? It is the soil. All soils do not react in the same way to climate. The sun's rays will warm one kind of soil much more than another; with the same rainfall some soils become wetter and remain wetter than others. In a short journey we may tread many kinds of soil, each bearing its own characteristic plants. Climate determines the broad features of the vegetation, but the minor differences in the flora are due to the character of the soil and the way it behaves towards the external sources of heat and moisture.

The relations between soil and climate must therefore be considered under two aspects :

I. The reaction of the soil to water.

II. The reaction of the soil to heat.

I. Soil and Water.-The most important soil or edaphic factor is the amount of available water present. This clearly depends upon- 
(a) The amount of water entering the soil ;

(b) The character of the water; and

(c) The power of the soil to retain it.

\section{upon- \\ (a) The Amount of Water entering the Soil depends}

1. The amount of water received from above-i.e., upon the rainfall, and upon the percolation of water from rivers and lakes, springs, and adjacent sheets of water.

2. The amount of water sucked up from below. This depends upon the size of soil-particles, the presence or absence of ground-water, and its depth below the surface of the soil during the vegetative season.

(b) The Availability of this Water to Plants depends, as we have already shown, upon its chemical nature. The roots of plants can only absorb very weak alkaline solutions. For this reason, if the proportion of material in solution in the water is greater than a certain small amount (1 to 3 per cent.), or if souring acids be present, the soil, though it may be physically wet, is physiologically dry, and little water is absorbed. The soil also must be well aerated, otherwise the water present is useless.

(c) The Amount of Water retained by the Soil depends upon its physical properties, and the physical properties are all directly or indirectly connected with the size of the particles forming the soil.

The Physical Properties of the Soil, and their Relations to Water.-The rock-fragments forming the soil vary in size from large stones to an impalpable dust, which, when dry, remains for a long time suspended in water, and which, when wet, becomes compacted into a greasy, heavy clay. The particles, however, touch one another at a few points only, leaving between them pores, or spaces, which are normally filled with water and air. In ordinary soils the water forms a film of varying thickness round the particles, air occupying the rest of the pore-space. As the particles are in contact, the water-films surrounding them are everywhere in continuity with one another. These films are elastic, and the withdrawal of water at any point sets up a flow of water along the adjacent films until equilibrium is restored. If a section of some coarse-grained soil containing water be examined, it will be seen that the water-films increase in thickness as we 
descend, until, at the level of the ground-water, all the pore-spaces are filled with water. Towards the top, the films become very thin and stretched, and if the section is sufficiently thick, the topmost layers may be perfectly dry. As the films become more attenuated, it is increasingly difficult to withdraw water from them, and at last a point is reached when no more water can be withdrawn without rupturing them. This last layer is very resistant; it is difficult to break, and constitutes' what is known as hygroscopic water in soils apparently dry. Hygroscopic water is of no service to plants because it cannot be drawn from the films. From all films thicker than these water may be withdrawn, but in decreasing quantity as we approach the hygroscopic limit. Such water is called capillary water, and this alone is available to plants. When all the pore-spaces are filled with water the soil is said to be saturated, or waterlogged ; if drainage is possible and the excess allowed to drain away, the water that is left remains as films round the particles, the rest of the pore-spaces being filled with air. When during a shower water percolates through a sandy soil, it passes down to the water-table through the water-films.

1. The Capillarity of the Soil.-The pore-spaces in the soil form a series of irregularly branching tubes. These tubes are everywhere in communication with one another, opening above into the air, and reaching below to the ground-water. The power of the soil to absorb and retain water depends upon the number and width of these capillary tubes. In a narrow tube the water ascends to a greater height than in a wide tube, and is more difficult to displace. In soils where the particles are very small and very close together, the capillary tubes are very minute, and much more numerous than in coarser soils, where the air-spaces between the particles are larger. The ascent of water, therefore, is greater in fine-grained soils than in coarse. The capillarity of the subsoil becomes very important when ground-water is present. With the level of the water-table at a certain depth, some soils may be able to make use of it by suction, while others may not.

2. The Water-Capacity of Soils.-There are two limits to the water-holding capacity of soils. The higher limit 
is when the soil is saturated and all the air-spaces are filled with water ; the lower limit, when the water present is reduced to the hygroscopic film. The former is the maximum, and the latter the minimum water-capacity. The maximum water-capacity obviously varies as the pore-space. Coarse-grained soils have less pore-space than fine-grained soils. In the former, the individual pore-spaces are larger, but there are fewer of them, and the total pore-space is less. For this reason the watercapacity of clay is greater than that of sand in the ratio of about 7 to 5. Peat has the highest water-capacity of all soils.

3. Water-Retaining Capacity of Soils.-This is measured by the amount of water a soil can retain after the excess of water is drained off. The water-retaining capacity of coarse sand is about 13 per cent. of its volume-i.e., 100 cubic feet of sand can absorb 13 cubic feet of water, and retain it without dripping. Compared with this, the water-retaining capacity of clay is 41 per cent. of its volume; that is to say, clay can hold and retain three times as much water as sand.

4. Permeability of Soils. - This is measured by the rate at which water is able to percolate, or soak through, a certain depth of moist soil. Water runs through loose sand more quickly than through soils of closer texture. Clay is almost impermeable, but the water that is absorbed is very tenaciously held, and it takes a long time to drain or dry it out.

5. The Absorptive Power of Soils. - If equal weights of different soils be exposed during the night, when the air near the ground is nearly saturated with water-vapour, they will be found, in the morning, to have increased in weight, but each to a different extent. The increase in weight is due to the amount of water absorbed: in one experiment it was found that 1,000 pounds of sand, exposed for twelve hours, increased in weight $1_{\frac{1}{2}}^{1}$ pounds ; the same amount of clay increased 35 pounds, and peat as much as 40 pounds.

II. Soil and Temperature.-The sun shines on all soils alike, but some become warm more quickly than others. For example, a dark soil absorbs more heat than a light soil, and a dry soil becomes warmer than a wet soil. In 
wet soils, the greater part of the heat absorbed is used up in evaporating the water, and very little remains to raise the temperature of the mass. A soil constantly damp is therefore cold. In a dry soil little water is present, and most of the heat absorbed is utilized in raising the temperature of the particles. In a wet country like ours a pure clay soil is not generally desirable, for, besides being cold and wet, it is heavy and expensive to work. In the South of France, however, where the climate is warm and dry, such a soil is valuable becxuse of its power of retaining water during long intervals of drought.

Aeration of the Soil.-The presence of an adequate amount of air in the ground is very important. The underground parts of plants have the same need of oxygen for respiration as the parts growing in the air. The oxygen passes into the roots in solution in water, or, if the roots are old and woody, through the lenticels, or air-holes, upon their surface. A poorly aerated soil is a soil deficient in oxygen, and therefore unfavourable to plant-growth. Deficiency of oxygen leads to imperfect respiration, and this entails a checking or lowering of all the vital functions, root-absorption among them. Deficiency of air in the soil also means the absence of bacteria and earthworms as well as the production of "souring" acids from rotting material, which has a still greater unfavourable effect upon absorption.

The Chemical Properties of the Soil.-Generally speaking, the chemical properties of the soil are far less important than its physical. In two cases only does the chemical nature of the soil seem to have a marked effect on the flora:

1. Salts.-No other salt is so universally present in soils as common salt (sodium chloride). Generally, the quantity is small, but in some localities the amount is considerable, especially along the margins of the sea, and in the proximity of salt lakes and marshes. The characteristic plants in these places are halophytes (Gr. halos, salt). These are succulent (e.g., glasswort, Fig. 10), a type usually associated with desert-conditions. In a desert rain seldom falls, but when it does the plants absorb as much of it as they can, and store it up in special tissues for use during the long intervening periods of drought. The seashore is a physiological desert. Though 
much water may be present, it is too salt to be of any use. Halophytes can digest salter water than most plants, but the percentage of salt in ordinary sea-water is too much even for them. Just as with plants in the physical desert, they can only get water when it rains. The fresh water entering the soil mixes with the salt water, and dilutes it sufficiently to make it available to the plants.

In hot, dry climates, as in Egypt and parts of India, there is a large accumulation of alkali salts in the soil, particularly of sodium carbonate. Sometimes they occur in such quantity as to form a white crust on the surface. Their presence inhibits plant-growth to as great an extent as an excess of common salt, and the natural vegetation is typically xerophytic.

2. Chalk. - Chalk-i.e., carbonate of lime-is insoluble in pure water, but when carbonic acid is present, it is converted into the soluble bicarbonate. The presence of the bicarbonate makes water " hard," and plants growing in chalky soils absorb it. Although most plants are indifferent to soils rich in lime, it seems certain that a few plants prefer them (calciphilous plants), while others avoid them altogether (calcifuges). The most pronounced calcifuges are: gorse, broom, bracken, foxglove, ling, heath, bogmoss (Sphagnum), and sundew. These are supposed to die in water containing more than $\frac{1}{2}$ per cent. of carbonate of lime. But it has been proved that if no other salts are present, the lime itself does the plants no harm. It seems that here, again, the important thing is not so much the nature of the body in solution as the amount dissolved. Some plants can stand a considerable quantity; others, like calcifuges, very little.

It is also stated that the general character of the vegetation living on a soil rich in lime is xerophytic. This is generally true, because most of our calcareous rockslimestone and chalk-form hills or downs, and the rock is porous and consequently dry. If, then, on limestone hills or chalk downs the flora is xerophytic, it is probably due to physical causes-wind, drought, etc.-and not to the chemical nature of the soil, unless, of course, the total amount of dissolved salts present in the water reaches a dangerous degree of concentration. 


\section{Comparison between the Physical Properties of Sand and Clay.}

Sand.

1. Particles large.

2. Individual air-spaces large; total pore-space small.

3. Cohesion of the particles very small.

4. Firm and gritty to the touch.

5. Maximum water-capacity small.

6. Amount of hygroscopic water small.

7. Water - retaining capacity small.

8. Very permeable to water.

9. Capillarity small.

10. A dry soil.

11. A warm soil.

12. When dry, is friable and does not crack.

13. Drainage natural and easy.

14. A sterile soil, since soluble matter is easily washed out of it.

15. A light soil, easy to work.

\section{Clay.}

1. Particles small.

2. Individual air-spaces small; total pore-space large.

3. Cohesion great.

4. Soft and greasy to the touch when wet.

5. Maximum water - capacity great.

6. Amount of hygroscopic water great.

7. Water - retaining capacity great.

8. Almost impermeable to water.

9. Capillarity great.

10. A wet soil.

11. A cold soil.

12. When dry, is hard and cracks.

13. Drainage difficult.

14. A fertile soil, since it is difficult to wash soluble matter out of it.

15. A heavy soil, hard and expensive to work.

Chalky soils occupy an intermediate position-in some characters more approaching sand, in others clay. The best soil is that which, while light and warm, is fertile in plant-food, and contains plenty of water, without appearing wet. No one of the above soils fulfils all these conditions, but by suitably mixing sand, clay, and chalk together a loam is obtained which answers most of these qualifications fairly well. 


\section{CHAPTER $\mathbf{X}$}

\section{THE BIOLOQY OF THE SOIL}

WE are now able to form an idea of the true nature of the soil in which plants live. In the preceding chapter we looked upon it as a mixture of rock-fragments supplied with a certain amount of water, air, and solar warmth. It is really much more than this. Upon its surface rests a covering of green, and within it dwells a living world of animals and plants which, by their activity, fit it to become an abode for the green vegetation that rises from it into the air and light.

A broad view of the soil will therefore include the following considerations :

1. The earth or soil itself, its physical and chemical properties.

2. The water contained in it.

3. The air contained in it.

4. The warmth received by it from the sun.

5. The humus contained in it.

6. Its living populations:-

(a) Its surface covering of green.

(b) Its underground inhabitants.

(i.) Plants-e.g., fungi and bacteria.

(ii.) Animals-e.g., earthworms.

Osmosis and Selective Absorption.-In the last chapter we described the mode of occurrence of water in the soil. The plant absorbs water through its root-hairs. These are in contact with the soil-particles, and consequently with the water-films surrounding them. When water diffuses from these films into the root-hairs, water is drawn along all the adjacent films until equilibrium is 
restored. In this way, the roots can explore for water a larger extent of soil than that actually occupied by the root-hairs, the suction extending farthest where the " capillary tubes" are narrowest.

In most cases the particles round which the waterfilms occur are insoluble solids, the films alone containing the soluble matters. In clay, however, the particles of which consist chiefly of silicate of alumina, the outer layers form with water a jelly-like material surrounding the grain. This jelly-like form of the silicate has a greedy attraction for water, and, when wet, swells like mucilage, blocking up the narrow pore-spaces. It is partly for this reason that wet clay is greasy to the touch, so difficult to dry, so absorbent of solutions, and almost impermeable to the passage of water.

The root-hairs present on the roots of plants are merely certain surface-cells very much elongated to increase the absorbing surface of the roots. There are no actual holes for the passage of water as there are in the leaves for the interchange of gases. The water passes through the walls of the root-hairs into the interior of the cells by a physical process known as liquid-diffusion, or osmosis. To reach the cell-sap, it is clear that the water must penetrate two very different membranes:

1. The outer cell-wall, or membrane, formed of cellulose, and non-living. This membrane is permeable to water and all watery solutions of mineral salts, whatever their strength may be. The activity of the diffusion-current depends upon the strength of the solution outside the cell compared with the strength of the solution inside, and it becomes greater as the difference between the concentration of the two liquids increases. If the soil-water is very dilute, there is an active current of water passing inwards. If, on the other hand, the external water contains a large amount of soluble salts, and its concentration approaches that of the cell-sap, the quantity of water diffusing inwards is very small; and if its concentration exceeds that of the sap, the current is actually reversed, water is withdrawn from the cell, and the protoplasm collapses (plasmolysis-Gr. plasma, the protoplasm ; lysis, loosening). The result to the plant is disastrous. It is for this reason that only very dilute solutions pass right through to the inside of the cell, and that 
absorption diminishes as the concentration of the external water increases. (Compare Halophytes, p. 88 ; and Chalk-Plants, p. 89.) The critical point is reached when the outside water and the cell-sap are of the same strength. Absorption then ceases entirely.

2. The second membrane through which the water has to pass to reach the central sap is the living protoplasm, which forms a film lining the inside of the cell-wall. Whereas the cellulose-membrane is permeable to all liquids of any degree of concentration, the protoplasmic membrane allows only certain solutions. to pass through it, and these only in a very dilute condition. One is a living membrane, and the other is not, and it is the living membrane which controls the intake of water, and determines in what proportion the various substances present in soil-water shall enter the plant. This is known as selective absorption. Thus, if two solutions of equal strength-one a salt of soda, and the other a salt of potash -are presented to a cell, a greater proportion of potash will pass through the protoplasm into the interior than of the soda. This happens to serve the plant very well, since potash is the more valuable salt.

The Qualities of Humus - Soils.-All soils supporting vegetation contain humus. Humus in quantity forms peat, and the qualities of peat depend upon :

1. The origin of the peat.

2. The nature of the plants forming it.

3. The amount of water contained in it.

4. The amount of soil mixed with it.

5. The amount of air contained in it.

6. The amount of lime in it.

7. The presence or absence in it of fungi, soil-bacteria, and earthworms.

The destruction of organic matter and its conversion into humus is the work of minute non-green vegetable microbes, known as bacteria. The first stage of the process, putrefaction, is effected by bacteria which are able to live without air-that is, without oxygen. These are called anä̈robic bacteria (Gr. a; an, not; aër, air). The further stages of decomposition are brought about by a succession of soil-bacteria, which cannot thrive without oxygen (aërobic bacteria).

The complete decomposition of organic matter by these 
aërobic forms leads to the formation of mild humus, which forms a slightly alkaline, well-aerated fertile soil. Mixed with earth, it forms mould, the most valuable of all soils-e.g., leaf-mould, peat-mould, etc., according to the origin of the humus.

When decomposition is checked, raw or acid humus is produced. This takes place when any cause is present which renders the humus unfit for the existence of aërobic bacteria-e.g. :

1. Deficiency of oxygen.

2. Excess of water excluding air.

3. Too low a temperature.

4. Deficiency of lime.

The acidity of raw peat is due to the fact that in the absence of sufficient oxygen and lime free "earth "-acids are produced which sour the soil.

If the causes which exclude the bacteria be removed by drainage, etc., the aërobic bacteria resume their sway, the humous acids disappear, and a mild humus is produced.

The presence of vegetable fibre in soil increases its capacity for water. Peat itself is a perfect sponge; it has a greater water-capacity than any other soil. Sour peat, whether wet or dry, is poor in nutriment, for the form in which the nutriment exists is not one available to plants; it contains many fungi, but few bacteria and no earthworms. Peaty matter is accumulating wherever vegetation is flourishing and the soil is cold or wet. Leafmould is forming in forests, mossy humus in bogs, fibrous peat on heaths.

\section{The Living Populations of the Soil.}

1. Soil Bacteria.-Countless swarms of bacteria-a few malignant, but the most so beneficent as to be indispensable to plant life-inhabit the upper layers of the soil. It seems likely that most of the chemical changes taking place in the soil, especially in its organic constituents, are due to their activities. The most important are the following:

(a) Nitrate - Bacteria. - The nitrogenous compounds present in decaying organic matter are decomposed in 
three stages. Each stage is effected by a different kind of bacterium. In the first, compounds of ammonia are produced, but these can only be effectively utilized as food by fungi. If air is plentiful, these ammonium - compounds are converted into nitrites, and finally into nitrates. In the form of nitrates, they constitute the sole source from which the green plant obtains its nitrogen.

(b) Nitrogen - Bacteria. -A few bacteria, however, are able to assimilate the free nitrogen that exists in the atmosphere, just as green plants assimilate carbonic acid gas. These

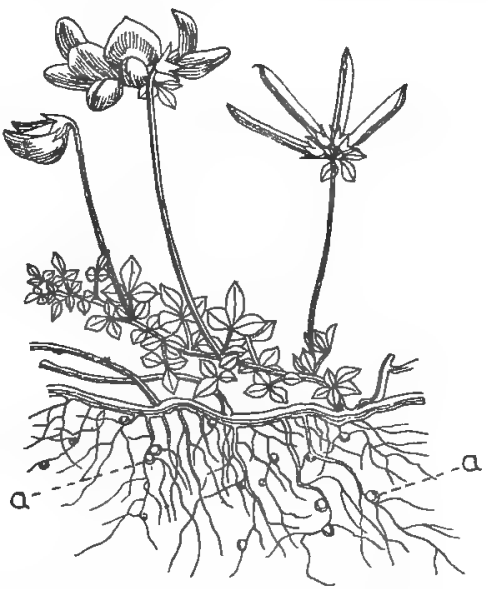

Fra. 27. - Brid's - Foot Trefort (Lotus corniculatus), SHOWING ROOTNodULes (a). bacteria are present in all well-aerated soils. By their agency the soil is always being replenished with nitrogen, for when they die their bodies are decomposed and nitrates produced.

(c) Root-Nodules.-Other bacteria which utilize atmospheric nitrogen inhabit the bodies of green plants. They swarm in the nodules, or swellings, which occur so abundantly on the roots of leguminous plants-e.g., peas, beans, clover (Fig. 27). For this reason, leguminous crops may be raised in a soil from which nitrates are excluded; they make no demands upon the soil for this salt, and if they are dug into the ground at the end of the season, they actually increase the amount of available nitrogen present in it (see Symbiosis, p. 132).

2. Soil Protozoa.-Minute unicellular animals occur in enormous numbers in the soil and play a prominent part in determining its fertility. These protozoa feed on the soil bacteria, and if present in too great abundance hinder, or even prevent, the formation of nitrogenous salts. In such cases, by partially sterilizing the soil by means of antiseptics, and particularly by heating it, its 
fertility is improved; and this effect has been attributed to the consequent destruction of the harmful soil protozoa.

3. Earthworms.-Charles Darwin, in his classic work on Earthworms, has revealed to us the rôle played by these humble creatures in Nature. They inhabit most soils containing a mild alkaline humus, which they pass through their bodies, depositing the "casts" upon the surface. They are thus always transplanting soil, bringing it from below and exposing it to the air-ploughing, as it were, the land. Darwin estimated that several inches of soil are thus displaced in a century, and he attributed the gradual burial of stones and the sinking of old masonry to their agency. Worms also honeycomb the soil, pushing their tunnels several feet, or even yards, below the surface. This permits the free circulation of air in the deeper layers of the soil, keeping them sweet for the long exploring roots of the deeper-rooted trees.

4. Fungi.-In all moist soils rich in humus fungi abound. Not being green, these plants can make no carbohydrate. They live on rotting vegetation, much as bacteria do; but whereas bacteria are concerned chiefly with the nitrogenous compounds, fungi attack the carbohydrates, which they remove from the soil.

\section{Manures.}

1. Natural Manure.-This consists of plant or animal remains, or animal excrement, which are added to the soil to replenish its fertility. It is usually exposed on or near the surface for a time, to allow it to rot or ferment ; afterwards it is dug into the ground, so that the soilbacteria may get to work on it. To prevent the volatile compounds formed during the decomposition from escaping into the air, and to prevent the formation of free acids which would sour the ground, lime is added to the manure.

It is important to remember that manure in itself is not plant-food ; it is only a source of plant-food. It must become rotten, and then be allowed to remain in the ground till the soil-bacteria have converted its organic material into mineral salts before plants can be said really to feed on it. In market-gardens, manure is employed not only as a source of food for plants, but also as a source of heat for raising early vegetables. For the latter pur- 
pose it is placed in a compact mass below the plants, that it may ferment, and the heat evolved during the putrefaction warms the soil above and stimulates the growth of the plants rooted in it.

2. Artificial Manures.--These are manures applied to the soil in a form which requires no further decomposition by soil-bacteria-e.g., the nitrate, potash, soda, and phosphatic manures of commerce. Guano, being very rich in nitrates, belongs practically to the same category. They should all be applied in very dilute solutions (p. 92).

3. Living Manures.--There have been several attempts in recent years to place on the market extracts of soilbacteria. They are intended to make poor soils fertile, or to increase the weight of the crops taken from them. Extracts of root-nodules are regarded in some quarters with special favour. The seeds are infected with the extract before sowing, or the ground is watered with it when the plants are coming up.

\section{The Rotation of Crops.}

Different crops withdraw from the soil its nutrient salts in different proportions, one crop demanding more of one salt than another. For this reason, the same crop raised year after year in the same soil would soon impoverish it. To obviate this, crops are grown in rotation, each crop differing from the rest in its demands upon the soil. By this means, nutrient substances are not withdrawn from the soil more quickly than they can be replaced by the ordinary methods of manuring.

As an example of the rotation of crops, we will set forth the so-called Norfolk, or Four-Year Rotation, popular on light sandy soils in this country. It will be seen that the same crop is never raised from the same field two years in succession, but only at intervals of four years :

\begin{tabular}{|l|c|c|c|c|}
\hline & First Year. & Second Year. & Third Year. & Fourth Year. \\
\hline First field - & R. & B. & L. & W. \\
Second field & B. & L. & W. & R. \\
Third field - & L. & W. & R. & B. \\
Fourth field & W. & R. & B. & L. \\
\hline
\end{tabular}


L. = A Leguminous Crop-e.g., clover, a deeply-rooting plant, which is sown as a catch-crop. In a wet country like ours it is not advisable to let the ground lie fallow in order to allow time for nitrates to accumulate in preparation for a crop demanding much of this salt, for the frequent rains wash them out almost as soon as they are formed. To obviate this, catch-crops like clover are put on the land. Clover has bacterial nodules on its roots, and if the crop is eut or eaten off the land, and not uprooted, it enriches the soil with nitrogen; and at the same time consolidates it by its vegetable fibre and increases its water-capacity.

W. = Wheat, which is generally sown in autumn as soon as the catch-crop is ploughed in. It is a deeprooted cereal, which makes a great demand on the soil for silica and potash, as well as nitrates. It prefers a rather heavy soil.

R. = Root-Crops-e.g., turnips, swedes, etc. Two out of the three preceding crops- viz, barley and wheatmake exhausting demands upon the soil, and they follow so quickly upon each other that very few opportunities are allowed to clean and prepare the ground thoroughly. Root-crops, however, are not sown before the spring, and this allows time for the land to be deeply ploughed and cleared of weeds. Root-crops also require a good deal of manure to encourage the production of large fleshy roots. This is therefore the right time to add plenty of manure to the soil, much of which will be available for succeeding crops.

B.= Barley, a shallow-rooted cereal with similar demands to those of wheat. Being a surface-feeder, barley gets its nutriment from the upper layers of the soil, and for this reason it follows the root-crop, while the ground is still rich with manure. Wheat is a deep feeder, and naturally follows later, when the nutriment from the manures has sunk deeper in the soil. On heavy soils oats are generally substituted for barley.

Different soils require different rotations, and agricultural practices vary even on the same soils.

Moreover, it has now been shown that rotation is not really necessary to prevent the soil becoming impoverished. With proper treatment and scientific manuring the same crop may be taken year after year from the same ground without diminishing its value. 


\section{The C reulation of Nitrogen.}

After what we have said in this chapter, we can now complete the balance-sheet of the atmosphere, which we left unfinished on p. 79.

1. The Sourees of Nitrogen in the Soil.--(1) The nitrogenous compounds present in the soil are produced, as we have seen, by the agency of bacteria in the decomposition of humus.

(2) During thunderstorms, in the path of the lightning, oxygen and nitrogen unite, and the resulting oxides of nitrogen are swept down by rain into the soil as nitrous acids ; these are readily oxidized and combined as nitrates.

(3) Certain soil-bacteria, some living free in the soil and others located in root-nodules, are able to fix or assimilate the free nitrogen of the air. The latter is ultimately restored to the earth in the form of nitrates (p. 95).

2. The Losses of Nitrogen in the Soil.-(1) The nitrates and ammonium-compounds taken up by plants are restored to the soil when the plants decay. If the plants are eaten by animals, the ingredients are returned to the soil in their excreta, or finally in their bodies after death. The loss to the soil in this case is only temporary.

(2) Nitrates and ammonium-compounds are very soluble in water, and much of what is formed in the soil is carried away by water and lost in the sea.

Everywhere, and at all times, there is leakage of nitrogen from the soil. The loss is made good from the air in the ways we have described. The air, in fact, is the ultimate source of all the fixed nitrogen in Nature, just as it is the source of all its carbon.

\section{Soil-Cultivation and Fertilizers.}

The basis of fertility is good husbandry. Plant and soil analyses help very little in determining what a plant requires or what a soil wants. The chief need of the soil is an adequate and continuous supply of water. How important this is may be inferred from the expenditure of so many millions of pounds in regions where prolonged drought makes cultivation precarious or impossible. There is always some water in the soil and the amount 
increases as we get into the deeper layers. During dry weather water is being constantly brought to the surface by capillary attraction. The advantage of hoeing the ground in dry weather depends upon the fact that by so doing we cut off the upward water-columns an inch or so from the surface and so prevent the rising water from running to waste by evaporation. It also encourages the plants to send down deeper roots into the soil in search of water. The principles of soil-fertility and the reaction of plants to fertilizers are as yet very imperfectly known, and much of what we do in practice is the outcome of long experience rather than the result of scientific research. In general we know that a soil deficient in plant-food is not likely to produce good crops, while a soil rich in such material will do so; also that some crops take out of the soil certain ingredients which can be replaced by some form of manuring; and, also, that certain fertilizers benefit certain plants or have a general beneficial action on their growth. Thus the chief functions of the three great chemical fertilizers in common use are:

1. Nitrates, by supplying nitrogen, encourage growth of roots, stems and leaves.

2. Potash, by its action in facilitating the processes of photosynthesis, promotes the production of starches and sugars, and is therefore usefully applied to potatoes, root-crops and fruit-trees.

3. Phosphates, by stimulating the vital activities, encourage early and abundant flowering and fructification.

The choice and efficiency of manures depend upon many other things than the mere putting into the ground of the chemical substances which a plant needs. The soil is, to a large extent, a living medium, a busy factory in which aerobic bacteria are preparing plant-food. The most important of these bacteria are those which convert nitrogen-yielding substances into nitrates and those which manufacture nitrates from atmospheric nitrogen (see p. 94). The rate at which this nitrification goes on in the soil may be regarded as the index of its fertility. An immense number of aerobic bacteria occur in all fertile soils, and anything that diminishes the number and activities of these bacteria diminishes the fertility of the soil. The proper nitrification of the soil is the first requisite. It 
varies with the climate, the season, the physical state of the soil, its humus-content, its chemical reactions, its aeration, and the presence or absence of deleterious micro-organisms or their products. Continued cropping does not necessarily exhaust a soil, and when it does it is probably due not so much to the depletion of the nutritive salts as to its failing powers of nitrification. Nitratebacteria can only flourish in a well-aerated and alkaline soil. Hence the importance of digging deep and liming well. Under conditions of bad culture, even with no lack of manure, the soil becomes sour and foul. The aerobic bacteria diminish, and in their place anaerobic bacteria and other denitrifying organisms make their appearance and impoverish the soil. In some cases it has been shown that certain toxic substances, acids and aldehydes, are excreted by the plants themselves; and it is alleged by some authorities that with continued cropping these may accumulate to such an extent as to thoroughly poison the ground. This has not been proved, but even if it is so good cultivation will remove them. Moreover, nitrogen is the most easily lost of all plant-foods. Owing to the extreme solubility of most of its compounds, it is easily washed down beyond the roots, or it may be dissipated into the air as gas by the agency of anaerobic bacteria. To retain the nitrogen in the soil it is again necessary to use plenty of lime. Lime, and in its less active form chalk, is, in fact, the most important of all manures. It not only favours nitrification by correcting acidity, but it liberates plant-food from manures and minerals, at the same time fixing it in a form which preserves it in the soil and makes it available for plants.

The amelioration of the soil for the production and conservation of nitrogen likewise favours the availability of other chemical suzstances needed by plants, particularly phosphoric acid and potash. Labour and lime, together with large and regular supplies of organic matter in the form of manures, will secure conditions of fertility in practically all soils. 



\section{PAR'T II}

\section{THE LIFE OF THE INDIVIDUAL PLANT- PL.ANT BIOLOGY}

\section{INTRODUCTION}

Botany may be divided into two branches:

1. Morphology (Gr. morphe, form), which deals with the form, structure, origin, and development of plantorgans and their relations with one another. This branch includes- $(a)$ external morphology, dealing with the outward form of organs; and (b) internal morphology, dealing with the morphology of the minute cells and tissues of which the organs are composed.

2. Physiology (Gr. physis, nature, inherent qualities), which deals with the functions of the organs.

Thus we may consider a leaf with respect to its form, size, and structure ; we may trace its origin and development, and compare it with other leaves and organs. This is examining the leaf morphologically. Or we may direct our attention to the work or functions performed by the leaf, its vital activities-assimilation, transpiration, respiration-and consider how the particular leaf under notice performs them. This is looking at the leaf on the physiological side.

In dealing with the form and structure of any organ it is important to associate its form with its function. Variation of form means variation of function, if only in degree. Thus, suppose we compare two leaves-a hollyleaf with a lime. They are very different. One is thick, tough, shiny, and evergreen, and the main veins are continued as spines. The other is thin and deciduous. But modification in form implies modification in function. A green leaf has three main functions : it assimilates, it transpires, it respires. Each of these functions is modified as the form is modified, but which is the most important? On reference to p. 43 , we see that the tough evergreen 
leaf is a xerophytic form adapted to live through the winter, and that the purpose of its special characters is to reduce loss of water by transpiration within safe limits. The leaf of the lime has no such characters; it is equipped for summer use only. Again, assimilation is not so active in the holly as in the lime. A lack of nutrition is the result, and this is actually expressed in the leaf by the spines. The spines are modified veinstructures between which the leaf-tissue has failed to develop. On well-grown plants growing in good soil the leaves tend to lose their spines because they are better nourished.

Thus each leaf has written upon it functional signs that the physiologist can read, even if only imperfectly. We understand a structure when we know the reason for it-that is, when we know its function. A plant is a living thing. It lives in a certain environment, and the nature of that environment, acting through its vital functions, is expressed in its outward form and inward structure.

The study of organisms as living things is Biology (Gr. bios, life). To connect form with function, and both with environment, is to make botany a biological study. With morphology alone we have little to do; in ecology, morphology is quite dominated by biology.

This biological method of looking at plants is quite recent. It requires an accurate knowledge of the main facts of physiology, and this our forefathers did not have. Physiology grew as the science of chemistry and physics developed. But our ancestors saw form clearly enough, although they knew little of the functions that underlie form, and still less of the relations between form and environment. The early botanists studied plants as they found them-in the garden, in the field, in the herbarium. They examined the outward form, marking and recording resemblances and differences. Upon these morphological characters they founded their classifications and generalizations. It must be granted, however, that broad or general views can only be obtained when plants are collected into groups, and the simplest and most natural groupings are those which are founded upon the resemblances and differences of external form.

Even at the present time it is found convenient for 
most purposes to rely upon morphology as the basis of classification. Our flowering plants, for example, are divided into groups, called Natural Orders, which are based entirely on morphological relations. Generally the form and characters of the flowers are taken, the vegetative bodies of plants varying too much to enable us to make much use of them as a basis of classification.

Biologically, however, other classifications are possible. Plants may be grouped together according as they resemble one another biologically, and it is the biological groupings of plants and parts of plants that are important in ecology.

As an example, we have already in Part I. classified plants according to their relations to water, dividing them first into two main groups, Water-Plants and LandPlants, and then the land-plants further into Hygrophytes, Mesophytes, and Xerophytes, according as the amount of water available is abundant, adequate, or small. In this classification form and structure were regarded merely as the expression of physiological need, and we selected water since it is the most important of all the ecological factors and lies at the base of nutrition. This division takes no account of relationships. Plants which are widely separated in descent may fall together in the same ecological grouping. Thus the Cacti and Euphorbias are plants which have no relationship at all to one another, but when growing in deserts they approach one another so closely in form and characters that it is difficult to distinguish between them apart from their flowers. It is a case of parallel development. Growing under similar conditions, surrounded by the same environment, these two races have, in the course of ages, succeeded in adapting themselves to the same conditions in the same way. On the other hand, two closely-related species may be widely separated ecologically, one being adapted to one mode of life, the other to another. One, for example, may be a hygrophyte and the other a zerophyte. The genus Senecio, to which the groundsel and ragwort belong, is remarkable in this respect. It is of world-wide distribution, and contains a huge number of species. But it includes plants of the most diverse habit. Some are annuals, others perennials ; some are alpines, some marsh-plants, some pronounced 
xerophytes; some climb, some have succulent leaves, others leaves hoary with hairs; one has leaves like ivy, another leaves like flax, another leaves like heath; but the flowers are the same in all.

In Part II. we have to deal chiefly with biological divisions based upon functional similarities and dissimilarities. Land-plants, for example, will be divided1. According to their Longevity (Chapter XI.).

2. According to their Frequency of Seeding (Chapter XI.).

3. According to their Mode of Growth (Chapter XII.).

4. According to their Mode of Nutrition (Chapter XIII.). 


\section{CHAPTER XI}

DIVISION OF TERRESTRIAL PLANTS ACCORDING TO THEIR LONGEVITY AND FREQUENCY OF SEEDING

\section{Division of Plants according to their Longevity.}

1. Annuals.-These plants live through one or part of one vegetative season and then perish, after providing for the continuance of the race by the production of seede.g., poppies, groundsel, chickweed. There are two kinds of annuals :

(a) Those which germinate from seed in the spring, and perish towards the close of the vegetative season-summerannuals-e.g., poppy.

(b) Those which germinate from seed in the autumn, forming small plants with a few leaves, arranged on the rosette plan, close to the ground, and continue their growth in the following spring-autumn-annuals. They flower early, and perish before the hottest part of the summer sets in. Annuals belonging to this class must seed very freely because the fatality among the seedlings during the winter is very great.

In both cases there is a season during which the plants are not seen at all. In the case of summer-annuals this season is the period of vegetative rest, winter; in the case of autumn-annuals, which are vernal bloomers, it is the summer, when hot, dry conditions bring about a period physiologically unfavourable to the plants. The latter are found chiefly in dry steppe-regions, or in sandy and stony places which become very hot and dry in summer. They are not common in England, but a few are found on sand-dunes, a habitat specially remarked for summer drought-e.g., the vernal whitlow-grass (Draba verna), the early forget-me-not (Myosotis collina), and the small mouse-ear chickweed (Cerastium semidecandrum). 
Gardeners obtain early spring flowers by sowing hardy annuals at the end of summer. These germinate in the autumn and bloom early in the spring, and the flowers then last longer than usual-e.g., cornflower, poppy, sweet pea.

The fecundity of some annuals is so great and the lives of the individuals so short that several generations are produced in the course of the year-e.g., Poa annua, groundsel, chickweed, shepherd's-purse.

Annuals are characteristic of temperate regions, where there is a marked alternation of seasons, and the summer is sufficiently long to allow the plants to proceed from seed to seed again. The seed, in which the young plantlet hibernates, is a pronounced xerophytic structure, and can withstand the most extreme and prolonged hardships (see p. 74). The great majority of the so-called weeds of cultivation are annuals, as naturally they must be, for they are destroyed regularly at harvest-time, and their propagation is dependent entirely upon the seed left behind in the ground after the crop and its weeds have been removed. There are very few annuals among alpines and aquatics.

2. Biennials.-These plants, as the name implies, live during two vegetative seasons. During the first they produce leaves and manufacture food, which is stored up in their underground parts for use the next season, when they flower, seed, and die-e.g., turnip, carrot, foxglove, burdock, mullein. The swollen underground organs found in biennials at the end of the first season are merely temporary reservoirs of food. During the formation of the seed, a steady migration of food-material takes place from these organs, which become depleted, and ultimately shrivel up. Essentially, biennials differ little from annuals, and especially from those which we have called autumn-annuals. They only seed once, and under unfavourable conditions they may even flower the first year and die, while in a few cases strong and vigorous plants, enjoying the advantages of a good soil and a happy habitat, may live for several years. The latter is frequently the case with wild biennials grown in gardense.g., wallflower, foxglove.

3. Perennials.-Perennials are plants which live for more than one year, and seed several times before they die. All parts of a perennial have not the same longevity; some parts live longer than others. The leaves of a 
deciduous tree, for example, fall at the end of summer, and must, therefore, be renewed annually. Perennials may be classified according to the longevity of their assimilating parts :

(a) Evergreen Perennials.-The leaves of these plants live through the winter ; they may last several years, but sooner or later their vitality fails, and they drop. They do not, however, all fall off together, and the plants are never leafless. Winter-green plants, if land-plants, are all xerophytes outside the Tropics. They are characteristic of climates which are hot and dry during summere.g., the Mediterranean laurels and myrtles; where summer and winter are both inhospitable seasonse.g., the coniferous forest; or where the winter season is very long-e.g., alpines.

(b) Deciduous Plants. - In these certain of the vegetative organs, always including the leaves, are shed annually:

(i.) Deciduous Trees and Shrubs, in which the shoots are all long-lived, and only the summer-green foliage is annually shed. They fall simultaneously at the approach of winter, leaving the trees bare. In some coppiced plants, however, the leaves may not all fall together. The oak, for example, when pruned in hedges, forms the usual plate of cork across the base of the leaves at the end of summer, the leaves die, but the final rejectment by the splitting of the separation-layer is not completed, so that many dead leaves remain on the tree during a large part of the winter-falling gradually, as they are blown off. A still more familiar instance of pruning interfering with leaf-fall is the privet (Ligustrum enlgare), planted everywhere in gardens and hedges. When kept well pruned, many of the leaves remain alive and green upon the bushes till the new leaves break from the buds in spring. Pruning is an artificial way of reducing transpiration, and acts, therefore, as a xerophytic adaptation.

(ii.) In other plants the smaller twigs are shed annually as well as the leaves.

(iii.) In others the leaves die and all the shoots except those close to the ground. These bear the renewal-buds, and in many cases leaves as well-e.g., chrysanthemum.

(iv.) Herbaceous Perennials.-Here the destruction of the aerial parts is complete. The individuals, however, 
remain alive beneath the soil in the form of various xerophytic structures from which new shoots arise in the spring (see Geophytes, p. 62).

Underground Perennating Organs found in herbaceous perennials :

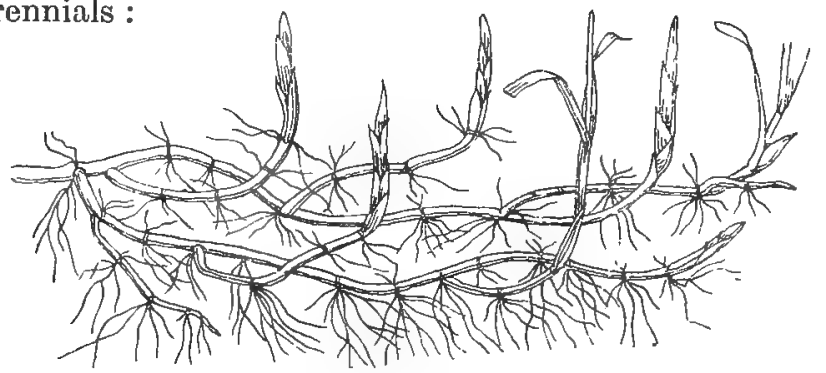

Fia. 28.-Underaround RHizome of Codoh-Grass.

1. Rhizomes.-These are perennial underground stems bearing scales, buds, and roots (Figs. 28, 29). Rhizomes are not roots, though they are underground and carry roots. The leaves on subterranean stems are scaly when they do not come above ground, because, being in the dark, chlorophyll does not develop. The buds occur in the axils of these scales, or terminally at the extremity of

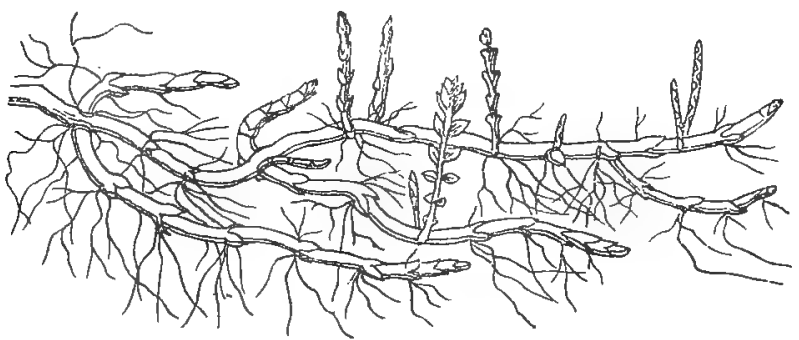

Fia. 29.-Undergrodnd Rhizoma of Mint.

the branches. Rhizomes are more or less thick and fleshy, containing a store of food-material which migrates to the brood-buds when they develop the aerial stems. When the rhizome is short, thick, and erect, as in some ferns, it is known as a root-stock.

2. Tuberous Structures.-These are fleshy, hibernating organs stored with food. The fleshy part may be either 
stem or root. In the potato (Fig. 30) the tubers are the swollen tips of underground stems, and the "eyes "upon them are the buds. In the dahlia some of the roots which grow from the base of the stem become tuberous. In the lesser celandine and some orchids, buds at the base of the stem develop an adventitious root which becomes large and tuberous. The fleshy tuberous roots of biennials are generally complex structures. The part from which the buds arise is stem. In the carrot and turnip the greater part of the tuber is derived from hypocotyl, that portion of the axis that lies between the primary root and the cotyledons; the lower part, bearing rootlets, represents the primary root. In the swede

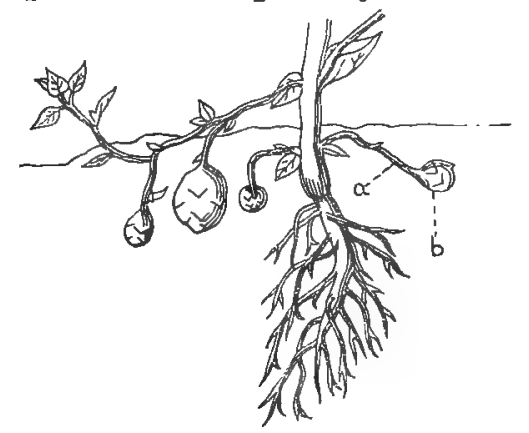

Fro. 30.-Basar Part of Potato Plant.

$a$, underground branch bearing stem-tuber $b$. To the left branches of an aerial shoot are producing tubers.

(Fig. 31) the stem forms a collar at the top of the tuber ; most of the rest is hypocotyl. In the kohlrabi (Fig. 32) (German, cabbage-turnip) a big round tuberous body projects from the soil, the surface of which is covered with leaf-scars; this is stem. In the dandelion and chervil the carrot-like tap-roots are perennial. In the false oat (Arrhenatherum avenaceum) the perennating function is assumed by the base of the stems, the internodes of which become swollen with food, forming chains of little tubers (Fig. 33).

3. Bulbs and Corms. - These are compressed buds, or rhizomes, capable, by reason of the food they contain, of living an independent life. Corms are solid bulbs, the food being stored in a short tuberous stem which is covered 
with membranous scales; in bulbs the food is in the leaves, which are thick and fleshy, the stem being reduced to a flattened disc, bearing roots (see p. 156).

\section{Classification of Plants according to their Frequency of Seeding.}

This is a more scientific method than by longevity, which is governed by the seasons. We have already pointed out that there is no strict line of division between



Fig. 31.-Swede, SHOWINe TUBerOUS HYPOоTYL. (REDUCED.)

$$
\text { u, "collar." }
$$

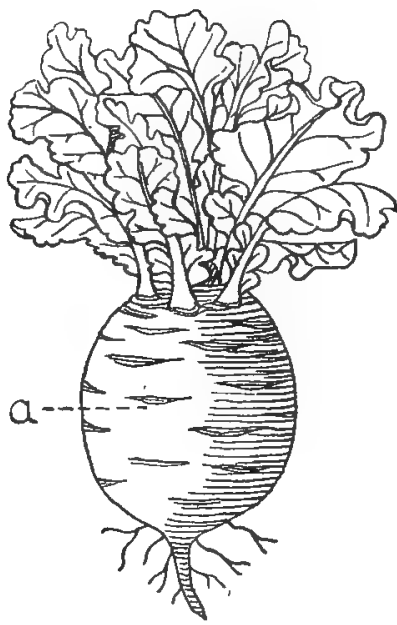

Fig. 32. - KoHLrabi, SHowine Tdberous Stem bearing LeapSoARs $(a)$. (REDUCed.)

annuals and biennials, or between biennials and perennials, and the estimation of age by the seasons fails altogether in the case of plants which live in those parts of the Tropics where there is no climatic interruption in the development of the vegetation.

According to the frequency of seeding, plants are divisible into two groups :

1. Monocarpic Plants (Gr. monos, once; carpos, fruit), which produce seed once and then die, and -

2. Polycarpic Plants (Gr. poly-, many), which fruit more than once in their lifetime. 
The first class includes all annuals and biennials, and those perennials, native and foreign, which flower after several seasons' growth and then perish. All these are, biologically, annuals. The most remarkable monocarpic perennial is the American aloe, Agave americana. This wonderful plant grows very slowly, forming a gigantic rosette of long, thick, fleshy leaves, two or three each year. At last it flowers, bearing a huge inflorescence,

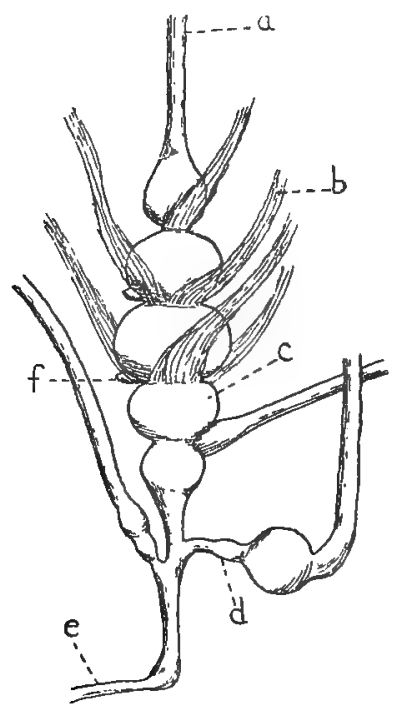

Fig. 33.-Falsh-OAt Grass (Arrhenatherum avenaceum). (RrodUth.)

$a$, erect flowering shoot; $b$, decayed leaf-bases; $c$, swollen internode; $d$, lateral branch; $e$, horizontal part of rhizome; $f$, axillary bud.

reaching in some cases a height of 20 feet. It lives to a great age before flowering, sometimes a hundred years. But the act of flowering and fruiting is so exhausting that the plant is unable to survive it, and it dies. This aloe is therefore, in spite of its longevity, biologically, an annual, for, like all annuals, it seeds once and dies.

To the polycarpic group are assigned all trees and shrubs, herbaceous perennials, and geophytes. 


\section{CHAPTER XII}

CLASSIFICATION OF PLANTS ACCORDING TO THEIR MODE OF GROWTH

\section{Terrestrial Plants, rooted in the Soil.}

THe following grouping is based upon the position of the leaves on the stem, and the habit of the stems with regard to light :

1. Plants with Cauline (i.e., stem or shoot) Leaves only :

(a) Plants with erect stems.

(i.) Annual herbs.

(ii.) Herbaceous perennials.

(iii.) Shrubs and bushes, branching freely from the ground.

(iv.) Trees with trunks.

(b) Plants with prostrate stems.

(c) Plants with climbing stems.

(d) Cushion-plants.

The Cushion-Plant branches freely at the ground-level, forming a multitude of short erect stems. Most of the leaves are near the extremity of the stems, the leaves below being smaller and generally wider apart. Such plants may be looked upon as an approximation, through xerophytic conditions, to the rosette-form, by the pulling down to the ground of long-stemmed plants in such a way that the whole plant forms a mosaic of small loose rosettes raised only a few inches above the soil. Many alpines and some maritime plants form these low cushions -e.g., moss-campion (Silene acaulis), mossy saxifrage (Saxifraga hypnoides), sea-purslane (Honckenya peploides), and mountain-avens (Dryas octopetala). 
2. Plants with Radical Leaves only :

(a) Rosette-plants-e.g., dandelion. The daisy is really a cushion-plant, but the stems have sunk below the level of the ground, producing on the surface a number of distinct rosettes.

(b) Some bulbous geophytes-e.g., crocus, wild hyacinth.

3. Plants with both Radical and Cauline Leaves :

(a) Most biennials.

(b) Some herbaceous perennials-meg., oxtongue ( $\mathrm{Hel}$ minthia echioides), rock-cress (Arabis), and some hawkweeds.

(c) Grass-like plants with tufted habit-e.g., tussockgrasses, like Aira flexuosa and Holcus lanatus, and some sedges.

Except in geophytes, these differences of habit are due to the many and varied methods adopted by plants to secure for themselves an adequate amount of sunlight. Leaves, as the chief assimilating organs, seek to take the most favourable light-position. Trees effect this by lifting up, on tall trunks, a crown of foliage above the surrounding vegetation. The leaves of rosette-plants grow close to the soil and smother other plants that might shade them. Plants with prostrate trailing stems thread their devious ways among the lower vegetation. seeking out favourable spots where their leaves may catch the light. The creeping habit of long frail stems leads to the scrambling habit, in which the stems hook and catch on to other plants, scrambling over their backs into the light. From the scrambler to the climber is a short step. Epiphytes (see p. 121) malke their light-position secure by perching on the elevated branches of trees.

Climbing Plants.-These have long weak stems, and solve the problem of reaching a position of advantage by climbing up the bodies of other plants. They derive no nourishment from the supports upon which they lean, although occasionally they injure them by intercepting the light which properly belongs to them. Climbing plants were divided by Charles Darwin into the following groups :

1. Scramblers, or Hook-Climbers.-These are the least specialized of climbing plants, and are not far removed 
from those of prostrate habit. The latter may easily, if circumstances favour, become scramblers. True scramblers, however, are provided with special organs to aid them-hooks, prickles, barbs, or recurved bristles. These grappling structures are not to be associated with the sensitive climbing organs of true climbers, for they are not sensitive to contact, and have no movements of their own. The bramble or blackberry (Rubus fruticosus) and the dog-rose (Rosa canina) are provided with large recurved hooks, which arise as emergences upon the stems and leaves. In the moss-rose and Rosa spinosissima the emergences are straight, and not fitted for climbing ; they serve only for defence. The goosegrass, or cleavers (Galium Aparine), scrambles up the hedges by its rough stems and leaves, which are armed with a multitude of small reflexed bristles.

2. Twiners.-The weak stems of these plants twine round supports, provided that these are not too thick nor too smooth. The growing tips are sensitive, and describe slowly and regularly circles or ellipses. This spontaneous movement is known as "circumnutation" (Lat. circum, around ; nuto, I nod). In the black bryony (Tamus communis) the apex describes one complete revolution in about two and a half hours. By means of these movements the stem is enabled to come into contact with supports which it otherwise would fail to reach. On reaching the support, the stem twines round it. Some plants twine clockwise, others counter-clockwise, but for every plant the direction is fixed, the habit having become hereditary.

(a) Twiners climbing counter-clockwise, the usual habit: Phaseolus vulgaris (scarlet runner), Wistaria chinensis, Convolvulus sepium (Fig. 34), Polygonum Convolvulus, Cuscuta (dodder, Fig. 42).

(b) Twiners climbing clockwise: Humulus Lupulus (hop, Fig. 35), Tamus communis (black bryony), Lonicera (honeysuckle).

Wistaria and hop connect this group with the scramblers, the former having recurved spiny stipules, and the latter T-shaped stiff hairs.

Solanum Dulcamara (woody nightshade) is a feeble climber, and may climb either way. In the open, where the light is strong, it is a low bush, not climbing at all. 
In the shade of hedges the stems become etiolated and weak, and the plant climbs. Polygonum dumetorum is another imperfect twiner.

3. Tendril-Climbers.-Tendrils are organs specialized for climbing. While growing, they are sensitive to contact, and their free ends circumnutate. On touching a support, the tendril twines round it. The free portion between the support and the plant then takes on a spiral twist, a reversal-point naturally occurring in the middle, since both ends are fixed and incapable of movement (Fig. 36). The object of this is to bring the stem closer to its support, and at the same time to increase the strength

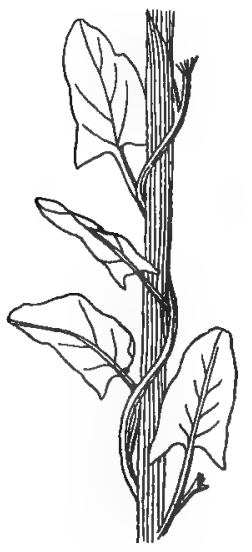

FxG. 34.-Convolvulus (BNDW TWINING COUNTER - CLOCKWISE. (REDUOED.)

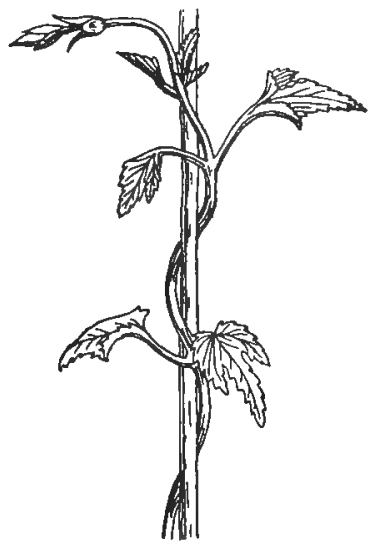

Fra. 35. - Hop, TWINING ClookWISE. (RHDUCED.)

of the anchoring cable. The closer the plant is to its support and the stronger the cable, the less liable is it to be wrenched away from it by the wind and damaged. When twining has ceased, the tendril thickens and becomes woody, thus making the connection permanent and durable.

The hooks and bristles of scrambling plants are opportune outgrowths from the surface of the plant. They are neither leaves, roots, nor shoots. Tendrils, on the other hand, represent definite plant-organs-leaves or portions of leaves, stem-structures, or even roots. We mean by this that the rudiment of the tendril started as one of 
these organs, but in the course of its development it became modified as a climbing organ, and gradually assumed the form and functions of a tendril.

The Morphology of Tendrils-(a) Modified Stem or Shoot Structures.-These generally occur in the position of flowering shoots, and so may be regarded as modified floral branches. Their morphological nature may be established from the fact that they arise in the axils of leaves (passion-flower, Fig. 36), or themselves bear leaves or the vestiges of leaves, or even

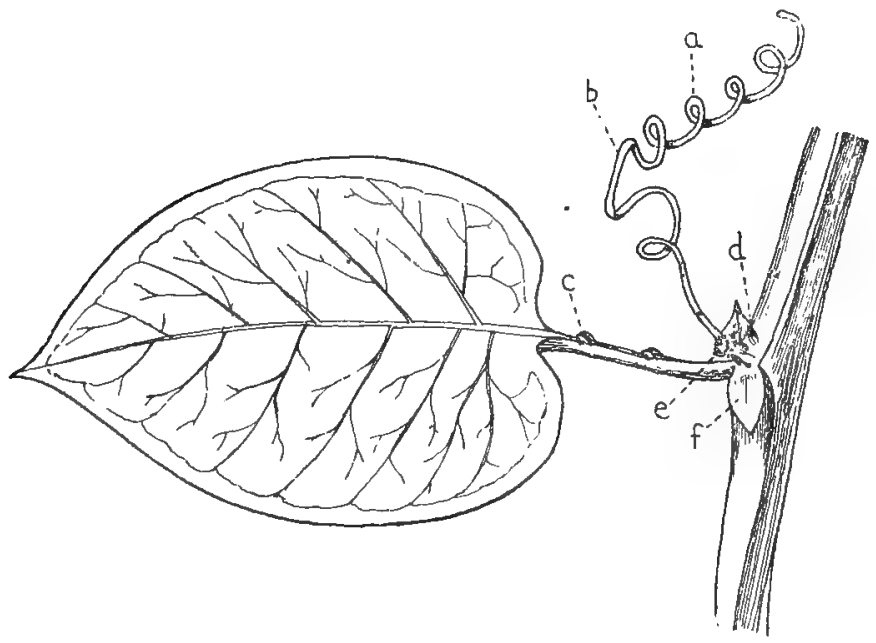

Fra. 36.-Passton-Flower. (REddoed.)

$a$, brancle-tondril with reversal-point at $b$; $c$, extra-floral nectary; $d$, vegetative bud; $e$, flower-bud; $f$, stipule.

flowers (vine). They may be branched (vine) or unbranched (passion-flower.) In the virginia-creeper, $A m$ pelopsis Veitchii (Vitis inconstans or Veitchii), each branch of the tendril bears at its tip a small adhesive pad, which cements the tendril to the wall (Fig. 37).

(b) Modified Leaves or Parts of Leaves-(i.) Leaflets.In peas (Lathyrus) and vetches (Vicia) some of the terminal leaflets are modified into tendrils. In the everlasting pea all but two leaflets are modified, and the stem becomes winged and green (Fig. 38). In Lathyrus A phaca every leaflet becomes a tendril, and the work of assimila- 
tion is taken over by the stipules, which are large and leaf-like.

(ii.) Stipules.-In Smilax (sarsaparilla), a climber frequently seen in greenhouses, the tendrils are in the position of stipules. Climbing hooks may also be present.

(iii.) Leaf-Tips. - In the climbing lily (Gloriosa superba), another foreign greenhouse-plant, the tips of the leaves are prolonged into strong cord-like tendrils.

(iv.) Petioles.-The garden - nasturtium (Tropocolum majus) and Clematis have sensitive leaf-stalks. On reaching a support, they curve round it, and then become tough and indurated, thus enclosing it firmly.

4. Root-Climbers. - These climb by adventitious roots, which arise in great number on the shaded side of the stem. They act as suckers, pinning the branches to the wall or to the tree up which the plant climbs-e.g., ivy (Hedera Helix). No suckers, however, occur on the flowering shoots, which turn away from the wall and grow outwards towards the light.

In many plants the morphological nature of the tendril is doubtful. In the vegetable-marrow (Cucurbita), cucumber (Cucumis), white bryony (Bryonia dioica), and other Cucurbitaceæ, the tendrils have been variously described as modified leaves, stipules, shoots, and even roots. It is possible, however, that in these cases the tendrils are not modified forms

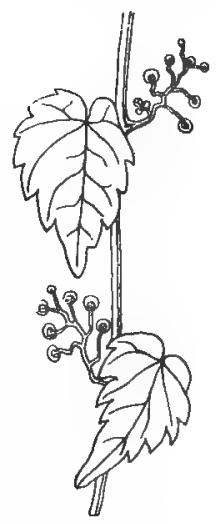

Fig. 37. Stem. TENDRILS OF Ampelopsis Veitchii, sHowING SUOKERS. (REDUCED.) of other organs at all, but are organs, sui generis (Latin, of their own kind)-that is, organs which have arisen and have been developed for the purpose which they serve, never having been anything else but what they are.

Climbing plants begin their existence as deep-shade plants, the shade being produced by the vegetation upon which they climb. In the Tropics most are inhabitants of forests ; in this country they are found in thickets and hedges. Here the partial light produces effects which are ordinarily associated with plants grown in darkness. Such plants have a long weedy appearance, with weak 
trailing stems and small leaves. The long internodes are the direct result of weak light; the small leaves are due to malnutrition, resulting from the impoverishment of the chlorophyll through lack of light. In extreme cases the chlorophyll becomes yellow or etiolated, and ceases to make starch altogether; the plant then starves to death.



Fig. 38.-Everlasting Pan with Lfap-Tendrils and Winged Stem. (REDUCED.)

The evolution of the climbing habit may be traced in several of our common British plants. The woody nightshade shows how an ordinary plant may become a twiner. The common fumitory (Fumaria officinalis), and its near relation, the climbing corydal (Corydalis claviculata), give us an idea of one method by which the tendril may be evolved. These two plants are occasional climbers, with large, much-dissected leaves. The leaflets are small, and the whole leaf appears to be more or less sensitive, so 
that the main leaf-axis and its branches may all alike take part in attaching the plant to a support. There is no doubt that a similar general sensitiveness preceded, in evolution, that localized and specialized sensitiveness which, in other climbers, is confined to the tendrils. This sensitiveness, which accompanies partial etiolation in weak light, and which makes the evolution of the tendril possible, is probably due to the fact that etiolated stems and shoots, through their rapid growth, have soft tissues with no strong woody elements during their sensitive period. Sensitive movements can only be associated with organs whose tissues consist of thin-walled cells, turgid with water.

There are not many native climbers in temperate climates. In tropical rain-forests, tree-growth is so luxuriant that the forest-floor is always plunged in partial gloom. Climbers with great twisted woody stems sprawl over the undergrowth, and loop themselves from tree to tree, climbing towards the light they need so much. Among the few woody climbers (lianes) we possess are the clematis, honeysuckle, and iry.

\section{Epiphytic Plants, perehed on Trees.}

Epiphytes are plants which grow and pass their lives perched upon the elevated parts of other plants, chiefly the branches of trees. They are anchored to their supports in various ways, usually by clasping roots. As a result of their position, they have a precarious watersupply, and invariably show xerophytic characters. The most common epiphytes are found among the lower plants, -lichens, liverworts, mosses, and ferns. The most abundant epiphyte everywhere is the lichen, which shows wonderful adaptations to extreme conditions. Generally, however, epiphytes are only found in moist shady places, and this is especially true of the flowering epiphyte, which is rare in the temperate regions of the world. In the Tropics, on the other hand, they form a feature of the vegetation of the dripping forests, the home of the epiphytic orchids and bromeliads. In this country we have no true flowering epiphyte. Accidentally, however, many plants are epiphytic. In humid mountain glens we may often see plants growing on other plants-ashes 
on oaks, stonecrop on the aged branches of trees, and various ferns, especially the polypody. The true epiphyte, however, is a xerophyte amid vegetation markedly hygrophytic. It has a special mode of seed-dispersal, for the seeds have to be lifted and deposited in places far above the ground-level. They are exceedingly small and light, as in orchids, or they are enclosed in fleshy and sticky fruits, which birds carry and drop, among the branches of the trees.

Climbing plants and epiphytes which use other plants for support are said to form guilds with them. Without their aid climbers would fail to develop. Epiphytes, on the other hand, can and do grow in soil, if there is no vegetation around to obscure the light. 


\section{CHAPTER XIII}

CLASSIFICATION OF PLANTS ACCORDING TO THEIR MODE OF NUTRITION

1. Green plants.

2. Non-green plants-

(a) Saprophytes,

(b) Parasites.

3. Insectivorous plants.

4. Symbiotic plants.

1. Green Plants.-These plants are autotrophic, or selfnourishing. They are able, by means of the chlorophyll present in their green cells, to form, during sunlight, carbohydrate from carbonic acid gas. The nitrogen required for the synthesis of proteins is obtained, not from the air, but from mineral salts present in the soil.

2. Non-Green Plants. - These, not possessing chlorophyll, are unable to make carbohydrate for themselves. They must therefore obtain it from sources outside their own bodies-i.e., they are heterotrophic. Not needing light for photosynthesis, they generally live in darkness. According to the nature of the source from which they obtain their food, non-green plants are divided into two groups-Saprophytes and Parasites.

(a) Saprophytes (Gr. sapros, rotten).-These are colourless-that is, non-green-plants which obtain their carbohydrate from the rotting products of vegetable or animal remains. Animal excrement, since it contains organic material exposed to decay, is a minor source. The majority of fungi are saprophytes; not being able to make sugar for themselves, they get it from the humus in which they grow. Soil-bacteria are saprophytes, and so are all those bacteria which initiate putrefaction or bring 
about destructive changes of any kind in organic matter. All plants, green or not, if supplied with sugar and the proper mineral salts, can build up proteins, so there is no reason why the proteins required by saprophytes for their nutrition should be obtained in the same way as the carbohydrates. Saprophytes, as a rule, make their own proteins, but most of the nitrogen required is absorbed in the form of ammonium-compounds, in which humus is richer than in nitrates. At the same time, there is little doubt that proteins, if present, are also absorbed and utilized in the economy of the plant.

(i.) Total Saprophytes.-There are very few total saprophytes among the higher flowering plants in this

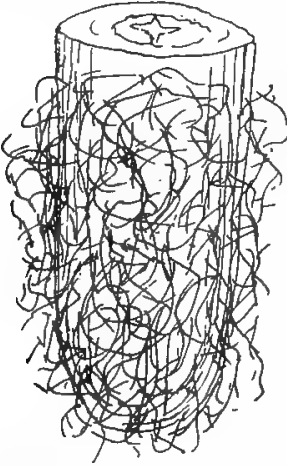

Fia. 39.-Apex of A ROOT INVESTED WITH a Mycorhiza. (MagNIFIED.) country, and a curious feature in them all is that they do not absorb the products of decay from the humus directly, but through the intervention of a mycorhiza, a subject-fungus which inhabits the roots or stems, and replaces the root-hairs of the higher plant (Fig. 39). The British flowering saprophytes are:

Neottia Nidus-avis, the bird's-nest orchid, a leafless saprophyte, frequently occurring in the humus of moist woods, especially under old beeches and in hazel-copses.

Monotropa Hypopitys, the yellow bird's-nest, a saprophyte with scaly leaves found occasionally in the humus of fir, beech, and birch woods.

Corallorhiza innata, the coral-root, a very rare saprophytic orchid found in boggy woods. It has a muchbranched fleshy rhizome, but no roots (Fig. 40).

Epipogum aphyllum, a yellow orchidaceous plant, possessing neither leaves nor roots. It has been found only once in this country.

Saprophytes are all descended from green ancestors, but owing to their mode of life the presence of chlorophyll is rendered unnecessary, and it has disappeared; the leaves, not being required for purposes of nutrition, have degenerated into scales or vanished altogether. The chief factor in their degeneration has, no doubt, been the 
mycorhiza, associated with their roots. The saprophyte at first made use of it merely to obtain water, but in the course of time it increased its demands, and at last came to rely upon it for all its food. Since light is unnecessary, saprophytes can escape competition by living in the densest shade of forests, where a green plant could not exist.

(ii.) Partial Saprophytes.-Many green plants also possess a mycorhiza, and indirectly, therefore, live on humus. This is the case with many of our forest-trees, which inhabit a soil rich in a somewhat acid humus-e.g.,pine-and with plants living in peat-e.g., heath. The mycorhiza is at first external on the roots and functions merely as root-hairs, but in those cases where it penetrates deeply in the tissues, its value to its partner increases, and it passes on to it something more than water; in fact, conditions are being established which, in the course of time, may lead to the degeneration of the green plant into a colourless saprophyte.

(b) Parasites (Gr. parasites, one who sups at another's table).These obtain the materials for their nutrition-carbohydrate and protêin-from living hosts, animals or plants. Among the lower plants many fungi are parasitic, and some that are saprophytic are capable of becoming so, if circumstances



TIG. 40. - Corallorhiza innata (CORAL - ROOT ORCHID).

Note the scale-like leaves, underground stem, and absence of roots. allow. Swarms of bacteria are parasites, and though some are harmless, or even beneficent, others are malignant and give rise to disease. These lower plants are usually internal parasites, inhabiting the tissues of animals or plants. Higher plants which are parasitic attach themselves externally to the bodies of other plants, and by means of special sucking organs - haustoria - penetrating the tissues, absorb nutriment from them. The depend- 
ence of the parasite upon the host may be partial or complete :

(i.) Partial or Hemi-Parasites.-These possess chlorophyll, and so can make carbohydrate for themselves. They are generally found attached to the roots of other plants, which they tap for water; but, like other parasites, they take all they can get, and though water is their chief need, food may be absorbed as well. The British partial parasites, with the exception of Thesium humifusum (bastard-toadflax), belong to the Natural Order Scrophulariaceæ, and include the following plants, which live attached to the roots of grasses by means of haustoria: Euphrasia (eyebright), Rhinanthus (yellow rattle), Pedicularis (lousewort), Melampyrum (cow-wheat), and Bartsia. All these plants live in grass-communities. Grass-roots form a turf so thick that no other shallowrooted plant has a chance in competing with them for water. Daisies, dandelions, and other plants growing in meadows have long roots which penetrate the turf, and so they are not really in competition with the grasses. These hemi-parasites, however, are shallow-rooted. Being forced, then, to compete with the grass-roots, they solve the difficulty by constraining their rivals to their service. They fix their own roots upon theirs, and tap them for water. But that they take something more than water is proved by the fact that, in a field where yellow rattle is abundant, the grass is poor and sickly, and much of it dies before the season when it should be mown for hay.

(ii.) Total Parasites.-These are devoid of chlorophyll, and depend entirely upon their hosts for food. In the British flora the following are total parasites among the flowering plants : Lathroa (toothwort), Orobanche (broomrape), Cuscuta (dodder). The first two belong to the Orobanchaceæ, a Natural Order. which differs very little from the Scrophulariaceæ, in which most of the partial parasites are included.

(1) Lathræa squamaria (Fig. 41).-The toothwort is parasitic upon the roots of trees, chiefly poplars, hazels, and beeches. Its body consists of a thick, much-branched rhizome, closely set with curious fleshy, tooth-like scales, of a grey or dusky-purplish colour, overlapping each other and arranged in four ranks. Each scale is hollow, enclosing an irregular chamber, which is open to the exterior 
by a small hole on the under side near the base. The walls of these chambers are covered with peculiar capitate hairs, which at one time were looked upon as glandular, secreting a digestive fluid for the purpose of consuming the bodies of minute animals which were unfortunate enough to find their way into the chambers. In this way, it was said, the plant obtained a supply of nitrogenous food. But it is now known that the toothwort is not an insectivorous plant at all; the capitate hairs are watersecreting structures-water-glands. The entire plant lives underground in soil where the atmosphere is always moist. Transpiration is, under these circumstances, small, and the plant finds it difficult to get rid of excess of water. This is especially so in spring, when the roots of the host are drawing a large quantity of water

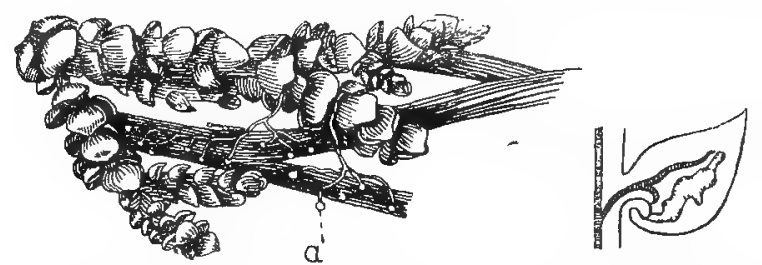

Fra. 41.-Lathroea squamaria (ToOthwort), showiva UNDerarodND Shoot bigaring Scalte-Lmavis, a'trached to the Roots of Hazel by Absorbing Suckers (a). (Aftrer Kerngr.)

To the right a section through one of the hollow scale-leaves.

from the soil for the use of the opening buds and expanding foliage. The supply of water to the parasite is consequently equally vigorous, and the plant gets over the difficulty by excreting the excess in liquid form by the glandular hairs. In June long spikes of pale, fleshcoloured flowers grow up through the soil into the air, and as these are the only parts that ever appear above ground, the plants are difficult to locate except when in flower. Glands similar to those found in the leaves of the toothwort occur in the subterranean buds of certain hemiparasites-e.g., Bartsia - and may serve a similar purpose.

(2) Orobanche. - This genus includes several species, nine of them British. They are brown scaly plants, attached to the roots of various hosts, such as grass, ivy, hemp, clover, etc. Some species confine their attention 
to one definite species of host, and are never found on any other. Others are not so particular. The drain upon the host is generally so great that it prematurely perishes ; fields of clover are sometimes ruined by the parasite.

(3) Cuscuta-dodder; one native species, $C$. europoea, but several aliens; N.O. Convolvulaceæ (Fig. 42). The life-history of this climbing parasite is very interesting. The seed germinates on the ground, thrusting out a short anchoring root. Then a long attenuated filament grows out, devoid of leaves. This is the primary shoot. It is colourless, and its growing apex is sensitive and displays active circumnutation (p. 116). It grows rapidly, form-

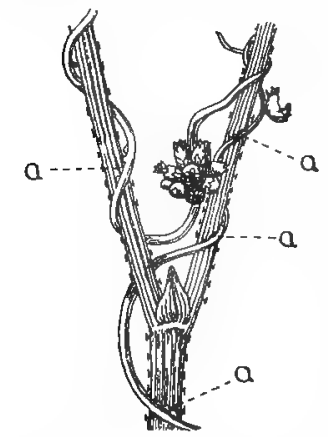

FIG. 42,-Cuscuta (DoDDER) GROWING ON HOP.

a, absorbing suckers (haustoria). ing loops along the ground until the food-material stored up in the seed is exhausted. If by this time the circumnutating tip does not meet a suitable host it dies. If it does, the sensitive thread twines round its stem, putting out suckers which penetrate the tissues of the host at every point of contact. Having established itself securely, the rear part dies away, and for the rest of its life the dodder is free from any contact with the soil. It lives on its host alone, leafless and rootless, strangling its benefactor with a multitude of brown threads. These in the course of time bear clusters of white, bell - shaped flowers, covering the host with flowers not its own. After setting its seed the parasite perishes. The dodder is found on a variety of plants: heath, gorse, thyme, wood-sage, etc.

The Mistletoe (Viscum album, Fig. 43) is a parasite of peculiar interest. It is a green leafy plant, and yet it possesses a highly elaborate and most effective mechanism for the absorption of nutriment from its host. It is a shrubby evergreen, and in the course of time the base of its stem becomes so embedded in the tissues of the host that host and parasite appear to form one plant. In spite of its colour, the plant is a total parasite, all its food being drawn from the host. Chlorophyll is present, but it 
is inefficient, and little or no starch is formed in the leaves. The colour is a dull yellowish-green, and the chlorophyll is probably on the verge of extinction. The branches are repeatedly forked, and each branch bears at its extremity two tough evergreen leaves, and no more. The terminal bud between the leaves always bears an inflorescence, which later on in the year is represented in the female plants by a number of white viscous berries. When these fall, vegetative growth is continued from buds which develop in the axils of the two leaves, and in this way a regular system of forking results. From these facts it is evident that the mistletoe is well on its way to become a colourless, leafless parasite. In total parasites both pigment and leaves vanish or degenerate through disuse. In Nature everything which has outlived its usefulness tends, sooner or later, to disappear.

3. Insectivorous Plants.These are green plants which, by a special mechanism, entrap and digest small insects. The British representatives are :

(a) Drosera (three species), the sundew, a bog-plant.

(b) Pinguicula (four species), the butterwort, a bog-plant.

(c) Utricularia (four species), the bladderwort, a submerged aquatic.

(a) Drosera. -D. rotundifolia and D. longifolia (Fig. 44) occur in peaty bogs. They are small rosette-plants, and the leaves are furnished with a multitude of stalked glands or tentacles, which are reddish in colour, and crowned each with a glistening globule of gum. Small insects, chiefly flies, attracted possibly by the coloured and glistening tentacles, alight upon the leaf, and are held fast by the gum, caught, as it were, in a kind of birdlime. The leaf is sensitive, and the contact of the insect sends an impulse through it; the edges rise, the tentacles curl over towards 
the centre, while other glands, sessile upon the surface, pour over the unfortunate victim a digestive fluid. This secretion is similar in nature and effect to the digestive juices present in the stomach of animals. The insect is quickly killed, and the nitrogenous constituents of its body are dissolved and absorbed into the leaf. It is curious that only small fragments of proteinaceous material, such as bits of meat and white of egg, excite movement in the tentacles; everything else behaves as

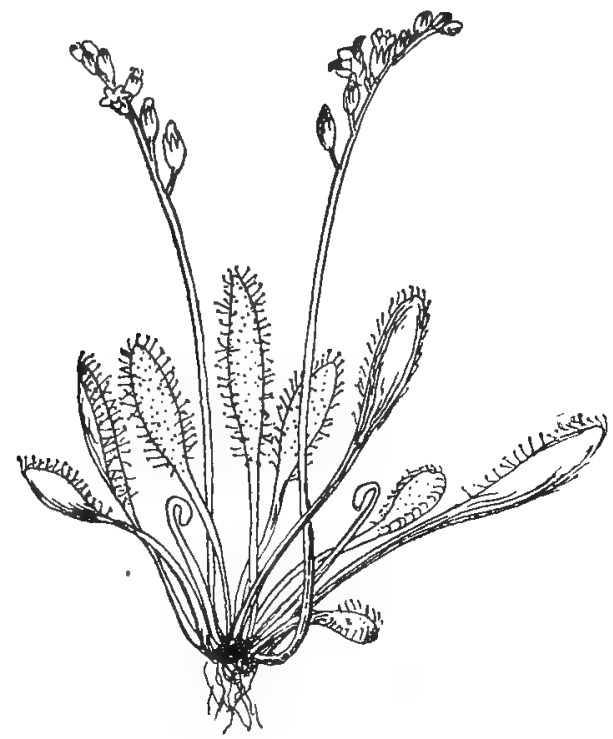

Fra. 44.-Drosera longifolia (StNDEW).

dust, to which the tentacles are absolutely insensible. Darwin, however, found that the tentacles are sensitive to traces of ammonium-salts.

(b) Pinguicula vulgaris (Fig. 45), the butterwort, is common in peat-bogs, especially in mountainous districts. In North Wales it is remarkably abundant above 1,000 feet. This is another rosette-plant with a few ovate fleshy leaves, covered with sessile glands, some of which secrete a digestive liquid, and others sticky mucilaginous drops. The leaves always remain open, and in dry, sunny weather, when the air is filled 
with multitudes of flying insects, they become veritable cemeteries.

Both of these plants live in bogs, the butterwort, on the whole, preferring the sweeter parts, while the sundew is indifferent. In bogs the water is sour and deficient in nitrates. There is plenty of nitrogen present, but, as it is mostly in the form of humous acids or ammonium-compounds, little use can be made of it. The insectivorous habit in these bog-plants is correlated with the need for nitrogen in a place where it is deficient. Not being able to get sufficient from the soil, the plants entrap living insects, and secure a supply of protein from the dissolving bodies of their prey.

(c) Utricularia vulgaris, bladderwort (Fig. 46), a submerged freefloating aquatic found in ditches. It has no roots. The leaves are large and much-divided, floating in suspension just below the surface of the water. In summer the flowering shoots emerge from the water, lifting into the air a spike of conspicuous flowers, pollinated by insects. Upon the submerged leaves, at the base of some of the green, thread-like segments, occur small, bladder - like structures, which give the plant its name (Lat. utriculum, a bladder). Each of these hollow chambers is pro-

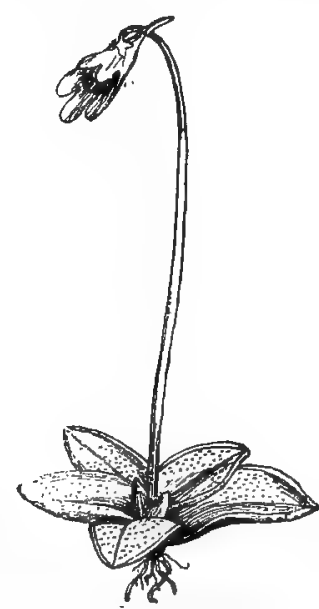

Fra. 45.-Pinguicula vulgaris (BDTTERWORT). vided with a hinged door, which is easily opened from without, but cannot be opened by pushing from within. Over the entrance is a brush of bristling hairs, and round the mouth of the bladder occur a number of glandular hairs. Small crustacea, such as Cyclops (water-fleas), poking about among these hairs for food, and possibly attracted by the secretions of the glandular hairs, push open the trap-door and enter the chamber. The door closes behind them, and they are entrapped. Inside, they soon die either of suffocation or starvation, and the products of their decaying bodies are absorbed. The interior walls of the bladder are covered 
with stellate hairs, but their function is doubtful, since, as far as we know, no digestive fluids are poured out over the bodies of the victims.

Our English fly-catchers are poor things compared with the insectivorous plants of the Tropics and the Southern Hemisphere. The mechanism of the pitcherplant, Nepenthes, is one of the wonders of the vege-

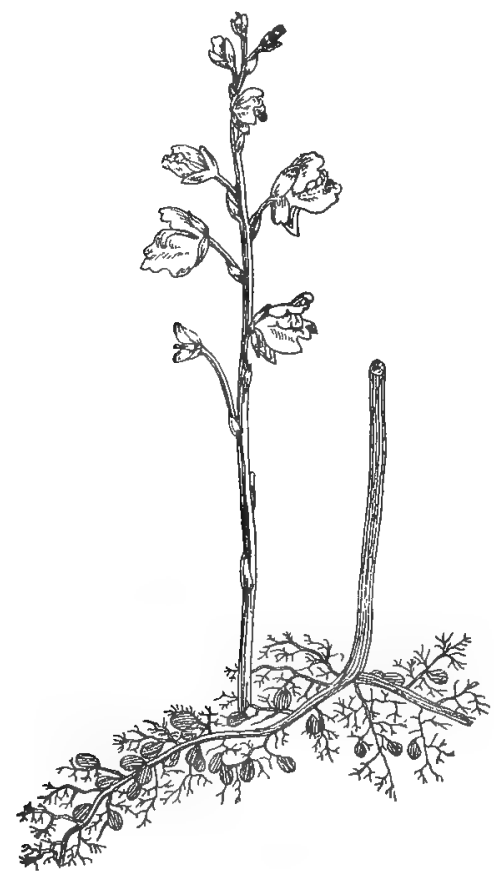

Frg. 46.-Utricularia vulgaris (BLADDERWORT), SHOWING BLADDERS ON SUBMERGed Dissected Leaves aND ABSENCE OF ROOTS. table world, while in Venus's fly-trap, Dioncea, the two halves of the leaf snap together as soon as an insect touches one of the trigger-like hairs on its surface.

4. Symbiotic Plants (Gr. syn, together ; bios, life). - We have already considered one case of intimate association between two living plants - the parasite and the host (p. 125). But in this case the advantage is entirelyone-sided. The parasite lives at the expense of the host; it takes everything, and gives nothing in return. In symbiosis, however, two plants live together, but the relation is one of partnership, both plants benefiting equally by the associa-

tion. The most remarkable instance of symbiosis is the lichen, a dual plant, consisting of a fungus and an alga living together, and forming what appears to be one plant. The alga, being green, makes starch; the fungus makes use of this, and in return not only gives shelter and protection to the alga, but tenaciously stores up within its slimy walls a supply of water which keeps 
the alga always moist. The mutual advantage of this association is evident from the almost universal distribution of lichens. The lichen lives in conditions where the fungus or the alga alone could never exist. It flourishes at the limits of vegetation. The dominant plant near the polar snows is the Iceland moss (Cetrario islandica), a lichen, which is also found on lofty mountains. Encrusting lichens are found on dry rocks and walls where no other vegetation can grow.

We have come across two other cases of symbiosis in previous chapters :

(1) Mycorhizas (p. 124).

(2) Root-nodules in the Leguminosæ (p. 95).

It is possible also that many of the chemical changes taking place in the soil, and hitherto referred to the activities of soil-fungi (p. 96), may in reality be the result of symbiotic activity, algæ co-operating with fungi to bring about the observed phenomena.

Symbiosis occurs not only between plant and plant, but also between plants and animals. The most familiar instances, taking the term "symbiosis" in its widest sense, are to be found in the relations which exist between insects and flowers in pollination, and in a minor degree between birds and fruit in seed-dispersal. Insect-pollinated flowers attract insects with pollen and honey. In some cases the flower provides shelter for their eggs and nutriment for the subsequent broods-e.g., Yucca and certain species of Ficus (fig). But in pollination the relations between the insects and the plant are temporary and often accidental. They have arisen through the association of two needs, one ever reacting upon the other-namely, the need of the insect for food, and the need of the plant for pollination. A much closer association is that which has been found to exist between certain plants and antsmyrmecophily (Gr. myrmex, ant). Attention was first drawn to this by Belt (The Naturalist in Nicaragua) in his description of the marvellous bull's-horn acacia (Acacia cornigera). The stipules of this plant take the form of large hollow thorns, which harbour a species of warlike ants. These protect the tree against the ravages of leaf-cutting ants, which, in the absence of its martial defenders, would very quickly strip the tree bare of leaves and permanently injure it. In return for this 
service the plant provides the resident ants not only with shelter, but with all the food they require.

We have no conclusive example of myrmecophily in the British flora. The presence, however, of extra-floral nectaries suggests in some cases relations with ants. Ants on their way to plunder the flower are side-tracked by these offers of food. In the same way the honey-dew on the leaves of the lime and maple may serve to attract ants. What service the ants perform in return for this food is not clear ; they may possibly destroy the eggs of injurious insects.

There is no line of demarcation between the symbiosis which benefits and the parasite that destroys, or the insects that merely rob. All alike must live, and even in symbiosis the friend may become a foe, and assume the privileges of a master instead of the rights of a partner. In many a case of symbiosis one of the partners is a parasite in disguise. 


\section{CHAPTER XIV}

\section{THE DEFENSIVE EQUIPMENT OF PLANTS}

WE have already, in the first part of this book, dealt with the modifications found in plants which secure them against the perils of unfavourable environment, and especially lack of water. In the present chapter we are concerned with the modifications which serve to defend their possessors against the attacks of living enemies.

These enemies fall into two classes:

1. Those which feed on the tissues, producing diseasee.g., bacteria and parasitic fungi.

2. Those which feed on the tissues, injuring the plant by the loss of the parts eaten, but not necessarily giving rise to actual disease and injuring the plants vitallye.g., grubs, caterpillars, slugs, beetles, aphides, birds, and browsing animals. The eel-worm, however, is a pest which produces deadly disease in herbaceous plants, especially when young.

There is, as usual, no absolute distinction between the two sources of injury. Any form of injury to essential organs, especially those concerned with nutrition, may so damage the individual as to set up a condition of feeble health, which may result in disease and even in death.

In surveying the weapons of defence-that is to say, those modifications which serve to protect plants against injury liable to be inflicted upon them by living organisms - we shall consider separately-

1. The fruit and the seed.

2. The seedling.

3. The adult plant.

1. The Fruit and the Seed.--Here it is important that while the fruit is eaten the seed should be preserved. It is generally found that animals devour the fruit and 
reject the seeds. This serves the plant very well, for the result is the distribution of the seed.

(a) Fruits.-Before the seeds are ready for dispersal, the ripening fruits must be protected against weather, against disease, and against the chances of being prematurely eaten and destroyed. This is secured in various ways. Many succulent fruits contain antiseptic oils, aromatic or bitter principles, or similar substances equally unpleasant to animals searching for food, and germs that might destroy. Unripe fruits are hard, sour, unattractive, and unpalatable. Some have a bitter rind like the orange, others are covered by a coating of wax, others are furnished with disagreeable hairs, and others are defended by an armour of spines.

Among succulent fruits we have the stone-fruit, or drupe -e.g., peach-and the soft-fruit, or berry-e.g., grape. In the drupe the fleshy part is eaten by birds, and the stone containing the seed is rejected. To keep the fruit from drying up before the seeds are ripe, as well as to keep off external water, the outside is protected by a dense elastic skin, frequently covered over with wax or "bloom"-e.g., plum. This wax is antiseptic, and preserves the fruit against the attack of fungi and bacteria, which would cause it to go rotten before it is ripe enough to attract the birds. It is important, therefore, that the continuity of the skin should be kept intact, since wounds and abrasions lay bare the deeper unprotected tissues, and expose them to disease. In the berry the whole fruit is fleshy, but the seeds are hard and indigestible. Even if they are swallowed by birds, the seeds pass uninjured through their bodies. Some berries-e.g., deadly nightshade-are poisonous, and can only be eaten with impunity by a few birds which have become constitutionally used to them.

Nuts have either tough leathery shells or hard stony cases. These prevent the seeds from being eaten except by those animals whose teeth are strong enough to open the shells, and which alone are capable of effectively distributing the contents. At the same time some means are always adopted to protect the nuts while they are young and tender. In some cases the sepals enlarge and envelop them. In the acorn and hazel, bracts coalesce and form cupules (Fig. 47) ; in the beech and chestnut they form spiny shells (Fig. 48). 
Dry fruits, like capsules, are not worth eating. Other fruits escape destruction by concealing or disguising their presence. Protective mimicry is common among animals and insects, but it is only observed here and there in the vegetable world. Thus, some ripe fruits appear like dead twigs-e.g., wallflower; others are like small stonese.g., smooth and dull-coloured achenes. Sometimes, however, mimicry may serve to attract attention. Thus, the achenes of the marigold resemble caterpillars. Birds pick them up and carry them some distance before they find out their mistake.

(b) Seeds. - On p. 108 we pointed out that the seed was the xerophytic structure par excellence, with a wonderful tenacity of life, and with an extraordinary capacity for withstanding long periods of the most unfavourable con-

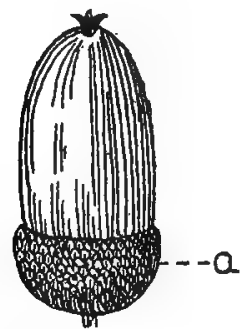

FIg. 47. - ACORN WITH HARD CUPULe (a).



Fig. 48.-Edible Chastinut, with Three Nuts $(a)$ enclosed in Spiny Cupdle $(b)$.

ditions. This hardiness is brought about by the withdrawal of water, so that the seed becomes partially desiccated, and the embryo is reduced to a state of suspended animation. Activity is only resumed when, on germination, water is absorbed and the cells become turgid. The xerophytic characters of the seed are primarily a protection against natural perils-drought, cold, etc. - but the withdrawal of water renders them hard, and therefore impossible as food to swarms of living creatures. Dry structures are not subject to disease, since fungi and bacteria only flourish where moisture is abundant. Apart from this, however, seeds show special protective devices. Many are small and dull in colour, so that they cannot easily be distinguished from the soil particles among which they lie. It is another case of 
protective mimicry. Others are bitter and unpalatable, some are even poisonous-e.g., seeds of laburnum, bitter almonds, and nux vomica.

2. The Protection of the Seedling.-The seedling is exposed to many dangers, many hardships, and countless enemies. Nevertheless, though many perish, some survive. At the same time, plants when very young show less in the way of protective devices than at any other period of their existence. In most cases they survive by sheer force of numbers. In seedlings, indeed, we do not look for much in the way of defensive equipment apart from a good constitution, and this seems all that is necessary. The early stages of germination are carried on below ground. This in itself is a protection to the seedling in its youngest and most helpless condition ; it is sheltered by the soil above it from wind and weather, and concealed from the observation of a host of predatory foes.

3. The Adult Plant.-The soft and nourishing tissues of plants, besides being delicate and subject to injury from weather, are exposed to a multitude of living enemies of all kinds-animals, insects, parasites, and diseases. An ordinary tree-e.g., the oak-is the prey of countless foes. Insects deposit their eggs within its soft tissues. From these eggs arise destructive pests in the form of voracious grubs and hungry caterpillars, which devour everything within their reach. Some attack the stems and leaves, others the roots, others the flowers. The bite of insects and the deposition of eggs beneath the skin lead to the formation of unsightly galls, which, while they provide food for the subsequent grubs, at the same time circumscribe the limits of their damage. Fungi are still more formidable enemies, and to them the majority of plantdiseases is due. No one can have failed to observe the damage caused by these parasites. Seedlings rot and perish; spots and tumours appear upon the leaves and shoots of trees; fungal outgrowths disfigure the branches. Even the flowers are not exempt from injury. The anthers may be filled with black smut instead of pollen, and the ovary filled with grubs instead of ovules.

Lastly, fresh green leaves and shoots, turgid with nutritious and palatable sap, offer no mean inducement to browsing animals in search of food. Many plants may 
be seen dwarfed and cropped close to the ground, where rabbits abound; others, doubtless, are entirely exterminated through the ravages of the resident animals.

The structures found on plants which serve as a means of defence against living enemies were not actually called into existence for that purpose. The leaves of the holly, for example, are not tough and spiny to protect the plant against the hungry mouths of animals, although, being prickly, they do as a matter of fact serve that purpose. Nor does the gorse grow its thorns and the bramble its prickles to make their bodies disagreeable eating. True, the thorn and the prickle do secure their owners from injury where browsing animals abound, and in the course of time plants not so protected might in such localities become exterminated. But the animal is not the cause of the thorn. Thorny plants would grow even if no browsing animals existed on the earth. They are characteristic plants in dry, hot regions where extreme xerophytic conditions prevail. In a xerophyte the transpiration-current is poor and slow. The plant is consequently badly nourished, and the spiny or prickly habit is simply the result of this defective nutrition. In xerophytic regions vegetation is scanty, and the animals are not too well supplied with food. The few plants that are found there would consequently stand a poor chance of surviving if they did not possess some means of keeping off their destroyers. But the very evils from which they suffer provide a means of safety. Dearth of water means lack of food. Lack of nourishment sets up all kinds of physiological disturbances. It affects assimilation, transpiration, respiration, and growth. As a result, leaves become tough and indigestible; buds become provided with scales, and form gummy excretions ; spines, thorns, and prickles develop at the expense of assimilating tissue, while gums, waxes, oils, and bitter and poisonous juices form and collect in the organs. Once being produced, and being found at the same time useful, these things have been preserved by Natural Selection, and a specialization has been marked out for them upon the lines of protection and defence. Protective resemblance sometimes serves as a means of defence against animals, as in the case of certain succulent plants, like species of Sedum and Mesembryanthemum, which have the appearance of stones. 


\section{External Protective Equipment of Adult Plants:}

(a) Cork.-Cork is water-proof and air-proof. The cells of which it is composed are empty and filled with air. It resists the bites of insects, and keeps out bacteria. Wounds are dangerous to plants just as to animals, because on wounded surfaces delicate tissues are exposed to bacterial and fungal infection. In plants an antiseptic tissue, called callus, rapidly forms over a wounded surface, and gradually assumes the characters of true cork. When leaves are shed, the scars are covered with a layer of cork, which seals the wounds of abscission. The lenticels, or breathing-holes, found on bark are more or less filled with a loose, powdery form of cork, which permits a limited interchange of gases between the plant and the external air, but is proof against the invasion of germs.

(b) Cuticle.-The properties exhibited by cork are due to the impregnation of the cell-walls with wax. The superficial walls of the epidermal cells form a continuous membrane-the cuticle-which is thickened and impregnated with a somewhat similar waxy substance. It is therefore impermeable and antiseptic. It forms the limiting skin covering all the exposed parts of plants not protected by cork. and acts much in the same way as cork.

(c) Thorns. - A thorn is an aborted shoot. Instead of ending in a bud, the shoot, through lack of nutrition, ceases to grow, and ends abruptly in a hard pointed thorn. Thorny plants are xerophytes; they dominate the bush and scrub vegetation of semi-deserts. British examples: sloe or blackthorn (Prunus spinosa), gorse (Ulex), hawthorn (Cratcegus Oxyacantha).

(d) Spines.-This term is usually applied to an aborted leaf or parts of a leaf, due to disturbances in nutrition. The leaf-veins of the holly end in pointed spines, because the intervening leaf-tissue has not developed. In the barberry (Berberis vulgaris) every leaf on the long shoots is reduced to a branched spine (Fig. 49). In the false acacia (Robinia pseudacacia) the stipules become sharp and spiny (Fig. 50). In Carlina and Centaurea Calcitrapa the involucral bracts of the inflorescence end in spines.

(e) Prickles. - These are outgrowths of the epidermis and subjacent tissue. They are, in fact, little more than large multicellular hairs; they contain no vascular tissue, and 
can be removed, more or less easily, from the plant. The prickles of the rose and bramble are structures of this nature.

The prickles of thistles are indurated, sharply-pointed hairs, set over all parts of the assimilating surfaces. They probably arose in the course of Natural Selection among stiff-haired xerophytes, being favoured by against animals. Besides these prickly hairs, spines are also present on the leaves. In this

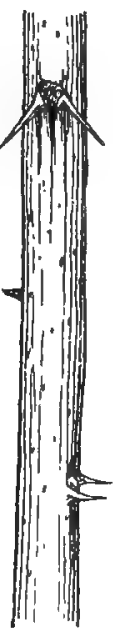

Fig. 49.-STEM OF BARBERRY WITH LEAF-SPINES.
Fig. 50.-False Aoacia (Robinia pseudacacia) WITH SPINY STIPULES.



FTa. 51. - Stingiva HATR OF NETTLE. (HighLy Magnified.)

case continued growth has been checked at certain points along the leaf-margins, with the result that sharp-pointed spines have been produced. Thistles naturally inhabit dry waste places, but their efficient protective equipment fias enabled them to spread over fields and pastures.

( $f$ ) Stinging Hairs. - These are also epidermal outgrowths, and they are only skin-deep-e.g, the stingingnettle (Urtica, Fig. 51). They are broken by a slight touch, the sharp point enters the skin, and an acrid fluid is automatically injected into the wound. 


\section{Internal Protective Charaeters.}

These consist in the presence in the tissues of substances noxious or unpalatable to animals and antiseptic to diseases. They are either formed as natural by-products in the economy of the plant (calcium oxalate), or they arose, in the first place, as a result of certain physiological disturbances, set up by causes that interfered with nutrition or respiration. But, however formed, they have subsequently proved useful to their possessors, and have developed and specialized in the struggle for existence.

(a) Latex.- This is a fluid, generally milky in appearance, which is found in some plants, contained in special cells, tissues, or vessels. It is always powerfully antiseptic, generally very acrid, and in some cases even poisonous. When poured over wounded parts, latex congeals and keeps off the germs and spores of disease. All parts of the greater celandine (Chelidonium majus) contain an orange juice. In one important section of the Compositæ- the Cichorieæ-all the plants possess a milky latex-e.g., dandelion (Taraxacum), lettuce (Lactuca), hawkweed (Hieracium), goat's-beard (Tragopogon), and sow-thistle (Sonchus). The Natural Order to which the spurges belong-the Euphorbiacea-is characterized by the presence of latex. The great economic importance of latex is realized when we consider that rubber is obtained from the latex of certain tropical plants.

(b) Gums, Resins, and Turpentines.-These bodies are either excreted by special glandular cells, or are formed as the result of the disintegration of certain tissues. They are commonly found in xerophytes-e.g., pines, firs. Being antiseptic, they all constitute a means of defence against bacteria, while their unpleasant taste and physical properties teach animals, by experience, to avoid eating the tissues in which they occur.

(c) Bitter Principles, such as tannin, found in the bark and lignified tissues of many trees-e.g., oak-as well as in galls. Quinine is a bitter alkaloid obtained from the bark of Cinchona (Peruvian bark).

(d) Fixed Oils are found chiefly in seeds. They constitute reserves of food which in many cases make them palatable for man and beast-e.g., walnuts, brazils, 
almonds, hemp-seed, etc. (see p. 148); but in some the oil is poisonous or strongly purgative-e.g., castor-oil seed, croton seed, etc.

(e) Volatile Oils.-These give to plants their scent. In flowers they act as an attraction to the pollinating insects, but in many cases the whole plant is strongly scentede.g., mint, lavender, sage. Camphor is an aromatic crystalline substance distilled from the wood of the camphor-tree ; it is poisonous.

(f) Calcium Oxalate.- This salt is poisonous, but it is produced naturally in the economy of plants, as a byproduct in the assimilation of proteins. It is generally deposited in the form of hard gritty crystals within the tissues (rhubarb-roots). In combination with potash, oxalic acid occurs in sorrel. Crystals of calcium oxalate are specially abundant in the outer leaves of some bulbs, where they certainly serve a protective purpose. On one occasion at Kew the outer leaves were stripped off the bulbs of the Roman hyacinth; but the bulbs, thus deprived. of their protective armour, were found to be quickly destroyed by snails.

(g) Free Acids. - These occur very commonly in unripe fruits, making them sour and uneatable. Citric acid is abundant in the lemon, but in smaller quantities it is present in many of our commonest fruits-e.g., cranberry, cherry, and rose-hips. Mixed with an equal proportion of malic acid, it is found in raspberries, red and black currants, bilberries, and.wild strawberries. Unripe apples and pears contain malic acid only. As the starch of the unripe fruits becomes converted into sugar, these acids gradually disappear, and the fruits become sweet and palatable.

(h) Alkaloid Poisons.-The most deadly organic poisons known to the chemist are found in plants. Digitalin is obtained from the leaves of the foxglove (Digitalis purpurea); strychnin from the seeds of Strychnos Nux-vomica; belladonnin and atropin, from the deadly nightshade (Atropa Belladonna); aconitin from the root of Aconitum Napellus; morphia from the juice obtained from the unripe capsules of the opium-poppy (Papaver somniferum). But in most of these cases the whole plant is more or less poisonous, and this may extend even to the flowers and fruits. In the aconite the very honey secreted in the flower is poisonous. 
Symbiotic Insects.-We have already drawn attention to the fact that certain plants make use of resident insects as a protection against other insects (myrmecophytes, p. 133). If the under surface of the leaves of the lime and beech be examined, small nests of hairs will be found in the angles between the veins. In these tiny grottoes swarm multitudes of minute insects which may possibly perform a service to the plants upon which they live by devouring the spores and germs of disease. 


\section{CHAP'TER XV}

Prants differ from animals in many ways. We have drawn attention to some. In the matter of the storage of food-reserve we have another. Animals rarely store up food in their own bodies for future use; to some extent hibernating animals do, and there is the remarkable case of the fat-tailed sheep of Thibet which store up fat in their tails. Plants, on the other hand, by the very nature of their economy, are compelled to make and store up food in preparation for periods when a great demand for nourishment is made. Most plants have to make provision for the formation of flowers and seeds. For this a large amount of food-material is required in a very short time, and in many plants the whole of their vegetative activities seems to be a preparation for this function. The annual, for example, accumulates reserves until flowering, when a migration of food-material takes place from all parts of the plant towards the flowers; the foodmaterial, elaborated by the parent, passes into the seeds, and the drain is so exhausting that the plant dies. Herbaceous perennials prepare for the winter by storing up reserves of food in their perennial parts undergrounde.g., in bulbs, rhizomes, tubers, etc. When spring comes, a current of food-material pours from the seats of storage towards the opening buds, and is utilized for the rapid growth of the aerial shoots and leaves. Trees also accumulate great reserves of food. When the buds open in the spring, the demand for nourishment is very great, and the ascending stream of watery sap, enriched with foodmaterial drawn from the stores of reserve, passes into the unfolding leaves.

The most common form of food-reserve is starch. The cells of the potato are filled with grains of starch: 
cereal seeds are starchy; rhizomes, bulbs, and tubers possess large stores of starch. In a few cases the reserve is sugar : the fleshy root of the beet is loaded with it; the onion is sugary; so are some seeds. In other seeds oil is a form of reserve-e.g., nuts-and in a few cases the reserve is even stored up as cellulose in the cell-walls, which then become enormously thickened-e.g., the datestone. Nitrogenous food-reserves are found chiefly in seeds, but, unlike carbohydrates, they rarely give rise to conspicuous swollen structures.

\section{The Seats of Storage of Food-Reserves.}

In what follows, food-reserves in plants are only dealt with in so far as these stores are serviceable to man, either as a source of food, or on account of their value for

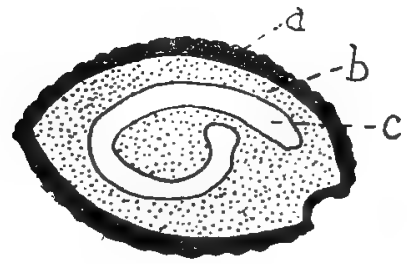

Fig. 52. - Longitudinat Serchion of Albuminots Seed of ONion. (MAGNIFIED.)

$a$, seed-coat; $b$, endosperm; $c$, embryo. economic purposes.

1. The Seed.-The foodmaterial stored up in seeds is for the use of the young plant during its germination, and during that period of infancy known as the seedling-stage, when it is unable adequately to supply its own needs. In albuminous seeds (Figs. 52, $53,54)$ this reserve of food
cells of the endospermlies outside the embryo in the cells of the endosperm-
e.g., wheat, iris, spindle-tree, poppies, buttercups, and all the Umbelliferæ. In exalbuminous seeds (Fig. 55) the food is stored in the embryo itself, usually in the cotyledons, which are then large-e.g., pea, bean, acorn, sunflower-but sometimes in the hypocotyl-e.g., brazil-nut, which is, botanically, not a nut at all, but a seed with a hard shelly coat.

(a) Carbohydrate reserves occur in the form of-

(i.) Starch, in starchy seeds-e.g., the cereal grains, wheat, barley, rice, etc., which yield flour when ground.

(ii.) Sugar, in sugary seeds-e.g., some varieties of maize.

(iii.) Cellulose-e.g., date and other palm seeds.

(b) Protein occurs in the form of amorphous particles 
(aleurone grains) or crystals, which may be either distributed generally throughout the storage cells, or relegated to a special layer, as in wheat. The seeds of leguminous plants-e.g., peas, beans, lentils, pea-nutsare very rich in proteins, which occur in the form of aleurone grains scattered throughout all the cells.
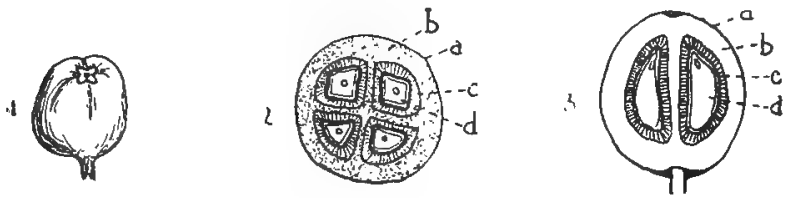

Fig. 53.-Four-Stemded Drupg of Holly. (Magnified.)

1, entire fruit; 2 , transverse section; 3 , longitudinal section. u, outer skin ; $b$, succulent part ; $c$, stone; $d$, seed, with minuto embryo ombedded in endosperm.

(c) Fats and Oils. - These are either derived from carbohydrates, or they may be produced by the disintegration of proteins. Well-known oily seeds are nuts (hazel, walnut, coconut), castor-oil seeds, linseed, etc.



Fia. 54.--Long itudinal Section of Albuminous Seed of Poppy. (Magnified.)

$a$, seed-coat ; $b$, endosperm ; $c$, embryo.

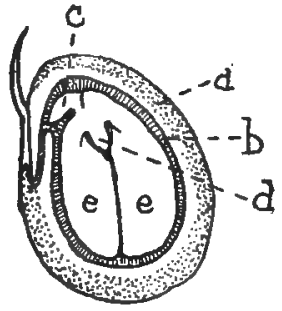

Frg. 55.-Longitudinat Section of Froti of Garden NastorTidm, showing Exalbuminous Seed. (Magnified.)

$\boldsymbol{a}$, fruit-wall (pericarp); $b$, seedcoat; $c$, young root; $d$, young shoot; $e$, sced-leaves.

Starchy seeds constitute the most important source of food to man. In most civilized nations one or other of the cereal grains forms his staple diet-e.g., wheat, from which white bread is made ; rye, made into black bread on 
the Continent; oats, barley, rice, maize or Indian corn, and millet. Indian or great millet (Sorghum vulgare) is the staple food of the people living on the dry plains of India; it is also largely grown in parts of Africa under the name of dura, Guinea or kafir corn. Maize (Zea Mais). contains more sugar and oil than most cereals; it is the only cereal which we owe to America; in South Africa it is called "mealies."

Wheat is the most valuable of all the cereals, and the general demand for it among the more prosperous of mankind is increasing every year. Besides starch, flour contains protein and a small quantity of oil. A large part of the protein in wheat is contained in a special layer of cells lying close to the surface of the grain. In the best white flour this is removed with the outside husk, with the result that the flour is deprived of a large part of its nourishing qualities.

Oily Seeds are of more importance to man as a source of oil, extracted for industrial purposes (see-p. 152), than as food, although some, e.g., pea-nut, sesame-seed, coconut, and the dessert nuts, are largely eaten, whilst from the oil of the coconut, palm kernel, cotton-seed, pea-nut, cocoa-bean, etc., margarine and other edible fats are made; refined cotton-seed, pea-nut, and sesameseed oils are also used as salad oils.

2. Fruits.-Fruits in which any considerable quantity of food-stuff is stored are fleshy. These fruits are particularly adapted to attract the attention of birds and provide them with food, but the seeds are preserved from destruction either by being hard and indigestible, or by being enclosed in hard shells (p. 136). The formation of large fleshy fruits seems at first sight a very extravagant means of providing for the dispersal of the seed, but the method is an extremely efficient one, for there are few other means by which seeds can be carried so far or distributed over so wide an area as by birds.

Cultivated Fruits.-Many succulent fruits have been cultivated by man from very early times, and in the Tropics some, like the banana, form his staple diet. Other examples are apples, pears, plums, cherries, apricots, peaches, gooseberries, blackberries, raspberries, red and white currants, grapes, strawberries, oranges, lemons, figs, 
dates, pineapples, mulberries, melons, cucumbers, and marrows.

The Banana (Musa Sapientum) is one of the most prolifio of food-plants. A single cluster may contain as many as 160 to 180 fruits and weigh 80 pounds. It is propagated. by suckers arising from the base of the stem, and a new sprout will begin to bear fruit in three months. The tree grows in the wet forest-regions of the Tropics, and supplies food all the year round. With its leaves the savage thatches his hut, and when he moves his homestead, burns out a now clearing, plants his suckers, and waits for Nature to do the rest.

A few fleshy fruits are rich in oil-e.g., olives and oilpalm fruits, and serve either as food for man or as a source of oil for industrial use.

Many fruits provide food for birds, but not for man. They are either insipid, nauseous, noxious, or poisonouse.g., the hips of roses (sometimes made into jam), haws of howthorn, berries of the black and white bryony, nightshade, mistletoe, privet, elder, mountain-ash, strawberry-tree, arum, etc.

By cultivation man has considerably improved many of his fleshy fruits, the succulent and juicy tissues being developed at the expense of the harder parts intended by Nature for the protection of the seeds. Most of the more specialized fruits are propagated vegetatively by cuttings, grafts, suckers, etc., in order that the qualities of the parent may be preserved in the fruit. So long and so extensively has this been practised, that in some cases the efficiency of the seeds has been diminished to such an extent that they have become sterile. Apples, pears, and plums are seldom raised from seed, the existing varieties being chiefly the outcome of careful selection during many generations without the intervention of seed. Other foodplants have suffered in the same way. The "seed" potatoes of the gardener are not seeds, but specially selected tubers; even when potatoes are raised from seed, tubers of eatable size can be obtained only by planting the small tubers produced in the first year. In the banana the seeds are quite useless; while the seed of the sugar-cane is unknown under natural conditions, and can be obtained only by carefully selecting the parents and pollinating the flowers artificially. 
3. Storage of Food in Subterranean Organs-(a) Tubers. -(i.) Stem-tubers-e.g., potato, Jerusalem artichoke.

(ii.) Root-tubers-e.g., sweet potato.

(b) Rhizomes-e.g., ginger, arrowroot.

(c) Fleshy Roots.-(i.) Of biennials-e.g., carrot, turnip, parsnip, swede, mangold, radish, beet.

(ii.) Of perennials-e.g., Manihot utilissima, the mandioc, from which tapioca is obtained.

(d) Bulbs-e.g., onion-the leaves of which are full of sugar.

4. Edible Aerial Organs, yielding most of our table vegetables.

(a) Stems.--(i.) Sugary pith-e.g., sugar-cane. Maplesugar is obtained by boring holes in the stem of the sugarmaple, a native of North America, when the sap is setting towards the opening buds in spring.

(ii.) Starchy pith-e.g., the sago-palms-from which sago is obtained.

(b) Leaves-e.g., cabbage, lettuce, spinach.

(c) Buds - e.g., brussels - sprouts, from a variety of cabbage.

(d) Young Shoots-e.g., asparagus.

(e) Petioles-e.g., celery, rhubarb.

(f) Inflorescences-e.g., cauliflower, broccoli, artichoke.

5 . Seedlings-e.g., mustard and cress.

Fodder-Plants.-Animals, in the main, eat the same vegetable food as man. Most of our domestic animals are vegetable feeders, and in these the digestive organs are adapted to the consumption of large quantities of raw vegetation. The chief fodder-plants are grasses, leguminous herbs, and root-crops. Other important feeding-stuffs for livestock include oats, maize, beans, bran, etc. (from the milling of wheat), and oil-cake (the residue left after the oil has been pressed out of oil-seeds).

Accessory Food-Products.-We eat and drink many substances derived from plants which are not strictly food at all. They are either consumed as aids to digestion, or, because of their stimulating properties, they are employed in the preparation of beverages. Others act medicinally as drugs.

(a) Spices and Condiments.--These have little or no actual food-value. They serve merely to stimulate appetite or to render food more pleasing. The principles 
contained in them arise as the result of certain chemical changes taking place within the plant, and, most probably, in connection with the respiratory functions. Respiration begins with the inception of oxygen, and usually terminates with the elimination of carbonic acid gas. If the process is interfered with in any way, organic by-products are formed, and if these turn out to be useful to the plant, their formation tends to become habitual, and the disposition to produce them becomes hereditary.

These substances are found in mustard (ground seeds of Brassica spp.), pepper (ground fruits of Piper nigrum), ginger (rhizomes of Zingiber officinale), cloves (dried flower-buds of Eugenia caryophyllata), nutmeg (seed of Myristica fragrans) capers (flower-buds of Capparis spinosa), chillies (fruits of Capsicum annuum), watercress (shoots of Nasturtium officinale), horse-radish (rhizome of Cochlearia Armoracia).

The bases of flavourings are volatile oils. They are generally obtained by distilling the parts of the plants where they are present with water-e.g., fruits of vanilla, aniseed, caraway, and coriander; cloves; stems and leaves of peppermint; cinnamon bark; and the rind of the lemon. In some cases the whole plant is used, either fresh or in a dried state-e.g., thyme, sage, mint.

(b) Beverages.- Infusions of tea, coffee, and cocoa are universally used as beverages. Alcohol is obtained by fermenting sugar with yeast, either directly from a vegetable sugar or indirectly from starch. The range of intoxicating drinks is almost as great as the range of man himself. Sugary liquids, capable of fermentation, are obtained from all kinds of plants-sprouting barley (beer and whisky), grapes (wine, brandy, liqueurs), potatoes, rye, and maize (inferior spirits), sugar-cane (rum), agave (pulque), coconut (arrack, toddy), honey (mead), millet (kafir beer), etc.

(c) Drugs.- - Hundreds of drugs used in medicine are prepared from plants-poisons, antiseptics, narcotics, anæsthetics, etc.-all capable of producing more or less profound disturbances in the physiological activities of the human body. Peruvian bark, or Cinchona, is the source of quinine, the opium-poppy the source of morphia. Tobacco may be regarded as a mild drug. The following plants, growing in England, have been used at one time or another in medicine: buckthorn, broom, cherry- 
laurel, hemlock, woody nightshade, foxglove, rhubarb, spurge-laurel, chamomile, gentian, valerian, dandelion, nettle, etc.

Economic Botany is the study of plants from the point of view of their utility to man. We have already dealt with the most important side of the subject--human food. But plants have many other uses to man besides nutrition. They offer to him material by means of which countless needs are satisfied and many activities served. Every part of the plant is used in one way or another. The hard tissues which give support to the plant or serve as water vessels find many uses. When they occur in bundles in the stem or leaf they are extracted in long strands (fibres) for use in making textiles and rope (flax, jute, hemp, Sisal, etc.); whilst the large compact masses of woody tissue of trees are utilised as timber. The soft woods used for building are mainly from coniferous trees (deal and larch), and the hard furniture woods from dicotyledonous trees (mahogany, oak, walnut, rosewood, beech, etc.). Many fibrous stems are utilised entire or are merely split-e.g., canes and bamboos (for furniture, etc.), straw (for hat-making), rushes and osiers (for baskets), etc. Another use for the fibrous tissue is in the manufacture of paper, for which purpose soft woods (pine and spruce) and esparto-grass from North Africa and Spain are now mainly employed; the better kinds of paper, however, are made from old rags, which, of course, were originally produced from vegetable fibres.

Seed-hairs provided for the dispersal of seeds are utilized in the case of cotton and kapok. Waste materials and by-products formed by plants are turned to account by man in the case of gums and resins, turpentine, rubber and gutta-percha, dyestuffs, and tanning materials. Food reserves in the plant are employed for industrial puirposes as well as for feeding man. Oil for making paints and varnishes is extracted from linseed; for soapmaking, from oil-palm fruits, palm-kernels, dried coconuts (copra), pea-nuts, sesame-sced, cotton-seed, and many others; for illuminating, from rape and colza-seed, etc.; and for lubricating, from castor-seed, etc. Starch for dressing textiles and for laundry work, and for the manufacture of glucose and industrial alcohol, is obtained from potatoes, rice, etc.; whilst the cellulose reserve of the ivory-nut is used for making buttons. 


\section{- CHAPTER XVI}

\section{REPRODUCTION-MODES OF VEGETATIVE REPRO- DUCTION}

Reproduction is the multiplication of individuals. It is brought about by the detachment of portions of the parent plant, which develop directly or indirectly into new plants. The portions detached may be either single cells or cell-masses. In the higher, or seed-plants, with which we are here concerned, two modes of reproduction prevail :

1. The vegetative mode of reproduction, by the detachment of certain parts or organs from the parent-plant, which parts or organs are able to grow up directly into new individuals.

2. The sexual mode of reproduction, which results in the formation of seed.

There is one very important biological difference between the two modes of reproduction. In the vegetative mode, since detached portions of the parent, buds, shoots, etc., grow up directly into new individuals, the qualities of the parent are continued unaltered in the descendants. Even the characters acquired by the parent during its own life are reproduced in the offspring, generally without any appreciable loss in quality. In this way a single plant, distinguishod above its fellows by the excellence or peculiarity of some quality in leaf, flower, or fruit, may be multiplied indefinitely for many generations, the descendants repeating faithfully the characters of their predecessors. Many horticultural plants are sports, or freaks, characterized by the possession of some unusual habit or character. This may have arisen in the seed itself, as in the case of the Shirley poppy, or suddenly in the form of bud-variation, upon the adult plant- 
e.g., the weeping varieties of ash and willow, and the variegated varieties of $A u c u b a$, privet, maple, geranium, etc. When the sporting character arises in the seed, it is generally transmitted by seed; when it does not, vegetative modes of reproduction are alone capable of preserving it. We have already drawn attention to the fact (p. 149) that the best varieties of cultivated fruits are multiplied by vegetative means, and that if this is done indefinitely the seeds tend to become obsolete. It follows from this that the vegetative mode of multiplying individuals, if very successful, is likely to outrun, and finally to supersede, the sexual mode by seed. The common elm, for instance, is so easily propagated by cuttings and rootsuckers that fertile seed is rare in this country.

Nevertheless, for the great majority of plants, reproduction by seed is either the only method, or it is the method which must occasionally intervene to preserve the continuity of the race. A long course of vegetative reproduction tends, in many cases, to exhaust the stock, and many domestic races so reproduced are only saved from extinction by careful and selective cultivation. Sometimes even then constitutional delicacy becomes at last so pronounced that new strains are started by crossing with wild stocks and raising a more vigorous race from seed.

In those plants which reproduce vegetatively as well as by seed, one mode usually predominates over the other. If conditions are favourable for vegetative development, the vegetative mode prevails; if they are unfavourable, seed. Thus, the lesser celandine (Ranunculus Ficaria) multiplies equally well by tubers and seeds. In damp shady places tubers are formed in abundance, and there are few flowers. In dry sunny spots few tubers are formed, but the plants flower freely, and seed is produced in abundance. The production of seed bears an inverse proportion to the number of tubers formed.

\section{Modes of Vegetative Reproduction.}

1. By Underground Stems or Rhizomes (p. 110).-Any portion of the rhizome which bears a bud, and contains a sufficient store of reserve-food, is capable of independent existence-e.g., couch-grass (Fig. 28), dog's-mercury, iris, wood-sorrel, mint (Fig. 29), etc. 
2. By Creeping Stems, Runners, Suckers, and Ofisets.Stolons, or runners, are weak prostrate shoots, lying upon the surface of the ground, which root at their extremity, while the terminal bud gives rise to an erect stem bearing leaves-e.g., strawberry (Fig. 56). Suckers are under-

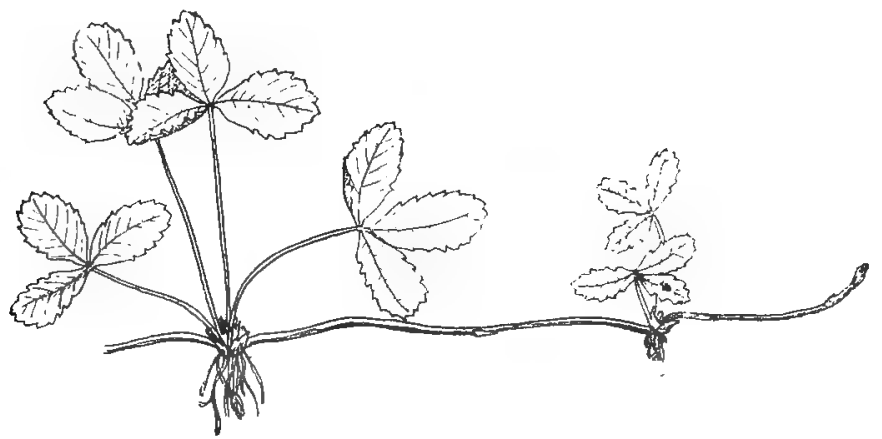

Fig. 56.-Runner of the Strawberty.

ground branches which ultimately turn up and enter the air as vertical stems-e.g., mock-orange, rose, raspberry. In some cases buds arise adventitiously on roots, and form suckers-e.g., elm (Fig. 57), poplar, hawthorn, lilac, rose, raspberry, barberry, apple, plum, apricot, peach, etc. The connections may ultimately die, and the new plants



Fra. 57.-SUCKER OF TlM.

consequently lose connection with the parent. Cutting down the plants to the ground, or uncovering the soil so as to expose the roots to the air and the light, stimulates the formation of these buds. Offsets are short runnerse.g., houseleek (Fig. 58), London-pride. These are rosetteplants ; short stolons arise from the axils of the outer leaves, 
run a few inches along the ground, root, and at their extremity form new plants. Thus, in the autumn, a parentplant may be seen surrounded by a circle of descendants. When the old plant dies the stolons perish, and the offspring become independent. Creeping stems : in some prostrate plants the ordinary stems and shoots creep along the ground and root at the nodes. By the dying away of the main stems the branches are liberated as separate plants-e.g., ground-ivy, creeping Jenny.

3. Bulbs and Corms (p. 111).-These are compressed shoots or buds, capable of rooting, and, by reason of the food-reserves they contain, capable of independent life. In bulbs the food-material is stored in swollen leaves, the stem being relatively small; in corms the stem becomes swollen and filled with food, the leaves being reduced to scales which enclose and protect the stem. In both cases

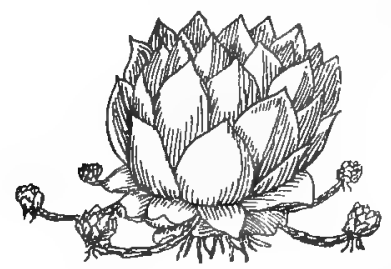

Fia. 58. - Hodseleek, with new plants arise as buds in the axils of leaves.on the old bulb or corm, but their development proceeds along different lines in different plants.

In the tulip (Fig. 59) the bulb consists of a short axis bearing four or five thick, loosely-arranged scale-leaves which entirely ensheath the stem; these are enclosed by a single thin, dry, brown scale, which effectively prevents evaporation of water from the storage-leaves. The centre is occupied by the flowering shoot and the young foliageleaves. In the spring, as the flower and leaves grow into the air, the food passes into them, and the fleshy foodscales shrink somewhat. A bud in the axil of the innermost scale now begins to grow. Surplus food in the scale-leaves, together with food manufactured in the foliage-leaves, pours into it, and the bud gradually assumes the form and proportions of a bulb. By the time this new bulb has completed its development the flower, foliage-leaves, and old scale-leaves have withered. In this way a new bulb is produced each year. In the larger bulbs more than one bud may develop, and in this way multiplication is secured. The production of several buds instead of one is insured by removing the flowering 
shoot in the old bulb during the resting period. The food that was destined for the flower is diverted and used in the production of numerous small bulbs. Lilies, hyacinths, etc., are regularly propagated by this method. The scales of the hyacinth are also slit up, and when placed in a warm, moist atmosphere as many as a hundred tiny bulbils may be formed along the cut edges, and after several seasons these become big flowering bulbs.

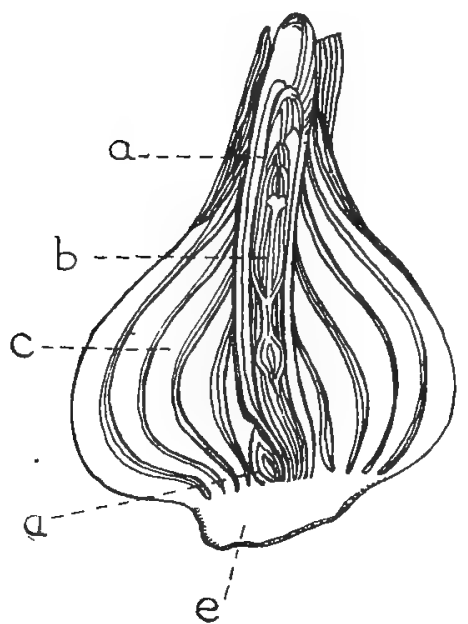

Fia. 59.-TULIP BULB OUT LoNGITUDINAILY.

$a$, foliage-leaves ; $b$, flower ; $c$, fleshy scale-leaves; $d$, axillary bud,, which swells to form next year's bulb; $e$, stem.

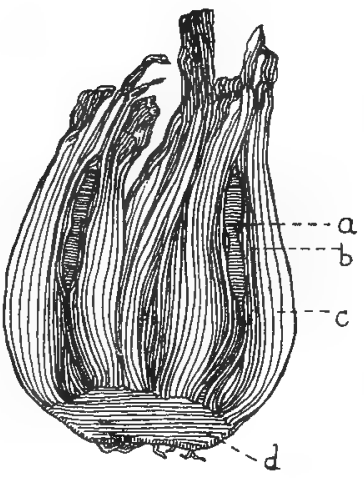

Fia. 60.-Narcissus Bulb cut LONGITUDINALLY.

$a$, flower ; $b$, young foliage-leaves ; $c$, fleshy bases of old foliageloaves; $d$, stem.

In the narcissus (Fig. 60) the scales are numerous and tightly packed; they are the bases of old foliage-leaves. The flowering shoot and young foliage-leaves are again situated in the centre of the bulb, but after flowering the food passes into the bases of the leaves, and the upper parts die away, leaving broad, jagged, membranous ends. In this way the original bulb gradually increases in size, and may persist for several years. A bud in the axil of one of the central foliage-leaves becomes the flowering shoot of the succeeding year. The narcissus multiplies by the formation of new bulbs, which arise as buds in the 
axils of the outer scale-leaves. The new bulbs are enclosed by the scale-leaves of the parent for several years until they become sufficiently big to burst the now withered leaves, and separate as distinct plants.

The structure of a typical corm can be observed in the crocus (Figs. 61, 62). The swollen part consists entirely of stem, enclosed by fibrous scales placed one above the other, as in ordinary shoots. The apex of the stem is occupied by one or more flower-buds, together with a

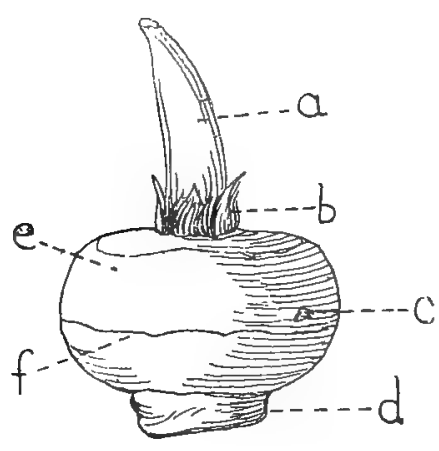

Fia. 61.-Croods Corm tN Resting Condition, with Enveloping Scale - Leaves Removed to SHOW SoldD StEM $(e)$.

$a$, bud; $b$, remains of previous year's foliage-leaves; $c$, axillary bud, which later swells to form a new small corm ; $d$, previous year's corm, now shrivelled; $f$, scar of scale-leaf.

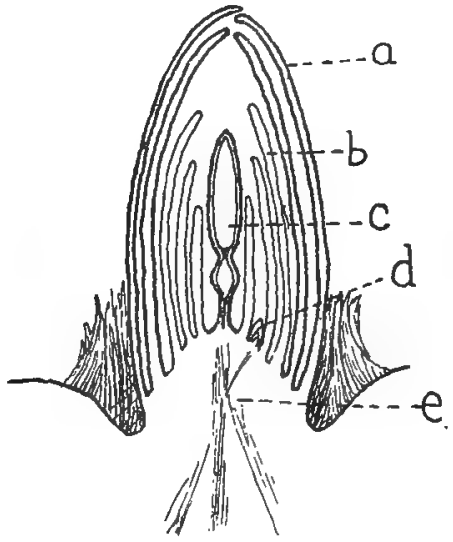

Frg. 62.-Longitudinal Section OF THE BUD SHOWN IN FIa. 61 .

$a$, cover-scales ; $b$, foliage-lesves ; $c$, flower; $d$, axillary bud, which becomes next year's flowering shoot; $e$, stem, which swells to form next year's corm.

number of young foliage-leaves, the whole being covered by a series of white scales forming a large conspicuous bud. During the vegetative period the part of the stem from which the leaves and flowers arise becomes filled with food drawn from the old corm and the foliage-leaves. It gradually swells, and forms a new corm on top of the old one. A bud in the axil of one of the foliage-leaves becomes the flowering shoot of this new corm, whilst the cover-scales of the original bud turn brown, and form the 
protecting sheath round the swollen stem. The old corm, drained of food, withers away, and the young one sinks down to occupy its place. The descent is assisted by the contraction of thick and fleshy roots (Fig. 63). In the autumn-crocus (Colchicum autumnale), which belongs to the Lily family, the new corm is formed at the side of the old one, and contractile roots are unnecessary.

In large corms more than one corm is formed at the top of the old one, each of flowering size. In addition, a number of much smaller corms are formed as buds in the axils of the outer brown scales. These take a year or two before they have stored sufficient food to provide for flowers. Thus all the new corms are seated directly on the old one. This is not at all a good method, for they are so close together that some at least die through lack of food and air, brought about by overcrowding. Montbretia, a common garden plant, closely related to the crocus, has escaped this peril by producing a number of thin horizontal shoots, the tips of which swell out into new corms, often separated several inches from the parent and from each other.

4. Tubers (p. 110) are swollen perennating organs, which,

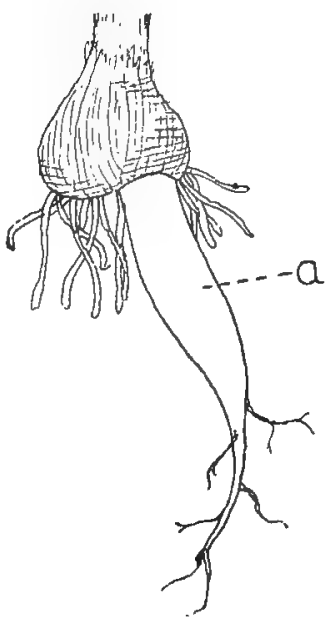

Fig. 63. - Young Crocus Corm, with ThICK, FLESHY, Contractile Root (a).

when detached, give rise to new plants. In the potato the tubers are stem structures containing a large quantity of starchy food-reserve, and bearing buds ("eyes"). When potatoes are planted, the eyes sprout and give rise to aerial shoots. A potato may be cut into pieces, and each portion will grow, provided it has an eye and sufficient reserve-food to give the new plant a start. In the lesser celandine the tubers are formed from axillary buds (p. 111). On the death of the parent the tubers become detached, and develop independently. In damp, shady places the lesser celandine develops long 
weak stems. Some of the leaves bear tuberous buds (bulbils) in their axils, but they have the same structure as the underground tubers. Subterranean leafy bulbils are found in Saxifraga granulata (the meadowsaxifrage), and these form the chief means of propagation.

5. Aerial Bulbils.-These are fleshy brood-buds which arise on aerial stems. They become detached, fall to the ground, root, and grow into new plants. In the tiger-lily they develop in the axils of the lower leaves, and when the plant dies they separate. In some species of onione.g., Allium vineale-they replace some or all of the

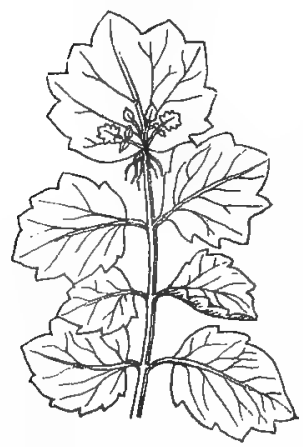

Fig. 64.-Radical Leaf OF CUCKOO - FLOWER (Cardamine pratensis), SHOWING ForMLATION of New Plantlets on Terminal Leaflet. (Afuter Korner.) flowers. In very wet places, such as water-meadows, it is rare to find any flowers at all on the plant. In drier places, where the chances against the survival of the bulbils are increased, flowers are produced instead.

6. Viviparous Plants.-New plants sometimes appear on the most unlikely parts of plants, and almost any organ may, if the proper stimulation is present, become the seat of vegetative budding. Thus the leaves of Begonia become viviparous (Latin vivus, alive; pario, I produce) if they are pegged to the ground and their veins slit across. Buds are formed adventitiously at the lower ends of the severed veins. From these buds little plants arise, which, if separated, take root easily in the soil and grow. Similar plantlets are formed on the radical leaves of the cuckoo-flower (Cardamine pratensis) when growing in wet, fertile meadows (Fig. 64). In many alpine grasses - e.g., Poa alpina and Festuca ovina - the flowers become transformed into plantlets (Fig. 65). The stimulation in all these cases is produced by the accumulation of excess of nutritive material at certain points. In the Begonia the retreat of the sap down the leaf is stopped at the points where the yeins are severed and the buds arise. In the alpine grasses flowers are not produced because of the 
extreme cold, and the food destined for them goes into the little plants instead.

7. Multiplication by Detached Shoots-e.g., some aquatics (see p. 53).

It is clear from this that the vegetative mode of reproduction in all its various forms is really one of buddetachment. Bulbs, corms, and bulbils are obviously only buds rich in food-reserves. Cuttings, fragments of rhizomes, runners, suckers, and tubers are modified bud-bearing shoots. In viviparous roots and leaves buds arise on organs which normally do not bear them. It seems, indeed, as if any part of a plant, which contains soft tissue capable of growth, may produce buds if a sufficient stimulus is present. One condition is always necessary-abundance of food at the points where the buds are destined to form. The stimulus in most cases is provided by some check taking place in the ordinary processes of growth, and a transference of vegetative activity to new centres - the brood-buds. The bud is, therefore, the basis of vegetative multiplication in the higher plants, and its success is due to-

1. The reserve-food stored up in the bud itself or in organs closely connected with it.



Fra. 65. - Poa alpina, SHOWING REPLACEMENT OF FLOWERS BY VIVIPARous Plantlets. (After KERNER.)

2. Its power of developing adventitious roots, without which independent life would be impossible.

3. Its xerophytic nature, enabling it to remain in a resting or dormant condition during the periods unfavourable to vegetative growth.

4. In many cases to the protection secured to it by living underground. 


\section{CHAPTER XVII}

\section{REPRODUCTION BY SEED-POLLINATION}

The Flower (Fig. 66). - The essential parts of the flower are the stamens and the pistil. The stamens are the male reproductive organs. Each stamen typically consists of a stalk, or filament, surmounted by an anther, which contains four chambers filled with pollen. The female reproductive organ is the pistil, which occupies the centre of the flower. The most important part of the pistil is the ovary, consisting of one or more closed chambers, in which the ovules are developed. The ovary is generally prolonged into one or more styles, each of which is terminated by a surface specialized for the reception of the pollen-the stigma. The stigmatic surface is covered by a multitude of short nipple-like hairs, secreting a sweet, sticky liquid, which holds fast the pollen as soon as it comes into contact with it. The outer floral structures are more leaf-like, and constitute the perianth (Gr. peri, round; anthos, flower). The perianth may be either green or coloured, or the outer floral leaves may be green and the inner ones coloured, in which case the parts are distinguished as calyx and corolla. The corolla consists of a number of petals, often large and conspicuously coloured, to attract insects, and frequently joined together to form a tube of varying length. The calyx, formed of sepals, is green, and serves chiefly for the protection of the flower in the bud.

\section{Reproduction by Seed.}

The seed is the result of the fusion of two sexual cells within the body of the ovule. One of these cells-the male, or fertilizing cell-is formed within the pollen-grain; the other--the female, or egg-cell 
-is formed inside a large cell-the embryo-sac, which is developed in the tissues of the ovule. The egg always remains where it is formed, and therefore the male cell must be brought to it. In the higher seedplants-the Angiosperms (Gr. angios, a vessel ; sperma, seed)-the ovules are enclosed in the ovary, and the pollen-grains can be brought no nearer to the ovules than the stigma. In the lower group of seed-plantsthe Gymnosperms (Gr. gymnos, naked), pines, firs, cypresses, larches, yews-the ovules are not enclosed, but lie exposed to the air. In this case the pollen can be borne direct to the entrance of the ovule. The first step in the production of seed is the conveyance of the pollen to the stigma of the pistil, or in the case of Gymnosperms to the ovule itself. This is termed pollination. When the pollen-grain is deposited upon the stigma it germinates. A long thread-like tube grows out of the grain, penetrates



Fra. 66.-Diagram of Flower at Tme of Frrtilzation: (After Prante and VINES.)

$u$, calyx ; $b$, corolla ; $c$, stamens ; $d$, anther ; $\epsilon$, pollen-grains ; $f$, tube of germinating pollen-grain; $g$, stigma; $h$, style ; $i$, ovary ; $k$, micropyle of ovule; $l$, egg-cell ; $m$, embryo-sac; $n$, integument of ovule; $r$, receptacle.

the style, and makes its way towards the ovule. The body of the ovule within which the egg is formed is surrounded by one or two coats, but a hole, or pore, is left in the coats-the micropyle (Gr. mikros, small; pyle, gate)which affords a passage to the interior. On entering the ovary, the growth of the pollen-tube is directed towards the lips of the micropyle. A liquid secreted at the micropyle attracts in some way the elongating tube. The tip of the tube enters the ovule, and, reaching 
the embryo-sac, discharges into it a nucleus, which fuses with the nucleus of the egg-cell. The egg-cell, thus fertilized, divides and develops into the new plant-the germ or embryo of the seed. The fusion of the male cell with the egg constitutes the act of fertilization, and by it the ovule becomes the seed. It is preceded by pollination-that is, by the transference of the pollen from the stamens in which it is formed to the stigmas upon which it germinates. After fertilization, great changes take place in the ovules, a stream of foodmaterial pours into them, and their coats become modified into protective envelopes for the seed. When these changes are completed, water is withdrawn and the seed passes into a resting or dormant state, from which it only emerges at germination.

The success of the seed, from the biological point of view, is due to its efficiency in preserving the life of the embryo during periods inhospitable to growth, and to the ease and certainty of its dispersal by natural agencies.

\section{Pollination.}

The pollen which reaches the stigma comes either from the same or from another flower. In the former case the flower is said to be self-pollinated; in the latter, cross-pollinated. The terms "self-" and "crossfertilization" are often used in the same sense. This is justified when pollination is followed by fertilization, but when we are only concerned with the means by which pollen is deposited on the stigma, and not what happens to it afterwards, it is better to use the term "pollination," reserving "fertilization" for the act of sexual fusion itself.

Self-Pollination (autogamy, Gr. autos, self ; gameo, I marry).-Autogamy is only possible when stamens and pistil are both present in the same flower. The seeds so produced give rise to offspring which more closely resemble the parent than plants produced by the co-operation of distinct parents. Self-fertilization is very common among plants, even among those which seem specially adapted for cross-pollination. On the publication of Charles Darwin's works on fertilization in flowers, people were so struck with the wonderful adaptations among flowers for 
cross-pollination that they were inclined to minimize the importance and extent of self-fertilization, which was regarded as not merely undesirable, but, as a general rule, positively harmful to the race. This is an exaggeration, for in most cases self-fertilization can certainly take place for many generations without impairing in any way the vigour of the stock. At the same time, the importance of cross-fertilization in maintaining a good average race is unquestioned, and Robert Knight, in 1837, was no doubt right in the main when he said that self-fertilization was not possible for a perpetuity of generations without the intervention of cross-fertilization.

The truth of the matter is that self-fertilization has no more harmful effect on future generations than vegetative reproduction; probably less. Vitiated habits and objectionable characters acquired by a parent are transmitted by vegetative multiplication, but not by seed, even when self-fertilized, unless they have become so pronounced as to impair the nutrition and check the development of their possessor. The same is true of in-breeding in animals. If the parents are sound, the progeny is sound. The danger arises when unsoundness comes in. By inbreeding this is intensified ; by cross-breeding it is modified or eliminated. Again, self-pollination is economical, a large number of seeds being fertilized with the minimum expenditure of pollen. Moreover, the certainty of pollination is greater than in cross-pollinated plants, and generally the output of seed in these plants is very great indeed. This accounts for the wide distribution of autogamous species, and the rapidity with which they conquer new ground. Many of the commonest and most widespread weeds are self-pollinated-e.g., groundsel (Senecio vulgaris), chickweed (Stellaria media), shepherd's-purse (Capsella Bursa-pastoris). These all have small inconspicuous flowers which rarely open. Many other weeds are only occasionally cross-pollinated, and even in ordinary insectpollinated flowers self-pollination very often steps in when cross-pollination fails. The garden-pea, in spite of its attractions, is invariably self-pollinated. In some plants seeds are formed in flower-buds which never open. These closed or cleistogamous buds (Gr. cleistos, closed) are found in many species of Viola, wood-sorrel (Oxalis), and stitchwort. These plants are visited by few insects 
at any time. During the summer they bloom freely, but few fruits are formed. In late summer and early autumn, when cold, damp weather is frequent, flower-buds form which never open, and these always produce a full complement of seed.

Cross-Pollination.-The pollen may come from a different flower on the same plant (geitonogamy, Gr. geiton, neighbour) or from another plant. Geitonogamy is not far removed from self-pollination, for the sexual elements are both derived from the same plant, though the relationship is not so close as between the stamens and pistil of the same flower. In true cross-pollination two distinct plants must co-operate, one contributing the pollen, and the other the ovules.

Agents of Pollination.-In self-pollinated flowers the pollen either falls by its own weight upon the stigma or the two are brought into contact by the bending of the stamens or styles. In cross-pollinated flowers an external agent is required to carry the pollen from one flower to another.

1. Water.-Water carries the pollen only in the case of a few water-plants where the flowers are completely submerged all the time. Most flowering aquatics send up their flowering shoots above water, and these are pollinated in the same way as land-plants. The floral habits of a plant are more conservative than its vegetative organs, and the persistence of the aerial mode of pollination in aquatics affords strong evidence of their terrestrial origin. The grass-wrack (Zostera) found on muddy shores is an example of water-pollinated flowers. It flowers below water. The pollen is long and thread-like, and of the same density as sea-water. It is borne passively to the stigmas by the movements of the water, just as in windpollinated plants the pollen is carried passively through the air by the wind.

2. Wind.-In wind-pollinated flowers the pollen is light and powdery. It is produced in enormous quantity, for the wind bloweth where it listeth, and the chance of the pollen reaching its proper destination-i.e. the stigmas of a flower of the same species-is very small. Anemophilous flowers (Gr. anemos, wind ; phileo, I love) have no need for attractive and sweet-scented corollas. Not being visited by insects, they secrete no honey. The 
flowers are small and inconspicuous, but the stigmas are large and feathery, and project beyond the flower. The anthers burst when the air is dry, and clouds of golden dust are shot from them. If they burst in wet weather, rain would wash the pollen upon the earth, and it would be wasted. In many wind-pollinated flowers the pistils ripen first, so that they may be ready to catch the first pollen that is wafted along their way. Among windpollinated plants are many of our lofty forest-treespines, oaks, beeches, poplars, elms, birches-bushes like the hazel, climbers like the hop, water-plants like Myriophyllum, weeds like stinging-nettles and plantains, and all the grasses, reeds, and sedges. Most of our catkinate trees (p. 180) are wind-pollinated, and they flower very early when the trees are bare of leaves. The presence of the leaves would obstruct the passage of the pollen to the flowers. The oak flowers after the leaves are out, but the position and form of the leaves are such that they interfere very little with the passage of the pollen through the tree. If foliage is present, the wind-pollinated flowers are raised well above the leaves-e.g., grasses. In the pine the pollen is provided with floats.

There is little doubt that in the evolution of flowers wind-pollinated flowers preceded insect-pollinated flowers, the advance being made in the direction of economy of material and of increasing certainty of pollination. But of existing flowers, some that are wind-pollinated have always been so-e.g., conifers; others have degenerated from insect-pollinated ancestors. The latter usually show signs of their degradation. The pollen may be still somewhat sticky-e.g., Poterium Sanguisorba ; remnants of attractive corollas may persist-e.g., Thalictrum minus ; and honey may even be secreted-e.g., Rumex, Poterium.

3. Insects.-Flowers pollinated by insects are called "entomophilous" (Gr. entomon, insect). Unlike the wind, the movements of insects are directed by a definite purpose. They visit flowers, sometimes for shelter, occasionally as a suitable place to deposit their eggs, but generally in quest of food. The adaptations of flowers to insects and of insects to the flowers which they visit are very curious and wonderful. Beauty of form, colour, scent, and honey are all adaptations which have arisen among flowers for the attraction of insect-visitors. 
All flowers were once pollinated by wind; they were small, green, and inconspicuous. This method, however, entailed tremendous waste of material, and with it all seed-production was uncertain, since pollination was left to chance. When wind, as an agent of pollination, began to be replaced by insects, waste was diminished, and seedformation became more certain. Provided it possessed. adequate material to serve as food for insects, any flower which happened to be a little more conspicuous than its fellows by certain traits of form or colour, or which betrayed its presence to them by some pervading scent, was bound to receive greater attention. Insects would visit it in greater number, and the production of seed would become greater and more certain. Now, this would be a distinct benefit to the plant, and plants so equipped would be better fitted than others to survive in the struggle for existence. This is what has actually happened. Every advance made by the flower in the direction of making it more attractive to insects has been a gain. It has given its possessor an advantage over its competitors which, being less efficient, have been gradually but inevitably ousted from their habitats.

As plants have specialized in these directions, the pollinating insects have specialized too. Their mechanism of flight has been modified for rapid and easy movement from flower to flower. They have acquired more skilful means of attachment, and the organs by which they extract honey have developed into wonderful instruments of precision. As the corolla-tube became longer, and the honey more and more concealed, their tongues have become longer and more specialized. The evolution of the insect has kept pace with the increasing specialization of the flower and the increasing difficulty in obtaining honey.

Entomophilous flowers offer two kinds of food to their insect-visitors, and they may be divided into two classes, according to the nature of the food which they offer-

1. Pollen-Flowers, which contain no honey, and are visited by insects for the sake of the pollen alone. The anthers are large and generally numerous, and the quantity of pollen formed is very great. The pollen is taken home by bees, and kneaded into a kind of pollen-bread for the grubs. Pollen-flowers include the rose, clematis, pæony, marsh- 
marigold, rockrose, St. John's-wort, the sweet-scented spiræa, broom, and gorse. The first entomophilous flowers must all have been pollen-flowers. With the arrival of honey, an additional food was offered, and great economy was effected in the production of pollen.

2. Honey-Flowers, which secrete honey or nectar. Honey is a fluid rich in sugar secreted by special glandsnectaries-which may occur on almost any part of the flower. It is usually, however, secreted by a definite tissue belonging to the receptacle at the base of the ovary-e.g., convolvulus (Fig. 67) - or the stamens-

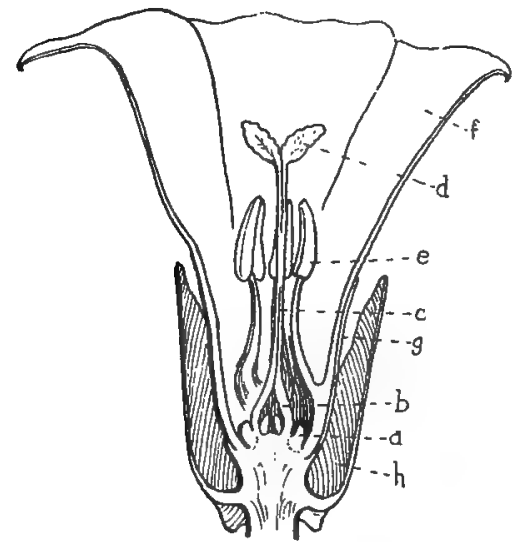

Fig. 67.-Convolvulus sepium : Lonattudinal Section of Flower.

$a$, nectary; $b$, superior ovary ; $c$, style; $d$, stigmas ; $e$, stamens; $f$, petals ; $g$, sepals; $h$, bracts.

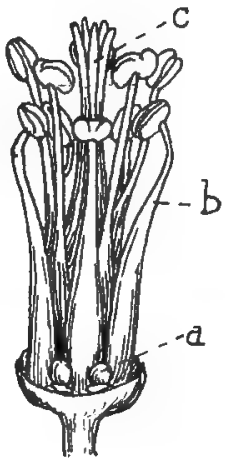

Frg. 68. - Flower of Geranium, WITH SEPALS AND Petals Removed to show HoNey-GLaNDS (a).

b, stamens; $c$, carpels.

e.g., geranium (Fig. 68). In flowers with inferior ovaries, a part of the ovary-wall usually secretes it-e.g., narcissus. In other flowers nectaries occur on the petals-e.g., buttercup (Fig. 69) ; the swollen base of the styles-e.g., Umbelliferæ (Fig. 70) ; as appendages of the stamens-e.g., violet; or they may be specialized organs which are modified stamens or petals-e.g., possibly many of the Ranunculaceæ (Figs, 71, 72). It is possible that the secretion of honey was first stimulated by the irritation caused by the insects biting into the soft tissues at the base of the flower for nutritious juices. 
Flowers are visited by any honey-seeking insect capable of extracting the honey. Some of the smaller flowers secrete a great deal of honey, but as it is more or less freely exposed, a large number of insects are able to reach it. Some of the Umbelliferæ and Compositæ, for instance, with only slightly-concealed honey, are visited by an enormous number of insects-e.g., dandelion and Senecio Jacobrea. The hogweed (Heracleum Sphondylium) is said to be visited by 118 different insects-possibly a record among British plants. Scabious and Jasione montana are also plants visited by a host of insects. In some cases insect-pollination is so certain that the power of

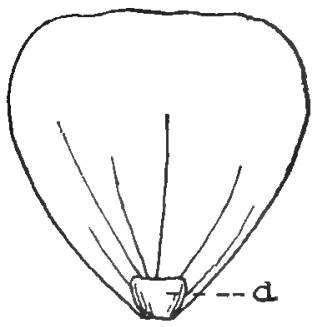

Fig. 69. - Putal of ButtrerCUP WITH NECTARY (a) AT BASE.



Frg. 70. - Fennel : Longrtudinal SeCtion OF FLOWER.

$a$, nectary ; $b$, inferior ovary; $c$, stigma; $d$, stamen ; $e$, petal.

self-fertilization is said to have been lost. With the increase in size and complexity of the flower, and the more effective concealment of the honey, the smaller insects with short tongues are excluded, and in extreme cases the honey is so deep or so difficult to get at that only the strongest or longest-tongued bees and Lepidoptera (butterflies and moths) can effect its extraction. Lepidopterous flowers have usually long, narrow corollatubes or spurs-e.g., toadflax and red valerian. The honeysuckle opens between seven and eight in the evening, when it becomes' strongly scented. The tube is more than an inch long, and can only be explored by the very longest-tongued moths-e.g., hawk-moth. There is 
so much honey in the tube that it is sometimes half full, when it can just be reached, though with difficulty, by the humble-bee. The only effective visitor to the largeflowered climbing convolvulus-Convolvulus sepium-is the hawk-moth. In many highly specialized flowers heavy structures have to be pushed aside before the honey can be obtained-e.g., snapdragon, calceolaria, gorse, broom. Mock glands occur in some flowers-e.g., grass of Parnassus. Sham nectaries, in the form of little green knobs, are found at the base of the corolla-lobes in the woody nightshade.

Some flowers have very few visitors. This is either because they are so specialized that very few insects can get at the honey, or because they are disagreeable to all but one or two insects. In extreme cases, flowers, though seemingly well adapted to insects, seldom get a visitor, and have to rely upon their own pollen. The violet is a case in point. By scent, form, and honey it seems a plant flaunting everything that could attract insects ; but few come, and seeds are usually formed by selffertilization in closed buds. Other flowers seem to be

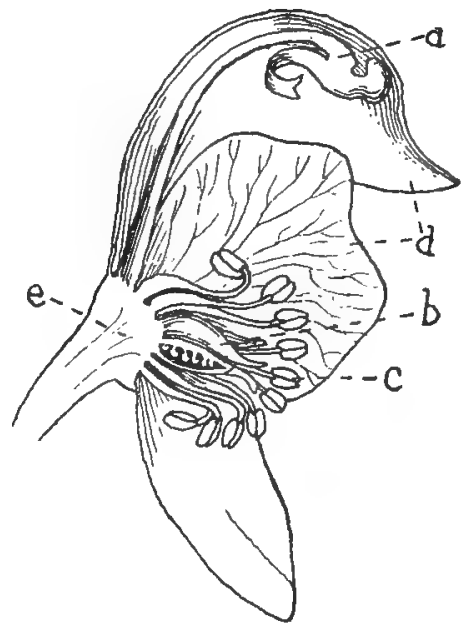

Frg. 71. - Monk's - Hood : LongiTUDINAL SECTION OF FLOWER.

$a$, honey-leaf ; $b$, carpels ; $c$, stamens ; $d$, sepals ; $e$, receptacle. adapted to one insect, and no other. They are probably disagreeable to other insects. For example, Lysimachia vulgaris, the yellow loosestrife, is only visited by one insect-a bee (Macropis labiata); Trifolium repens, the white clover, relies on the humble-bee; and the white bryony (Bryonia dioica) is pollinated exclusively by the bee Andrena florea.

Since the position of the nectaries determines so largely the kind of insects visiting the flowers for food, we may roughly divide entomophilous flowers 
into three classes, based upon the availability of the honey :

1. Those with freely-exposed honey, which may be. visited by all kinds of insects, even those with the shortest tongues (flies, beetles, short-tongued bees, wasps)-e.g., saxifrages, galium, ivy, most of the Umbelliferæ, barberry, hedge-mustard, spindle-tree. Many of these flowers are small, but their conspicuousness is increased by the massing of them together (see paragraph on inflorescences, p. 178), or they make their presence evident by a strong scent. Short-tongued insects are not efficient pollinators, because they seldom confine their attention to one species of flower. Such flowers are also more

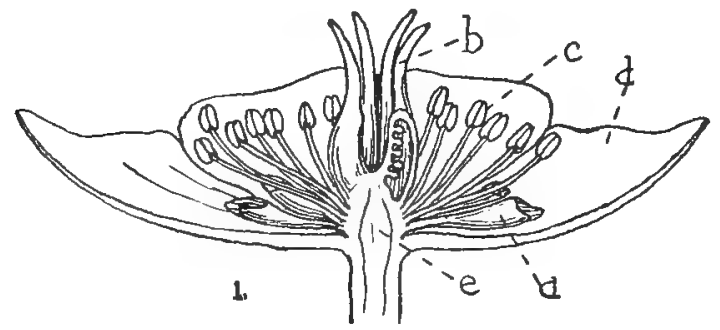

2

Fig. 72.-Christmas Rose (Helleborus).

1, longitudinal section of flower: $a$, honey-leaf ; $b$, carpels ; $c$, stamens; $d$, sepals; $e$, receptacle. 2 , honey-leaf, enlarged.

exposed than others to insects which rob them of honey, but are useless in effecting pollination. They are also liable to have their honey spoiled by rain.

2. Flowers with half-concealed honey. These are, evolutionally, flowers of a higher type than Class 1. Their honey lies deeper, and is more difficult to get at. It is more protected from rain, and is less exposed to the ravages of unwelcome guests-e.g., buttercup, stonecrop, many Crucifers, potentil, etc. There is every gradation between the flowers of this class and the preceding. The insects have tongues between 2 and 3 lines long (a line is $\frac{1}{12}$ inch). They are mostly short-tongued bees and the longer-tongued flies. Among the unbidden guests of flowers are the wingless and crawling insects-e.g., ants. They enter the flower on foot, but before the honey is reached the path is often stopped by viscid secretions on 
the flower stalks-e.g., Silene, Lychnis-or by obstructing hairs on the calyx or at the entrance of the flower. The extra-floral nectaries which occur on some plantsplum, cherry-laurel-may serve the purpose of diverting these marauders.

3. Flowers with fully-concealed honey.

(a) Honey concealed in short flowers-e.g., geranium, willow-herb, bramble, veronica, mint, ling, etc. This group excludes the short-tongued insects entirely, the flowers being pollinated by long-tongued flies and mediumtongued bees, butterflies, and moths. These insects are larger and much more skilful in extracting honey than the smaller short-tongued insects, and they usually confine their attention to one species of flower as long as possible. In this way there is less waste of pollen and a greater certainty of pollination.

(b) Flowers in which the honey is concealed at the bottom of long tubular corollas, or spurs. These are the most specialized of entomophilous flowers, and are only visited by the longest-tongued insects-bees, butterflies, and moths. Many of the largest and most irregular flowers are visited by the humble-bee-a strong, heavy insect with a long tongue. This bee has the vicious habit of boring through the base of the corolla and illegitimately removing the honey without pollinating the flowers-e.g., bell-heather, dead-nettle, toadflax, foxglove, Canterbury bell, columbine. Through the holes thus made smaller insects can enter and complete the plunder. To this class belong the larger Leguminosæ, Scrophulariacæe, and Labiatr, many orchids, and those flowers pollinated exclusively by butterflies and moths-e.g., evening-primrose, Lychnis, species of Silene, tobacco-plant, honeysuckle, primroses, etc.

\section{The Pollinating Insects.}

1. Bees (Hymenoptera).-Bees are either short-tongued (ground - bees), medium-tongued (hive-bees), or longtongued (humble-bees). They collect both honey and pollen. The pollen is usually rolled up and carried away in little packets on the hind-legs. Bees are the most important of all pollinators, not only because of the length of their tongues, but also because of their strength, 
intelligence, and skill. Humble-bee flowers : larkspur, deadly nightshade, foxglove, white clover; hive-bee: Viola-canina; short-tongued bees : mignonette.

2. Butterflies and Moths (Lepidoptera).-Most of these insects are long-tongued, and some of them have tongues longer than any bee. One of the hawk-moths has a tongue which, when fully extended, is over a foot in length. These insects do not enter the flower, but hover over it, and often without touching the flower at all, shoot out their tongues into it for the honey. They are not strong insects, and are unable to move aside the heary structures which bees can, nor can they bite holes through the tissues. Butterflies generally fly by day, and the flowers they visit are generally red or blue. Many moths fly at night, and the flowers they visit are white or bright yellow, the only colours visible at a distance in the dim light of the evening. Flowers pollinated by night-flying moths are also strongly scented, and many of them only open in the evening when the moths are about - e.g., tobacco - plant, evening-primrose, Silene nutans. The evening-lychnis (Lychnis vespertina) is white, and opens between 6 p.m. and 9 a.m.; the day-lychnis (L. diurna) is a bee-flower, red in colour, open all day, and closed at night. It has a shorter tube than the nightblooming moth-flower. The apple is white, strongly scented at night, and pollinated chiefly by moths.

3. Wasps.-One or two flowers in the British flora are visited exclusively by wasps. One is the figwort (Scrophularia), with small, dull-purple, open flowers, having a rather disagreeable smell. On a warm sunny day an enormous number of wasps may be seen hovering about these flowers. Wasps are not very efficient agents of pollination, because, unlike bees, they do not, as a rule, confine their visits to the same species of flower for any length of time.

4. Small Insects (e.g., flies, beetles, bugs, etc.).-The flowers visited by these insects are usually small and open, and the honey, even if slightly concealed, is easily attainable. They are stupid creatures, and enter at random any flower they meet. A few flowers, however, are specially adapted for fly-pollination. They have a disagreeable odour, resembling that of carrion, but very pleasant to flies. The flowers are so constructed that 
they act as fly-traps, holding their pollinators captive until their duty is accomplished. The most familiar flytrap in England is the cuckoo-pint (Arum maculatum), found under shady hedges everywhere. The inflorescence is a long spike (spadix) of small unisexual flowers (Fig. 73), partially enclosed in a great sheathing bract, the spathe. The female flowers are borne lowermost upon the spadix, and consist of a large number of pistils without any perianth. A short distance above these are the male flowers-a multitude of almost sessile stamens. Then comes, at the constriction of the spathe, a brush of downwardturned hairs, which partially close in the chamber below. The spadix ends above in a long, dark-coloured, club-shaped organ, whose dark purple colour and disagreeable smell are so attractive to flies. Flies, attracted by the showy spadix, enter the inflorescence, push their way through the neck of the spathe, and enter the chamber where the flowers are. Once in, they cannot get out, for the forest of pendent hairs bars the exit. But the quarters are comfortable, and there is plenty of food. The pistils ripen first, and are pollinated by the flies when they first enter the chamber. Each stigma, when ripe, secretes a drop of honey, and the flies, in their

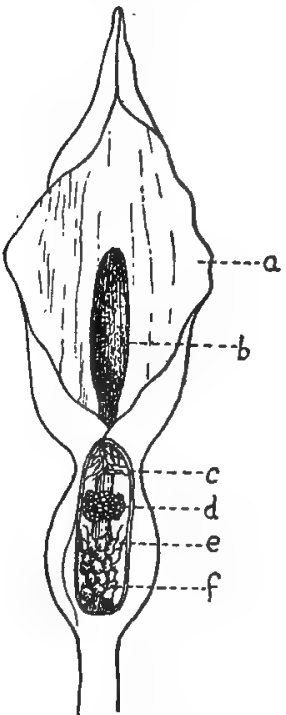

Frg. 73. - IntLonescher of Cockoo-PrNT (Arum maculatum). (REDUCED.)

$a$, spathe; $b$, fleshy axis of spadix; $c$, hairs at constriction of spathe; $d$, staminate flowers; e, sterile pistillato flowers; $f$, fertile pistillate flowers. movements to get at it, dust any pollen they may have on their bodies upon the receptive stigmas. After a while the stamens mature, and, bursting, powder the insects with pollen. At the same time, the flower begins to fade, the hairs dry up, and the spathe droops and falls over, leaving an open passage for the insects. They fly out, but, having become accustomed to the darkness of the trap, they make for 
the nearest opening arum, and enter it. The birthwort, or Dutchman's-pipe (Aristolochia), is another fly-trap, formed on similar lines to the arum, but in this case it is a single flower which acts as a trap, not an inflorescence (Fig. 74).

Pollination by Animals other than Insects.-In England this is negligible. If it happens, it is only accidental. In the Tropics, however, sun-birds and humming-birds,

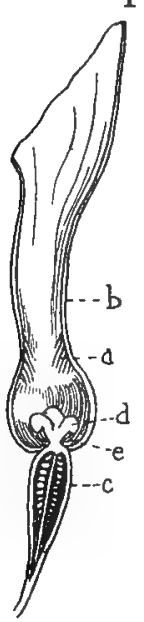

Fig. 74. - LonaITUDINAL SECTION OF UNFERTILIZED FLOWER of Aristolochia. (REDUCED.)

$a$, down n ardpointing hairs; $\bar{b}$, porianth; $c$, ovary; $d$, stigmas; $e$, stamens. with brilliant plumage and long, pointed beaks, regularly visit flowers for the sake of the honey, and indirectly act as pollinators. Certain flowers--e.g., Aspidistra-are said to be pollinated by slugs.

\section{Devices which tend to Prevent Self- Pollination.}

1. The separation of the male and female organs (stamens and pistils) in space-that is, the stamens are in one flower, and the pistil in another. Between these any pollination at all must be cross, and a pollinating agent is necessary to carry the pollen to the stigma. Both flowers may occur on the same plant, but in different flowers (moncecious, Gr. monos, single; oikos, home). They may occur in the same inflorescence, mixed with bisexual flowers, as in many Umbelliferæ and Compositæ, or they may occur on different shoots, as in the hazel. In diceious plants (Gr. $d i$, two) the pistillate flowers occur on one plant and the staminate flowers on another-e.g., willow, poplar, box, perennial dog's-mercury, etc.

2. Dichogamy (Gr. dichos, apart), the separation of the sexes in time-that is, the stamens and pistil of the same flower do not ripen together. When the stamens ripen first, the pollen is shed before the stigmas are receptive, and when the pistil is mature there is no pollen available from the same flower. When the stamens ripen first, the 
flower is said to be protandrous (Gr. protos, first ; andros, male); when the pistil, protogynous (Gr. gyne, female). The flowers, in these cases, may be regarded biologically as unisexual, being male when the stamens are ripe, and female when the pistils. The two periods, however, generally overlap, and during this time self-pollination is possible. In most flowers the stamens ripen first, but a few are protogynous-e.g., plantain, figwort, Christmasrose, most grasses, and all fly-traps. The pellitory (Parietaria officinalis) exhibits very pronounced protogyny. The style protrudes from the flower before the bud opens, and by the time the stamens are ripe the stigmas have fallen off.

3. The Mechanical Structure of the flower is such that the pollen cannot, naturally, get deposited upon the stigmas of the same flower-e.g., orchid, iris. These flowers, therefore, must be cross-pollinated, and if they are entomophilous, the insects touch and pollinate the stigmas on entering the flower, and on leaving it move the floral parts in such a way that the pollen they bear away is not deposited on the stigmas.

4. Dimorphic and Trimorphic Flowers.-The primrose is dimorphic-i.e., it has two kinds of flowers (Gr. di, two; morphe, form). In one the anthers are situated upon the corolla-tube at a higher level than the stigma; in the other the positions are reversed. Charles Darwin showed that effective fertilization is only brought about when the stigma of a long-styled or pin-eyed form is pollinated by pollen from the stamens of the short-styled or thrum-eyed flower, and vice versa - that is to say, pollination with the best results takes place between organs at the same level. In the purple loosestrife (Lythrum Salicaria), a marsh and river-side plant, three kinds of flowers occur, three levels being interchangeable among two whorls of stamens and the stigma. Here, again, pollination between organs at the same level is best, and these must be in different flowers.

In all bisexual flowers, however efficient the devices tending to prevent self-pollination, it is always possible for it to occur. In some cases it regularly takes place if cross-pollination fails. The flowers of the Composite family, for example, always set a full head of seeds, and this could not happen if self-pollination were impossible. 
As a matter of fact, in this order the flowers actually provide against the failure of cross-pollination. The stigmas after a while, whother pollinated or not, curl over their tips, and explore the withered anthers or style for any stray pollen that may happen to be still clinging to them, thus insuring fertilization for every ovule.

The subject of pollination is extremely wide and varied, but we have not the space to describe in detail the many curious devices found in flowers to prevent self-fertilization, nor to give an account of the wonderful adaptations for pollination by long-tongued insects. In some cases specialization has been carried to such a length that fertilization is dependent upon the visit of one kind of insect only, so that, in its absence, no seed is formed. The limits, then, of the plant and the insect are coterminous. In other cases the insect and the flower have so adapted their habits to each other's needs that the life-history of the one is not completed without the aid of the other. We do not say that this is advantageous to the flower. It is not. The disappearance of the insect means the extermination of the flower.

\section{Inflorescences and Pollination.}

Flowers may be solitary, or more usually arranged in groups on special stems. An inflorescence is a shoot devoted entirely to the production of flowers. Most solitary flowers are large and conspicuous, and insectpollinated-e.g., poppy, water-lily, wood-anemone.

\section{Axis of Inflorescence Elongated:}

1. Raceme, flowers stalked.

2. Panicle, a branched raceme.

3. Spike, flowers sessile.

(a) Catkin, pendulous, flowers unisexual.

(b) Spadix, axis fleshy, flowers unisexual and surrounded by a spathe.

4. Cyme, flowers usually stalked, axis terminating in a flower.

\section{Axis of Inflorescence Short :}

5. Head or capitulum, flowers sessile.

6. Umbel, flowers stalked. 
In the raceme (Fig. 75) the youngest flowers are at the apex. In some cases the stalks of the flowers are so adjusted in length that all the flowers are brought to the same level-e.g., the corymb of the Crucifers (Fig. 76). The whole mass of small flowers is thus made more conspicuous. After fertilization the axis of the inflorescence lengthens, separating

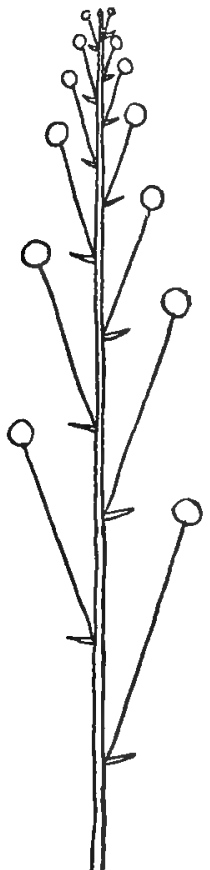

FIG. 75.-DiagraM OP RACEME.

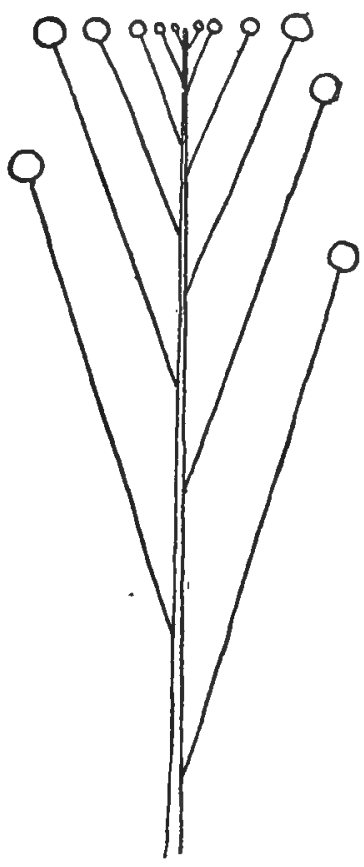

Fio. 76.-Diagram of Corymi.

the fruits. When the flowers of the raceme are separated by long internodes they are large-e.g., foxglove.

The number of flowers is increased when the axis of the raceme branches, and this type-the panicle - is found in the lilac and horse-chestnut among insect-pollinated flowers, and many grasses among the wind-pollinated ones. In the clovers and medicks the axis is short, and 
the flowers, which are small, are clustered into head-like racemes.

The spike (Fig. 77) and its variety, the catkin, are represented chiefly by wind-pollinated plants-e.g., plantain, hazel, alder, birch. Some grasses possess compound spikes. The orchids have stalkless flowers on an elongated axis, and, morphologically, these inflorescences are spikes; but the usually long inferior ovary behaves as a stalk,

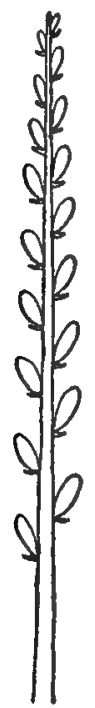

Fig. 77.-Diagram of SPIKE.

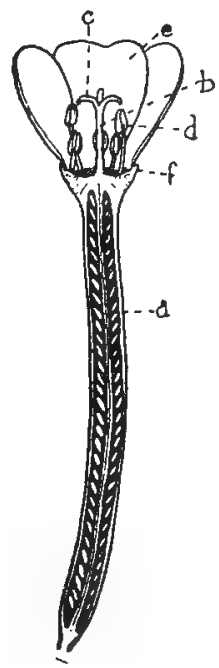

Fig. 78. - WhiLOW-HERB : Long ITUdTAL SECTION OF FLOWER SHOWINO LONG, Stalk-LIKe INFERToR OVARY (a).

$b$, style; c, stigmas; $d$, stamens ; e, petals ; $f$, sepals.

so that the flowers stand away from the axis, and biologically the inflorescence is a raceme. The same is true of the evening-primrose and some willowherbs (Fig. 78).

The cyme (Fig. 79) is found in the Pink family and the valerians. The main axis ends in a flower, and one or two branches arise immediately below, which in their turn end in flowers. This method of branching continues until a large usually flat-topped inflorescence is produced. 
The head (Fig. 80) is the characteristic inflnrescence of the Dandelion family, the scabious, thrift, etc. The flowers are small, very closely packed, and sarrounded by a ring of small leaves (bracts).

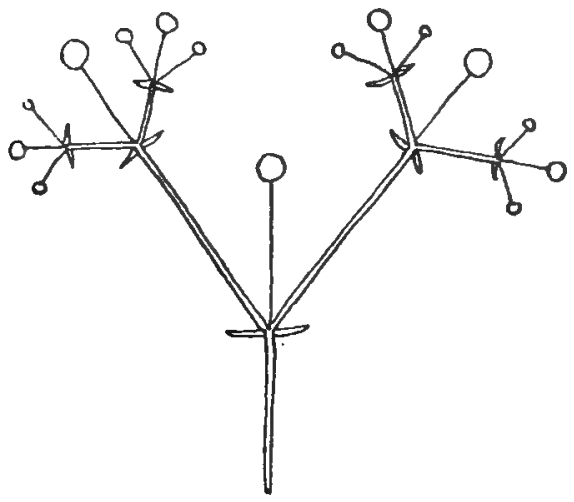

Fyo. 79.-Diagam of Crme.

The umbel (Fig. 81) occurs in the Parsley family (the Umbelliferæ), the onion, narcissus, pelargonium, etc. The flowers are again usually closely packed, and in some of the Umbelliferæ - e.g., hogweed-the outermost petals of

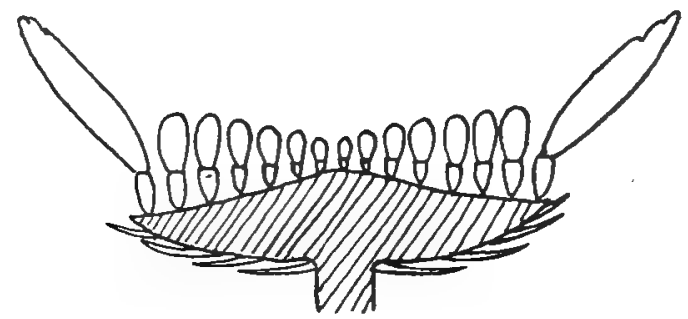

Fig. 80.-Diagram of Head (Capitulum).

each flower are enlarged to increase the size and conspicuousness of the whole cluster.

In considering the biological significance of the various forms of inflorescences, we see that in all cases the flowers are so arranged as to increase the chances of pollination. 
The collection of small flowers into conspicuous masses is brought about by different plants in different ways. In entomophilous flowers the massed inflorescence is an



Fra. 81.-Diagram of Compotnd Umbet.

advantage, because the whole cluster can be pollinated by a single insect during one visit, and in wind-pollinated flowers the chances of pollination are improved if the area is increased by multiplying the number of flowers. 


\section{CHAPTER XVIII}

\section{FRUITS ANDSEEDS}

Among the higher plants, multiplication by seed is almost universal. The various modes of vegetative reproduction supplement it, but only in a very few cases do they altogether displace it. For this reason the higher plants are called Spermaphytes, or Seed-plants, in contrast to the lower plants, or Cryptogams, which multiply by spores, and not by seed.

The Fruit.--Seed-plants are divided into two groups, according to whether the seeds are enclosed in fruits or not. The Angiosperms, or higher flowering plants, bear seeds enclosed in fruits. This fruit is usually developed from the ovary. All parts of the flower are looked upon as modified leaves, and the leaf-structures which form the ovary are known as carpels. If the carpels are separate, the ovary is said to be apocarpous (Gr. apo, from, distinct ; carpos, fruit); if they are united, syncarpous (Gr. syn, together). The number of carpels forming the ovary may be one or many, and according to their mode of union one or more seed-chambers are formed. The ovary is, therefore, a closed structure containing one or more chambers, in which one or more seeds are developed. When the ovules are fertilized and become seeds, accompanying changes take place in the carpels, and these become the enclosing walls of the fruit, and constitute the pericarp (Gr. peri, round). In the lower group of Seed-plants, the Gymnosperms, the seeds are not enclosed in carpels, but are exposed on shoots or seed-bearing leaves-e.g., conifers. Nevertheless, even in Gymnosperms seed-protection is not unprovided for. In the pine, for example, during the development of the seeds, 
the scales which bear them enlarge and become woody. Being closely packed together in a cone, and overlapping, they cover the young seeds completely. By the time the latter are mature and ready for dispersal, the hard woody scales have become very dry and gape apart, thus allowing the seeds to be blown out by the wind.

True fruits are developed from the ovary alone. Where other parts of the flower contribute to its formation, the fruit is said to be false.

In classifying plants, we pointed out that two methods were possible- the morphological and the biological. The same is true of fruits. We may base our classification either upon the nature and development of the structures involved in the formation of the fruit (morphology), or upon the purposes which these serve (biology). Thus, all the succulent fruits form a single biological group, serving to attract birds, and the dispersal of the contained seeds is effected by their agency. But morphologically they differ very widely, the fleshy part being variously derived. In the grape the entire wall of the ovary or pericarp forms the succulent portion of the fruit ; in the plum only a part of the pericarp is succulent, the rest forming a stone which encloses the seed; in the hip, haw, strawberry, and apple it is the receptacle-the portion of the flowering axis upon which the flower rests- which forms the fleshy part of the fruit. There are thus many morphological ways of attaining the same biological end, and in a biological classification the end attained forms the basis of grouping, and not the morphological means employed to bring it about.

\section{Morphological Classification of Fruits.}

In a morphological classification the difficulty is to select such morphological features or characters which will enable us to separate fruits into natural and obvious groups. For example, let us attempt to base a classification upon the number and cohesion of the carpels, thus :

1. Fruits derived from an ovary of one carpel:

(a) One-seeded.

(b) Many-seeded. 
2. Fruits derived from an ovary formed of more than one carpel :

(a) Carpels separate:

(i.) Each one-seeded.

(ii.) Each many-seeded.

(b) Carpels united :

(i.) Each one-seeded.

(ii.) Each many-seeded.

This looks satisfactory as far as it goes. Let us proceed further, and consider :

1. Whether the carpels split open to allow the seeds to escape (dehiscent fruits) ;

2. Whether the carpels merely separate (schizocarps); or

3. Whether the fruit is indehiscent.

The attempt to combine this with the preceding grouping results in confusion, which becomes worse as we still further break up the divisions.

Moreover, biological necessities obtrude themselves during the development of the fruit, and seriously affect the number of ovules or the number of parts of the ovary. Thus, an ovary may be formed of several carpels, with one or two ovules in each. While the fruit is forming, one ovule may get the start of the rest, monopolize all the available food, and reduce the fruit to a one-seeded indehiscent structure-e.g., nuts. It is difficult in a case like this to decide in what group the fruit should be placed, and whether more stress should be laid upon the fruit as it is or what it was when it started. In any case, we cannot separate biology from morphology.

We will consider another difficulty. The majority of fruit-classifications bravely start off with the primary division into-

1. True fruits.

2. False fruits (pseudocarps).

In the first, the fruit is assumed to be derived from the ovary alone; in the latter, other parts of the flower are involved, usually the receptacle. The whole inflorescence may constitute a single fruit, in which case flowering shoots also are involved, as in the fig. Among true fruits are included those derived from an inferior ovary-e.g., 
fruits belonging to the Natural Orders Compositæ, Umbelliferæ, and Amaryllidaceæ. An inferior ovary, however, is always, to a greater or less extent, merged with the receptacle, and, strictly speaking, all such fruits should be called "false." The true achene is a fruit derived from a one-seeded superior ovary. It is dry and indehiscent. In the Compositæ the fruit is one-seeded and indehiscent, but it is the product of two carpels and an inferior ovary. The ovule is basal, arising from the receptacle; the carpels merely roof in the chamber at the top. The fruit, therefore, is actually more receptacle than carpels, and is, therefore, not a true fruit at all. By calling it a cypsela the difficulty is not faced. Biologically, of course, it is an achene. In other inferior ovaries the ovary is sunk in the receptacle, and the carpels line the chamber of the fruit, but do not constitute

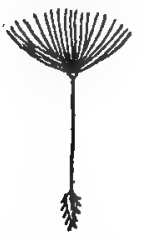

Fig. 82.-ACHENE

(CYPSELA) OF

Dandelion. the whole of the fruit-wall-e.g., narcissus.

This illustrates some of the difficulties in the way of any strictly morphological classification of fruits, and a purely biological division is equally unsatisfactory, since it classes together fruits of the most diverse origin and development. The following classification is a compromise. It is to be regarded as one of convenience only, sanctioned to some extent by custom and practice, but neither logical nor strictly scientific:

I. Dry Fruits, formed by the carpels alone, or, if the receptacle plays any part at all, it is insignificant.

1. Achenial Fruits.-Pericarp dry, indehiscent, oneseeded.

(a) Achene, derived from a one-seeded ovary.

(b) Nut, derived from a several-seeded ovary.

Here the achene (Gr. $a$, not ; chenos, a splitting) is used in a wide biological sense, and includes all one-seeded fruits, whether inferior or superior, or formed of one or more carpels. The term is thus made to include such varieties as the cypsela (inferior fruit, Fig. 82), the caryopsis (fruit superior, but pericarp fused with the seed - e.g., grasses), and the samara, or key (the winged achene of the ash, Fig. 83). As the fruit contains only a single 
seed, there is no reason for the pericarp to dehisce. The whole fruit is distributed as a single seed, and germinates as a seed. For this reason many achenes are popularly called seeds-e.g., sunflower, buttercup, strawberry-pips, corn-grains, etc.

A nut is a dry indehiscent several-seeded fruit, which becomes one-seeded by abortion. The hazel-nut is derived from a twochambered ovary formed of two carpels containing several ovules. In some cases nuts are enclosed in false envelopes developed from bracts-e.g., the acorn lies in a cupule, or cup, formed of a multitude of coalescent bracts (Fig. 84) ; the hazel is partially enclosed in a membranous cupule; beech-nuts (mast) and edible chestnuts are enclosed, three together, in a spiny fleshy shell (Fig. 85).

2. Capsular Fruits.-These are dry, many-

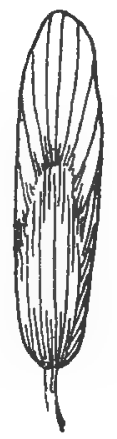

FIa. 83. -

SAM ARA OF AsH. seeded fruits which split open to allow the seeds to escape. The dehiscence may take place in various ways:

(a) By pores-e.g., poppies, snapdragon (Fig. 86).



FIa. 84.-NUT (ACORN) OF OAK-TREE.

a, cupule.



Fic. 85. Frutt of Enible ChestNOT.

$a$, nuts ; $b$, cupule.

(b) By teeth, into which the top of the capsule separates-e.g., Lychnis, Silene (Fig. 87).

(c) By lids-e.g., henbane, pimpernel (Fig. 88), plantain.

(d) By longitudinal splitting-e.g., willowherb, violet, bluebell, wallflower, Iris (Fig. 89). 
The term "capsule" is used in the widest sense, and includes many varieties:

(a) Formed from one carpel :

(i.) Liegume.

(ii.) Follicle.

(b) Formed from more than one carpel :

(i.) Siliqua and silicula.

(ii.) Capsule proper.

The pod, or legume (Fig. 90), is formed from one carpel, and splits down the two seams, back and front-e.g., pea. The fruit is characteristic of the Leguminosæ, but in some plants the pods are curiously modified. In medick (Medicago), the pods are rolled up in a spiral, and in the



Fig. 86.-Porous

CAPSULE OF SNAPDRAGON.

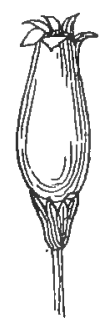

Fig. 87.-TOOTHED

CA P S UL E OP Silene.

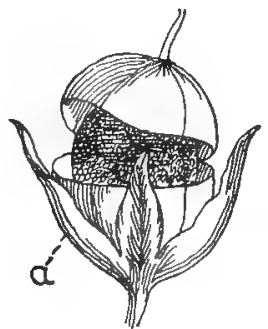

Tig. 88.-CapsUle OF ScaRLet Ptmpernel, Splitting TRANSVERSELY.

u, persistent calyx.

smaller species they become two- or even one-seedede.g., $M$. lupulina. In other cases the pod becomes separated into one-seeded sections by transverse partitions, forming a jointed pod, or lomentum. These split off consecutively, beginning at the top, and releasing the seeds one by one-e.g., sainfoin (Fig. 91). In the radish the siliqua similarly becomes many-jointed.

A follicle is a pod which splits down one seam only, usually the inner or ventral-e.g., larkspur (Fig. 92).

The siliqua (Fig. 93) is characteristic of the Wallflower family - the Cruciferæ. It is formed of two carpels joined down the middle by a partition. The carpels split away from below upwards, leaving the seeds upon the partition, from which they are easily detached. A silicula is a short and broad variety of the siliqua-e.g., shepherd's-purse. 


\section{FRUITS AND SEEDS}

All other capsular fruits not pods, follicles, or siliquas are termed capsules. They may be formed from inferior as

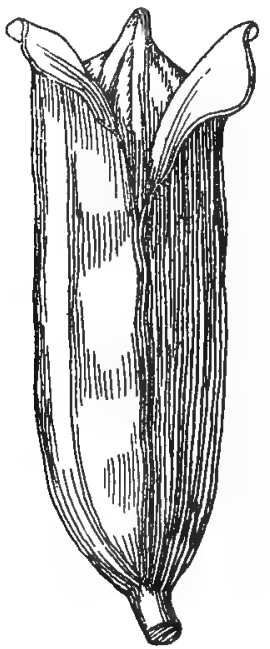

Fid. 89. - CAPSULE OF Iris, SPLITTING LONGITUDINALLY.

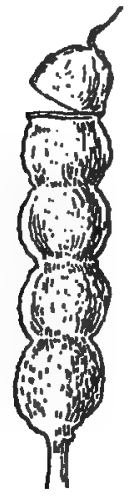

Fra. 91.-Lomenton or SaINForN.



Fra. 90. - LegUME or Orobus SPLIT DOWN BOTH SFaMs.

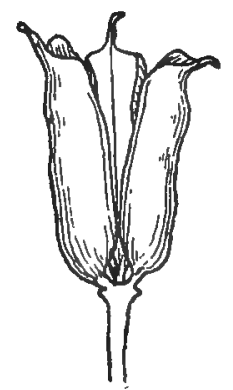

Tra. 92.-Group of ThrRe FoL. LICLES OF MONK'S-HoOD, SPLI' DOWN ONE SEAM ONLY.

well as superior ovaries-e.g., narcissus, orchid, willowherb. In a few cases the capsules are somewhat succulent, causing them to dehisce explosively-e.g., balsam, wood- 
sorrel. The horse-chestnut forms a curious kind of capsule. Its o chambered, with two seeds in each chamber. But one seed in one chamber alone develops; the others abort. Two of the chambers are crushed out by the pressure of the successful seed, and the result is a one-seeded fruit. Occasionally two seeds share the food

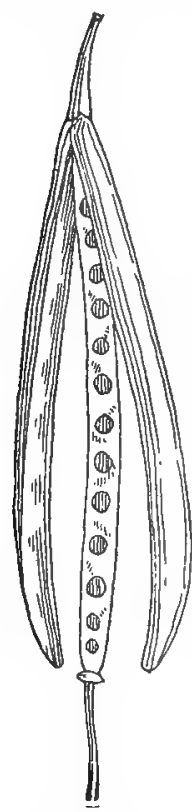

Fig. 93.-SHIQUA OF MUSTARD, SHOWING THE Two VALVES SPLIT AWAY FROM CENTRAL Partition. between them, and we get a two-seeded "nut." When ripe, the outer shell, which is thick and succulent, splits apart into three pieces, and the seed is released.

3. Schizocarps (Gr. schizo, I split), or separating-fruits, are derived from syncarpous ovaries formed from two or more carpels. There are usually as many chambers as there are carpels, with one seed in each. When the fruit is ripe, the carpels separate from each other into a number of one-seeded indehiscent sections (mericarps: Gr. meros, a part). Each of these is biologically an achene.

In the maple and sycamore (Fig. 94) the fruit consists of two or three winged carpels, which ultimately separate into one-seeded portions. It is a double samara, or key. The fruit generally leaves the tree whole, forming a kind of shuttlecock, which spins round in the wind and describes a zigzag course in its descent.

In the geranium five carpels split away from each other and from a column which is an upgrowth of the receptacle. In the cultivated geraniums (Pelargonium), the style forms a curved awn set with a fan of silken hairs. In the wild geraniums, or crane's-bills (Geranium), the hairs are absent, and the mericarps break away from the column with such force that in some species (G. Robertianum, $G$. lucidum, G. phoeum, G. molle, and G. pusillum) the seeds are actually shot out of their carpels; the mericarps are then known as cocci. In the stork's-bill (Erodium, Fig. 95) a spirally-twisted awn is provided with a fan of 
hairs. The awn is hygroscopic, winding up in dry weather, and uncoiling in damp. When it falls to the ground, the fruit may be blown along by the wind, or, if the wind is insufficient to move it, it will slowly crawl about by the winding and unwinding of the awn. On reaching a soft spot, the movements of the awn will force the pointed end of the mericarp into the soil ; here it is anchored fast by the reflexed bristles which cover its beak.

In the Umbelliferæ the schizocarp, which is inferior, splits into two one-seeded portions (Fig. 96). In the mallow (Fig. 97) and hollyhock the ovary is superior and

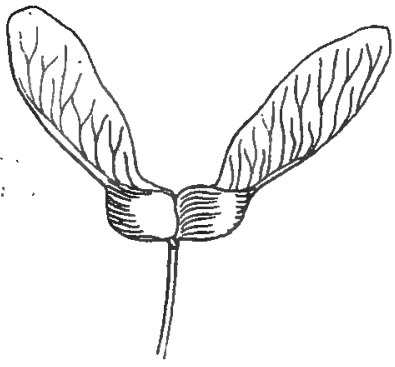

Frg. 94.-Double Samara OF SYCAMORE.

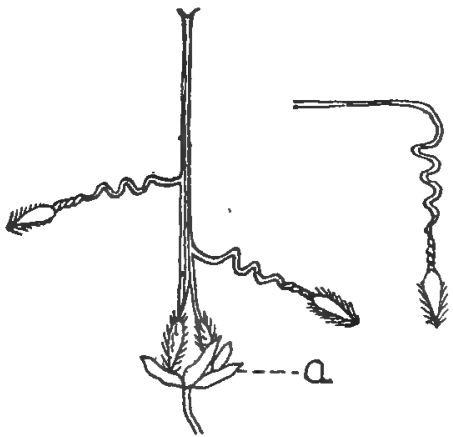

Frg. 95.-Schuzocarp OF STORk's-BrLI (Erodium), SHOWLTG MERICARPS SPLITting away from Cemtral Ptillar.

$a$, persistent calyx. To the right a completely detached mericarp.

multilocular, and separates into numerous achenial sections. In the Labiatæ the fruit consists of four nutlets derived from a two-carpelled ovary. This ovary was originally two-chambered, with two seeds in each chamber, but by the ingrowth of the wall, four chambers are formed, each containing one seed. The chambers then separate, and we get four little nuts.

Generally speaking, we may say that in a dry syncarpous fruit, if each chamber contains but one seed, the carpels separate into one-seeded indehiscent portions ; if many seeds are present, each chamber splits open to allow for the escape of the seeds, and we get a capsule. It is simply a question of biological convenience. 
II. Succulent Fruits.-1. Formed from the carpels only, or, if the receptacle takes part, it is not predominant:

(a) Fruit not capable of being broken open-e.g., Drupe, a usually one-seeded stone-fruit.

(b) Fruit easily broken open and seeds liberatede.g., Berry, usually many-seeded.

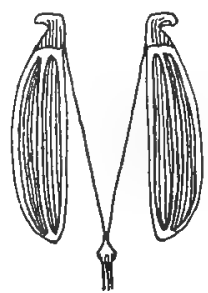

Fig. 96. - Schizocarp (CREMoUARP) OF FENNEL, SHOWING THE Two Mericarps split apart.

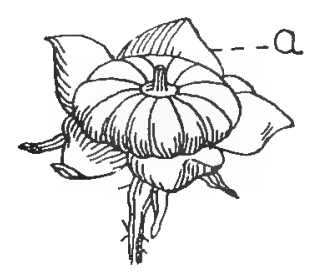

Fig. 97.- SCHIYocanP of Mariow.

$a$, calyx.

In the drupe (Fig. 98)-e.g., plum-the pericarp is differentiated into three layers: the outer skin (epicarp) tough, and covered with wax or hairs; the middle part Ileshy (mesocarp); the inner (endocarp) hard and stony,



Frg. 98.-Drupe of Peach cut longitudinally. $a$, outer skin ; $b$, fleshy portion ; $c$, stone; $d$, seed.

enclosing one and sometimes two seeds. In the blackberry and raspberry the fruit is an aggregate of little drupes, the product of a single flower; the ovary consists of a number of free carpels, each of which separately becomes a drupe. In the mulberry, on the other hand, 
a fruit very similar in appearance to the blackberry is the product, not of a single flower, but an inflorescence.

In the berry (Fig. 99) all the pericarp is soft except the outer skin, which is tough and elastic, and covered with wax (grapes) or hairs (gooseberry). The seeds are hard and indigestible. The gooseberry is an inferior berry.

2. Fleshy fruits in which the receptacle, or some part of the flower or inflorescence other than the carpels, predominates. They are all "false" fruits. In the pome the fruit is inferior, and the succulent portion is receptacle which has become fused with the carpels. In the apple the true fruit is the core, which is formed of five carpels, each containing one or two seeds. In the haw, the fruit of the hawthorn, the fleshy receptacle

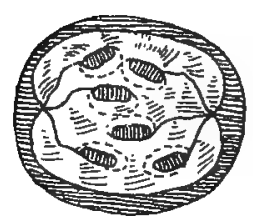

Fig. 99.-Frutr of GooseBERRY.

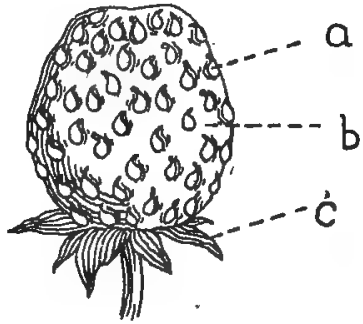

Fia. 100.- "Pseddocarp" of STRAWBERRY.

$a$, achenes; $b$, succulent receptacle; $c$, persistent calyx.

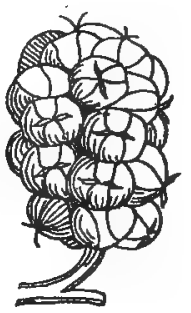

Frg. 101.-MULTIPLE FROTT OF MULberRy.

encloses one or two hard nuts. In the rose a large number of achenes are enclosed in a cup-shaped receptacle, which forms the succulent portion of the fruit. This is biologically a berry, just as the pome is biologically a drupe. In the strawberry (Fig. 100), another rosaceous plant, the receptacle, instead of enclosing the achenes, as in the rose, swells out into a succulent mass, carrying the tiny achenes on its surface.

In other cases the fruit is not the result of the maturation of a single flower, but of a whole inflorescence. In the mulberry (Fig. 101) the fruit consists of a number of little drupe-like bodies, each of which is the product of a single flower; the fleshy portion is formed from four fused perianth-leaves. In the fig. (Fig. 102) the axis of the inflorescence forms a hollow, pear-shaped fruit, which 
becomes fleshy, bearing a huge number of small achenes - "seeds" - on its inner surface. In the pineapple the bracts of the inflorescence become fleshy and coalescent. In this connection it may be noted that whenever the bracts are persistent in the fruit, they are to be regarded as part of it, biologically. They are usually concerned only in its protection, but in some cases they do more; in the lime, hornbeam, pineapple, and hop, they take a prominent part in its dispersal.

\section{Biological Classification of Fruits.}

The primitive and paramount purpose of the fruit is the protection of the seed. The dispersal of the seed is a derived function, but in the evolution of fruits this has

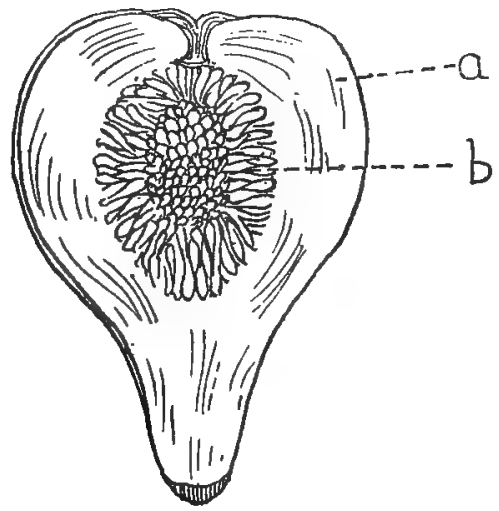

Frg. 102.-Fruit of Fra.

$a$, succulent inflorescence-axis ; $b$, remains of flowers.

gradually increased in importance, so that the specialization of the fruit is almost entirely directed to this end. If the fruit is indehiscent, it is the fruit itself which is dispersed. If it is dehiscent, the opening of the fruit is dependent upon favourable atmospheric conditions-e.g., dry air and wind-and in some cases the seeds themselves are provided with mechanisms for further dispersal. In this connection drupe-like fruits, whether true or false, must be looked upon as indehiscent, since they are dispersed whole, or practically wholo-e.g., plums, apples-while 
berry-like fruits, whether true or false-e.g., grapes, gooseberries, hips, etc.-are to be regarded as dehiscent, the fruit being broken open by birds. The biological classification of fruits and seeds depends upon the agents of their dispersal :

1. Wind-Dispersed Fruits and Seeds-(a) Fruits.-These are invariably one-seeded-e.g., achenes and mericarps. They are either light or small, or, if large, they are smooth, so that they may easily be rolled along over the surface of the ground. Some are specially provided with hairs or wings. The achene of the dandelion (Fig. 82) has a hairy pappus, derived from the calyx; which acts as a kind of parachute. In the thistle the pappus is sessile (Fig. 103). The achene of clematis (Fig. 104) is provided with a long feathered awn, derived from the style; while the mericarps of the stork's-bill (Erodium) and the pelargoniums have curved awns

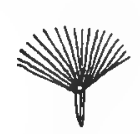

Frg. 103.-Achene (CrPshia) OF ThISTLE.

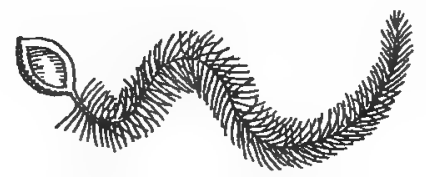

Fig. 104.-Achene of Cemmatis with Feathery Styli.

furnished with a fan of spreading hairs. Winged achenes are found in the samaras of the ash (Fig. 83) and the mericarps of the sycamore and maple (Fig. 94).

(b) Seeds.-These are borne in capsules, which only dehisce when the weather is warm and dry, or when it is windy. The dehiscence is caused by the desiccation of the walls or parts of the walls. In most cases the seeds are very small and light. In the poppy the capsules are shaken by the wind, and the seeds jerked out through the valves. The dust-like seeds of the orchids are the smallest known. In pods the seeds are often largee.g., peas and beans-but they are smooth and round, and over an even surface they may be blown along by the wind some distance from the parent plant. In a few cases the seeds are provided with special mechanisms for wind-dispersal ; in the willowherb, willow, and poplar, they are feathered, like little thistle-fruits ; in the pine they are winged. 
2. Explosive Fruits and Seeds.-In explosive fruits, the walls, when ripe, suddenly explode, and ejest the seeds with some force into the air. In the balsam, touch-menot (Impatiens Noli-me-tangere), and wood-sorrel, the walls are somewhat succulent, and explode suddenly through the tension set up in warm, dry weather by the rapid loss of water from them. The geraniums afford an excellent example of explosive schizocarps (see p. 190). In the squirting cucumber, a berry-like fruit becomes so turgid that it bursts, shooting out a watery pulpy mass in which the seeds are embedded. In the wood-sorrel (Oxalis Acetosella) the seeds are not only expelled from the capsule, but out of their own arils ; in this case the seeds themselves may be regarded as explosive. The pods of the gorse and the siliquas of the cuckoo-flower (Cardamine pratensis) pop in dry weather. In the Viola the seeds are shot away one after another from the open capsule, by the drying and contraction of the margins of the dehisced sections (Fig. 105).

3. Fruits and Seeds distributed by Birds.-These are generally succulent, in which case some provision is always made to prevent the seeds from being eaten. In berries the seeds are hard and indigestible; in drupes the seeds are enclosed in a stone, and this is always dropped. Some seeds ejected from capsules are covered with a succeulent coat-the aril; this is eaten by birds, and the kernel within rejected-e.g., spindle-tree, foetid iris, wood-sorrel. Among the conifers the seeds of the yew and juniper have succulent integuments; in the yew it is an aril ; in the juniper fused bracts.

Seeds of all kinds are eaten by birds, and many are destroyed in this way, especially the grains of cereals. Some of them, however, may, by some accident, escape complete destruction and get distributed.

Darwin points out that birds may be the means of dispersing seeds in another way. If the ground is damp, they pick up a good many seeds on their dirty feet. In one case he found that eighty seeds germinated from a small pad of soil which he took from the foot of a bird.

4. Animal-Dispersed Fruits and Seeds.-(a) Seeds eaten by animals-e.g., nuts and oily seeds-are enclosed in tough skins or hard shells which have to be torn or broken open before the food can be obtained. Many are de- 
stroyed, but some are carried away and dropped, others stored in holes and forgotten.

(b) Adhesive fruits and seeds become attached to the hairy coats of animals, and may be carried considerable distances before they are finally dropped or rubbed off. In burdock the achenes are smooth, but the involucral bracts enclosing the head are hooked; the fruits of cleavers (Galium Aparine) and enchanter's-nightshado (Circcea lutetiana) are covered with short stiff bristles; the achenes of avens (Geum) are hooked (Fig. 106). In Bidens (the bur-marigold), the achenes are armed with barbed prongs (Fig. 107); in agrimony the receptacle is covered on the outside with hooked bristles.

5. Water-Borne Fruits and Seeds.-Aquatics which flower and fruit under water must obviously have their

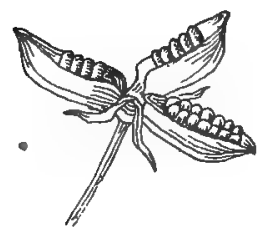

Fig. 105. - DeHISCED CAPSUle of Violet.

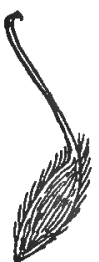

Fia. 106.-ACHene or Avens (Geum), WITH HOOKED STYLY.

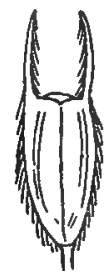

FIG. 107. - ACHENE (CYPSELA) OF BoRMarigold (Bidens).

seeds dispersed by water. Seeds dropped into water may float and be carried some distance and washed up on land. Dry fruits often contain a considerable amount of enclosed air. If such fruits fall into water, they float and may be driven along the surface of the water by the wind. In this case the agent of distribution is the wind, not the water. Few special structures for water-dispersal are found among English fruits. In the white water-lily, however, the fruit is a large berry, containing a large number of seeds. Each seed is surrounded by a spongy aril, containing cavities filled with air. When the fruit opens, the seeds float up to the surface of the water, and are drifted about until the aril rots, when they sink. In fresh water seeds may germinate while floating on the surface-e.g., willowherb. If driven ashore by the wind, they may continue to live. 
6. Distribution of Seeds by Man.-Man, intentionally or otherwise, is not the least important of seed-distributors. Wherever his merchandize goes, the seeds of his native flora accompany it. For this reason a rich alien flora is generally developed in waste places about docks. Most of these strangers soon die out, but here and there some flourish and establish a permanent foothold in the country-e.g., the thistle in Australia.

of all the agents of seed-dispersal, the most efficient, excluding man, are the birds and the wind. If the seeds are heavy, the wind carries or drives them a very short distance ; explosive fruits seldom eject the seed beyond a few feet; creeping fruits cannot travel far; animals do not generally wander far from their homes, physical barriers, natural enemies, and family ties seriously limiting their freedom. But the paths of the air are free, and oppose no obstacles to flight. Birds travel through the air much faster and much farther than animals traverse the land. So efficient is this method of dispersal, especially for large and heavy seeds, that plants whose seeds are so dispersed can afford to expend a large part of their substance in making large fleshy envelopes for a small number of seeds, instead of using up all the food in the production of as many seeds as possible. Migratory birds travel every year enormous distances, but as the migrations are north and south, the birds pass through latitudes which differ so widely in climate and seasons that the seeds they may bear with them are seldom capable of establishing a successful footing where they fall. Small light seeds, however, especially if equipped with floats, are carried a long way by the wind. These also have the advantage of being produced in great numbers. This accounts for the fact that plants possessing small wind-borne seeds, as a rule, travel faster along the roads of conquest than those which depend for their dispersion on birds. Moreover, the wind follows the lines of latitude more closely than birds, with the result that the dispersal of wind-borne seeds is effected through more uniform climates than seeds carried by birds in their migrations. 


\section{PAR'I III}

THE BRITISH FLORA: ITS EVOLUTION AND PRESENT DISTRIBUTION 



\section{CHAPTER XIX}

\section{VARIATION AND THE EVOLUTION OF SPECIES}

WHEN we look round upon this land of England, its pleasant fields and placid meadows, its hedgerows, pools, and woods, and the long stretches of purple heath and desolate moor, the question naturally arises, Whence did it all come? What is the past history of these fields, these woods, these vast hosts of many-tinted flowers? Is it possible for us to learn something of the previous history of these humble populations-their struggles and conquests, to understand why one race has established a dwelling-place here and another there, and to reconstruct in mental vision the part each and all have played in the development of that vegetation which constitutes to-day our native flora?

These questions occur to the inquiring mind, but to most there is no answer. Our knowledge, however, is increasing, and every year some light is being thrown upon the dark places.

The plants which we see around us are unlike those whose remains are preserved to us in the rocks. The further we recede in time, the more unlike the vegetation becomes to that which is living to-day. The number of different forms now inhabiting this country is enormous. In the London Catalogue of British Plants over 2,000 species of seed-plants and ferns are enumerated. Whence arose this great assemblage of plants and this wealth of variation? Two theories are possible. Either each species is constant and was separately created - the Special Creation theory-or they have all arisen by modification and variation from pre-existing forms, more or less unlike them, developing under the control of natural laws- the Evolution theory. It is now generally agreed that only the latter theory can account for the facts. 


\section{The Evolution Theory.}

We have already drawn attention to the idea of evolution in the case of vegetation inhabiting places where water or food is scarce. We showed that only plants which were specially modified or equipped for these conditions could successfully live in these regions. We pointed out that spines and prickles, and the defensive equipment of plants generally, have arisen gradually from variations which benefited their possessors and gave to them an advantage in the battle of life. Aquatic flowering plants were not always aquatics. Their ancestors were land-plants which were driven into the water through stress of competition, and which gradually evolved variations more and more useful for an existence in water. In the evolution of the flower we showed that the line of development was a progressive adaptation to insect-visits for the purposes of pollination.

The present statement of the Evolution theory is due to Charles Darwin, who died in 1882. The publication of his Origin of Species on November 24, 1859, forms a landmark in the long history of the progress of human knowledge. As applied to plants, it may be summed up as follows: The present races of vegetable forms have not existed unchanged, as we now find them, from the beginning. They are descended from ancestors which appear less and less like them as we recede into the past. The plant-remains, preserved to us in the rocks, prove this. Our present flowering plants are late arrivals on the scene. According to the theory, there has been a slow and gradual change of organisms, each a little better than its predecessor to live and multiply. Accompanying this advance there has been a remarkable increase in variety of form and specialization of structure.

\section{Natural Selection.}

Plants, like animals, tend to multiply so rapidly that if there were no obstacles to its increase a single race might, in the course of time, overrun the whole earth. As a matter of fact, the number of individuals belonging to a particular race remains pretty constant from year to 
year. What, then, are the causes or checks which operate to prevent the spreading of a race of plants in proportion to its output of new individuals? The answer is the struggle for existence, resulting in the survival of the fittest, or, as Darwin called it, Natural Selection. One plant has to compete with another for room, food, and light. In this struggle the strongest win and the weaker go to the wall. The competition of plants for the right, to live is as keen and remorseless as among animals, and most of all between members of the same species. Different species make different demands upon the soil and the sunlight. Plants belonging to the same species have similar needs; between these the struggle for existence is the fiercest.

If, then, one individual happens to possess a character which the others have not, or possesses a character in a higher degree than its neighbours, and if this character puts its possessor at an advantage in the struggle for existence, this plant is more likely to survive than its competitors. Further, if this character, making, as it does, for usefulness and efficiency, can be transmitted to its descendants, the latter will form a new species, marked off from its predecessors by this advantageous character, and superior, by the possession of this character, to the race from which it sprang.

This, according to Darwin, explains the origin of new species, which depends, therefore, upon the truth of the following statements :

1. Variation.-Though offspring are like their parents, no two individuals, though born of the same parent, are ever identically alike. Each tends to vary, and sometimes the variation is very great.

2. Survival of the Fittest. - In the struggle for existence the fittest survive, and the weak are ousted by the strong.

3. Adaptation to Environment.-The land-surface upon which plants grow has been in ages past subject to many changes-changes of climate, changes of soil, changes of physical conditions. Plants which did not vary so as to develop characters enabling them to adapt themselves to these changes inevitably died out; those that did survived and flourished. A race flourishes when it is in equilibrium with its surroundings, and is most secure 
when its adaptation to the environment is most complete. Its extirpation means that competing races are better fitted for the new conditions than it is itself. Success in any environment is reached by different plants in different ways. Every habitat has a varied flora. Many species of plants, often differing widely in form, live together in the same society, under the same conditions. Each has solved the problem of adaptation on lines of its own.

Having thus established that new species have arisen naturally from old, it remains to explain in what way a new specific character may be acquired. Two solutions to this problem have been suggested :

1. The Theory of the Accumulation of Minute Differences.-This was the theory which Darwin, after some hesitation, adopted. According to this view, a specific character-that is, a character distinctive of a specieshas been produced by the accumulation, from generation to generation, of very small variations. When a variation in a certain direction useful to the plant is initiated, the progress in each generation, or series of generations, is very small. It is the gradual accumulation of these minute differences, transmitted faithfully from one generation to the next, that at last constitutes a new and distinctive character, the sign of a new species. Unfortunately, Darwin had no proof of this, and several serious objections have been urged against it. One is that the intermediate forms linking up the new specins with the old have never been observed. The missing links are not found in Nature.

2. The Mutation Theory.-This theory, which has gained ground rapidly in late years, is associated with the name of De Vries. It was the outcome of Weismann's researches on heredity and Mendel's laws of heredity in hybrids. Darwin's theory apparently received sanction from the old principle that Nature never makes a leapNatura non facit saltum-but, according to the mutation theory, evolution proceeds, not by the gradual steps of minute differences, but by sudden leaps and bounds. Each leap, or saltation, constitutes a new species. There are no intermediate steps, and consequently no missing links. If this theory is true, a given species remains absolutely constant for long periods of time, displaying no appreciable variation from one generation to another. 
Then comes a period, relatively short, when, under the stimulation, perhaps, of changing environment, the plant loses its balance and begins to produce offspring unlike itsalf. Variations occur suddenly in many directions; some are useful, others are not. Each form, however, is constant, and, if hybridization does not interfere, breeds true to seed. These new forms, or mutants, arising from a parent-plant during a period of mutation, are called by De Vries elementary species. The fate of these elementary species must be decided by Natural Selection. Those that are adapted to the environment will flourish and multiply, those that are not will perish. Natural Selection is the sieve through which they all must pass.

The value of these rival theories must be tested by experience. There is little to guide us at present, but such evidence as we possess seems to be in favour of the mutation theory. In the first place, it explains the absence in Nature of transitional forms, and it does not involve the supposition that acquired characters may be transmitted. At the same time it alters the position that Natural Selection, the theory of the survival of the fittest, has occupied in the Darwinian theory. In the latter it plays the first part ; in the former it plays only a secondary part, sifting out from among the variations produced those which are of importance to the race for perpetuation. Last of all, De Vries has discovered one plant, a species of evening-primrose-Enothera Lamarckiana-actually in a state of mutation, throwing off a number of elementary species. The Irish yews are all derived from one plant in Ireland which was a mutation of the common yew, and all the copper-beeches in cultivation are derived from two or three sports which have arisen independently in several localities in Europe. The peach is regarded as a mutation of the almond, and the nectarine is undoubtedly a mutation of the peach.

The one conclusion which we can draw from the Evolution theory, however stated, is, shortly, this : that the present vegetable forms have been derived by modification or amplification from pre-existing forms, and that there has been no break in the development of the vegetation under the control of natural laws from the earliest times to the present. We look upon the vegetation as a great family of more or less related forms having a con- 
nected family history, which can be expressed as a genealogical tree with many branches, whose stems and roots lie deep in the ages of the past, and upon the tips of whose final branches rest the flowers of to-day.

But although the general development has been one of advance along certain lines of specialization, some forms, as might be expected, show evidences of retrogression-that is, after having advanced to a certain point, they have gradually gone backwards. This is generally the result of special modes of life. Many plants which now appear simple in form and structure have really been derived from more specialized ancestors. This is the case with the flowering water-plants and those plants which, like saprophytes and parasites, are dependent for their food on external sources, dead or alive. Flowers also show reductions. For example, many flowers which are now pollinated by the wind were once visited by insects, but that they are degraded is shown by the fact that, in many cases, traces are still found in them of their entomophilous ancestry (see p. 167). 


\section{CHAPTER XX}

\section{THE ORIGIN OF THE BRITISH FLORA}

THE British Isles form a group of islands resting on a submarine platform, or shelf, attached to the continent of Europe. The depth of the narrow seas which separate them from the mainland and from each other is nowhere more than 100 fathoms, and in many places it is much less. Beyond the west coast of Ireland and the Western Isles of Scotland this ledge shelves steeply down to the deeps of the Atlantic Ocean.

Islands are generally classified into two great groups, according to their mode of origin :

1. Continental Islands, which, like our own, are detached portions of continents. They are never far distant from the mainland, of which they once formed a part, and they are united to it by a submerged platform of varying depth. Their detachment was due to a general subsidence of the land and the encroachment of the sea over the low-lying parts. Continental islands repeat or continue the geological structure of the adjacent continent, and their animal and vegetable life has been derived from it, mainly before the intervening land-connections were broken. The vegetation of such islands, therefore, resembles in its main features the flora of the continent to which it belongs. It is a reduced copy of the continental flora.

2. Oceanic Islands.-These are generally found in deep water far away from the edges of any continental land. They are of volcanic or coral origin, and as they have never had any connection with the continent, their flora and fauna must have reached them over the intervening sea by wind or current or flying birds.

Continental islands are further divided into two groups 207 
according to the length of time which has elapsed since they became severed from the mainland :

(1) Recent Continental Islands, which have been detached in recent geological times-that is, during the later Tertiary Period. They are, in all cases, included within the 100-fathom line drawn round the coast of the continent to which they belong. Their flora differs little from that of the mainland, except that it contains a fewer number of species, while the number of isolated or peculiar forms is very few indeed-e.g., the British Isles, Newfoundland, Japan.

(2) Ancient Continental Islands, on the other hand, have been isolated from the mainland for a much longer period. The separating seas are much deeper ; the depth is always over 100 fathoms, and sometimes nearly 1,000 fathomsthat is, more than a mile-e.g., Australia, New Zealand, Madagascar. These islands also received their vegetation from the mainland, but their long separation from it has resulted in great differences between the continental and insular floras. But processes of evolution are slow, and long isolation would naturally cause the vegetation of the island to diverge gradually from that of the mainland, because the conditions governing its development would not remain the same in the two regions. On the island the evolution of the flora would be carried out undisturbed by competition from without, for the intervening sea forms an effective barrier against extensive migration. The mainland, on the other hand, is continually exposed to invasion, and at all times the native flora has had to defend its territories against the victorious advance of colonizing forms. For this reason, races which, through the keen competition, have died out on the continent, might survive on the islands; while, on the other hand, the more recent arrivals on the mainland may be absent from the islands.

A feature of ancient islands is the number of peculiar or endemic forms which occur in their flora. Endemic plants are plants which are found growing in one country or locality, and nowhere else. They may either be the survivors of races, once widely spread, which have long since disappeared in the struggle for existence elsewhere, or they may be entirely new forms, the products of evolution in a particular locality, which have not yet had time 
to spread into now territories. Most endemic forms are merely the survivals of nearly extinct races; new forms, if successful, are virile and aggressive, and spread very quickly.

Now, the British Isles form a group of recently detached continental islands. The separation from the mainland of Europe began when the Ice Age was passing away and the great ice-sheets began their retreat along the lowlands, now occupied by the North Sea, northwards towards the mountains of Scandinavia. It is probable that the passage of the Straits of Dover was forced when the Rhine was dammed back by the great glaciers blocking the outlet towards the north at the close of the Glacial Epoch. Sufficient land-connections, however, must have remained, interrupted by no greater barrier than rivers, long enough after the Ice Age to allow of the establishment of the present flora in these islands in all its essential details before their final separation from the Continent by several miles of sea. It is probable, how : ever, that before the colonization was complete these islands had already become isolated, and that the last arrivals came in the form of light seeds driven by the wind over the narrow straits, or carried on the feet of birds over the intervening sea.

We are thus prepared for the fact that the flora of Great Britain is practically identical with that of Europe, though somewhat reduced. The connection with the Continent is, geologically, so recent that we should hardly expect to find a single flower in Great Britain which is not also found in similar situations on the Continent, and, as a matter of fact, not a single truly indigenous species peculiar to our flora and unknown on the Continent is to be found throughout the land. Among our rarer plants, however, a few varieties have been described which are said not to occur elsewhere, but it is extremely doubtful whether these are really distinct races, or, if they are, whether they are really absent from the European flora. Among these plants are : Helianthemum Breweri, a variety of the spotted rock-rose, found only in Anglesea and two or three localities in Ireland; Enanthe fluviatilis, a floating aquatic closely allied to $A$. Phellandrium, the great water-dropwort ; and Hieracium iricum, n mountain hawkweed. 
The past history of the British flora, then, is part and parcel of the history of the flora of Northern Europe. The population of this region with its present plants dates from the close of the Ice Age. During the Glacial Epoch Northern and Central Europe were completely buried beneath a sheet of ice, much as Greenland is to-day. The vegetation previously existing was destroyed or driven south into Northern Africa, which was then connected with Europe by several land-masses stretching across what is now the Mediterranean Sea. As the Ice Age passed away, and warmer conditions prevailed, the ice melted, and the bare earth became exposed. A great host of advancing forms moved northward in the track of the retreating glaciers, and repopulated the abandoned territories. At first the soil, so recently relieved of its icy burden, provided but a poor habitat for plants. The climate also was still very cold. The pioneers of the migration were those plants which were fitted to endure the greatest hasdships. At first they had no competitors. The struggle for existence was not with one another, but with the hardships of their environment. But as time went on, and climatic conditions improved, fresh invaders appeared in the territories prepared by the pioneers ; fierce competition ensued, and while some seized, as conquerors, the pleasant places, others perished or survived only in less favoured habitats where competition was not so keen. In the struggle the pioneers were the first to suffer. Adapted to live, unmolested by competitors, in cold or alpine conditions, they were unable to compete successfully with their rivals, and before the advance of lowland and temperate forms, this vanguard of the northern plant-migration was restricted to the mountains, where its descendants still remain.

The alpine flora of Europe is almost the same everywhere. The same flowers grow on the mountains of Wales and Scotland as on the Scandinavian highlands, the Alps, and the Pyrenees. Stranger still, the alpine flora of Africa, America, and even Australia and New Zealand, differs little from our own-so little, indeed, that some have suggested that the Scandinavian flora once dominated the earth, and that its remnants survive upon the highlands everywhere to this day. 
Discontinuous Floras.-The present distribution of alpine plants is an illustration of what is known as a discontinuous flora. Such a flora is limited to certain widely separated spots, between which no plants of the same kind are found at all. Most plants have a wide range, being found, more or less frequently, in many adjacent countries; but each plant has its limits of distribution. These limits are determined by the barriers which it cannot pass-e.g., mountain chains, masses of water, unfavourable climate or soil. But although the presence of these barriers may explain the distribution of most plants, it does not explain the existence of plants in discontinuous areas. To understand this, we need to find out something of the past history of the land, its changes of contour, and alterations of level, as well as the secular changes of climate to which it has been subjected. All these things have produced in the past an ebb and flow of the vegetation, and with each change, physical or climatic, stragglers were left behind, which have given rise to the discontinuous floras of to-day.

The Lusitanian Flora.--More striking still than alpines are certain plants found in the south-west of England and in the west of Ireland, which do not occur elsewhere nearer than Spain and Portugal. For this reason the term "Lusitanian" has been applied to these plants, from Lusitanio, the old Latin name for Portugal. How are we to account for their presence in the British Isles? It is not likely that they crossed the intervening sea, although it is possible that some may have been introduced by birds-e.g., Arbutus Unedo-by early invaders, or in merchandise by boats from Mediterranean ports. It is more probable, however, that most of these species arrived naturally by land during the time when the west of England was much nearer the coast of Europe than it is to-day. We know, as a fact, that Ireland was once not only joined to England and England to the Continent, but that to the south of our islands dry land extended at that time to the westward far beyond the present limits of France. Over this land, now submerged, low-lying, and enjoying a climate remarkably mild and moist, these plants may have orept up northwards from Portugal to the south-western parts of Britain, and, conditions having remained suitable, they 
have kept their station there to this day, although the sea has long since submerged the road by which they came.

The epoch preceding the Glacial Period was remarkable for the warm conditions that then prevailed over northern Europe. In England an almost tropical vegetation flourished, and a temperate climate extended into the regions which are now within the Arctic Circle. The cause of this great oscillation between the warmth of the preGlacial Period and the cold of the Ice Age is not known. During this period Great Britain formed a continuous part of the Continent. Man had not yet appeared. Animals similar to those now found in tropical and subtropical regions lived in the country-e.g., the lion, crocodile, hippopotamus, and rhinoceros ; while forming a part of the flora were such plants as sarsaparilla (Smilax), magnolla, bamboo, swamp-cypress (Taxodium), sumach, tulip-tree (Liriodendron), fig, the evergreen oak, walnut, and laurel-plants whose nearest relatives are now found native only in the warmer regions of the globe. It seems, then, natural to suppose that the Lusitanian vegetation is a remnant of this southern flora which crept up northwards with the increasing waves of warmth, and passed to Great Britain over the territories now submerged beneath the English Channel. During the Ice Age Iroland, Scotland, and all England north of the Thames were refrigerated; but it is supposed that in some sheltered spots in the southern peninsulas of England and western Ireland, and especially in the pre-glacial extensions westwards, conditions remained sufficiently mild to preserve remnants of the southern flora out of which has ultimately developed the Lusitanian flora now existing in the country. This may be true, but the explanation is beset with difficulties. Though the south of England was not actually under ice, conditions must have been very severe there, and it is hard to understand how such plants could have found anywhere so near the ice-sheets a retreat sufficiently mild to preserve their existence. Some of them would have been killed by a climate only slightly more severe than they experience to-day-e.g., Arbutus Unedo. Towards the close of the Glacial Period it is probable that the first great step towards the complete severance of Great Britain from the Continent took 
place by the bursting of the water through the low neck of land between Calais and Dover, and the opening up of a sea-passage to the west. When, after several alternations of cold and warmth, permanently temperate conditions at last set in; the sea intervened between the coasts of England and France, and it is hard to see how the southern flora could have crossed this barrier, even supposing that the width of the channel was much less than it is to-day. It is a curious fact, however, that the seeds of our Lusitanian plants are very small and light, and include none of the larger kinds found on the Continent. It is possible, therefore, that some of these seeds were driven across the narrow straits by the wind, especially during storms, and, surviving the passage, found a genial home on the other side of the Channel; others may have arrived on the feet of birds.

The whole problem of the Lusitanian flora is very difficult. At the root of the inquiry lies the debated question of bygone climates and earth-movements, and here the gaps in the record are so great that at present a satisfactory solution is impossible. The difficulty is still further complicated by the presence in the west of Ireland of several plants which are only found elsewhere in America.

The Lusitanian Flora, occurring in the west of Ireland (or in Devon and Cornwall) and in the Iberian Peninsula, comprises the following plants :

London-pride (Saxifraga umbrosa), very common on the rocks in the mountainous districts in the west of Treland; the Pyrenean heaths (Erica Mackayi, E. mediterranea, and Dabocia polifolia), all more or less abundant in the west of Ireland; the Cornish heaths (Erica vagans and $E$. ciliaris); the wild strawberry-tree (Arbutus Unedo), extensively cultivated in the south of England, but only found wild round the shores of the beautiful Lakes of Killarney ; Pinguicula grandiflora, a butterwort found in Cork and Kerry ; P. lusitanica, west of England and Ireland; the Irish spurge (Euphorbia hiberna), found also in Devon ; Saxifraga Geum, west of Ireland ; S. hirsuta, Gap of Dunloe, near Killarney; Lobelia urens, Devon and Cornwall ; Habenaria intacta, an orchid ; Helianthemum guttatum, the spotted rock-rose, occurring in Galway, Cork, Anglesea, and Jersey; Arenaria ciliata, on the 
limestone cliffs in Sligo; Simethis bicolor, Kerry and Devon; and Inula salicina, found only on the shores of Lough Derg, in Galway.

More remarkable still, a few plants are found in the west of Ireland and not elsewhere on the continent of Europe. They occur, however, in North America, and it has been suggested that they may have travelled over that lost continent, Atlantis, which some people have supposed once stretched across the Atlantic between Europe and America. It is pretty certain, however, that in pre-glacial times land did extend in that direction, running from the north of Scotland to Iceland and Greenland, and from Greenland to the mainland of America. Along this highway the horse possibly travelled into Europe, for this animal is American in origin, and with it might have come plants, of which three only still remain to tell the tale. These American plants are: Spiranthes Romanzoviana, west of Ireland; Eriocaulon septangulare, Connemara and the Hebrides; and Sisyrinchium angustifolium, a plant allied to the iris, found in the west of Ireland.

Last of all we have that rare and extremely beautiful filmy fern, Trichomanes radicans, the Killarney fern, which occurs in a few places in the wet, shady recesses of rocks near the Lakes of Killarney, in North Wales, and in the Isle of Arran. Elsewhere it is found only in the Azores, the Canary Islands, and the island of Madeira.

English Plants absent from the Irish Flora.-While some plants are found in Ireland, and nowhere else in Great Britain, there are others unknown in Ireland which are quite common in England. Among them are the following :

Black bryony (Tamus communis), white bryony (Bryonia dioica), herb-paris (Paris quadrifolia), snowdrop, lily-ofthe-valley, butcher's-broom, hop, wayfaring-tree (Viburnum Lantana), mistletoe, wild service-tree (Pyrus torminalis), Ulex minor, traveller's-joy (Clematis Vitalba), and Myosurus minimus, the mousetail.

The absence of these plants from Ireland is, in most cases, due to the fact that Ireland was separated from Great Britain before the latter was separated from the Continent, so that many species must have arrived in England too late to cross over into Ireland. For this 
reason Ireland contains fewer species than Great Britain, just as Great Britain contains fewer species than France or Germany.

Native Plants and Aliens.-Plants which grow wild, and which we have every reason to believe have always formed part of our flora since the advent of man, are called indigenous, or native. Those which have been introduced since otherwise than by natural meanse.g., birds or wind-are aliens. Now, there are aliens and aliens. Some may be quite recent intruders, others came very early when the first cultivators disturbed the soil ; some have competed successfully for a long period of time with the native flora, and have spread far and wide over the land ; others spring up, flourish for a time, and then die out; others are mere casual strays, seen here and there, and seldom in the same place two years together. The following various kinds of aliens have been distinguished :

1. Denizens.-Plants which we know or have reason to suspect are foreigners, but which have so successfully established themselves in natural or wild and closed habitats among the native flowers that they now form a constituent part of the flora-e.g., Elodea, Impatiens fulva, Claytonia perfoliata and C. alsinoides, Crocus, cyclamen, snowdrop, and probably the gooseberry and red and black currants.

2. Colonists.-These are generally more recent immigrants, and do not, as a rule, compete on equal terms with the native vegetation. They are found in artificial habitats-that is, on ground disturbed by man, where there are always bare spots open to settlement. Most of the commoner weeds of cultivation are colonists in this sense (see below).

3. Casuals are aliens which appear here and there, but never secure a permanent foothold even in artificial habitats. They soon die out, either because they fail to produce efficient seed, or because the conditions are against them in the struggle for existence. Some are weeds brought with seed from other lands, some arrive with merchandise, some are relics and escapes from cultivation, others mere garden throw-outs.

Weeds of Cultivation.-This is a term applied to those plants, generally annuals, which are found on cultivated 
or disturbed ground, or in waste places near it, and seldom, if ever, anywhere else. They are all aliens, although many of them are so common and widespread that they are generally regarded as native. Of these long-established aliens, found only in artificial habitats, the following are the most familiar :

Poppies, wild radish, corn-cockle, common vetch (Vicia sativa), shepherd's-needle, sweet cicely, chicory, milkthistle, corn-bluebottle (Centaurea Cyanus), the Canadian fleabane (Erigeron canadense), chamomile, the fumitories and brassicas, most of the chenopodiums, some spurges, ivy-leaved toadflax, Geranium pusillum, Veronica agrestis, V. arvensis, Lycopsis arvensis, Verbena offcinalis, black horehound (Ballota nigra), pennycress (Thlaspi arvense), white lychnis (Lychnis vespertina), Cerastium arvense, the common mallow (Malva sylvestris), melilot, goutweed (A2gopodium Podagraria), fool's-parsley (ADthusa cynapium), corn-marigold (Chrysanthemum segetum), the corncampanula (Campanula hybrida), Stachys arvensis, Urtica urens, the slender fox-tail grass (Alopecurus agrestis), Bromus arvensis, and even such common and universal weeds as shepherd's-purse, treacle-mustard, common nightshade (Solanum nigrum), charlock (Sinapis arvensis), sow-thistle (Sonchus arvensis), the white and red deadnettles (Lamium album and purpureum), and possibly also the common stinging-nettle (Urtica dioica).

It is interesting to observe in how many cases the specific name indicates the nature of the plant as a weed of cultivation-e.g., arvensis = belonging to the ploughed field, agrestis = belonging to cultivated ground, sativus and segetum = sown. Most, if not all, these plants came in the track of cultivation from Asia as it spread gradually westwards-first through the Mediterranean region, and then over northern Europe. Many of them have naturally found their way to the New World, and even to our distant colonies. 


\section{CHAPTER XXI}

\section{THE CLASSIFICATION OF PLANTS}

BRFORE we can classify plants we must give each a name. For many plants this was done in the native tongue long before much real knowledge of any kind was obtained about them, and naturally the name given had reference to some character or association which they possessed. Plants were first seriously studied for the medicinal properties, real or supposed, imputed to them. Some had the power of healing diseases, or, at least, of alleviating their distress; others had magical properties, and were used in religious ceremonial or witchcraft, according as the power attributed to them was good or bad. Herbalists were the first doctors, and the earliest Floras were Herbals.

Thus the bindweed, arrowhead, cat's-tail grass, dog'stail grass, cock's-foot, cotton-grass, old man's-beard (Clematis), hart's-tongue, ox-tongue, touch-me-not, bedstraw, bird's-foot trefoil, coral-root, stork's-bill, goat'sbeard, monk's-hood, silver-weed, and toothwort are all names derived from some obvious character of the plant. Herb-Robert, St. Dabeoc's-heath, and herb-Christopher were sacred to saints. St. John's-wort was sacred to the Apostle, and possessed mystical and magical virtues. In other cases the connection was more fanciful-lady'sfingers (lady in flower-names generally refers to the Virgin Mary, very often in her mythic rôle of Venus), lady's-tresses, lady's-smock, shepherd's-needle, shepherd'spurse, Jacob's-ladder, milk-thistle, and Dutchman's-pipe. Some very beautiful names have survived : daisy (= day'seye), heartsease, meadowsweet, forget-me-not, honeysuckle, poor man's weather-glass, and traveller's joy. Many had medicinal properties: lungwort, stitchwort, 
birthwort, rupture-wort, fleabane, gout-weed, lousewort, scabious, scurvy-grass, spurge, whitlow-grass.

This nomenclature was clumsy and unsatisfactory. Many plants remained nameless. The names applied to others were vague, referable to one plant in one district, and to another in another-e.g., the sea-purslane is either Arenaria peploides or Atriplex portulacoides. The same plant, too, had many aliases. In other cases a common name covered a multitude of species-e.g., buttercup, stonecrop, tare, vetch, violet. For scientific purposes this nomenclature was impossible. Besides, science is cosmopolitan; it recognizes no race and no boundaries. What was wanted was a definite name for every plant, and one which botanists of all countries could use and understand.

Many attempts were made to remedy this state of things, but the honour of founding a system of nomenclature which was destined to be universally adopted belongs to Linnæus, a Swedish botanist, the bicentenary of whose birth was celebrated all over Europe in 1907. He gave each plant two names, each thrown into a Latin form. The first was the name of the genus, the second that of the species. For example, there are many kinds of buttercups, all of which bear a strong family likeness to one another, especially in the flowers. Linnæus gave the generic name Ranunculus to the family group, and his description of the genus was an enumeration of those characters in which the various buttercups agree with one another. The genus as a plant does not exist; only species exist. The genus is an abstraction, invented for the convenient purpose of denoting a group of species which possess many characters in common. Each species agrees with the characters ascribed to the genus, but differs from every other species by one or more characters, which never vary.

The classification of plants is based upon similarities and dissimilarities, but it is a matter of choice what particular characters we select for comparison. Similarity very often implies relationship, and this is especially true in the case of the flower-the most conservative part of the plant, and the part least affected by external conditions. In a natural system of classification it is necessary to select those characters for comparison which denote 
relationship. In grouping species together into genera, Linnæus recognizes this bond of union between species; but in his wider groupings he abandoned the natural system, and separated the genera into divisions based upon the number of stamens in the flower. This gave him a convenient key for the identification of plants, but it was extremely artificial, and afforded no glimpse of their true affinities. A more natural system was outlined afterwards by Linnæus himself, but the working out of a natural system of classification has been the work of his successors. In British floras the system of Bentham and Hooker is generally adopted; on the Continent and in modern treatises that of Engler is followed. No classification can be said to be quite satisfactory, and none ever will be until the last word on plant-relationships has been said, and we are very far from that at present.

The Unit of Classification.-Every exact science is based on units. In physics and mathematics these are purely arbitrary. In botany, as in zoology, the species is regarded as the unit of classification. Each species is supposed to represent a definite race of plants. Before the idea of evolution became prevalent, most people thought that the species originated by an act of special creation, and remained unchanged and unchangeable throughout all time; others thought that the species was mutable, but that the genus was not. Linnæus, for example, looked upon the genus as a special creation, but not the species derived from it. We know now that the species is, at most, only a relatively constant thing. No two plants even of the same parent are exactly alike, and observation will show that considerable variation occurs among the members of the same species. When these variations are pronounced and apparently constant, we call the variation a variety. What, therefore, constitutes a variety and what a species? The question is a very difficult one to answer. What one person will call a variety another will call a true species. The Floras are full of instances of this kind. In fact, there are two schools of botanical systematists - those who lump together under the same specific name as many varietal forms as possible, and those who separate them out, wherever possible, as true and distinct species. Bentham. 
and Hooker regard all the forms of the water-buttercup as inconstant varieties of one species, which they name Ranunculus aquatilis ; in Babington's Flora, fifteen of these varieties are raised to specific rank. Bentham and Hooker divide the hawkweeds (Hieracium) into four species. This variable genus has been split up by others into a bewildering multitude of species. In Babington, the number of critical forms described as true species is 210 , besides numerous sub-species and varieties. Other genera with polymorphic species are the bramble (Rubus), Rosa, Euphrusia (eye-bright), and Salix (willow).

What, then, is there to guide us in this matter? In the first place, we must know exactly what a variation is, and, fortunately, upon this considerable light has been thrown during the last few years.

Variations are of two kinds :

1. Inconstant Variations, due to the environment, such as accidents or inequalities in light, soil, climate, or nutrition. These affect, within certain limits, the form, size, hairiness, and duration of the leaves and shoots, the general habit of the plant, and, in some cases, the colours of the flowers. These qualities, however, are not constant. They are characters acquired by the individual plant as adaptations to its environment. If the environment changes, these characters change, too. They are not transmitted, but every plant gradually assumes them during its own individual life, providing the conditions favourable for their production are present. Such varieties have no right to rank as critical species; they are merely forms, not distinct and constant races. Thus the prostrate maritime variety of broom found in Cornwall (Cytisus vulgaris, var. prostratus) is a mere form, with no claim to specific or even varietal rank, any more than luxuriant garden specimens have. The seeds of this plant, when sown in the garden, grow into the ordinary form of broom.

2. Constant Variations.-These are not dependent upon accidents of environment, and always breed true to seed. They are true races, and have a right to rank as species, if the species is to be regarded as the unit of classification.

In practice, however, the difficulty is to decide what variations are constant and what inconstant, and the 
difficulty is increased by the ease with which very closely allied forms hybridize with one another-e.g., the numerous forms of willows, roses, brambles, and hawkweeds.

One of our native geraniums is the bloody crane's-bill (Geranium sanguineum). It has a diffusely-branched stem and large purple flowers. G. prostratum, found on the sands of Walney Island, Lancashire, has a dwarf tufted stem, with small flesh-coloured flowers. Is the latter plant a mere variety of $G$. sanguineum, or is it a separate race? We cannot say; we must know how its seeds behave in another environment before we can decide. In the west of Ireland there grow together two saxifrages-Saxifraga umbrosa and $S$. Geum. According to Babington, these are distinct species; according to Clement Reid, they are divergent forms of the same plant, for he saw growing among them a nearly complete series of intermediate forms.

Hybrids.- Hybrids are neither species nor true varieties. The hybrid being produced from a seed which is formed by the co-operation of two parents, with certain distinct characters, shares the characters of both, either latent or expressed, or in an intermediate form. But the seeds of hybrids do not breed true. Some of the descendants will be hybrids like the immediate parents; others may share the hybrid characters in a different way; while some will always revert back to the pure form of the ancestral types.

The unit of classification must, then, be the distinct race, which breeds true to seed. According to what we have said, this, in general, will be the species; but where the species is subdivided into varieties which breed true to seed, then these constant varieties will become the units. De Vries gave the name "elementary species" to varieties which breed true to seed. Inconstant variations have no claim to varietal rank ; they are only of biological interest, indicating the range of variation within the same species. The characters of the true variety are permanent and inherited. In horticulture new varieties are being constantly produced. In one sense these are rarely new. In flowers, most of them are hybrids. In this case man assists Nature by bringing into breeding contact two forms which are seldom or never found together. In crops they are generally the isolated forms of already 
existing races. Most of our agricultural crops are aggregate races containing an enormous number of elementary species mixed together. An ordinary sample of seeds may contain several. If these are sown, and among the plants produced one is seen to be conspicuous by characters which are likely to increase its value as a crop, this individual is isolated; its seed is carefully collected and sown apart, and very soon a new variety is placed on the market. In this case, man puts Nature through a sieve, and selects out for cultivation those forms which he considers most valuable. The rapid spreading of late years of a knowledge of the Mendelian principles of heredity has also proved a great benefit to agriculture, by producing true races from mixed breeds and sporadic sports and varieties (see Appendix II., The Mendelian Theory). 


\section{CHAPTER XXII}

\section{PLANT ASSOCIATIONS AND FORMATIONS}

In the course of this book we have made several attempts to classify plants ecologically. The simplest and most obvious was to divide the vegetation into types according to their appearance when beheld as masses of individuals in the landscape. This physiognomic grouping gave us the great types of vegetation which we know as woodland, moorland, grassland, and desert (p. 16). We found that these types could only be associated with a definite kind of climate if subdivided according to climatic differences. This led us to a climatic grouping of plants (p. 16). Later on, in dealing with the relation between water and plants (Chapters II. to VI.), and then with the relation between water and the soil (Chapter IX.), and, last of all, between the soil and the plant (Chapter X.), we were forced to enlarge our conceptions of climate. Most of the climatic factors act indirectly upon the plant through the soil, and when we come to consider the details of the vegetation, the soil as the exponent of climate becomes more and more important (p. 84).

We pointed out on p. 17 that a satisfactory and scientific ecological grouping of the vegetation can only be obtained if we take into consideration all the external factors of the environment influencing the vegetation. Some factors, of course, are more important than others, but almost any factor may, in some place or another, assume an importance which will leave a stamp on the vegetation growing there. Considered thus, the term habitat has a special meaning when used in ecology. If means the abode of a plant or community of plants as biologically conditioned by the factors of the environment. In defining the habitat of any plant, therefore, we must 223 
take into consideration not only the soil in which the plant is growing, but the amount of rainfall, the temperature, intensity of light, and wind.

\section{The Ecological Units of Vegetation.}

1. Plant-Associations. - By "plant-association" we mean an assemblage of plants of definite floristic composition associated with a definite biological habitat. Each association may be recognized, as a rule, by the presence of one most abundant or dominant plant, which gives the name to the association-e.g., the cotton-grass association of wet moors (p. 254); or several plants may be equally abundant-e.g., the Festuca-Agrostis association of dry grassland (p. 250). The cotton-grass association is found only on moorlands where the rainfall is very high and the conditions favourable for accumulation of deep peat. It is true the cotton-grass grows in other places, but only in this habitat does it become so abundant as to constitute a definite association.

Occasionally, however, the association is not distinguished merely by the dominant plant, but the plants growing with it must be taken into consideration. For example, Calluna vulgaris (heather) may be dominant on damp moorlands and also on dry stony heaths, but the association is not the same in the two cases. The habitat is different, and this is expressed, not in the dominant plant, but in the other plants present-moistureloving plants being found in the one and dry-loving plants in the other.

The same difficulty is experienced, but to a much greater extent, in ecological as in systematic botany, when we attempt to define the exact limits of the units. The systematic unit - the species - however, is much more constant; only in comparatively few cases do they overlap or run into one another; whilst in the ecological unitthe association-this is always so.

One habitat seldom passes suddenly into another-there is a more or less gradual transition; and, in the same way, associations are not sharply marked off from each other. Thus, in walking up a moorland slope, one may pass a heather-moor, an Erica Tetralix-association, and finally reach the cotton-grass association; but the 
boundary between them is ill-defined, just as the amount of moisture present in the soil gradually increases, and the peat becomes deeper, yet the associations themselves are quite distinct from one another.

The moorland-associations are of wide extent, sometimes covering miles of country, for the habitat is the same over extensive areas. Where the habitat varies rapidly, however, one association passes quickly into the next. On the shelving bank of a river or lake, for example, the plants which constitute the reed-swamp (p. 241) are arranged in zones running parallel to the bank. Each zone constitutes a separate association, dominated by a single plant and associated with a definite habitat, determined by the depth of the water. Yet each association may be only a few feet in width.

2. Societies.--Occasionally a patch of ground within an association is tenanted by a plant-community which differs in its main features from the main association. Such a community is called a plant-society. It sometimes owes its presence to a local peculiarity of the soil, as in the case of the rush society found occasionally in damp hollows within the grassland association of clay soils, or it may be due to a sub-dominant plant becoming locally dominant, through the plant spreading from one centre, either by vegetative means or by a colony of seedlings springing up round the parent plant.

3. Formations.-We have already drawn attention to a unit of a higher order than the association in the case of a reed-swamp. This exists in a definite biological habitat, or, more strictly, a series of very closely related habitats, which only differ from each other in one factor-the depth of the water. To a unit of this kind we give the name formation. If the water of the reed-swamp is uniformly deep, the plants are not zoned, but intermingled with one another, in which case we have a very mixed association which is equivalent to the formation. It is an association because of its definite floristic composition, and a formation because the environment constitutes a definite biological habitat.

A sand-dune is a plant-formation containing a number of different associations. The rainfall, temperature, exposure to wind and light are the same throughout; but the texture of the soil varies, and this determines the 
distribution of the associations. On the seaward side we find loose drifting sand covered with an association of sea couch-grass; an association of marram-grass occupies the dune-crest; and, farther back, on the more consolidated sand, an association of low-growing herbs; and, finally, either an association of pasture-grasses or heather. These associations merge into one another, and in the course of time, as the sand consolidates, one association is replaced by another. The formation thus has a past history, and, while it is still open, a future. When once closed-i.e., when the soil is entirely occupied by close-growing vegetation-it can be further altered only by changing climatic or soil-conditions modifying the biological nature of the habitat. In many cases we do not know the past history of a formation; but on the moorland a study of the plaint-remains in the peat gives us a clue, not only to the past vegetation, but also the climate and other factors of the habitat (see p. 249); whilst in a sand-dune pasture the past is being written for us in the vegetation of the younger parts.

Close by the sand-dune we may find an area of wet, salt soil occupied by a salt-marsh formation. This differs considerably from the plant-formation of the sand-dune, and the differences are due almost entirely to the nature of the soil, for the elimatic conditions are practically identical in the two cases. Generally speaking, the soil is always the chief factor in determining the plant-formation; climate plays a relatively subordinate role.

To sum up, then, the larger differences in habitat serve to differentiate the formations; the minor differences in each habitat, the associations. No hard-and-fast rule can be laid down as to what constitutes a larger or a minor difference, any more than we can say what constitutes a generic or a specific character in systematic botany.

\section{The Study of the Association.}

In England we rarely have to deal with natural associations-i.e., with associations undisturbed by man or his domesticated animals. Traces only of the great forests that once covered the country now remain, and much of the woodland we see has been planted. Within the cultivated area nearly all our grassland is artificial; 
the ground was once or is still being periodically broken by the plough and sown with seed. Even the moorlands, where farmsteads are absent, have been interfered with for the rearing and preservation of game. But the greatest departure from the natural association is mado in cultivated ground regularly ploughed and sown with crops. Here are found a number of agricultural weeds, mostly annuals and aliens, which, following in the track of civilization, have spread over all our arable fields and the waste places near, where the ground is frequently disturbed (see p. 215).

Yet, in spite of all this interference by man, the departure from the natural association is really not very great. The trees found growing in a plantation are trees which, after c.ll, are suitable to the soil, and in many cases they would be found growing there naturally. The flowers of the field are wild, and the struggle for existence between plant and plant, and association and association, goes on much the same as if man did not interfere at all. Man only modifies or assists the conditions under which Nature acts; he works and prepares the ground for the change from one association to another (as in draining a marsh or moor, or cutting down a wood), but the association that comes in is natural enough in all its main characters.

The chief associations belonging to each type of vegetation will be described later on, but, generally speaking, any association should be examined frequently during the year, and the following points recorded:

1. The dominant plant or plants-i.e., the most common or the most conspicuous plants.

2. The sub-dominant plants, which accompany the dominant forms, and, in a few places, supplant them.

3. The other plants occurring in the association-noting whether they are social or scattered, abundant, frequent, local, rare, or casual.

4. The succession of plants in flower throughout the year.

5. The number of different species in flower at the same time.

When two or more plants are dominant at the same time, or when one plant is dominant at one time of the year and others at a different time, the underground parts of the plants should be examined, for the roots 
frequently explore the ground at different levels. This is shown well in a wood where bluebells, bracken, and grasses show a distinct stratification (Fig. 108).

To make a complete study of an association, something more than a mere list of plants should be made. The habitat, which determines the distribution of the plant, should be examined in detail, and the adaptation of the plants to their environment carefully studied. The physical and chemical nature of the soil and the under-

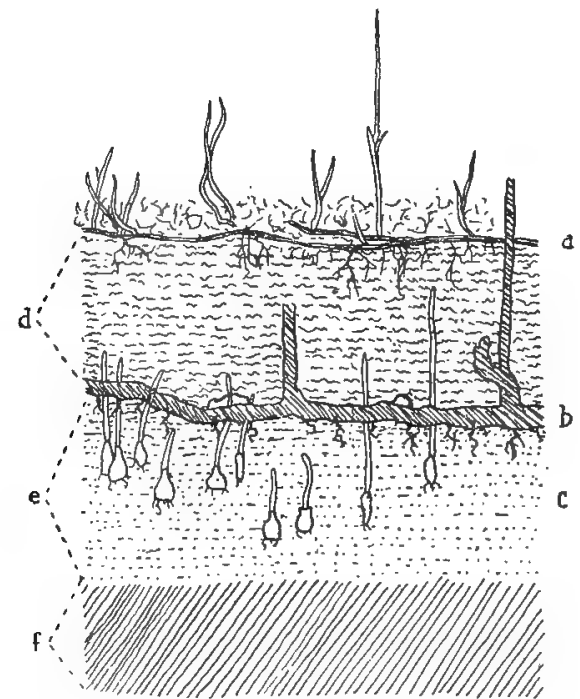

Fig. 108.-Section of Soll in a Wood, showing Straterication of Plants. (AfTer Woodhead.)

$\alpha$, Holcus mollis ; b, Pteris aquilina; $c$, Scilla nutans; $d$, humus ; $e$, light loam ; $f$, stiff clay.

lying rock; the rainfall, its total amount, and the number of wet days in the year; the humidity of the air; the temperature of both air and soil, recorded, if possible, at frequent intervals throughout the year; the amount of water in the soil, and, what is of very great importance, the character and amount of the substances in solutionare all factors of the habitat which require careful study in a detailed survey of the vegetation. As examples of what can be done in this respect the papers on "Ecology of Woodland Plants," by T. W. Woodhead, 
and "Marsh Vegetation," by Professor Yapp, included in the Bibliography, and numerous papers in the Journal of Ecology, should be consulted.

In a large district, where many associations exist, the limits of each type should be recorded on a map, and distinguished by some definite system of colouring, as in the vegetation survey-maps of Smith, Moss, Lewis, Pethybridge, and others.

The following summary of the associations and groups of associations to be dealt with is taken, with slight modification, from W. G. Smith's Botanical Survey of Scotland: III and IV, Forfar and Fife:-

A. Associations with a Water-Supply comparatively rich in Plant-Food.

I. Forest.

1. Dry or moist soils:

(a) Oakwood - Associations. - On nonpeaty soils at low and moderate elevations (p. 269).

(b) Oak-Birch-Heath Association. - On dry, coarse, sandy, and dry peaty soils at low elevations (p. 271).

(c) Birchwood - Association. - On noncalcareous soils at high elevations (p. 271).

(d) Ash-Oakwood Association.-On calcareous clays, marls, impure limestones, and calcareous sandstones (p. 272).

(e) Ashwood-Association.-On limestones (p. 272).

(f) Beechwood - Association.-On chalk in the south-east of England and on oolite in the Cotswold Hills (p 272).

2. Wet soils :

Alder and Willow-Thickets (p. 243).

II. Herbaceous Associations.

1. Dry or moist soils:

(a) Lowland and Sub-Alpine Pastures (p. 258). 
(b) Limestone-Pasture (p. 259).

(c) Alpine Pasture (p. 259).

2. Wet soils, with accumulation of organic matter :

Marsh (p. 244) and Reed-Swamp (p. 241).

3. In water :

Vegetation of Lakes, Streams, and Ditches in the lowlands (p. 234).

\section{B. Associations with a Water-Supply Poor in Mineral Food.}

\section{Forest.}

Coniferous Woods.-Soils poor, chiefly sand and peat, liable to excessive moisture and to drought (p. 273).

\section{Herbaceous Associations.}

1. Dry soils :

Vegetation of Fixed Sand-dunes (p. 282).

2. Moist soils more or less mixed with peaty humus :

(a) Grass-Heath. - Grassy turf, with heath-plants ; moisture variable, water retained in soil by pcat, but periods of drought occur (p. 250).

(b) Calluna-Heath.-Soil poor, with mixture of peaty humus; drainage good, and moisture not well maintained, therefore liable to drought (p. 252).

3. Substratum of continuous peat; moisture variable according to depth of peat and rate of drainage.

(a) Heather-Moor--On sloping ground ; soil poor and covered with a felted layer of peat (p. 252).

(b) Erica Tetralix-Moor. - Peat deeper and more continually moist than (a) (p. 253).

(c) Molinia cæra'ea-Bog. - On badlydrained peat (p. $: 51$ ).

(d) Eriophorum-Moor.-On deep peat, 
rainfall high, moisture excessive, and drainage slow (p. 251).

(e) Myrica-Bog (p. 253).

(f) Sphagnum-Bog (p. 253).

(g) Vaccinium-Moor.-In alpine zone, replacing heather-moor, Eriophorum-moor, and grass-heath (p. 255).

4. Wet soils with much organic matter :

Juneus and Carex-Bogs (p. 246).

5. In water :

Vegetation of Highland Lochs and Moorpools (p. 238).

\section{Associations with Salt-Water.}

1. Dry soils :

(a) Sand-dune Ridges (p. 281).

(b) Rocks and Cliffs (p. 283).

2. Wet soils :

Salt-Marshes and Estuarine Marshes (p. 278).

3. In water :

Maritime Aquatic Vegetation (p. 275).

In "Types of British Vegetation," edited by A. G. Tansley, the plant associations occurring in the British Isles are grouped into fourteen formations, a summary of which is given below:

I. Plant-formation of Clays and Loams.-Soil damp, poor in lime. Associations: (1) pedunculate oakwood; (2) scrub; (3) grassland; (4) rush.

II. Plant-formation of Sandy Soil.-Soil coarse and dry, frequently poor in nutritive salts and tending to become acid. Associations: (1) dry oakwood; (2) scrub; (3) grass-heath.

III. Heath Formation.-Soil sandy or gravelly, with a surface layer of dry peat, rainfall heavier than in II. Associations: (1) oak-birch-heath; (2) heath; (3) pine-wood.

IV. Plant-formation of the older siliceous Soils.Soil shallow, fine-grained and greasy when wet; forms " mild humus" when well aerated and wet acid peat when badly aerated, damp or wet; non-calcareous. Associations: (1) Sessile oakwood; (2) birchwood; (3) scrub; (4) mat-grass; (5) moor-grass. 
V. Plant-formation of Calcareous Soils. -The abundance of lime in the surface soil or just below the surface is the determining factor. Three sub-formations are recognized: (a) that of Older Limestones, $(b)$ that of chalk, and $(c)$ that of Marl and Calcareous Sandstones. Associations: ashwood ( $a$ and $b$ ), beechwood $(b)$, ash-oakwood $(c)$, scrub $(a, b$, and $c)$, grassland $(a, b, c)$, limestone heath $(a)$, and limestone pavement $(a)$.

VI.-Fresh-water Aquatic Formation.-Includes four sub-formations: $(a)$ of foul water, $(b)$ and $(c)$ of waters rich and poor, respectively, in mineral salts, and $(d)$ of quickly-flowing streams.

VII. Marsh Formation.-Soil saturated, but little or no peat developed. Associations: (1) alder-willow; (2) herbaceous marsh.

VIII. Fen Formation.-Wet, peaty soil, chiefly in East Anglia; ground water mainly telluric, rich in mineral salts and alkaline in reaction. Associations: (1) carr (woodland); (2) fen (herbaceous).

IX. Moor Formation.-On wet peat in both lowlands and highlands; ground water mainly or entirely aerial, poor in mineral salts and acid in reaction. Associations : (1) bogmoss; (2) Rhynchosporum (lowland only); (3) cottongrass; (4) Scirpus lacustris (upland only), (5) Molinia; (6) Nardus; (7) bilberry; (8) heather moor; (9) birchwood (lowland only); (10) pinewood (lowland only).

X. Aretic-Alpine Grassland Formation.-Develops only at high altitudes. Not yet sufficiently studied to admit of the recognition of different associations.

XI. Formation of Mountain-top Detritus.-Associations: (1) moss-lichen; (2) Rhacomitrium heath; (3) Rhacomitrium moor.

XII. Aretic-Alpine Chomophyte Formation.-Develops on alpine crags and corries. Associations: (1) open communities on exposed rock-faces; (2) assoc. of sheltered ledges; (3) assoc. of shade chomophytes; (4) assoc. of hydrophilous chomophytes.

XIII. Salt-Marsh Formation.-Associations: (1) glasswort; (la) cord-grass; (2) general salt-marsh; (3) Glyceria; (4) sea-rush; (5) assoc. of spray-washed cliffs and rocks.

XIV. Sand-Dune Formation.-Associations: (1) strand plants; (2) sea couch-grass; (3) marram grass; (4) dune scrub; (5) dune grassland; (6) dune marsh. 


\section{CHAPTER XXIII}

\section{AQUATIC VEGETATION}

Is Chapter V. we discussed the conditions of life under which hydrophytes exist, and the structural peculiarities which they exhibit in response to their environment. We are here concerned more with the distribution of the plants in fresh water (for marine aquatics see Chapter XXVIII.).

The aquatic vegetation throughout all temperate regions is remarkably constant. Not only do we find the habit of the various plants similar in all parts of the world, but the same species may be found in all countries. Thus the commonest British aquatics, Ranunculus aquatilis (water-crowfoot), Lemna minor (duckweed), and species of Potamogeton (pondweeds), are spread over the entire Temperate Zone of Europe, Asia, and America, and even occur in the southern hemisphere in Australia. This widespread distribution is accounted for by the ease with which detached portions of the plant can be carried in water-currents (p. 54), and the seeds by migratory water-fowl. The latter are the most efficient of all birds for the dispersal of seeds; they settle down only in the neighbourhood of water, and any seeds of aquatics adhering to the mud on their feet are pretty sure of finding a congenial home. The temperature of the water and other conditions of life vary little in different countries, and once a plant or seed has reached a new district it finds all its surroundings favourable to growth, and it becomes established. In civilized countries the barge is the most efficient of all carriers of water-plants. Many plants may be conveyed over whole continents, through rivers and their connecting canals, attached to the bottom of the barge. The Canadian pondweed (Elodea cano- 
densis), for example, was introduced into this country from America about 1842, spread rapidly over the whole of Britain, and extended into western Europe; and the rapidity with which it spread was probably due chiefly to its being carried on barges into canals, and thence by birds, which find the shoots tasty eating, into other pieces of water.

Associations of aquatic plants are usually of an open type. Competition between the various plants is not keen, and almost any plant suited to the particular situation may obtain a footing. The distribution of the different associations depends on a number of factors, of which the following are the most important: the rate of the current, the depth of the water, the amount of mineral salts in solution, and to a slighter extent on altitude. The rate of the current may be taken as a convenient basis on which to classify the associations, and in this way the following groups may be distinguished:

1. Associations in swiftly-flowing water-e.g., mountaintorrents, cascades, and waterfalls.

2. Associations in slowly-flowing water-e.g., ordinary rivers and streams.

3. Associations in standing water-e.g., lakes, ponds, and ditches.

\section{Swiftly-F'owing Water.}

Associations belonging to this group are not common in this country, and no flowering plants are included. Mountain-torrents and waterfalls can only exist where the underlying rock is extremely hard; all loose material will be washed away, and the only substratum on which plants can grow is the solid rock. This makes it impossible for a plant possessing ordinary roots to obtain a hold. If a seed were to germinate in a sheltered crevice in the rock, as soon as the plant produced leaves it would be torn away by the current. The only plants which can exist under these conditions are those which possess special disc-shaped holdfasts which cement the plant to the rock. These plants may form encrustations close to the rock, as in some green algæ and diatoms, or they are smooth, slippery plants which bend before the current and offer little resistance to it-e.g., some liverworts (Scapania undulata) and mosses (Fontinalis antipyretica): 
The only group of flowering plants which has become adapted to life under the water of cascades are the Podostemaceæ of Ceylon and Central Africa. In most of these the stems and leaves are absent, and the plant consists of a small, flat, green root which is fixed to the rock by special holdfasts called haptera. The minute flowers spring from the root, and in this stage the plant appears more like a fruiting moss than a flowering plant. This is a remarkable adaptation to environment.

\section{Slowly-Flowing Water.}

On the bed of rivers and streams there is usually an abundance of fine material in which plants can root, and the vegetation consequently reaches a much greater degree of development than in swiftly-flowing water. Freefloating plants naturally cannot exist, except under the shelter of reeds near the banks, owing to the current. In the centre of the stream, where the current is strongest, if the water is not more than 3 or 4 feet deep, plants with long ribbon-like leaves are found (pp. 50, 51). These leaves offer but a slight resistance to the current, and the plants are in little danger of being uprooted. Most of the plants in this situation grow usually in standing water, but, owing to the different conditions, the form of the plant in stagnant water is not the same as in flowing water. Sagittaria sagittifolia (arrow-head), for example, grows commonly in ponds, and possesses large arrow-shaped leaves which stand up erect in the air, but in flowing water all the leaves are long and narrow, sometimes reaching a length of over 2 feet, yet only $\frac{3}{4}$ inch wide. Similarly, Potamogeton natans (broad pondweed), which has floating leaves 2 to 4 inches long by 1 to $1 \frac{1}{2}$ inches broad when growing in standing water, produces narrow current-leaves over 18 inches long. Other plants associated with the foregoing are : Myriophyllum spicatum (water-milfoil), forms of the water-crowfoot-e.g., Ranunculus fluitans, which has submerged leaves only, the segments of which are long, narrow, and parallel-and Potamogeton pectinatus (fennelleaved pondweed), a submerged plant with very thin stems and narrow grass-like leaves. Nearer the rivermargin, in shallower and more slowly-moving water, 
occur other submerged species of Potamogeton (Fig. 18), Elodea canadensis, and other submerged, rooted aquatics mentioned in the next group.

In the centre of much-used canals the vegetation is very similar to that of streams, the motion of the barges producing a well-marked current. Out of reach of the barges the vegetation may be that typical of still water.

\section{Standing Water.}

Aquatic plants reach their greatest development in still water. Unless the water is much disturbed by animals, as in cattle- and duck-ponds, or when polluted by sewage or the refuse from chemical works or coppermines, it becomes the home of a vast assemblage of plants, and it is a common sight in summer to see the whole surface of a pond covered with the white blossoms of the water-crowfoot.

Ponds and lakes in the lowlands are always better inhabited than those in the highlands. The chief reason for this difference is that the water of the former is usually derived from the drainage of large areas of soft rock, and consequently contains a considerable amount of nutritive material in solution. The water of a highland loch, on the other hand, comes from a comparatively small area of hard rock, and the amount of material in solution is conspicuously less. The highland type of vegetation is not necessarily restricted to high altitudes; it may occur at lower levels in water poor in mineral salts. At the same time, altitude does play some part in bringing about differences in the vegetation. At high levels the water is often frozen in winter to a depth below the limits of plant-life, and few plants can survive such extreme conditions. In the lowlands the water is seldom frozen to a depth of more than a few inches, and the plants can hibernate in the warmer layers below. In some cases special hibernating shoots are produced (p. 54), and many possess rhizomes. Annual plants are extremely rare (p. 54).

The plants of a lake or pond usually show a more or less pronounced distribution in zones depending on the depth of the water. Each zone is often dominated by a single species, in all cases a rooted plant, forming a 
distinct association. The deepest parts of lakes do not receive sufficient light to support green plants, and the only vegetation consists of colourless bacteria. In a lowland lake or pond, travelling from the deeper to the shallower water, the following zones may be met with :

1. Chara and Nitella (stoneworts), often forming a dense pasture.

2. Elodea canadense.

3. Potamogeton (several species) and Myriophyllum.

4. Nymphoea alba and Nuphar lutea (water-lilies).

5. Water-crowfoots.

6. Glyceria fluitans, an aquatic grass, and Zannichellia palustris (horned pondweed), a grass-like plant, both with narrow floating leaves.

7. Polygonum amphibium.

Where the water is uniformly deep, as in shallow ponds, ditches, and rhines, these plants may occur together, forming a mixed association. Other rooted aquatics present, but not usually in such quantity as to constitute a separate association, are: Hippuris vulgaris (mare's-tail), in which some of the very narrow whorled leaves on the flowering shoots are above the surface of the water; Hottonia palustris (water-violet), entirely submerged, with finely-cut leaves; Callitriche aquatica (water-starwort), with narrow, widely-separated submerged leaves, and a rosette of crowded, floating, broader leaves: this plant is amphibious, and can also grow on wet mud, with all the leaves in the air. Pilularia globulifera (pillwort), a water-fern, and Littorella lacustris (shore-weed), which have awl-shaped leaves, are also as commonly found on the wet margins of lakes as submerged in water.

Living amongst the rooted plants may be found many free-floating forms. These are either entirely submerged, as in Ceratophyllum demersum (hornwort) and Vtricularia (bladderwort, Fig. 46), which possess very finely-divided leaves, and Lemna trisulca (ivy-leaved duckweed), with short, narrow leaves ; or the leaves are floating, as in the other species of duckweed (Lemna minor, L. gibba, etc.), and Hydrocharis Morsus-rance (frogbit, Fig. 109), which has the appearance of a miniature water-lily. In small ponds these free-floating plants with floating leaves, especially the duckweeds, may become dominant, and prevent the growth 
of submerged plants by forming a dense covering through which no light can penetrate. In such cases there is usually a well-marked periodicity in the development of the vegetation. In the spring and early summer the submerged plants grow luxuriantly, until the duckweed has multiplied sufficiently to form a thick covering, after which they cease to grow. In some places in the south of England a floating water-fern (Azolla caroliniana) has become established. This is a native of the southern

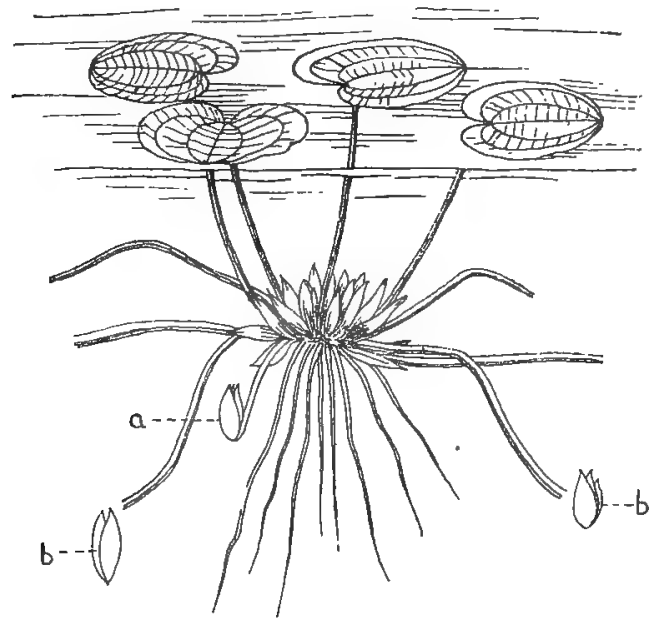

Fic. 109.-Hydrocharis Morsus-rana (Froabit). (ATTER KerNer.)

part of North America, and during the warmer months of the summer, when the temperature is about that of its native country, it grows so rapidly that even the duckweed is destroyed, and nothing is seen on the surface of the water but the bronze-coloured fronds of the fern.

The aquatic vegetation of highland lochs and pools is very poor, both in the number of species and individuals. Characteristic plants are Isoetes lacustris (quillwort, Fig. 110), Lobelia Dortmanna (water-lobelia), and Subularia aquatica (awlwort) - all very similar in habit, with a short thick "root-stock" bearing a tuft of submerged erect cylindrical leaves, 2 to 4 inches long; Sparganium natons (floating bur-reed), with floating leaves; Potamogeton 
lucens (shining pondweed), entirely submerged; yellow water-lily, mare's-tail, Pilularia, Myriophyllum, and Chara.

The water of pools which occur on peaty soil contains a large amount of soluble organic matter, and the vegeta-

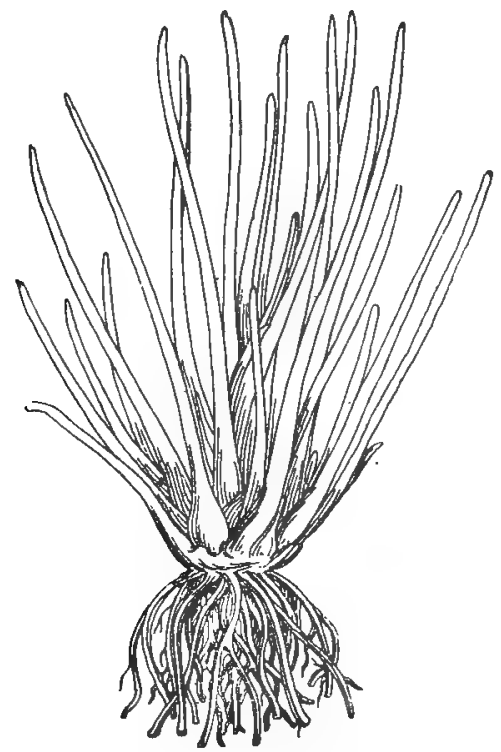

Fro. 110.-1 Isoetes lacustris (QUILLWOBT).

tion is characteristic. The most frequent plants are the bladderworts, Potamogeton natans, Scirpus fluitans (floating club-rush), Myriophyllum spicatum, and water-violet. 


\section{CHAPTER XXIV}

\section{VEGETATION OF THE MARSH AND BOG}

IN a marsh or bog the water-level rises to the surface of the ground, or above it. The roots, rhizomes, and in some cases the lower parts of the erect stems, are thus situated in water, but the greater part of the assimilating organs are in the air. This constitutes the chief difference between the marsh-plant and the true aquatic (hydrophyte), in which the entire plant is in water. There is, however, no sharp line of distinction between the two, some plants growing equally well under either condition-e.g., Polygonum amphibium and Apium inundatum (p. 28). The leaves of the marsh-plant standing out into the air can transpire like those of an ordinary land-plant, but the air is laden with moisture, and the rate of transpiration is slow-i.e., the conditions favour the development of a hygrophytic type of vegetation (p. 63). Often, however, as in bogs, a considerable quantity of humous acid is present, which hinders absorption, and in all cases absorption practically ceases in the winter, when the soil-water is very cold or possibly frozen. To meet these adverse conditions, xerophytic characters must be present in the plant. In the bog, where absorption is difficult throughout the year, the xerophytic characters are often permanent; but in the sweeter marsh the plants usually exhibit xerophytic characters (e.g., perennating structures) in the winter only; in the summer they are typical hygrophytes (see hygrophilous tropophytes, pp. 62, 63).

Annual plants are more abundant than in the aquatic vegetation, but they are still few, and these are found only in the drier parts, where the mean water-level is never above the surface. The temperature of the soil 
in the wetter parts is low for the greater part of the year, and only becomes warmed by the summer sun. The vegetative season is consequently short, and annuals have no chance of completing their life-cycle before the renewal of the adverse period. In the drier parts competition with perennials prevents the annual from becoming firmly established. The most common marshannuals are: Ranunculus sceleratus (celery-leaved buttercup), Impatiens fulva (orange balsam), Peplis Portula (water-purslane), Bidens cernuo and B. tripartita (burmarigolds), Pedicularis palustris (marsh-lousewort), Polygonum Hydropiper (water-pepper), and Juncus bufonius.

The associations of plants growing in water-laden soil may be separated into three groups, according to the character of the water:

\section{Associations in Fresh, Sweet Water.}

1. Reed-Swamp: the lower part of the plant is submerged in often deep water.

2. Woodland or Bush-Swamp: associations of woody plants in marshy soil.

3. True Marsh: water may reach the surface, but lower part of the plants not submerged.

\section{Associations in Sour, Acid Water.}

4. Bog.

III. Associations in Salt Water.

5. Salt-Marsh (see p. 278).

\section{Reed-Swamp.}

The reed-swamp is found along the margin of rivers, canals, lakes, etc. It reaches its greatest development, as in the case of aquatic vegetations, in the lowlands where the water is rich in mineral salts. It is either absent from the shores of highland lochs, or is very scanty. The reed-swampt closely approaches the associations of aquatic plants in many characters, and is sometimes regarded as a constituent of the aquatic formation. The lower parts of the plants are always submerged, and many floating aquatics occur amongst the stems. The dominant plants are monocotyledons and horsetails, plants of a social or cæpitose habit, with long, erect, 
narrow leaves. Where the water varies in depth, the plants become arranged in zones, or associations. In the deeper part Scirpus lacustris is usually dominant; next to this, on the landward side, is a zone of Phragmites communis. Other associations may be dominated by sedges (Carex), Typha latifolia (bulrush or reed-mace), and Equisetum limosum (horsetail). These plants, however, have a wide range, and where the water is uniformly shallow the deeper-growing forms invade the shallower zones, and a mixed association is the result. The Phragmites-association is the commonest, and may extend for miles along the banks of rivers, especially in the brackish water of estuaries. The dominant plant often occurs to the complete exclusion of all others. The narrow upright leaf, combined with the cæspitose habit, allows the plants to grow very close together, and produce a deep shade in which no broad-leaved plant can live.

Where the vegetation is not very dense, dicotyledons and broad-leaved monocotyledons occur. Plants of this type which grow in the deeper water are : Enanthe fistulosa and $W$. Phellandrium (water-dropworts), Sagittaria sagittifolia, Alisma Plantago (water-plantain), and Damasonium stellatum (star-fruit, confined to some of the South-eastern Counties). These plants approach the hydrophyte in many respects, especially Enanthe Phellandrium, which possesses very finely-divided submerged leaves and broader aerial ones; whilst Sagittaria has already been referred to as growing as a true aquatic, with very long submerged leaves, in rivers and streams.

Nearer the bank, where the water is shallower, the plants have only a small part of their erect stems submerged. Narrow-leaved monocotyledons, not usually dominant, include: Iris Pseudacorus, Sparganium ramosum (bur-reed), Acorus Calamus (sweet sedge), Butomus umbellatus (flowering rush), Triglochin palustre (marsh arrow-grass), Phalaris arundinacea (reed canary-grass), Glyceria aquatica (reed manna-grass), Catabrosa aquatica (whorl-grass), and Alopecurus geniculatus (marsh foxtail). Of broader-leaved forms, the following commonly occur: Ranunculus Lingua (spearwort), $R$. Flammula (lesser spearwort), Nasturtium officinale and N. amphibium (watercresses), Hypericum Elodes (marsh St. John's-wort), A pium nodiflorum, and $A$. inundatum (marshworts)-the 
latter is often quite aquatic in habit, with finely-out submerged leaves and broader floating ones-Sium latifolium and $S$. angustifolium (water-parsnips), Scrophularia aquatica (marsh-figwort), Veronica scutellata (marshspeedwell), V. Beccabunga (brooklime), V. Anagallis (water-speedwell), Mentha aquatica (water-mint), Polygonum amphibium, P. Hydropiper, Rumex Hydrolapathum (great water-dock).

The reed-swamp may be succeeded on its landward side by true marsh or woodland-swamp, or damp meadows may extend almost to the water's edge. In the latter case, and also when a towing-path is present, the river-bank is occupied by a mixed assemblage of plants, dominated by sedges, grasses, and rushes. The roots or rhizomes of these plants are usually situated in saturated soil, but no part of the assimilating organs is under water. It is here that the annual marsh-plant finds a home (see list, p. 241). The most frequent perennials are: Thalictrum flavum (meadow-rue), Althcea officinalis (marsh-mallow), Spircea Ulmaria (meadow-sweet), Lythrum Salicaria (purple loosestrife), several species of Epilobium (willowherbs) and Mentha (mints), Valeriana officinalis, Eupatorium cannabinum (hemp-agrimony), Senecio aquaticus (marshragwort), Lysimachia vulgaris (yellow loosestrife), Lycopus europæeus (gipsy-wort), Scutellaria gatericulata (skull-cap), Stachys palustris (marsh-woundwort), Myosotis palustris (marsh forget-me-not), Symphytum officinale (comfrey), and isolated trees of willow, alder, and birch.

The dominant plants of the reed-swamp possess subterranean creeping stems which tend to travel away from land. Humus collects at the. base of the plants, and in lakes and ponds the bottom, through its accumulation, gradually rises. In this way a pond may be choked up and converted into a marsh. The danger is not so great in rivers, for the humus is carried away by the current, but even here the plants must be periodically removed to keep the water-way clear.

\section{Woodland or Bush-Swamp.}

The alder and willow, which are usually found sparingly in the reed-swamps, may become very numerous and form distinct associations along the margins of rivers; or they may extend for a considerable distance landwards 
if the soil is marshy. Some of the thickets possibly represent primitive woodland, but in most cases they are plantations. Osier-beds are artificial associations of Salix viminalis.

The dominant trees are: Alnus glutinosa (alder), Salix Caprea (goat-sallow), $S$. cinerea (grey sallow), and $S$. fragilis (crack-willow). Many other shrubs and trees are found in small numbers-e.g., ash, oak, Rhamnus Frangula (alder-buckthorn), $R$. catharticus (common buckthorn), Viburnum Lantana (wayfaring-tree)-the latter two only when the water is rich in lime-Viburnum Opulus (wild guelder-rose), Ligustrum vulgare (privet), Ribes (currant), and many other species of willow. The undergrowth consists of ordinary marsh-plants-e.g., Caltha palustris (marsh-marigold), Chrysosplenium oppositifolium (golden saxifrage), Cardamine pratensis (cuckoo-flower), Valeriana dioica (marsh-valerian), various species of mint, Myosotis palustris (marsh forget-me-not), Spirca Ulmaria (meadowsweet), Epilobium hirsutum (hairy willowherb), Molinia corulea, and shade-loving grasses, such as Aira coespitosa (tufted hair-grass), the rare Calamagrostis Epigeios, and the wood club-rush (Scirpus sylvaticus).

\section{True Marsh.}

Wherever comparatively fresh water accumulates in the soil to such an extent that the water-level is at or just above the surface-e.g., on the landward side of reed-swamps, in the neighbourhood of springs, or lowlying ground-a marsh flora springs up. The marsh differs from the reed-swamp chiefly in the level of the water, which has an important effect on the vegetation. No parts of the assimilating organs of the marsh-plants are under water, and the vegetation more nearly approaches that of dry land.

Peat tends to accumulate in the water of the marsh, for the amount of oxygen present is insufficient to enable bacteria to decompose completely the plant-remains. But disintegration takes place to such a degree that the peat is black and amorphous, very close in texture, and quite different from that of the bog (see p. 248). The partial decomposition of the vegetable remains results in the formation of humous acids, but the amount pro- 
duced is insufficient to exert much influence on the vegetation. The consequent absence of well-marked xerophytes forms one of the chief distinctions between the marsh-flora and that of the bog.

The water of the marsh comes from a wide area, and in the neighbourhood of streams is being constantly replenished, so that plenty of nutritive material is present. The well-nourished plants are quick-growing and tall, and the general aspect of the vegetation differs considerably from that of the bog, where the plants are slow-growing and dwarfed. The difference is well seen in plants which grow in both marsh and bog-e.g., the purple moor-grass (Molinia corulea), which grows to a height of 4 to 5 feet in Fenland marshes, but rarely reaches 2 feet when growing in bogs.

The vegetation is often of a very mixed character, broad-and narrow-leaved plants growing indiscriminately; but occasionally a narrow-leaved form becomes dominant, and gires rise to a pure association. Thus associations dominated by Molinia carulea, Phragmites communis, Cladium Mariscus, Juncus obtusiflorus, and other rushes, or various species of Carex, are to be met with. Other plants commonly found are: Ranunculus sceleratus, Caltha palustris, Viola palustris (marsh-violet), Stellaria uliginosa (marsh-stitchwort), Hypericum tetrapterum and H. quadrangulum (marsh St. John's-wort), Comarum palustre (marsh-cinquefoil), Parnassia palustris (grass of Parnassus), various species of Epilobium (willowherbs), Hydrocotyle vulgaris (marsh penny-wort), Valeriana dioica (marsh-valerian), Campanula (Wahlenbergia) hederacea (ivy-leaved bell-flower), Anagallis tenella (bog-pimpernel), Samolus Valerandi (brook-weed), Menyanthes trifoliata (bog-bean), Pedicularis palustris, Orchis latifolia (marshorchid), Iris, Triglochin palustre, Osmunda regalis (royal fern), various species of Equisetum and Eriophorum (cotton-grass).

Small areas of raised ground frequently occur in a marsh, and on these drier parts a different type of vegetation exists. Many of the plants of the river-bank occur (see list on p. 241), together with water-loving plants, like Phragmites, whose deep-seated rhizomes are situated in the wetter ground below.

In many parts, as in the Fen district, the marsh may 
be converted by proper drainage into good pasture-land, the typical marsh-plants disappearing, and the finer grasses taking their place. In other cases shrubs and trees appear on the drying marsh, and in the course of time a woodland-association is developed.

\section{Bog-Associations.}

The bog is related ecologically to both the marsh and the moorland. The water-level is at or above the surfare, as in the marsh, but the amount of humous acid present is great, and floristically the bog very closely resembles a moor. For this latter reason, most of the associations of bog-plants are better dealt with in connection with the moorland (Chapter XXV.).

The bog is best developed on the flat margins of highland lakes, and in places where the soil-water is derived almost solely from atmospheric precipitations-rain and dew-as on moors. In either case the water is deficient in mineral salts, especially lime, and this, together with the amount of humous acid present, has a great influence on the vegetation. Carnivorous plants, which are quite absent from the marsh, are here abundant; mycorhiza (p. 124) occurs on many of the plants, and Sphagnum (bog-moss), which can only exist in water containing a very low percentage of salts in solution, is common.

Naturally there can be no sharp line of distinction between the bog and the marsh, for conditions exist intermediate between those necessary for the typical development of either. Owing to the gradual accumulation of peat in a marsh, the water becomes more and more sour, whilst lime becomes less abundant ; bog-plants then begin to appear, and in time a typical bog may be built up on top of the original marsh.

The bog is sometimes spoken of as a high-moor, and the marsh as a low-moor. These terms do not refer to altitude, as is commonly supposed, but to the relative abundance of humous acids. A high-moor may develop in the lowlands if the conditions are favourable, and a low-moor at high levels.

Many associations of bog-plants may be distinguished Those which come nearest to the marsh are dominated by rushes (Juncus conglomeratus, J. supinus, J. articu- 
latus, J. obtusiflorus, etc.) or sedges. These plants oftea grow thickly to the exclusion of all others. In the more open parts some plants found also in the marsh occure.g., Ranunculus Flammula, Comarum palustre, Hydrocatyle, Stellaria uliginosa, Anagallis tenella, Menyanthes trifoliata, Parnassia palustris, Orchis latifolia, etc. But many others characteristic of sour soil are abundante.g., sundews, butterworts, Vaccinium Oxycoccus (cranberry), Andromeda polifolia, Erica Tetralix, Salix repens, Narthecium ossifragum (bog-asphodel), Selaginella selaginoides, Molinia corulea, etc.

The relation between the marsh-land and aquatic vegetation is shown in the following diagrams:

\section{In the Lowlands:}

Associations of aquatic plants in still water.

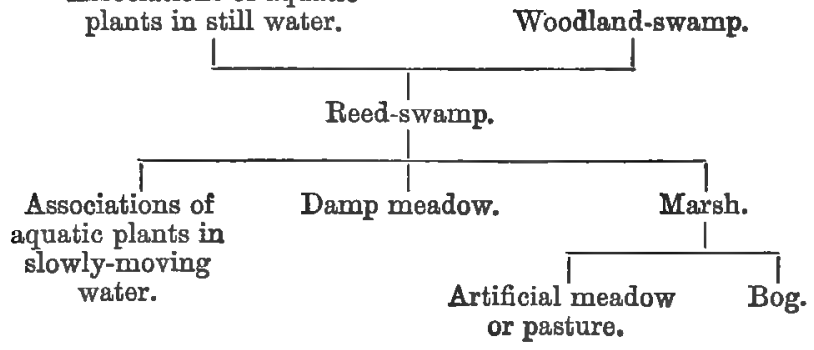

\section{In the Highlands :}

$$
\left.\begin{array}{c}
\text { Associations of aquatic } \\
\text { plants in still water }
\end{array}\right\}- \text { Reed-swamp-Bog. }
$$




\section{CHAPTER XXV}

\section{MOORLAND ASSOCIATIONS}

THRovghovt the country the term "moor" is applied to almost any stretch of treeless, barren land. It may be the wet peat-bogs of the uplands, the heather-clad regions of hill-slopes, or the dry heaths of the lowlands. The word, although used in apparently so wide a sense, is, nevertheless, a good one, for all these areas have something in common. They all occur on soil poor in nutritive salts, and contain more or less humous acids. Peat is present in all cases, varying in thickness from a few inches on the dry grass-heath to 30 feet or more on the wet cotton-grass bogs. It is the relative abundance of peat which determines the character of the vegetation of the moorland; and the amount of peat in turn depends upon the character of the underlying rock, the altitude, and the rainfall.

We saw in Chapter X. that vegetable remains are decomposed by bacteria, and, if the conditions are unfavourable for their growth, peat will accumulate. The following regions are those unsuited for the work of bacteria, and it is in these places that peat is formed and moorlandassociations develop :

1. In the lowlands where drainage is very bad, and where the water becomes stagnant. This means a lack of oxygen in the soil, whilst the evaporation from the surface keeps it cold.

2. At high altitudes where the temperature is low for the greater part of the year. If this is combined with a very heavy rainfall, bad drainage, and the accumulation of stagnant water, the conditions for peat-formation are intensified. It is under these circumstances that the cotton-grass bog reaches its greatest development. 
3. At any altitude where lime is quite absent from the soil, as on dry, sandy, or pebbly heaths, where any lime at one time present has been washed into the subsoil.

Peat seldom accumulates directly on limestone or chalk, for here the conditions are all in favour of bacterial action. Plenty of oxygen and lime is present, and the soil is warm, except at very high altitudes. When peat does form in a limestone district, it can usually be traced to the presence of a capping of some other material on the limestone. The great bogs of Ireland, for example, lie chiefly on limestone covered with boulder-clay.

The plant-remains in moorland-peat, in contrast to those in marshy peat, are well preserved. A section through a thick deposit will often show a well-marked stratification of the material from which the peat is formed. At one level Sphagnum may predominate, at another cotton-grass, whilst remains of birch and pine are frequent. From these different layers we can gain, not only an idea of the former vegetation, but also of the changes in climate which the district has undergone.

Humous acids are formed in all peaty soils, and, if present in large quantities, the absorption of water is rendered difficult, and the vegetation is of a pronounced xerophytic type, as on damp heather-moors and cottongrass bogs. Here the dominant plants are either heathlike plants with small evergreen rolled leaves (Figs. 9, 12), or grass-like plants with erect cylindrical leaves. Mineral food is scarce, especially the nitrates and phosphates of lime, potash, and magnesia, and plants which can obtain food from other sources than the mineral substances in the soil have a big advantage over their neighbours. Carnivorous plants, for example, which obtain a large proportion of their food from the bodies of insects, are common in the wetter parts ; whilst others-e.g., all the heaths, cranberries, and some grasses-obtain organic food through the agency of fungi (mycorhiza) which become attached to their roots.

The various associations of moorland-plants may be summarized as follows :

1. On dry, poor soils, drainage good:

(a) Grass-Heath, peat thin.

(b) Calluna-Heath, peat thicker.

(c) Vaccinium-Moor, alpine. 
2. On moist soils :

(d) Heather-Moor, peat deep.

3. On wet soils :

(e) Molinia cærulea-Bog, a modification of the grass-heath.

(f) Erica Tetralix-Moor, a modification of the heather-moor.

(g) Myrica Gale-Bog, intermediate between the marsh and the heather-moor.

(h) Eriophorum-Moor (cotton-grass moor), on flat summits where rainfall is high.

(i) Sphagnum-Bog, on constantly wet rocks, etc., where water is not very rich in humous acids.

\section{Grass-Heath.}

On well-drained soils possessing a thin covering of peaty material a grass-community becomes established. This grass-heath is similar in many respects to the natural pasture, but is at once distinguished by the presence of Calluna vulgaris (heather) and other heath-plants. It occurs on the steeper slopes of mountains, and occasionally on gravelly soil in the lowlands. Where the slope of the ground is more gradual, peat accumulates to a greater extent, and Calluna competes successfully with the grasses, with the result that an association intermediate between the grass-heath and the Callunaheath is formed. A similar intermediate association may develop through the artificial drainage of a heathermoor. The grass-heath in some cases arises as a substituted association when a Calluna-heath is used as grazing-land. The heather is destroyed to a greater or less extent, and grasses take its place ; but it soon reverts to its original condition if cattle are kept off the land.

Festuca-Agrostis-Anthoxanthum Association.-On the richer soils the dominant grasses are those of the natural pasture : Festuca ovina, Agrostis vulgaris, Anthoxanthum odoratum, and Aira flexuosa. Calluna is always very abundant, but in exposed places is usually dwarf. Ulex europceus (gorse) is also occasionally very abundant. Of typical heath-plants associated with the foregoing, Vaccinium Myrtillus (bilberry, whortleberry), Erica cinerea 
(usually dwarf), Salix repens, Polygala serpyllacea (heathmilkwort), Pedicularis sylvatica (lousewort), and Luzulo campestris are frequently found. Other characteristic plants are : Potentilla Tormentilla, Galium saxatile, Pteris aquilina, Thymus Serpyllum, Achillea Millefolium, Hieracium Pilosella, Campanula rotundifolia, Veronica offcinalis, Euphrasia officinalis, Teucrium Scorodonia, Rumex Acetosella, and various species of Rubus.

Nardus stricta-Association.-On poorer soils, especially in the sub-alpine zone (1,000 to 2,000 feet), Nardus stricta (matgrass), which is found sparingly at lower levels, becomes dominant. Festuca ovina, Aira flexuosa, and Agrostis vulgaris also occur, with Molinia crerulea in the wetter parts. Calluna is usually less frequent than in the preceding association, but Vaccinium Myrtillus is more abundant. Potentilla Tormentilla, Galium saxatile, Rumex Acetosella, and Luzula campestris are still very common, and mixed with these are plants characteristic of high altitudes-e.g., Juncus squarrosus, Lycopodium Selago, and L. clavatum.

Molinia-Bog. - Where the drainage is very bad and the soil wet, Nardus stricta is displaced by Molinia ccerulea. Associated with the latter are many bog-plants-e.g., Juncus effusus, $J$. conglomeratus, Eriophorum vaginatum (cotton-grass), Aira caspitosa, Narthecium ossifragum, Hydrocotyle vulgaris, Vaccinium Oxycoccus, Erica Tetralix, Rhynchospora alba, Carex (C. Goodenowii and other species), Sphagnum, etc. Above 2,000 feet the Molinia-bog passes over into cotton-grass moor.

Summit-Heath.-At high altitudes (1,500 to 2,500 feet) a summit-heath, intermediate in character between the alpine-pasture and the Vaccinium-moor, is developed. It consists chiefly of Nardus stricta and Juncus squarrosus, with Vaccinium Myrtillus sometimes sharing dominance. A few plants found at lower levels still persist-e.g., Aira Alexuosa, Potentilla Tormentilla, Galium saxatile, Euphrasia officinalis, and Luzula campestris-but alpine plants are frequent-e.g., Alchemilla alpina, Lycopodium Selago, L. clavatum, Empetrum nigrum (crowberry), Vaccinium Vitis-idoea (cowberry), Antennaria dioica, and in the wetter parts Rubus Chamomorus, Vaccinium uliginosum (mountain blaeberry), and Eriophorum. 


\section{Calluna-Heath.}

This association occurs in similar situations to the grass-heath, but on poorer soil, covered with a deeper layer of peat. The peat is composed of mosses characteristic of dry soils-e.g., Polytrichum and Dicranum.

Calluna vulgaris is almost exclusively dominant, with occasional areas in which Erica cinerea or Ulex europoeus is most abundant. Grasses are common-e.g., Festuca ovina, Aira flexuosa, and Agrostis vulgaris. This abundance of grasses distinguishes the Calluna-heath from the heather-moor. The remaining vegetation is that typical of dry soils, and includes most of the grass-heath plants. Rare plants found include Erica ciliaris and $E$. vagans, the latter confined to Cornwall, the former almost so, and Dabocia polifolia (St. Dabeoc's-heath), found only in Connemara (see p. 213).

Although most common on siliceous soils, this association is not confined to them, being found occasionally on limestone-e.g., Mendip Hills and Peak District. In such cases many plants of the limestone-pasture occur, in addition to the ordinary forms.

\section{Heather-Moor.}

The heather-moor occurs where the peat is deeper ( 4 to 5 feet) and wetter than that of the Calluna-heath, and is found chiefly on the more gentle slopes of mountain-sides. The peat is made up almost entirely of Sphagnum ; in fact, the heather-moor sometimes arises on top of a Sphagnum-bog. In other cases it is formed by the drainage of a cotton-grass moor.

The dominant plant, as a rule, is Calluna vulgaris, but in the wettest parts it is displaced by Erica Tetralix. The heather grows more luxuriantly here than on the Calluna-heath, and sometimes reaches a height of several feet. The thick dense growth forms excellent covert, and most of the "shooting moors" belong to this association. The associates of the heather are the same as on the Calluna-heath, but they are much less abundant. Erica cinerea, however, is usually very common, and moisture-loving plants are frequent. 
Erica Tetralix-Association.-In the wettest parts Erica Tetralix is dominant, and forms a distinct association within the heather-moor, characterized by the presence of a number of bog-plants-e.g., Drosera rotundifolia, Pinguicula vulgaris, Andromeda polifolia, Narthecium ossifragus, Rubus Chamoemorus, Vaccinium Oxycoccus, Myrica Gale (sweet gale), Salix repens, Sphagnum, Molinia coerulea, and various species of Juncus, Carex, and Eriophorum. Rare plants occurring in this association are : Erica ciliaris, more common here than on the dry Calluna-heath, and Erica Mackaii and $E$. mediterranea, confined to a few districts in western Ireland (see p. 213).

In many parts the Erica Tetralix-association merges gradually into the Sphagnum-bog or Eriophorum-moor.

\section{Myrica-Bog.}

In parts of the wet heather-moor, where water is very abundant, and sweeter than elsewhere, Myrica becomes dominant. A similar association is met with in lowlying districts where drainage is bad, and on the wet margins of the highland type of lake.

This association is intermediate between the wet heather-moor and the marsh, many of the plants of the latter being present-e.g., Ranunculus Flammula, Viola palustris, and Anagallis tenella.

Very abundant plants are: Molinia carulea and Erica Tetralix. Common or frequent plants, in addition to the above marsh-plants, are: Drosera, Pinguicula, Narthecium, Juncus species. Eriophorum vaginatum, Carex species, and Sphagnum. Calluna vulgaris occurs, but is not common.

\section{Sphagnum-Bog.}

Sphagnum is a peculiar moss with a big system of water-storing cells in its leaves, so that the plant hold, water like a sponge. The stem grows continuously at the apex; the lower part dies away, and gradually becomes converted into peat. The stem is clothed with living green leaves for about 6 to 8 inches below the tip, and as it is choked with water inside, it cannot 
live completely submerged, on account of the difficulty of obtaining sufficient air. The plant can only grow in quantity when the rainfall is heavy and the atmosphere very humid. Sphagnum-bogs develop commonly on wet, sloping rocks in mountainous regions. Here plenty of water is available at all times, but the slope of the rock allows the surplus water to drain away.

When the plant is growing luxuriantly, it forms a deep, loose covering in which other plants find a difficulty in taking root, and, further, only those plants which can keep pace with the upward growth of the moss can exist. All other plants will be smothered. The most frequent plants are those with long straggling stems, rooted in the firmer peat below-e.g., Vaccinium Oxycoccus, Rubus Chamcemorus, Empetrum nigrum, and monocotyledons with long narrow leaves, which can grow up between the moss-e.g., Narthecium, Eriophorum, sedges, and rushes. Erica Tetralix occurs occasionally; also Drosera rotundifolva, Pinguicula, and small creeping plants-e.g., Anagallis tenella, Campanula hederacea, and Selaginella selaginoides.

\section{Eriophorum-Moor.}

On the flat summits of moorland (1,250 to 2,000 feet), especially in the Pennines, vast areas are covered with an association of cotton-grass, locally known as mossmoors. The peat is always thick, sometimes reaching a depth of 30 feet, and saturated with the sourest water. The development of this association over large areas is dependent on very heavy and continuous rainfall-at least 40 inches per annum, since the only water which reaches it comes from above. At similar altitudes where the rainfall is less a heather-moor develops. The Eriophorummoor is also found at lower levels where water is abundant -e.g., the levels of Somerset. A very constant feature of these moss-moors is their shape. They are higher in the centre than at their edges, so that the general appearance is that of an inverted saucer. Bare peat is very common where water has denuded the surface.

Eriophorum vaginatum is usually dominant, sometimes 
E. angustifolium, and, in places, Empetrum nigrum. Rubus Chamcemorus and Vaccinium Myrtillus are abundant. Occasional plants are: Erica Tetralix, Calluna vulgaris, Drosera rotundifolia, Narthecium, Lycopodium Selago, Selaginella selaginoides, Carex canescens, and Scirpus ccespitosus. Sphagnum is quite subordinate. On the drier edges Calluna and Erica Tetralix become more common, and on the slopes the moor often passes over into a heather-moor.

\section{Vaccinium-Moor.}

Associations dominated by Vaccinium Myrtillus (bilberry) are in most cases essentially alpine (2,000 to 3,000 feet), but in Yorkshire the Vaccinium-moor is not determined by altitude alone; it invariably forms the skylimit of the moor where it is exposed to all weathers. The peat is much shallower than in the Eriophorummoor.

Two types of Vaccinium-moor may be distinguishedone a dry form, a climatic variety of the grass-heath or alpine pasture, and the other wetter, a climatic variety of the heather-moor, or Eriophorum-moor. In either case alpine plants are frequent. The dry type occurs on shallow peat liable to drought, and includes a large number of grasses-e.g., Festuca ovina, Aira flexuosa, Nardus stricta, etc., and other plants of the grassheath or alpine pasture. Alpine plants are: Alchemilla alpina, Empetrum nigrum, Phleum alpinum, clubmosses, etc.

- In the climatic variety of the heather-moor, Calluna is abundant, and in that of the Eriophorum-moor, the cotton-grass. Other plants found are: Erica Tetralix, Rubus Chamoemorus, Arctostaphylos Uva-ursi (bearberry); Betula nana (dwarf birch), and Azalea procumbens, confined to Scottish highlands; Trientalis europoea and Tofieldia palustris (Scottish asphodel), confined to North Britain. Cornus suecica (dwarf dogwood) is one of the most constant associates of Vaccinium in the alpine zone of North Britain.

The relation between the various moorland associations, or groups of associations, may be expressed in the follow- 
ing way. Variations due chiefly to altitude are indicated vertically; to moisture, horizontally; the wet types to the right, the dry to the left.

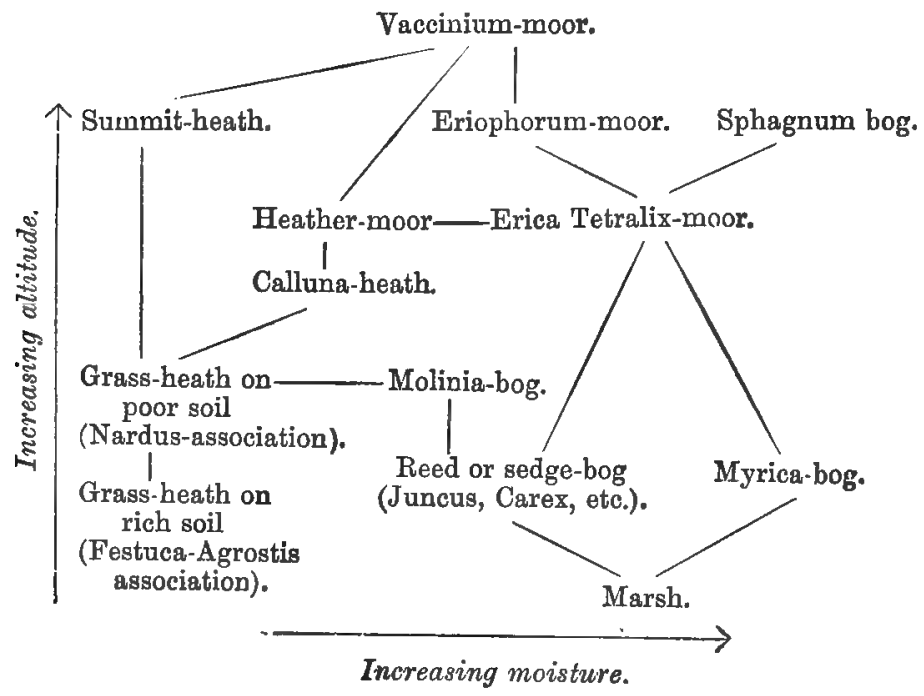




\section{CHAPTER XXVI}

\section{GRASSLAND ASSOCIATIONS}

\section{Natural Pasture.}

ON the more gentle slopes of hills and mountains the drainage is good, and the soil consequently dry. If an abundance of plant-food is available in the soil, grasses become established, and produce areas of natural pasture. Grassland of this kind is found at all altitudes from sealevel almost to the summits of the highest mountains, more especially where the rocks are igneous or calcareous. Sandstone hills rarely support a natural pasture, for plant-food is scarce, and the slopes become covered with grass-heath or calluna-heath (pp. 250, 252).

The vegetation has to rely for its water-supply almost entirely on atmospheric precipitations-rain or dew. Periods of drought are therefore frequent, whilst strong drying winds prevail for a large part of the year. These factors tend to favour the development of a xerophytic type of vegetation, which becomes more pronounced at high altitudes. 'The natural pasture forms the great sheep-runs of all hilly districts, and the continual grazing has a certain influence on the vegetation, many of the taller plants being cut down to a few inches, and prevented from producing flowers and seed.

The turf is usually dense and compact, formed of the fibrous shallow roots of the grasses, which monopolize the water and food in the upper layers of the soil. "The only herbs which can obtain a footing are perennial plants, whose long roots can explore the soil beneath the turf, or hemi-parasites (p. 126), which become fixed to the roots of the grasses and absorb much of their food from them-e.g., Euphrasia officinalis (eyebright) and 
Thesium humifusum (bastard toadflax). On very poor soils, or exceptionally dry ones, the turf is less dense, and a few annuals find room to grow-e.g., Linum catharticum (purging flax) and Arenaria serpyllifolia (thyme-leaved sandwort) on the dry chalk-downs. Most of the perennial herbs are rosette-plants-e.g., Hieracium Pilosella and Rumex Acetosella-or have prostrate stems-e.g., Galium saxatile and wild thyme. Not only are these plants protected from drying winds by placing their leaves close to the ground, but the growth of other plants in their immediate neighbourhood is to a large extent prevented. Mole-heaps, earth thrown out from rabbit-burrows, and other areas of disturbed ground, possess quite a different flora from the surrounding pasture, weeds of cultivation, both annual and perennial, being common.

The constitution of the flora of a natural pasture varies with the chemical nature of the soil and the altitude. On the very rich soils formed by the disintegration of igneous and metamorphic rocks the dominant grasses are much the same at all levels, but in the alpine regions the commonest plants associated with them are alpines not found in the lower regions.

Lowland and sub-alpine pastures on rich soil occur up to an altitude of about 2,000 feet, but their vertical range depends on the amount of water present in the soil ; on very dry soils they do not extend so high. The dominant grasses are: Anthoxanthum odoratum (sweet vernal-grass), Agrostis vulgaris (fine bent-grass), Festuca ovina (sheep's-fescue), and Aira flexuosa (waved hairgrass). The latter two grasses are well adapted for dry conditions, their leaves being rolled inwards, so that the lower surface, bearing stomata, are protected from the wind (p. 43). Nardus stricta, found occasionally here, but more commonly at higher levels, has similar rolled leaves. Other grasses frequently found are: Poa pratensis (smooth meadow-grass) and Triodia decumbens (heath-grass). Of rosette-plants, the commonest are: Hieracium Pilosella (mouse-ear hawkweed), Achillea Millefolium (yarrow, milfoil), Rumex Acetosella (sheep'ssorrel), Carlina vulgaris (carline-thistle), and Luzula campestris (field wood-rush). In many plants the leaves close to the ground are large, those on the erect stems 
small or narrow, so that the plants approach very closely to the rosette-plants in habit-e.g., Scabiosa Succisa (devil's-bit scabious), Campanula rotundifolia (hairbell), and Pimpinella Saxifraga (small burnet-saxifrage). The most abundant creeping plants are: Trifolium repens (Dutch clover), T. dubium (small yellow trefoil), Lotus corniculatus (bird's-foot trefoil), Galium saxatile (heathbedstraw), G. verum (lady's-bedstraw), and Thymus Serpyllum (wild thyme). Where the soil is calcareous, lime-loving plants are common-e.g., Linum catharticum, Polygala vulgaris (milkwort), Viola hirta (hairy dogviolet), and Helianthemum Chamoecistus (rock-rose). On dry soils heath-plants may be abundant-e.g., Ulex europous (gorse, furze) and Pteris aquilina (bracken), together with scattered dwarfed plants of Vaccinium Myrtillus (whortleberry) and Calluna vulgaris (heather, ling). When these plants are abundant, the natural pasture passes over into a grass-heath.

Alpine Pasture.-At an altitude of about 2,000 feet and over, a natural pasture may occur on rich soils. The dominant grasses are those found at lower levels, but Nardus stricta is more abundant, and may share dominance with the others, and the viviparous variety of Festuca ovina is common. But, above all, the alpine pasture is distinguished by the presence of alpine plants, of which Alchemilla alpina (alpine lady's-mantle) is a constant and abundant representative. Most of the herbs occurring at lower levels are found here, and, in addition, the following alpines : Poa alpina, Potentilla Crantzii (alpestris, alpine cinquefoil), Cerastium alpinum (alpine mouse-ear chickweed), Lycopodium Selago, $L$. alpina, $L$. clavatum (club-mosses), and-confined to Scotland or North Britain - Sagina Linnai (mountainspurrey), Oxytropis uralensis, Gentiana nivalis, and Kobresia caricina.

Limestone-Pastrire and Chalk-Downs.--The soil formed on a hill comirosed of limestone or chalk is invariably dry, for the rock allows the water to drain away very rapidly-the chalk to a much greater extent than the limestone. The rock itself is very soluble in water containing carbonic acid gas, and the soil-water consequently contains a large percentage of bicarbonate of lime. Many plants prefer a dry soil, and others a chalky one 
(see p. 89), and so we find the vegetation of limestone and chalk hills is made up of a mixture of these two types. The herbage on the windward side of the hill is short, the plants seldom rising more than an inch or two above the ground, but in the sheltered parts the plants grow more luxuriantly, and it is here that most of the calciphilous plants mentioned below are found.

The dominant grasses are Festuca ovina, Sesleria coerulea (in northern counties), Koeleria cristata, and Poa pratensis; common or frequent grasses are Agrostis vulgaris, Cynosurus cristatus (crested dog's-tail), Brachypodium pinnatum, and Briza media (quaking-grass). Aira flexuosa and Nardus stricta, so common on all other dry soils, are never found where lime is present-that is, they are typical calcifuges (see p. 89). The herbs found on the limestone-pasture and chalk-down include most of those occurring in the pasture on rich soil (p. 258). Other plants, associated with a dry soil, commonly found are: Potentilla Anserina (silver-weed), Veronica officinalis (common speedwell), Euphrasia officinalis, Cardurs acaulis (stemless thistle), and Daucus Carota (carrot). The calciphilous plants may be grouped according to their demand for lime as follows (those marked with an asterisk are more or less rare plants found only on chalk-downs in this country, although on the Continent, where they are more abundant, they may occur on other soils as well):

1. Confined to calcareous soil :

Hippocrepis comosa (horso-shoe vetch), Aceras anthropophora (green man-orchid), and Polygala calcarea (chalkmilkwort, found only on the chalk-downs of South England).

2. Almost exclusively found on calcareous soil :

Anthyllis Vulneraria (lady's-fingers), Ophrys musciferch (fly-orchid, gr,owing usually at the top of downs under the shade of bushes), Campanula glomerata (clustered bellflower), and Buxus sempervirens (box-tree).

3. Prefer calcareous soil :

* Anemone Pulsatilla (pasque-flower), Helianthemum Chamocistus (rock-rose), Polygala vulgaris (milkwort), Linum catharticum (purging flax), L. usitatissimum (common flax, linseed), L. perenne (perennial flax), Poterium Sanguisorba (lesser burnet), Viola hirta (hairy dog-violet), Äsperula cynanchica (squinancy-wort), Centaurea Calcitrapa (star- 
thistle), Picris hieracioides (hawkweed oxtongue), Scabiosa Columbaria (small soabious), Carduus acaulis (stemless thistle), *Phyteuma orbiculare (round-leaved rampion), Chlora perfoliata (yellow-wort), Erythroea Centaurium (centaury), Verbascum Thapsus and V. nigrum (mulleins), Inula Conyza (ploughman's-spikenard), Reseda lutea (wild mignonette), R. Luteola (dyer's-weed), Salvia Verbenaca (clary), Ajuga Chamcepitys (ground-pine), Plantago media (hoary plantain), *Thesium humifusum (bastard toadflax), Spircea Filipendula (dropwort), Spiranthes autumnalis (lady's-tresses), *Orchis hircina (lizard-orchid, extremely rare, found only in Kent), $O$. pyramidalis (pyramidal orchid), O. ustulata (dwarf orchid), Ophrys apifera (bee-orchid), *O. Arachnites (late spider-orchid, very rare, in Kent only), $O$. aranifera (spider-orchid), Habenaria conopsea (fragrant orchid), Carex Alacca, Juniperus communis (common juniper).

The following table exhibits the relationships of the natural pasture :

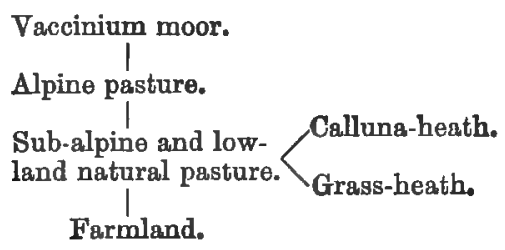

\section{Artificial Pasture and Meadow.}

In the region of deciduous trees, large areas of grassland exist in this country, on soil very rich in plant-food and with a high water-content. Most of this grassland is reclaimed woodland, and if allowed to fall out of cultivation would return to its natural condition, and once again become clothed with forest. In other cases marshes or bogs have been drained and converted into good pastureland or meadow.

Artificial grassland may be divided into two groups, according to the agricultural practices to which the land is subjected. Meadow-land is essentially hay-producing, one or two crops being removed annually, and only after the last crop has been cut are cattle allowed on the land. 
Pasture, on the other hand, is used only for grazing (see p. 20).

The continual removal of hay from the meadow tends to impoverish the soil, and fresh supplies of plant-food must be added in the form of manure, if profitable crops of hay are to be obtained. The manuring of the ground has a big influence on the growth of all the plants, both grasses and weeds, but in a different way. The grasses grow more luxuriantly, and form such a dense shade that many of the weeds are killed outright, whilst others are so injured by the lack of light that the seed produced is poor in quality and small in quantity, and in time these, too, disappear. At the experimental station at Rothamsted plots of meadow-land have received the same treatment for over fifty years, and the influence of manuring is strikingly shown by the relative proportion of grasses and weeds in the hay obtained from each plot. On unmanured ground less than half the hay was graminaceous herbage, over 39 per cent. useless weeds, and the remainder leguminous herbage-e.g., clover and bird's-foot trefoil, which has a fairly high dietetic value. On well-manured ground over 99 per cent. of the hay consisted of grasses and less than 1 per cent. of weeds. The age of the meadow also is an important factor in determining the abundance and character of the weeds. In temporary meadows, laid down to grass for one year only, a large proportion of the weeds are annuals-relics of the previous year's cultivation; but in permanent meadows they gradually disappear as time goes on, and in old meadows they are as rare as in the natural pasture.

The grasses required to produce good hay must be quick-growing, and this can only be when an abundance of water is present in the soil, and the climate is warm and humid. Meadows are consequently chiefly found in valleys and on low-lying ground. On hill-slopes the conditions are unsuited to the rapid growth of the herbage, and the land is laid down as pasture. This artificial pasture forms much better grazing-ground than the natural pasture, for the land is specially prepared, and the grasses are more luxuriant and selected for the purpose in view. The artificial pasture is usually kept for milchcows, the natural pasture for sheep.

The most common grasses selected for laying down 
grassland are: Lolium perenne (perennial rye-grass), Anthoxanthum odoratum (sweet vernal-grass), Dactylis glomerata (cock's-foot), Poa pratensis and $P$. trivialis (smooth and rough moadow-grasses), Alopecurus pratensis (fox-tail), Phleum pratense (Timothy-grass), Agrostis alba (white bent-grass), Holcus lanatus (Yorkshire-fog), Cynosurus cristatus (crested dog's-tail), Festuca pratensis (meadow-fescue), and $F$. ovina (sheep's-fescue). With these grasses are mixed intentionally certain leguminous plants-e.g., clovers-and on dry pastures these form a large percentage of the seed sown.

Weeds of Meadow-Land. - The character of the weeds in the meadow depends largely on the chemical and physical nature of the soil. The plants are tall-growing and, protected by the surrounding grasses, are mesophytic, with large thin leaves. Transpiration is often difficult, owing to the humid atmosphere, and many of the plants possess hydathodes (p. 27), by means of which the water is got rid of in a liquid form. Saxifraga granulata exhibits such a character in a pronounced degree; the water which is excreted contains a large amount of calcium carbonate, which is left behind on the leaf as a white chalky deposit when the water evaporates. They are for this reason often called chalk-glands. As in the natural pasture, competition is very keen, and all the weeds are perennial or hemi-parasites-e.g., Rhinanthus and Bartsia.

On damp, heavy soil the commonest weeds are: Rumex Acetosa (sorrel), $R$. crispus (dock), Ranunculus repens (creeping buttercup), $R$. bulbosus (bulbous buttercup), Plantago lanceolata (ribwort-plantain), Carduus palustris (marsh-thistle), Senecio vulgaris (groundsel), S. Jacobcea (ragwort), Orchis mascula (early purple orchid), Tragapogon pratensis (goat's-beard), Prunella vulgaris (self-heal), Lapsana communis (nipplewort), Lathyrus pratensis (yellow meadow-vetchling), Cardamine pratensis (cuckoo-flower), Geranium pratense (meadow crane's-bill), Spircea Ulmaria (meadow-sweet), Saxifraga granulata (meadow-saxifrage) ; and the rare Crocus vernus, Fritillaria Meleagris (snake'shead), and Colchicum autumnale (autumn-crocus, meadowsaffron). Rhinanthus Crista-galli (yellow rattle) is found in almost all meadows on clay land.

In low-lying meadows near rivers the water-level is 
often above the surface for part of the year, and many marsh-plants occur.

On drier land, as in chalk-districts, the characteristic weeds are: Chrysanthemum Leucanthemum (ox-eye daisy), Lotus corniculatus (bird's-foot trefoil), Silene Cucubalus (bladder-campion), Plantago media (hoary plantain), Anthyllis Vulneraria (lady's-fingers), Onobrychis sativa (sainfoin), Poterium Sanguisorba (lesser burnet), and Scabiosa Columbaria (small scabious). All of these are found on the damper soil, but more sparingly than on the chalk. Many orchids also occur-e.g., Habenaria conopsea, Orchis pyramidalis, 0 . maculata, Aceras anthropophora, Ophrys muscifera, and Listera ovata (twayblade).

Weeds of the Pasture.-The weeds of the artificial pasture vary only to a slight extent from those of the natural pasture, but they are usually less numerous. Rosette-plants and forms with prostrate stems are commonest-in one pasture only nine out of the forty-six species present had tall, erect stems. Of these the thistles (Carduus arvensis, C. lanceolata, and $C$. palustris) escape destruction by grazing animals owing to the spiny nature of their leaves, whilst buttercups (Ranunculus acris, $R$. bulbosus) possess a very acrid juice which warns off the cattle. A number of weeds are very common in the damp artificial pastures, but absent or uncommon in the drier natural pastures-e.g., daisy, dandelion, hawkweeds (Hieracium), hawkbits (Leontodon), hawkbeards (Crepis), cat's-ear (Hypochoris radicata), and cowslip (Primula veris). 


\section{CHAPTER XXVII}

\section{WOODLANDS}

IN these islands the rainfall is everywhere sufficient to maintain woods below a certain altitude (varying from 1,500 to 2,000 feet in different parts of the country). Only on moors and in bogs, where the cold, sour, unaerated peat is unfavourable to tree-growth, are woods impossible. Yet even here on the borders where the moor merges into the wood, one is ever advancing upon the other. It seems certain that many of our upland moors were onco wooded, but as the peat accumulated the woods wero gradually submerged by the moor ; in fact, remains of birch and pine have been discovered in peat far above the present limits of tree-growth (see p. 249). In other places where the moor becomes drier and air permeates the soil, trees gain upon the moor, following in the track of the invading ling and heath.

Woods are of two kinds- $(a)$ deciduous, $(b)$ evergreen. Evergreen trees are xerophytic, their leaves being retained during the winter, but evergreen woods are very poorly represented in our flora, and these have always been planted, except some of the pine-woods of Scotland.

\section{DECIDUOUS WOODS.}

Deciduous trees shed their leaves at the commencement of the cold season, and are leafless xerophytes in winter (see p. 60). The soil is generally rich in humus, well aerated, and well supplied with earthworms, soil-bacteria, and fungi. As soon as the humus so accumulates that it becomes sour, the earthworms and soil-bacteria disappear, and the wood is in danger of perishing and giving way to moor or heath. Our native forest-trees are few in number, and of these very few indeed are ever dominant (oak, beech, ash, birch). 
The undergrowth present depends upon :

1. The amount of light coming from above. \$some trees intercept much light and cast a deep shadee.g., beech and sycamore-and under these the vegetation is scanty or absent; others allow a considerable amount of light to penetrate through their loose crowns-e.g., oak, ash, birch-and this supports a rich and varied flora, both bushes and herbs. This is well seen in the accompanying maps (Figs. 111, 112), taken from Woodhead's paper on The Ecology of Woodland Plants, which show clearly that the distribution of the bracken is determined solely by the amount of light present, the soil varying in different parts of the wood from a stiff clay to a light sand.

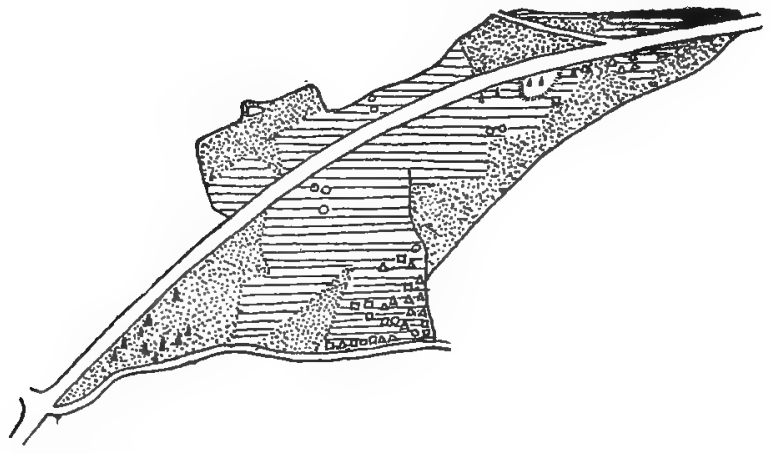

Fia. 111.-Map of a Wood, showing Distribution of Trees. (After WOODHEAD.)

shade-trees, Acer,
Ulmus, Fagus.

$=[$ Ulmus montana. $\Delta \Delta$ Acer Pseudoplatanus. A conifers.

2. The nature of the soil, the presence of mild or sour humus, and the amount of water present. The soil-factor usually determines the kind of plant which is found, and the light-factor decides its abundance.

The herbaceous or ground-vegetation in woods consists chiefly of shade-plants, their stems being tall or elongated, and their leaves often large. They are nearly all perennials, hibernating by rhizomes, tubers, or bulbs; annuals are rare. In the humus of moist, shady woods a few colourless saprophytes grow (Neottia, Monotropa), but epi- 
phytes, apart from a few ferns (e.g., Polypodium vulgare), mosses, liverworts, and lichens, are mostly accidental. Lianes, or woody climbers, which form such a characteristic feature of tropical forests, are merely represented in our woods by the honeysuckle, ivy, and clematis. Many of our forest-trees, living in soil rich in humus, are partial saprophytes, their roots being clothed with a mycorhizal fungus instead of root-hairs (see p. 124).

\section{Natural and Artificial Woods.}

These islands were once far more extensively wooded than they are now, although it is still a well-wooded country. Most of the huge forests which once covered

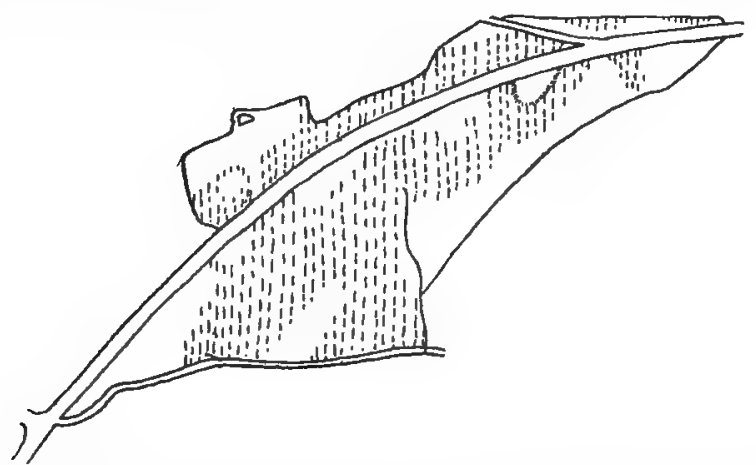

Fig. 112.-The Same Woon as in Fig. 111, showing Distribution of

Bracken. (AfTter WoOdhead.)

1:1'1

lilil Pteris aquilina (bracken).

the land have been cut down for economic purposes, or cleared to make way for cultivation and pasture. Much of what remains has been seriously interfered with and modified by man, by periodic cutting and replanting, and in many places new woods have been planted on arable land and pasture. Artificial woods are not always easy to distinguish from natural woods, especially when they are old-established, and felled portions have been replanted with trees native to the soil and common to the district. Natural woods regenerate themselves by seed, and in them trees are seen in all stages of development; 
seedlings, saplings, and great aged individuals are all mixed together, competing freely with one another for room and light. In plantations it is different; many, if not all, of the trees are of the same age; aliens are common - e.g., chestnuts, sycamores, elms, and firs-and trees not common to the district or soil-e.g., pine in most parts of the country, and the beech in the west; and if the plantation is recent the ground-vegetation is not typically woodland at all. In the course of time, however, these outof-place inhabitants of the undergrowth disappear, and true woodland forms take their place.

\section{Copses.}

Cutting or coppicing also modifies woods, and most of our woods are cut periodically, either gradually or en masse. In woods trees are generally felled ono here and one there, and new saplings put in their place. In copses, on the other hand, the whole wood is poriodically cut down, and then allowed to regenerate itself from the boles left in the ground. In the latter case the shade of the wood is banished, and with it most of the shadeloving woodland plants. Sun-loving forms come in from the adjacent pastures and heaths, and maintain their position until a new wood springs up from the ruins of the old, and increasing shade drives them out.

From what we have said, it is clear that although natural woods are not common in this country, many artificial woods--especially those which have been derived from ancient ones, or old plantations of native trees, and even coppiced woods before the trees are cut-stand very near natural woods, and give us a good idea of what the primitive woodland-vegetation of these islands was like.

\section{Thickets.}

In rough, uncultivated, and especially hilly places, and on the rocky sides of river-valleys, bushes and shrubs become more abundant than trees. In these places the soil is very shallow, and tree-growth is often dwarfed or stopped altogether. The most abundant bush in this country is the hazel, which in former times was extensively planted in woods for economic purposes, especially among oaks and ashes, which were periodically coppiced. 
The scar-woods of the limestone-dales of the Pennines are hazel-thickets, with ash as an occasional or frequent associate. Mountain-ash, hawthorn, holly, sloe, buckthorn, dogwood, elder, wayfaring-tree, and privet also occur, the first three being the most common. Plenty of light penetrates to the soil, and the ground-vegetation is rich and varied. Many plants of the limestone-cliff are present (see p. 290), as well as shade-loving forms. The latter include Sanicula europcea (wood-sanicle), Asperula odorata (sweet woodruff), Lathrcea squamaria (toothwort), Mercurialis perennis (dog's-mercury), Paris quadrifolia (herb-paris), Scilla nutans (wild-hyacinth), and several very rare plants-e.g., Polemonium caruleum (Jacob'sladder), Cypripedium Calceolus (lady's-slipper orchid, now almost extinct), Polygonatum officinale (Solomon's-seal), and Convallaria majalis (lily-of-the-valley).

The following classification of deciduous woods is that adopted by Moss, Rankin, and Tansley.*

\section{A. The Alder-Willow Series.}

Dominant trees: Alnus glutinosa, Salix cinerea, and S. Caprea. Found in very wet places, by marshes, streams, and in fens (see p. 243).

\section{B. Woods on Non-Calcareous Soils.}

I. Oak-Woods-(a) Lowland Type.-The damp oakwood occurs on clays, loams, moist sands and gravels, and clay-with-flints (covering large parts of the chalkdowns of south-eastern England), up to about 600 foet. It is most common in valleys and on alluvial plains rich in humus. The trees are more luxuriant than on the uplands, and they cast a deeper shade. The herbaceous ground-vegetation consists, therefore, either of shade-plants or early flowering perennials, which bloom before the trees are laden with foliage. Although the oak is dominant, many other trees are present, and in some places compete with the oak for dominance-e.g., ash, birch, hornbeam. The ash is typically a tree of the limestone, but it is common in damp lowlands as well, especially on

* "Tho Woodlands of England," New Phytologist, vol. ix., 1910, p. 113. 
deep marly soils. The birch is also common in the lowlands, but in the uplands it beats all trees, and ultimately entirely supplants the oak, ash, and beech at the higher altitudes of tree-growth on all kinds of soils. From the great admixture of other trees competing with the oak for dominance, these woods are often called mixed deciduous woods. The hazel is the most common shrub of the undergrowth, and in woods periodically cut oakhazel coppices are formed.

Vegetation of the Damp Oak-Wood-1. Trees.-Quercus Robur ( = pedunculata, with stalked acorns) is the dominant tree on deep soils, $Q$. sessiliflora (with sessile acorns) on shallow soils; ash, birch, beech, hornbeam; and of trees commonly planted-sweet chestnut, sycamore, poplars, lime, and elm.

2. Shrubs.-Hazel (most abundant), maple, sloe, hawthorn, elder, bramble, wild rose, honeysuckle, sallowwillow (Salix Caprea), holly, dogwood, and guelder-rose.

3. Herbaceous Undergrowth.-Anemone nemorosa, Primula vulgaris, Scilla nutans (on loose soils), Mercurialis perennis, Ranunculus Ficaria, Euphorbia amygdaloides (wood-spurge), Stellaria Holostea (greater stitchwort), Oxalis Acetosella, Viola sylvatica, Sanicula europoea, Geranium Robertianum, Epilobium montanum, Lamium Galeobdolon, Lysimachia nemorum (yellow pimpernel), Nepeta Glechoma, Lychnis dioica, Ajuga reptans, Prunella vulgaris; woodland-grasses: Milium effusum, Bromus giganteus, Brachypodium sylvaticum, Melica uniflora, etc.; ferns: Aspidium Filix-mas, Athyrium Filix-fomina, and in light soils Pteris aquilina.

(b) Upland Type.-A dry oak-wood is found on dry, non-calcareous soils at an altitude of 500 to 1,000 feet. The wood is more open than on the lowlands, and this favours a thick shrubby undergrowth and a luxuriant ground-vegetation. But this diminishes as the soil becomes drier and the altitude increases. The soil is deficient in humus, and the undergrowth includes a small proportion of heath-plants (ling, gorse, bracken, etc.) exhibiting xerophytic characters. As the altitude increases birches gradually succeed in dominating the oak, and at about 1,000 feet the oaks disappear altogether, while the birches continue up to the limit of tree-growth (1,500 feet in England). The ash is absent, and likewise 
the hazel, sallow-willow, dogwood, and guelder-rose, heath-shrubs taking their place. Characteristic plants are, in addition to those mentioned : Holly, Scilla nutans, Teucrium Scorodonia, brambles, wild rose, Potentilla Tormentilla, Rumex Acetosella, Anemone, Digitalis purpurea, Galium saxatile, Solidago Virgaurea, Hieracium species, the typical heath grass Aira flexuosa, and Holcus mollis.

II. Oak-Birch-Heath Association. - On dry, coarse, sandy soils or dry peaty soils in the lowlands, the birch and heath-plants which we found were present in the dry oak-wood become so numerous as to constitute a distinct association. This type is common round London on the dry beaths and commons--e.g., Bostall Heath and Keston Common. Silver birches are abundant, but the woods are very open, long stretches of ground being covered with grass (Aira flexuosa chiefly) or shrubs (ling, gorse, whortleberry, honeysuckle, and bramble). The characteristic shrubs and small trees are holly, mountainash, hawthorn, blackthorn, alder-buckthorn (Rhamnus Frangula), juniper, and white beam. Herbs characteristic of dry ground are common-e.g., Teucrium Scorodonia, Galium saxatile, and Potentilla Tormentilla.

This association is generally regarded as a stage in the degeneration of oak-wood into heath, brought about by a gradual increase in the dryness of the soil. The next stage in its deterioration is seen in the rough common dominated by bracken, gorse, and bramble, described in Chapter XXX.

III. Birch-Wood.-At high altitudes (above 1,000 feet) the dry oak-wood changes into a birch-wood, and thcre seems no doubt that the change is due entirely to climatic conditions. The oak cannot grow at these high levels, and the birch, freed from competition, becomes the dominant tree. The undergrowth is much the same as in the oak-birch-heath association, but mosses are very abundant. In the north of England, and more especially in Scotland, many of the plants characteristic of pinewoods (p. 274) are found in the birch-wood. 


\section{Woods on Calcareous Soils}

(e.g., chalk, limestone, marls, and other soils rich in lime).

I. Ash-Oakwood Association.-On deep calcareous clay a wood intermediate between the damp oak-wood and the ash-wood is found in many parts. The oak and ash share dominance. and the ground-vegetation is very similar to the damp oak-wood, but the wayfaring-tree, spindle-tree, and clematis are common here, yet rare in the oak-wood. The dogwood, privet, maple, sloe, and hawthorn also are far more abundant in this type of wood. Of the herbaceous undergrowth, the following are characteristic: Paris quadrifolia, Colchicum autumnale, Iris foetidissima, Epipactis media, E. purpurata, and Campanula Trachelium.

II. Ash-Woods.-These are the typical woods on limestone, where the soil is dry and poor in humus. The ash does not cast much shade, and the undergrowth is consequently rich and varied. The most frequent trees other than ash are the wych-elm (Ulmus montana) and hawthorn. Many lime-loving species are present-e.g., white beam (Pyrus Aria), wayfaring-tree, yew, Inula Conyza, Scabiosa Columbaria, Carduus eriophorus (woolly-headed thistle), Origanum vulgare, etc. Heath-plants are absent, except where the limestone is covered with glacial clay or marl from which the lime has been washed out.

This type of wood gradually merges into the ashoakwood at low altitudes, as the soil becomes damper, and at high altitudes birches replace the ash.

III. Beech-Woods. - The beech-wood is confined almost entirely to the chalk of South-East England, where it occurs as a zone on the borders of the damp oalk-wood which covers the clay-with-flints on the top of the Downs. It also occurs to the west of England on the oolitic limestone of the Cotswold Hills. The branches of the beech are placed horizontally, and the leaves being situated in one plane, cast a very deep shade, which prevents the development of all undergrowth except a few mosses-e.g., Leucobryum. Every autumn the ground receives an enormous harvest of falling leaves, and as these decay slowly they form another unfavourable factor for the production of ground-vegetation. The trees and shrubs present in the 
more open parts and on the outskirts of the wood are those of the ash-wood-e.g., hawthorn, white beam, wayfaring-tree, buckthorn, spindle-tree, dogwood, sloe, hazel, maple, elder, juniper, and yew. The herbaceous undergrowth includes, in the more open parts, wood-sanicle, wood - violet, dog's - mercury, enchanter's - nightshade, Helleborus viridis, and in the deepest shade the orchid Cephalanthera pallens, and the colourless saprophytes Neottia Nidus-avis and Monotropa Hypopitys. Also growing in the more shady parts are Daphne Laureola (spurgelaurel), Ruscus aculeatus (butcher's-broom), Atropa Belladonna (deadly nightshade), and Bunium flexuosum (pignut).

The relationship between the various deciduous woods is shown in the following diagram :

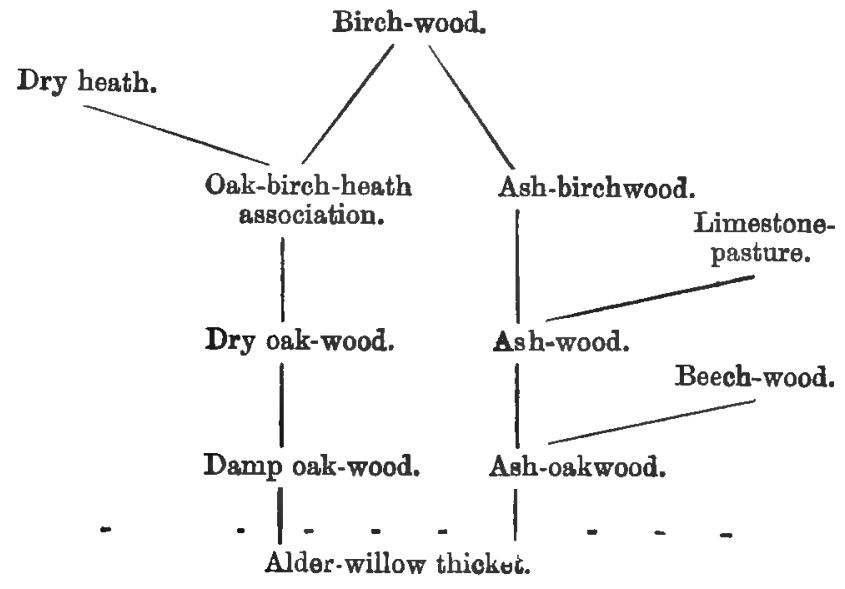

\section{EVERGREEN WOODS.}

The trees which constitute the evergreen wood in this country are Conifers (pines and firs), and it will be convenient to include with them another Conifer-the larchwhich is deciduous.

The pine, the most common of the Conifers, is a most accommodating tree in regard to its soil requirements. It will grow in any situation which is dry, whether physi. cally or physiologically. For this reason pine-woods and plantations are found on sandy plains at low altitudes, 
partially-drained peat-bogs, dry rocky crags and slopes along mountain valleys, and on heather-moors at high altitudes $(1,500$ to 2,000 feet). In most cases the pinewoods are artificial, but natural pine-woods occur in the Highlands of Scotland. The tree had a much wider range in former times, for remains have been found in the peat of the Pennines at an altitude of 2,400 feet, although at the present time the upper limit in that district is but 1,750 feet.

The spruce, Douglas-fir, and larch, which are frequently planted, reach higher levels than the pine. In the Pennines they occur up to an altitude of 2,015 feet. Above 1,800 feet the plants become dwarfed, and at the upper limits the spruce assumes a dense shrubby habit, 2 to 3 feet high, and often forming a low mat close to the ground. In Forfar a larch-wood extends up to 2,500 feet.

The pine produces as much shade as the beech when growing in close canopy, and this dense shade affects the plant itself as well as the undergrowth. The lower branches die away, leaving a long straight stem crowned by a mass of foliage. On the edge of the wood the branches persist right to the ground. Where the shade is most dense only a few mosses occur, and occasionally Monotropa Hypopitys. As in the beech-wood, the ground is covered with a thick layer of slowly decaying leaves, which likewise prevents the undergrowth from developing. In more open parts the chief woody plants are an occasional mountain-ash and birch, and invaders from the neighbouring heath-e.g., ling, whortleberry, and blackberry. Common herbs are Potentilla Tormentilla, Galium saxatile, Veronica Chamodrys, and Oxalis Acetosella.

A number of plants are found in the primitive woods or ancient plantations in Scotland and North England, and in many cases the relative age of a plantation can be determined by their presence or abundance. These plants include: Linncea borealis, Pyrola minor, $P$. media, $P$. rotundifolia, $P$. secunda, and $P$. uniflora (wintergreens), Trientalis europcea (chickweed winter-green), Listera cordata (small twayblade), and the colourless saprophyte Corallorhiza innata (coral-root orchid). 


\section{CHAPTER $\cdot$ XXVIII}

\section{MARITIME ASSOCIATIONS}

ON the seashore and the margin of estuaries the soil varies considerably; it may be sandy, shingly, rocky, or muddy, and the vegetation exhibits a corresponding diversity. The flora of a mud-bank is quite distinct from that of a sand-dune, and this in turn differs from the flora of rocks and cliffs. In all cases the land-plants are typical xerophytes, but the xerophytic character may be due to a variety of causes. It may be an adaptation to physiological dryness, as in the plants of a mud-bank where the water is strongly saline; to physical dryness, as in sand-dune plants where the soil contains very little water; or to the action of strong drying winds, as in those of cliffs. In this chapter, then, a number of distinct formations will be described. They are brought together merely for convenience, and not necessarily because they are related ecologically.

As is the case with other plants, the maritime plants group themselves naturally in two divisions-the aquatic vegetation and the terrestrial.

\section{Maritime Aquatic Vegetation.}

On the open spashore and in estuaries, where the water-level is altr ing with each tide, the aquatic vegetation is almost restricted to one group of plants-the seaweeds, or algæ. The absence of other plants is due chiefly to the difficulty of bringing about fertilization. The periodic rising and falling of the water makes it necessary that fertilization should be effected under water. Aerial flowering stems would be of no use, for the flowers are submerged at high tide and ordinary pollen destroyed; 
even if the flowers could adjust themselves to different levels, the waves and surf would keep them perpetually wet. The pollen-grains of a marine aquatic, therefore, must either be adapted for dispersal under water or the flowers must be cleistogamic (p. 165). At the same time the plant has to adjust its absorbing structures to suit the salt water. The only genus of British flowering plants which has succeeded in adapting itself to this mode of life is Zostera (grass-wrack), of which two species have been found in this country-Z. marina and $Z$. nana. They occur all round the coast in muddy estuaries of rivers, often growing where they are left uncovered by the receding tide. The pollen-grains are thread-like, and have the same specific gravity as sea-water, so they can float at any depth in the water, and be carried to the large stigmas. The plant is rooted in the mud, and its long, narrow, strap-shaped leaves offer little resistance to currents.

The reproductive cells of the algæ, on the other hand, are always adapted for life under water. They possess, as a rule, small hair-like structures, which by their movement propel the cells through the water.

In the brackish water which collects in ditches on saltmarshes the following aquatic flowering plants are found: Ruppia maritima (vassled pondweed), which has pollen very similar to Zostera ; Zannichellia pedunculata ; and a form of the water-crowfoot, Ranunculus Baudotii.

Seaweeds can only grow in abundance on a rocky coast. They are attached to the substratum by a small flat dise, and if a plant became fixed to loose sand or mud the first wave which came along would wash away plant and sand together. Almost the only exception to this is Chorda filum, which possesses a very long, thin, cord-like frond, the lower part of which may become embedded sufficiently deep in sand or mud to prevent the plant from being torn away.

We have seen in Chapter V.,p. 53, that the depth at which seaweeds grow is dependent on the presence of colouring matter in their fronds-the red seaweeds growing in deep water, the brown in shallower water, and the green ones quite near the surface. The brown seaweed is usually the dominant form, and these exhibit a zoning amongst themselves. The depth at which they grow depends on a 
number of factors, the chief of which are: their power of resisting desiccation both during their germination and vegetative growth ; their rate of growth, the more quicklygrowing plants forcing others to retire to higher levels; and on considerations connected with their reproduction.

In the deeper water, never exposed to the air even at the lowest spring-tides, Laminarias are dominant. Above this may be a zone of Halidrys siliquosa, only exposed for a short time at low water during spring-tides ; then one of Fucus serratus, uncovered at low water, but during neaptides for a short time only; higher still are zones of Fucus vesiculosus and Ascophyllum nodosum, exposed for longer periods; and then Fucus platycarpus, only covered by the highest tides. The spray-washed rocks, seldom submerged at all, are covered with the xerophytic fronds of Pelvetia caniculata. In this situation the plant is exposed to drying winds and the heat of the sun throughout the day, and excessive evaporation of water is prevented by the presence of a hard, thick, external layer almost impermeable to water.

\section{Maritime Terrestrial Vegetation.}

The associations of terrestrial maritime plants may be grouped according to the nature of the soil and elevation above sea-level as follows:

1. Muddy banks of estuaries, salt-marshes, etc.

2. Sandy seashore.

3. Pebbly seashore and shingle.

4. Rocks and cliffs.

5. Exposed slopes facing the sea.

The associations-with the exception of those of the last group, which are usually pasture-associations-are of an open type ; competition is not keen, and almost every plant, adapted by its structure for life in such surroundings, has a chance of surviving. One association is often rapidly replaced by another, as on sand-dunes, and changes in the distribution of the plants are always going on. As in other open associations, annuals are very abundant, both in individuals and species, and in some cases constitute the sole flora-e.g., Saticornia herbacea and strand-associations. 
1. Flora of Mud-Flats and Salt-Marshes.-On the muddy margins of estuaries, and in low-lying ground liable to periodic floods from the sea, the soil is saturated with saltwater, and the plants are typical halophytes, with fleshy leaves or stems (p. 88).

Usually submerged in the water of the estuary is a zone of Zostera, and above this, on the flat reaches, wholly

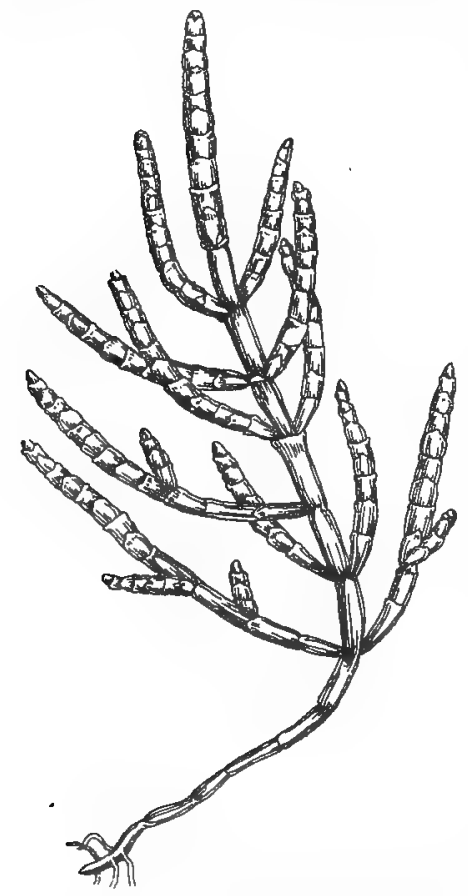

FIG. 113.-Salicornia herbacea (ANNUAL GLASSWORT). (AITER SOWERBY.) colonize the ground. The earliest of these new-comers are Glyceria maritima and Triglochin maritimum, which sometimes form a distinct zone above the Salicornia.

Out of reach of the highest tides the general salt-marsh flora develops. The vegetation is frequently of two types. In the wetter parts a salt reed-swamp develops, characterized by monocotyledons with erect, narrow leaves, 
and constituting an edaphic modification of the ordinary reed-swamp. The dominant plants are Juncus Gerardi, Scirpus maritimus, Glyceria maritima, and in some parts Phragmites communis also. Where the soil is drier the plants are not so tall-growing as in the reed-swamp; this type may be called a salt-meadow.

Characteristic salt-marsh plants are: Aster Tripolium (sea-aster), Statice Limonium (sea-lavender), Armeria maritima (thrift), Plantago maritima (sea-plantain), Salicornia herbacea, Spergularia salina (sea-spurrey), Sueda maritima (sea-blite), Atriplex portulacoides (sea-purslane), Artemisia maritima (sea-wormwood), Beta maritima (sea-beet), Triglochin maritimum (seaside arrow-grass), Cochlearia officinalis, C. anglica, and $C$. danica (scurvy-grasses), Glaux maritima (sea-milkwort), Atriplex littoralis (grassleaved orach), Scirpus triqueter, S. rufus, Hordeum maritimum (sea-barley).

2. Flora of Sandy Shores.-On sandy shores the conditions are quite different from the salt-marsh. Except within reach of the tides, the amount of salt present in the soil-water is comparatively small. The porous soil allows rain to drain away very rapidly, and the plants are subjected to long periods of drought. The xerophytic character of the plant, therefore, is not due to physiological dryness, but to physical. Yet the adaptations are the same in both cases-succulent plants are as common here as in the marsh; indeed, some are found in both situations 一e.g., thrift, scurvy-grass, sea-plantain, and beet.

Where strong winds prevail in a direction at right angles to the coast the sand is blown inland, and accumulates in long sand-hills or dunes running parallel to the shore. Unless the dune is completely covered with vegetationand this is rarely so-the sand is carried still farther inland, and a second or even third line of dunes arises on the landward side. The flora of the dune varies according to the compactness of the sand, and to some extent according to its chemical composition. Most of the sand consists of quartz-particles, and the soil is consequently very sterile, but when the remains of marine shells are present the soil is richer, and many calciphilous plants occur.

On the sand immediately above the mean high-water mark, and only covered at very high tides, a narrow zone of strand-vegetation occurs. The water within reach of 
the plants is heavily laden with salt, and they are therefore halophytes. The most frequent plants are low-growing annuals, which have no power of growing upwards when covered with sand, and this zone is consequently absent where the sand is advancing on the sea. Perennials are very rare, and occur sporadically, for the plants may be uprooted during storms, and only those which produce a large quantity of seed each year, as in annuals, can persist. The most common member of this association is Cakile maritima (sea-rocket), a fleshy-leaved plant belonging to the Wallflower-family. Several plants belonging to the Chenopod-family usually occur-e.g., Salsola Kali (saltwort), with short prickly leaves, Atriplex patula, $A$.

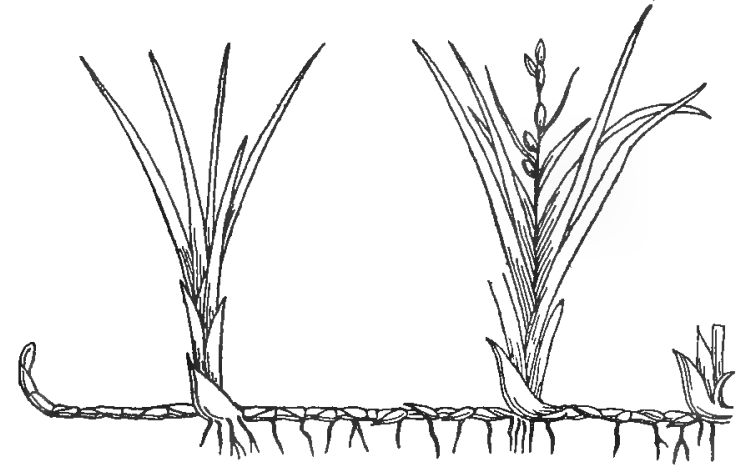

F1G. 114.-Carex arenaria, wITH RHIzome near Surface of SAND

hastata, A. Babingtonii (oraches), Chenopodium rubrum, and C. album (goosefoots). Arenaria peploides (sea-purslane) is the only perennial which is found at all constantly in this zone, and then only very sparingly.

Above the strand-vegetation the sand is usually loose. The first plant to colonize this drifting sand is Agropyron junceum (sea couch-grass); which possesses long underground rhizomes bearing tufts of leaves at intervals. The sand is held at the base of the leaves, and as it increases in amount so the leaves grow upwards, and retain yet more sand. In this way a low embryonic dune is built up. Carex arenaria (Fig. 114), a plant of similar habit to the sea couch-grass, is sometimes associated with that grass in forming these dunes. When the sand has been 
consolidated to some extent, other plants colonize the ground. Chief among these are Arenaria peploides, Eryngium maritimum (sea-holly), Glaucium luteum (horned poppy), Euphorbia Paralias, Cakile maritima, Convolvulus Soldanella (sea-convolvulus), and various species of Atriplex. Psamma arenaria (marram-grass) occurs sparingly in this zone, but once it gets a footing the sand collects very rapidly, for the grass is very quick-growing, and the incipient dune is converted into a high one. The Agropyron disappears, for it cannot keep pace with the growing dune.

Shifting Dunes.-The first line of high dunes is very characteristic in appearance. The seaward side is bare of vegetation, and rises at a sharp angle to the crest, where Psamma is abundant, and then slopes more gradually down on the landward side. The sand is being continually blown along, and for this reason the dunes are often called "shifting dunes." The term white dune is also used, referring to the fact that so much bare sand is exposed. The binding power of Psamma is much greater than the plants of the embryonic dune, and for this reason it is often planted in places where it does not grow naturally, in order to prevent the dunes from travelling inland. It is also frequently planted on sand-bunkers on golf-links.

The plants of the shifting dune are subjected to a number of factors which increase transpiration. The wind is strong, the light very intense, and the white sand reflects nearly all the heat of the sun, rendering the air extremely hot and dry. The surface-layer of sand is heated rapidly, and the water quickly driven off, so that both in regard to the soil and the air above it the dune is a true desert. Yet beneath this dry layer there may be an abundance of water, as is shown by the presence of freshwater marshes in many of the hollows. The adaptations to these xerophytic conditions take the form of erect cylindrical rolled leaves (Fig. 11), as in all the grasses except the lyme-grass ; the development of a surface-coating of wax, as in the latter plant, sea-holly, and horned poppy; succulent leaves, as in most of the plants other than grasses; the formation of thorns or spines, as in restharrow and sea-buckthorn; and in all cases the presence of very long roots which can explore the moister soil 
Missing Page 
Missing Page 
during storms may be washed with spray approximates very closely to that of a salt-marsh. Indeed, many plants are common to both. As in the salt-marsh, succulence is a very common character. The plants usually grow on ledges where the soil is thin and water scarce, whilst the light is often as intense and the exposure as great as on a sand-dune.

The most frequent plants met with in this situation are: Crithmum maritimum (samphire), Inula crithmoides (golden samphire), Statice auriculcefolia (sea-lavender), Armeria maritima (sea-pink, thrift), Plantago maritima, $P$. Coronopus, Cochlearia danica, Sagina maritima (seaspurrey), Spergularia rupestris, Sedum anglicum, and Asplenium marinum (sea-spleenwort). Of rarer plants, Cotoneaster vulgaris grows only on Great Orme's Head, Preonia corallina on Steep Holme off the coast of Somerset, Matthiola incana (sea-stock) in the Isle of Wight and at Ramsgate, Brassica oleracea (the wild type from which the cabbage, cauliflower, broccoli, kale, etc., have been derived) in a few places on the south coast of England, Lavatera arborea (tree-mallow) chiefly on the south and west coasts of England and Ireland, Ligusticum scoticum (lovage) confined to the coast of Scotland, North-East England, and North Ireland.

5. Exposed Slopes facing the Sea.-On the wind-swept cliff-tops and slopes facing the sea the vegetation is greatly affected by the strong drying winds. Pastureland usually covers the slopes, but the grasses are dwarfed and seldom flower. Any plant which rises above the level of the grass is cut down by the wind and destroyed. Consequently the plants which do persist must be as short as the grass. Plants which are 1 to 3 feet high in sheltered spots are reduced to 1 or 2 inches, or even less, on the wind-swept slopes. The flowers are not altered conspicuously in size, but they are considerably reduced in number. and hidden on minute stalks in a little nest of leaves. On the more exposed parts of Beachy Head the following plants are thus dwarfed, the figures in brackets indicating the height of the plants in more favourable situations : Phyteuma orbiculare (4 to 18 inches), Erythrcea Centaurium (6 to 18 inches), Scabiosa Columbaria (1 to 2 feet), Echium vulgare (1 to 3 feet), Centaurea nigra ( $\frac{1}{2}$ to 3 feet), Carduus acaulis (3 to 12 inches), Eicphrasia 
officinalis (1 to 12 inches). Anthyllis Vulneraria, Lotus corniculatus and Thymus Serpyllum are prostrate plants which never rise from the soil.

In many parts of western Ireland a similar type of vegetation is produced, but the dominant plants are not grasses, but plantains-e.g., Plantago maritima and $P$. Coronopus.

Where the ground slopes down nearer the sea the plants are liable to be covered with spray in the time of storm, and here many of the plants of exposed rock intermingle with those of the pasture. The latter invariably possess leaves much more succulent than when they grow inland. The following selected list of plants found on exposed slopes on the west coast of Cornwall is typical of such situations :

Maritime Species : Inula crithmoides, Statice auriculaefolia, Armeria maritima, Plantago maritima, Cochlearia danica, Spergularia rupestris, Euphorbia portlandica.

Inland Species: Anthyllis Vulneraria, Lotus corniculatus, Centaurea Scabiosa, Erythroea Centaurium, Hieracium species, Leontodon species, Polygala vulgaris, Thymus Serpyllum, Potentilla Tormentilla, Daucus Carota, Calluna vulgaris, Erica cinerea, and Ulex europous; the last three very dwarf.

Geranium sanguineum (bloody crane's-bill) is almost confined to these exposed slopes on calcareous soil. 


\title{
CHAPTER XXIX
}

\author{
VEGETATION OF ROCKS AND WALLS
}

\section{Alpine Rocks.}

THE alpine zone in this country extends from the limit of tree-growth (usually about 2,000 feet) to the summits of the highest mountains. It is on the sheltered rock-ledges in this region that the typical alpine plant, whose charactors have been described in Chapter IV., reaches its greatest development. Some are restricted to this zone, and all have their headquarters here. In the west of Ireland, however, their distribution is different: somee.g., the mountain-avens (Dryas octopetala), rose-root (Sedum Rhodiola), and yellow mountain-saxifrage (Saxifraga aizoides)-grow on rocks at the sea-level, whilst others never reach the 2,000-feet line. It is very difficult to understand why this should be so, for the climate is milder and more humid than any other part of the British Isles. The strong winds and gales which prevail for the greater part of the year, however, prevent the growth of many lowland forms, and alpines, naturally adapted by their tufted or rosette habit for an environment similar to this, might live there froe from competition. Although this may account for their presence at sea-level, it sheds no light on their absence from the higher zones, for competition does not drive the alpine up a mountain-side; it merely restricts its distribution to the higher levels.

Alpine plants occur in all situations - in exposed, windswept places, on the dry upper slopes (pp. 255, 259), and on wet peaty soil (p. 253)-but all the plants of these habitats, except those of the wettest bogs, grow also on rocky ledges and clefts. Here the surface-soil is very thin, but the cracks and crevices are filled with soil, and into this 286 
the plants send their exceptionally long roots in search of food and water. The rainfall is heavy on the mountaintop, and out of reach of the wind the plants suffer little from lack of water. But they are subjected to intense cold during the night and brilliant illumination in the daytime, whilst the air is rarefied. The first factor hinders absorption, and the others favour transpiration, so the plants are typical xerophytes, with rosettes of leaves or cushion-habit. Geophytes are very rare, owing to the absence of sufficient soil in which the plants could hibernate, whilst the short vegetative period prevents the establishment of most annuals. Indeed, there is no true alpine annual in this country, although lowland forms may exist at the highest levels-e.g., Euphrasia officinalis and Poa annua, at 3,980 feet in Perthshire. Many alpines are found in the neighbourhood of alpine streams and rills. Here plenty of water is available at all times, but the climatic factors mentioned above are as evident as on the rock-ledges, and the habit of the plants is the same.

Some of the rarest British plants, last survivors of an arctic climate (see p. 210), are found at high altitudes. The Highlands of Scotland are specially noteworthy in this respect. The following plants are found in a few localities only in Scotland: Arabis alpina (Skye), Draba rupestris (Ben Lawers, Perthshire, 3,000 to 3,980 feet), Arenaria rubella (Perth, 2,700 to 3,800), Sagina nivalis (Perth, 3,100 to 3,900), S. Boydii (Braemar), Astragalus alpinus, Oxytropis campestris (Perth), Saxifraga cernua (Ben Lawers, 3,800), S. rivularis (Ben Nevis, Ben Lawers, Cairn Gorm, etc., 3,500 to 3,900), Erigeron alpinum (Perth, 2,500 to 3,500), Gnaphalium norvegicum (Perth, Forfar, and Aberdeen), Lactuca alpina (Aberdeen), Menziesia ccerulea (Perth, 2,350 to 2,460), Gentiana nivalis (Perth, 2,400 to 3,450), Myosotis pyrenaica (Perth, 2,400 to 3,450), Veronica fruticans (Perth, 1,200 to 3,600); dwarf species of willow, $\frac{1}{2}$ to 2 feet high-Salix Arbuscula and S. lanata (Perth); Luzula arcuata (summits of several mountains-e.g., 4,290, Ben Macdhui, Aberdeen), Juncus biglumis, Carex alpina, C. rupestris, C. atrofusca (Perth, 2,600), Alopecurus alpinus, Phleum alpinum, Poa laxa. Other alpines confined to Scotland, but more widely spread than the foregoing, are: Cherleria sedoides, Sagina 
Linnoi, Oxytropis uralensis, Gnaphalium supinum, Veronica alpina, Juncus trifidus, Carex vaginata, Salix Myrsinites, S. reticulata, Athyrium alpestre, Azalea procumbens, Arctostaphylos alpina, Betula nana (1 to 2 feet high).

Only one alpine is confined to south Britain-Lloydia serotina-found in one or two places on the Snowdon range.

Many species of Saxifraga are found on the mountains of west or south-west Ireland, and nowhere else in the British Isles. Of these S. umbrosa (London-pride), widely scattered, and S. Geum, confined to Kerry and Cork, are members of the Lusitanian flora (see p. 213) ; S. hirsuta is found only in Kerry and Cork, S. elegans only in Kerry ; S. decipiens extends from western Ireland to western Scotland and north Wales; $\boldsymbol{S}$. cospitosa occurs very rarely in Kerry, Carnarvonshire, Westmorland, and Aberdeen. Arenaria ciliata has its only British station in the Ben Bulben range, west Ireland.

Other alpines found more or less abundantly in most mountainous districts throughout the British Isles are: Thalictrum alpinum, Draba incana, Cochlearia alpina, Thlaspi alpestre (not in Ireland), Silene acaulis, Cerastium alpinum (not in Ireland), Arenaria verna, Dryas octopetala, Alchemilla alpina, Saxifraga aizoides (rills), S. oppositifolia, S. hypnoides, S. stellaris (rills), Sedum Rhodiola (the only succulent alpine plant in this country), Antennaria dioica, Saussurea alpina, Polygonum viviparum, Oxyria reniformis, Salix herbacea, Empetrum nigrum, Poa alpina, Juniperus communis var. nana, Asplenium viride, Dryopteris montana, Cystopteris fragilis. Confined to northern Fngland and Scotland are: Potentilla Sibbaldi, Epilobium alsinefolium, E. alpinum, Linnoea borealis, Galium boreale, Salix Lapponum.

An interesting feature of the alpine vegetation is the presence of a number of plants found also on the seashore. Thus, Cochlearia groenlandica, Silene maritima, Armeria maritima, and Plantago maritima are almost as common on damp alpine ledges as on the wind-swept face of a seacliff. In other cases the plant is represented by a variety, and not the type-e.g., Sagina maritima var. alpina. Plants whose home is in the mountain may extend down to the sea-coast-e.g., Draba incana and Oxytropis ura- 
lensis, or a variety of the alpine form-e.g., Arenaria verna var. Gerardi.

Many lowland plants grow in the more sheltered places, even to the summits of the highest mountains. They are often dwarfed, and some-e.g., Poa annua and Frestuca ovina-seldom produce flowers, but multiply vegetatively (see p. 160). The following list, compiled largely from Williams's High Alpine Flora of Britain,* shows the highest range of the plants, usually in the Scottish Highlands :

Viola palustris, 4,000 feet. Galium saxatile, 4,000 feet. Euphrasia officinalis, 3,980 feet. Rumex Acetosa, 3,980 feet. R. Acetosella, 3,980 feet. Ranunculus acris, 3,980 feet. Achillea Millefolium, 3,980 feet. Poa annua, 3,980 feet. Cardamine flexuosa, 3,900 feet. Taraxacum officinale, 3,900 feet. Solidago Virgaurea, 3,900 feet. Campanula rotundifolia, 3,800 feet. Cardamine hirsuta, 3,800 feet. Festuca ovina, 3,770 feet. Thymus Serpyllum, 3,700 feet. Caltha palustris, 3,600 feet. Veronica serpyllifolia, 3,500 feet. Adoxa Moschatellina, 3,500 feet.

\author{
Lychnis dioica, 3,500 feet. \\ Tussilago Farfara, 3,500 feet. \\ Oxalis Acetosella, 3,480 feet. \\ Viola lutea, 3,450 feet. \\ Agrostis canina, 3,400 feet (Carran. \\ tual, Ireland). \\ Chrysosplenium oppositifolia, $\mathbf{3 , 4 0 0}$ \\ feet. \\ Heracleum Sphondylium, $\mathbf{3 , 3 0 0}$ \\ feet. \\ Stellaria uliginosa, 3,300 feet. \\ Potentilla Tormentilla, 3,300 feet. \\ Mercurialis perennis, 3,300 feet. \\ Sagina procumbens, 3,290 feet. \\ Viola Riviniana, 3,000 feet (Car- \\ rantual, Ireland). \\ Lotus corniculatus, 2,800 feet. \\ Anemone nemorosa, 2,750 feet.
}

On dry exposed rocks the only vegetation consists of close-growing lichens and minute mosses ; there is neither sufficient water nor nutriment to support flowering plants. On dry rocky summits, too, vegetation is scarce. Lichens -e.g., Cetraria islandica and species of Cladonia-and the woolly fringe-moss (Rhacomitrium lanuginosum) are usually common. The latter occasionally forms a thin layer of peat in which a few starved and stunted flowering plants become established-e.g., Empetrum, Vaccinium, Lycopodium Selago, Potentilla Sibbaldi, Gnaphalium supinum, Azalea procumbens, Salix herbacea, Juncus trifidus, Carex rigida, Festuca ovina. All except the last three are lowlying plants, which form a mat close to the ground, and so escape the full force of the wind.

* In Annals of Scottish Natural History, 1908-1910. 


\section{Sub-Alpine and Lowland Rocks.}

Below the alpine region exposed rocks and cliffs are frequent, especially in limestone districts. Where the rock is protected from the wind and supplied with plenty of water, shrubs and low trees"are common, in some cases forming thickets or woods, as in the scar-woods of the Pennines. But in exposed situations on vertical cliffs only xerophytic herbs become established. The general habit of the plants is similar to those of alpine rocks, for the environment is much the same. The cold, however, is not so severe, and the plants can grow in drier situations. Owing to this often extreme dryness, succulents-e.g., Sedum-are more abundant, but rosette-plants are still common. Competition is not severe, and many annuals are found, among them several autumn-annuals which flower early in spring, before the hot sun has parched the soil-e.g., Draba verna, Hutchinsia petrcea, Myosotis collina (see p. 107).

On limestone rocks the following plants may occur, in addition to the three annuals mentioned :

Rosette-Plants : Arabis hirsuta, A. stricta, Draba muralis, D. incana, Thlaspi alpestre, Saxifraga tridactylites, Hieracium Pilosella.

Suceulents : Sedum Telephium, S. album, S. acre, $\mathbf{S}$. reflexum, $S$. rupestre, $S$. anglicum.

Other Plants: Thalictrum minus var. calcareum, Helianthemum Chamcecistus, Dianthus coesius (Cheddar-pink, found only in the Cheddar Gorge), Arenaria serpyllifolia, $A$. verna, Geranium sanguineum, G. lucidum, Lactuca muralis, Parietaria officinalis, Festuca ovina, Asplenium Adiantum-nigrum, A. Trichomanes, A. Ruta-muraria, Cystopteris fragilis.

\section{Walls.}

The vegetation of a wall is in many of its features similar to that of ordinary rocks. The substratum is dry, and, as a rule, poor in nutritive material. The extent and variety of its flora will depend on the material of which the wall is composed, whether held together by mud or by mortar, and on its age. A brick wall is first tenanted by minute algæ, lichens, and mosses, which assist in the disintegration of the mortar, and so prepare 
the way for the germination of the seeds of flowering plants. The most common of these are Sedum acre, Sagina procumbens, Saxifraga tridactylites, Poa annua, Asplenium Ruta-muraria, and Cardamine hirsuta, and on old walls where more soil has collected, Parietaria officinalis, Linaria Cymbalaria, Lactuca muralis, Diplotaxis muralis, Epilobium lanceolatum, etc. On the wall-top mosses are abundant, and growing amongst them many annuals and a fow perennials characteristic of dry soilse.g., Capsella Bursa-pastoris, Cerastium vulgatum, $C$. semidecandrum, Erodium cicutarium, Valerianella olitoria, Filago germanica, Myosotis collina, Veronica agrestis, $V$. arvensis, V. serpyllifolia, Thymus Serpyllum, Antirrhinum majus, Cheiranthus cheiri, Arenaria serpyllifolia, Medicago lupulina, Sempervivum tectorum, Hieracium Pilosella, Rumex Acetosella, Centranthus ruber, many small grasses, and very frequently Polypodium vulgare.

The walls which bear the richest flora, however, are those built up of rough blocks of stones held together with mud. These are frequently built in rocky upland districts to separate fields, and represent the hedgerow of the lowlands. These walls become the home of many plants from the surrounding fields, and in addition to those in the preceding list the following are commonly met with : Jasione montana, Cotyledon Umbilicus, Lepidium Smithii, Geranium molle, G. lucidum, Sedum species, Erica cinerea, Calluna vulgaris, Genista pilosa, and many ferns, including Adiantum Capillus-Veneris, Asplenium laneeolatum, A. Adiantum-nigrum, A. Trichomanes, Ceterach officinarum, etc. 


\section{CHAPTER XXX}

\section{HEDAEROWS-CULTIVATED AND WASTE LAND}

WITHIN the area of cultivation the hedgerow forms one of the most striking features of the country. They are artificially made, and where not cleared and trimmed too scrupulously, and not ruined by dust, they form a rich and varied community of the waifs and strays of all kinds of associations. The hedge itself is made of trees and bushes, and at the top of the hedge-bank the soil is dry and shady. The deep shade prevents many plants from becoming established, but those with climbing stems or much-divided leaves are common. The former can reach the light by climbing to the top of the hedge, whilst the finely-cut leaf allows what little light there is to reach all parts of the plant. From the hedge slopes down the bank, which is warm and sunny on the south side if not overhung by trees. The north, shady side harbours a much richer flora than the other, and the plants are taller and more luxuriant. The light strikes the bank obliquely, and prostrate plants or rosette-plants, which place their leaves at right angles to the incident light, are common on the drier side. The effect of the lateral light is seen in the way some of the leaves, especially of seedlings, turn away from hedges (see Heliotropism, p. 68). At the bottom of the bank may run the ditoh, which was formed when the hedge-bank was built up. The flowers there are immigrants from the damp meadow or stragglers from the marsh, and if the ditch is always filled with water a mixed assemblage of aquatios will flourish (see p. 236). Then beyond this, bordering the road, may stretch a rough piece of grass, a place of refuge for outcasts from the pasture, or, if bare spots occur, from the cultivated field. The vegetation of the hedgerow is therefore very 
mixed and varied, and each division must be studied separately.

The influence of man is seen perhaps more in the hedgerow than anywhere else. Not only does the frequent clipping of the bushes and trees affect the vegetation underneath by letting in more light, but the woody plants themselves are affected-e.g., beeches and oaks which are periodically pollarded usually retain their leaves on the branches in a dried state during winter (see p. 109).

The Hedge itself.-The most common trees are: oak, elm, and ash ; horse-chestnut, willow, lime, poplar, hornbeam, pear, and wild plum are frequent; white beam is common on chalk soils.

Of bushes or shrubs, the hawthorn, hazel, elder, maple, and sloe (blackthorn) are most abundant. More or less common species are : privet, cherry-laurel, gorse, pollard beech and oak, dogwood, wayfaring - tree (Viburnum Lantana), and buckthorn (Rhamnus catharticus), the last three especially on chalk soils.

Climbers. - Scramblers : Rose, bramble, cleavers (Galium Aparine), crosswort (G. Cruciata), hedge-bedstraw ( $G$. Mollugo).

Twiners : Honeysuckle, Convolvulus sepium, hop, black bryony (Tamus communis), woody nightshade (Ślanum Dulcamara).

Tendril-climbers : Vetches (Vicia sepium and V.Cracca, leaf-tendrils), yellow meadow-vetchling (Lathyrus protensis, leaf-tendrils), Clematis Vitalba (sensitive petioles), white bryony (Bryonia dioica).

Root-climber: Ivy, attached to tree-trunks, or just as frequently trailing along the ground.

Herbs. - The following list includes most of the commoner hedgerow plants. Where the habitat is not stated, the plant grows equally well in the shade or in the more open parts.

Achillea Millefolium (yarrow, milfoil), dry, open ; divided leaf. Adoxa Moschatellina (moschatel), shade; divided leaf.

Agrimonia Eupatoria (agrimony), dry, open; divided leaf.

Ajuga reptans (bugle), damp, shade.

Alliaria officinalis (Jack-by-the-hedge).

Allium ursinum (ramsons), deep shade.

Arctium Lappa (burdock).

Arenaria trinervia (sandwort), shade; prostrate.

Artemisia vulgaris (mugwort), divided leaf. 
Arum maculatum (cuckoo-pint), shade.

Ballota nigra (black horehound).

Bellis perennis (daisy).

Calamintha Clinopodium (wild basil), dry, shade.

C. officinalis (calamint), dry, shade.

Campanula Trachelium (nettle-leaved bell-flower), shade.

Capsella Bursa-pastoris (shepherd's-purse).

Cardamine hirsuta (hairy bitter-cress), open, dry.

Carduus arvensis (field-thistle), open, dry.

C. lanceolatus (spear-thistle), open, dry.

Caucalis Anthriscus (hedge-parsley), shade; divided leaf.

Cerastium vulgatum (mouse-ear chickweed), open, dry; prostrate.

Chorophyllum sylvestre (wild chervil), shade; divided leaf.

C. temulum (rough chervil), shade; divided leaf.

Chelidonium majus (greater celandine), shade; divided leaf; found

only in neighbourhood of dwellings.

Circca lutetiana (enchanter's-nightshade), shade.

Conium maculatum (hemlock), divided leaf.

Digitalis purpurea (foxglove), shado.

Dipsacus sylvestris (teazle).

Epilobium angustifolium (rose-bay willowherb), damp, shade.

Eupatorium cannabinum (hemp-agrimony), moist; divided leaf.

Fragaria vesca (strawberry), divided leaf.

Geranium molle (dove's-foot crane's-bill), dry ; dissected leaf.

G. Robertianum (herb-Robert), shade; dissected leaf.

G. rotundifolium (round-leaved crane's-bill), dry.

Geum urbanum (avens), moist ; divided leaf.

Helminthia echioides (oxtongue), dry.

Heracleum Sphondylium (hogweed), divided leaf.

Hypericum perforatum (St. John's-wort), dry.

Inula dysenterica (Heabane), wet ditch.

Lamium album (white deadnettle).

$L$. Galeobdolon (yellow deadnettle, archangel), shado.

L. purpureum (red deadnettle).

Lapsana communis (nipplewort), dry.

Lathroa squamaria (toothwort), deep shade; parasitic on roots of hazel, elm, etc.

Linaria vulgaris (toadflax), dry.

Lithospermum officinale (gromwell), dry.

Lychnis alba (white campion), dry.

L. dioica (red campion), shade.

L. Flos-cuculi (ragged Robin), moist.

Malva sylvestris (mallow), dry.

Mercurialis perennis (dog's-mercury), shade.

Nepeta Cataria (catmint), shade.

$N$. Glechoma (ground-ivy), shade ; creeping.

Pastinaca sativa (parsnip), shade; divided leaf.

Plantago lanceolata (ribwort plantain), open, dry.

Potentilla anserina (silverweed), open, dry ; divided leaf.

$P$. Fragariastrum (barren strawberry), divided leaf.

Primula vulgaris (primrose), shade.

Ranunculus acris (acrid buttercup), open ; divided leaf.

$\boldsymbol{R}$. auricomus (goldilocks), shade; divided leaf.

$\boldsymbol{R}$. Ficaria (lesser celandine), wet ditch. 
$\boldsymbol{R}$. repens (creeping buttercup), open; divided leaf.

Rumex crispus (dock), open, dry.

$R$. obtusifolius (broad-leaved dock), open, dry.

Sagina procumbens (pearlwort), open, dry.

Scrophularia nodosa (figwort), damp, shade.

Sedum Telephium (live-long), dry, shade.

Senecio erucifolius (hoary ragwort), dry; divided leaf.

S. Jacobcea (common ragwort), dry ; divided leaf.

S. vulgaris (groundsel).

Sonchus arvensis (sow-thistle), dry.

Spircea Ulmaria (meadow-sweet), moist, shade; divided leaf.

Stellaria graminea, shade.

S. Holostea (greater stitchwort), shade.

S. media (chickweed), prostrate.

Symphytum officinale (comfrey), moist, shade.

Urtica dioica (nettle), dry.

Veronica Chamadrys (germander-speedwell), shade.

$V$. officinalis (common speedwell), dry, open.

Viola odorata isweet violet), shade.

V. sylvatica (dog-violet), shade.

Among grasses the most common are: Bromus sterilis (barren brome), B. mollis (soft brome), Arrhenatherum avenaceum (false oat), Avena fatua (wild oat), A. sativa (cultivated oat), Festuca Myuros (wall-fescue), Briza media (quaking grass), Brachypodium sylvaticum (false brome), Triticum repens (couch-grass), Agrostis vulgaris (fine bent-grass), Hordeum murinum (barley), Poa annua, and Aira flexuosa.

Where the climate is moist, ferns occupy an important position in the vegetation of the hedgerow. The most frequent are: Scolopendrium vulgare (hart's-tongue), Aspidium Filix-mas (male-fern), A. aculeatum (prickly shieldfern), Athyrium Filix-fomina (lady-fern); where the soil is sandy: Blechnum Spicant (hard fern), Asplenium Adiantum-nigrum (black spleenwort) and Polypodium vulgare (common polypody). In west Britain and Ireland Osmunda regalis (royal fern) is often common in the hedgerow-ditch.

The strip of waste ground between the hedge and the road is tenanted by is very mixed vegetation, especially if the soil is frequently disturbed. The first plants to appear are annuals-e.g., Poa annua, shepherd's-purse, and groundsel--but if left undisturbed the soil becomes covered with a grass-community, and many of the weeds disappear. In addition to many plants of the dry hedgebank, the following may occur : clovers, Medicago lupulina (black medick), Plantago major (great plantain), Melilotus 
officinalis (melilot), Ononis arvensis (rest-harrow), Filago germanica (upright cudweed), Matricaria inodora (scentless may-weed), Bartsia Odontites (hemi-parasitic on grasses), Malva rotundifolia (dwarf mallow), Potentilla reptans (creeping cinquefoil), Polygonum aviculare (knotgrass), many species of Chenopodium (goosefoot).

Commons. - In many parts of the country, within the region of cultivation, large stretches of waste land exist, on which the dominant plants are bracken, furze, and bramble. The soil is always very poor and dry, either sandy or stony. In many cases these commons are relics of cultivation. They are usually situated near towns, where land is valuable, and where every part of it is as far as possible utilized for raising crops, or used as pastureland. Woods on dry soils have been destroyed, and the land experimented with in this way, but it has often turned out unprofitable, and the land has been allowed to go to waste. Rough grasses and herbs are the first to obtain a hold on the soil, and then larger plants, including the three which are now dominant. The association is a very mixed one, and of an open character. Birches, and often oaks, are more or less abundant, and it seems probable that in the course of time a Birch-Oakwood association will once more occupy the soil (see p. 271).

The most abundant plants growing with the three dominant ones are dry-loving grasses-e.g., Festuca ovina, Aira flexuosa, Aira procox, Brachypodium pinnatum, Nardus stricta, and Agrostis vulgaris. Calluna vulgaris and Erica cinerea are often abundant, and many typical heath-plants-e.g., Thymus Serpyllum, Euphrasia officinalis, Lotus corniculatus, Hypericum pulchrum, Galium saxatile, Teucrium Scorodonia, Potentilla Tormentilla, P. reptans, Hieracium Pilosella, Rumex Acetosella, Veronica officinalis, Campanula rotundifolia, Stellaria graminea, Erodium cicutarium, Viola sylvatica, etc. Of woody plants other than those mentioned, the hawthorn, broom, and sloe are the most common.

Many of the wider strips of roadside-waste are of this character.

Cultivated Ground.-Where the land is periodically ploughed to receive new crops, weeds are very abundant. When the crop is in its seedling-stage, and earlier, the weeds have nothing to compete with, and can grow apace. 
Indeed, if the land is not properly cleaned, the crop itself is likely to succumb. Root-crops especially are liable to suffer in this way, for they are low-growing, and the weeds can grow up above them into the light and air. But the danger is not so great in a cornfield, for the cereals are quick-growing plants which effectually smother most others, and by the time the ears are ripe there are very few strong, healthy weeds left. The most frequent weeds, therefore, are annuals, which reach maturity early and produce an abundance of seed before the crop is big enough to injure the plants. Perennials are rare in the cornfield, for they not only have little opportunity of forming good seed, but their underground parts are cut up and destroyed by the plough. The only ones which are abundant are those like. the false oat (Fig. 115) or the couch-grass, which have subterranean stems stored with food. When these are cut up by the plough they are not destroyed, but actually increased in numbers, for any one of the little tubers of the false oat, or any portion of the couch-grass rhizome, will give rise to a new individual.

We have already seen in Chapter XX. that the true weeds of cultivation-i.e.,

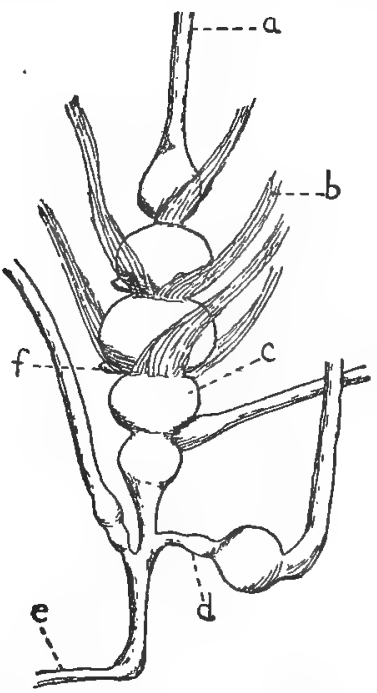

Fig. 115. - TUberots STEM OP False Oat-Grass. those which are found only in ground disturbed by man-are aliens; but many plants of our native flora occur as well. Those which do best as weeds are those with a good mechanism for the dispersal of the fruits or seeds-as fast as they are killed off in the field so they arrive again from their natural habitat. The most common of our native weeds are the following, those marked with an asterisk being annuals: *Myosurus minimus (mouse-tail), Ranunculus repens, $* R$. parviflorus, *Cardamine hirsuta, *Sisymbrium Thalianum (thale-cress), 
Silene Cucubalus (bladder-campion), Cerastium vulgatum, * Stellaria media, *Arenaria serpyllifolia, Sagina procumbens, *Spergula arvensis, *Geranium dissectum, *G. molle, *Medicago lupulina. *Trifolium pratense, ${ }^{*} T$. repens, $* T$. procumbens, *Alchemilla arvensis, *Caucalis nodosa, *Valerianella olitoria (corn-salad, a doubtful native), * Knautia arvensis (field-scabious), *Matricaria inodora, *Senecio vulgaris, Carduus lanceolatus, C. arvensis, *Anagallis arvensis, *Myosotis arvensis, *Convolvulus arvensis, *Cuscuta (dodder, parasitic), *Linaria minor, *Mentha arvensis, *Calamintha Acinos, *Stachys arvensis, *Galeopsis Tetrahit, *G. Ladanum, Plantago lanceolata, P. major, *Polygonum Convolvulus, Rumex species, F'estuca rubra (with rhizome). 


\section{APPENDIX I.}

Weismann's Law of Heredity, 1885.-This is based upon the almost absolute distinction in every plant and animal between the physical body or soma and the germcell, male or female, which the soma encloses, and which, when fertilised, becomes the germ of a new individual. The essential part of the theory is that the environment does not directly influence the germ-cells but only the soma, and that none of the characters acquired by the soma during its life-time alters the essential constitution of the germ-cell and is transmitted through it to the next generation. The germ-cell is therefore sacrosanct and race is everything; training and environment may improve or debase the individual but not the stock. This theory is directly opposed to the old conception of heredity, enunciated by Lamarck in 1809, according to which acquired characters may be transmitted as such from generation to generation. Though Weismann may have pushed his arguments too far, yet his theory in its broad bearings appears to be true and it has certainly stimulated subsequent research along healthy and fertile lines.

\section{APPENDIX II.}

The Mendelian Theory, 1865, 1901,-This theory of transmission fits in well with the Mutation or Saltation theory of variation and Weismann's theory of heredity. Gregor Mendel (1822-1884), the son of a peasant in Austrian Silesia, was a priest and afterwards abbot of an Augustine monastery in Brünn, Moravia, and his great discoveries in heredity form one of the most romantio chapters in modern science. His researches on peahybrids were published in 1865 in an obscure local periodical. They were neglected by the learned in his lifetime and for many years passed out of knowledge until 299 
de Vries unearthed them in 1896 and published them in 1901. Mendel selected the pea for two reasons: (1) because the flowers are self-fertilized and therefore under experimental control; (2) because they exhibit numerous characters which breed true-an almost ideal state of things for the purpose. Mendel marked out for experiment a certain number of differentiating characters and investigated their inheritance separately. Crosses were made between tall and dwarf varieties, coloured seedcoats and white, white and purple flowers, yellow and green-coated seeds, smooth and wrinkled seeds, etc. However the cross was made it was found that all the plants obtained by sowing these hybrid-seeds exhibited one only of each pair of contrasted qualities. The one quality so exhibited he called Dominant, and the other, which was apparently suppressed, the Recessive. Thus on crossing tall plants with dwarf, all the subsequent plants were tall. In the hybrids, therefore, tallness is dominant and dwarfness recessive. The seeds of this generation, produced by self-fertilization, were sown and both talls and dwarfs appeared among the plants obtained. The latent character, dwarfness, had thus reappeared in the second generation, and that in the proportion of 1 to 3. No intermediate forms occurred. On sowing the seeds of the second generation, obtained as before by self-fertilization, the seeds from the Rccessive (here dwarf) plants produced only dwarfs. and these were found to breed true from generation to generation. On the other hand, the seeds from the tall or Dominant plants, when sown, again produced both talls and dwarfs, the dwarfs always breeding true to type and the talls only true in the proportion of 1 to 2 . The talls which breed true are called pure Dominants; those that do not are hybrids or impure Dominants.

Thus on sowing the seeds of any generation the result is always:

Dominants : Recessives :: 3 : 1 .

The Recessives breed true, but only one-third of the Dominants; so that the real constitution of any generation, only to be ascertained by sowing its seeds, is:

$=\begin{array}{cc}\text { Pure Dominants : Impure Dominants or Hybrids : Recessives } \\ \mathbf{2}\end{array}$ 
This is Mendel's Law of Inheritance of unit-characters. It reveals:

1. That when unit-characters only are selected a hybrid is always like one or other of the parents.

2. That we oan only ascertain that such a cross is a hybrid by sowing its seeds, when the latent quality will reappear among the individuals of the next generation.

3. That when sufficient individuals are taken, a certain mathematical ratio is found to exist between the Hybrids, pure Dominants and Recessives of any of the succeeding generations.

Now this ratio, experimentally obtained and confirmed again and again, admits of a very simple interpretation. In the process of sexual reproduction the total number of possible gametic fusions, male $\left(\sigma^{\star}\right)$ and female ( $q$ ), which can be obtained by crossing a Dominant form $D$ with a Recessive form $R$ is obviously the number of combinations which can be formed by associating together the following couples:

$$
\begin{aligned}
& 6 \mathrm{D} \times \text { 으 } \mathrm{D}=1 \text { pure } \mathrm{D} \text {. }
\end{aligned}
$$



$$
\begin{aligned}
& q \mathrm{R} \times \delta \mathrm{R}=1 \text { pure } \mathrm{R} \text {. }
\end{aligned}
$$

Thus the Mendelian Law has a physiological basis, the constitution of the hybrid being explained by the principle of what is known as the Segregation of the Gametes in the generations that follow.

When two or more unit characters are combined the resulting ratios are more complicated, but several of these have been worked out mathematically and demonstrated practically.

An enormous amount of work has been accomplished during recent years on the transmission of all kinds of unit-characters in plants and animals, and in spite of much slipshod and misleading work which has been published as bearing upon Mendelian inheritance, many reliable results have been obtained, some of which have turned out to be of great economic value. No modern horticulturist or animal-breeder can now afford to be ignorant of this important discovery in the realm of heredity. It is even important in investigating the transmission of many human characters. 
Nevertheless, the law, unfortunately, cannot be universally applied. Some qualities blend in the hybrids, and there the law, as at present expressed, fails. Sooner or later it may be shown that Mendel's Law is only. a special case of a wider generalization. When this is found the whole problem of hereditary transmission is within sight of solution.

\section{APPENDIX III.}

Botanical Provinces.-At the present time the flora of the world is divided into a number of separate Botanical Provinces or Floral Regions, just as the world of living men is divided ethnologically into distinct racedivisions. Each Botanical Province is distinguished by the presence of certain groups of plants, species, genera or natural orders, which differ as we pass from one province to another, although the conditions of soil and climate may be similar. Different authorities divide up the earth differently, but the classification usually followed is that of Drude, who distinguishes fourteen Floral Regions. Europe is divided into only two Botanical Provinces: (1) the Northern, and (2) the Southern or Mediterranean Province, the boundary being formed by the Pyrenees and the Alps. The Northern Province extends from Europe through Siberia to the Pacific and also includes the northern portion of the American continent. The uniformity of the flora throughout the Northern Temperate regions of the world suggests, by itself, a former union between the old and the New Worlds, either across the Northern Atlantic or Behring's Strait or both, an inference which is supported by several other considerations.

This lack of uniformity in the present flora of the world was not always so. As far as we know it dates only from the Glacial Period. Before then there seems to have prevailed throughout geological history, with one exception, a great uniformity of climate and consequently of flora also. This one exception was the Permo-Carboniferous Period, when there were two marked Botanical Provinces in the world, the Northern Province, north of the Equator, and the Southern or Gondwanaland Province 
in the Southern Hemisphere. The latter was characterized by the dominance of a certain ancient and, of course, now extinct fern, Glossopteris, which is unknown among the fossil remains of the Northern flora. The problem of uniform climates and world-wide floras and faunas is one of the most interesting and puzzling in the whole range of science.

\section{APPENDIX IV.}

\section{BIBLIOGRAPHY.}

\section{General Works.}

Avebury, Lord: "British Flowering Plants." London, 1905.

Boulger, G. S.: " Plant Geography." London, 1912.

Bower, F.O. : "Botany of the Living Plant." London, 1919.

Goebel, K.: "Organography of Plants." Engl. ed. by I. B. Balfour. Oxford, 1900-1905.

Gray, Asa: "Structural Botany." London, 1900.

Jackson, B. D.: "A Glossary of Botanic Terms, with their Derivation and Accent." London, 1916.

Jost, L.: "Lectures on Plant Physiology." Trans. by R. J. Harvey Gibson. Oxford, 1907. (Suppl., 1913).

Kerner, A., von Marilaun: "The Natural History of Plants." Trans. and ed. by F. W. Oliver, with the assistance of M. Busk and M. Ewart. London, 1898.

Pfeffer, W.: "The Physiology of Plants." Trans. and ed. by A. J. Ewart. Oxford, 1900-1903-1906.

Schimper, A. F. W.: "Plant Geography upon a Physiological Basis." Trans. by W. R. Fisher, rev. and ed. by P. Groom and I. B. Balfour. Oxford, 1903.

Strasburger, E.: "A Text-Book of Botany." Engl. ed. rev. by W. H. Lang. London, 1912.

Warming, Eug.: " Ecology of Plants. An Introduction to PlantCommunities." Engl. ed. by P. Groom and I. B. Balfour. Oxford, 1909.

Willis, J.C.: "A Dictionary of the Flowering Plants and Ferns." Cambridge, 1919.

\section{The Soil.}

Daruin, C.: "The Formation of Vegetable Mould through the Action of Worms, with Observations on their Habits." London, 1881.

Hall, A. D. :

1. "The Soil." London, 1920.

2. "Fertilisers and Manures." London, 1910.

3. "The Feeding of Crops and Stock." London, 1911. 


\section{Biology of Shoots, Flowers, and Fruits.}

Belt, T.: "The Naturalist in Nicaragua." London, 1888, reprinted in Dent's Everyman Series. (Myrmecology).

Darwin, C.:

1. "The Movements and Habits of Climbing Plants." London, 1865 (1875).

2. "Insectivorous Plants." London, 1875.

3. "The Various Contrivances by which Orchids are Fertilised by Insects." London, 1862 (1877).

4. "The Effects of Cross and Self Fertilisation in the Vegetable Kingdom." London, 1876 (1878).

5. "The Different Forms of Flowers on Plants of the same Species." London, 1877 (1880).

Guppy, H.B. :

1. "Observations of a Naturalist in the Pacific between 1896 and 1899." Vol. ii. Plant Dispersal. London, 1906.

2. "Plants, Seeds and Currents in the West Indies and Azores." London, 1917.

Kerner, A., von Marilaun: "Flowers and their Unbidden Guests." Trans. by W. Ogle. London, 1878.

Knuth, P.E. O. W.: "Handbook of Flower Pollination." Trans. by J. R. Ainsworth Davis. Oxford, 1906.

Lubbock, Sir John:

1. "On Buds and Stipules." London, 1899.

2. "On British Wild Flowers considered in Relation to Insects." London, 1875.

3. "Flowers, Fruits, and Leaves." London, 1888.

Müller, H.: "The Fertilisation of Flowers." Trans. by d'Arcy W. Thompson. London, 1883.

Ward, H. Marshall.: "Trees, A Handbook of Forest-Botany for the Woodlands and the Laboratory." Vol. i. Buds and Twigs: Vol. iv. Fruits. Cambridge, 1904, 1908.

\section{Economic Botany.}

Freeman, W. G., and Chandler, S. E.: "The World's Commercial Produets. A Descriptive Account of the Economic Plants of the World and of their Commercial Uses." London, 1907.

Holland, J. H. :

1. "The Useful Plants of Nigeria." Kew Bulletin, Additional Series, ix. 1908-1911-1915 (in progress).

2. "Food and Fodder Plants." Kew Bulletin, 1919, Nos. 1 and 2, pp. 1-84.

Kew Gardens : "Official Guide to the Museums of Economic Botany.

No. 1, Dicotyledons. No. 2, Monocotyledons and Cryptogams."

London, 1907, 1895.

Lindley, J., and Moore, $T$. (eds.): "The Treasury of Botany." London" 1889. 
Prain, Sir David (ed.): "A list of Economic Plants Native or Suitable for Cultivation in the British Empire." Intro. by A. B. Rendle. Kew Bulletin, 1917, Nos. 7 and 8, pp. 241-296.

Watt, Sir George : "The Commercial Products of India." London, 1908. Willis, J. C.: "A Dictionary of Flowering Plants and Ferns." Cambridge, 1919.

\section{Variation and the Evolution of Species.}

Bateson, W.: "Mendel's Principles of Heredity." Cambridge, 1913.

Darbishire, A. D.:

1. "Recent Advances in the Study of Heredity." New Phytologist, vols. viii. and ix., 1909, 1910.

2. "Breeding and the Mendelian Discovery." London, 1911.

Darwin, $C$.:

1. "The Origin of Species by means of Natural Selection." London, 1859 (1872).

2. "The Variation of Animals and Plants under Domestication." London, 1867 (1875).

Doncaster, L.: "Heredity in the Light of Recent Research." Cambridge, 1910.

Lock, R. H.: " Recent Progress in the Study of Variation, Heredity and Erolution." Rev. by L. Doncaster. London, 1916.

Punnett, R. C.: "Mendelism." London, 1919.

Reid, G. Archdall : "The Laws of Heredity." London, 1910.

Seward, A. C. (ed.): "Darwin and Modern Science, Essays in Com. memoration of the Centenary of the Birth of Charles Darwin and of the Fiftieth Anniversary of the Publication of the Origin of Species." Cambridge, 1909.

Thomson, J. A. : "Heredity." London, 1919.

Vries, $H$. de:

1. "PIant Breeding." London, 1907.

2. "The Mutation Theory. Experiments and Observations on the Origin of Species in the Vegetable Kingdom." Trans. by J. B. Farmer and A. D. Darbishire. London, 1910-1911.

Wallace, $A . W$. .: "Darwinism." London, 1889.

Weismann, A.:

1. "Essays upon Heredity and Kindred Subjects." Trans. by E. B. Poulton, etc. Oxford, 1891-1892.

2. "The Germ-Plasm: A Theory of Heredity." Trans. by W. N. Parker, etc. London, 1892.

3. "The Evolution Theory." Trans. by J. A. Thomson. London, 1904.

\section{The Origin of the British Flora.}

Dunn, S. T.: "Alien Flora of Britain." London, 1905.

Forbes, Edward: "On the Connexion between the Distribution of the Existing Fauna and Flora of the British Isles, and the Geological Changes which have affected their area, especially during the Epoch of the Northern Drift." Mem. Geol. Surv. Great Britain, vol. i., 1846, pp. 336-432. 
Praeger, $R . L l$. . " A Tourist's Flora of the West of Ireland." Dublin, 1909.

Praeger, $R$. Ll.: "Clare Island Survey, Part X.: Phanerogamia and Pteridophyta." (Origin of the Flora.) Proc. Roy. Irish Acad.,

Vol. xxxi., 1911, pp. 1054-96.

Reid, C. : "The Origin of the British Flora." London, 1889.

Reid, C., Stapf, $O$., and others: "The Relation of the Present Plant Population of the British Isles to the Glacial Period." Report, British Association, Portsmouth, 1911, p. 573.

Stapf, O.: "A Cartographic Study of the Southern Element in the British Flora," Proc. Linn. Soc., 1916-17, pp. 81-92.

\section{The Classification of Plants.}

Rendle, A. B. : "The Classification of Flowering Plants, Vol. i." Cambridge, 1904.

Sachs, J. von: "History of Botany, 1530-1860." Trans. by H. E. F. Garnsey, rev. by I. B. Balfour. Oxford, 1890.

(For Species, Hybrids, Variation, see under "Variation and the Evolution of Species.")

\section{Plant Associations and Formations.}

I. Floras, etc.

Babington, C. C.: "Manual of British Botany." Ed. by H. and J. Groves. London, 1904.

Bentham, G., and Hooker, Sir J.D. : "Handbook of the British Flora." London, 1892.

Druce, G. C.: "List of British Plants." Oxford, 1908.

Fitch, W. H., and Smith, W. G.: "Ilustrations of the British Flora." London, 1916.

Hanbury, F. J. (ed.): "The London Catalogue of British Plants, 10th edition." London, 1008 .

"Hayward's Botanist's Pocket-Book." Revised and enlarged by G. C. Druce. London, 1909.

Hooker, Sir J. D.: "Student's Flora of the British Isles." London, 1884.

Moss, C. E.: "The Cambridge Pritish Flora." Cambridge, 1914 (in progress).

Praeger, $R . L l$. . "A Tourist's Flora of the West of Ireland." Dublin, 1909.

Rendle, A. B., and Britten, $J$. : "List of British Seed-Plants and Ferns." London, 1907.

Watts, H. MI.: "A School Flora." London, 1915.

Williams, F. N.: "The High Alpine Flora of Britain." Ann. of Scot. Nat. Hist., 1908, 1909, 1910. 


\section{General Works on Plant Associations and Formations.}

Baker, S. M.: "Zoning of the Brown Seaweeds on the Sea-shore," New Phytologist, vol. viii., 1909, p. 195; vol. ix., 1910, p. 54.

Brenchley, $W . E$., and Adam, $H$. : "Recolonisation of Cultivated Land allowed to revert to Natural Conditions." Journal of Ecology, vol. iii., 1915, pp. 193-210.

Clements, F.E.: "Research Methods in Ecology." Lincoln, Nebraska, U.S.A., 1905.

Clements, F. E. : "Plant Physiology and Ecology." London, 1907.

Clements, $F . E$. .: "Plant Succession: An Analysis of the Development of Vegetation." Publication 242, Carnegie Institution, Washington, 1916.

Jefferies, T. A. : "Ecology of the Purple Heath-grass (Molinia caerulea)." Journ. Ecol., vol. iii., 1915, pp. 93-109.

Moss, C. E. "The Fundamental Units of Vegetation." New Phytologist, vol. ix., 1910, p. 18.

Moss, C. E., Rankin, W. M., and Tansley, A. G.: "The Woodlands of England." New Phyt., vol. ix., 1910, p. 113.

Oliver, F. W.: "The Shingle Beach as a Plant Habitat." New Phytologist, vol. xi., 1912, p. 73.

Oliver, F.W., and Salisbury, E. J.: "Vegetation and Mobile Ground as illustrated by Sueda fruticosa on Shingle." Journ. Ecol., vol. i., 1913, pp. 249-272.

Pearsall, W. H.: "On the Classification of Aquatic Plant Communities." Journ. Ecol., vol. vi., 1918, pp. 75-84.

Smith, W. G.: "The Origin and Development of Heather Moorland." Seot. Geogr. Mag., vol. xviii., 1902, pp. 587-597.

Smith, W. G.: "The Distribution of Nardus stricta in Relation to Peat." Journ. Ecol., vol. vi., 1918, pp. 1-13.

Smith, W. G.. and Crampton, C. B. " Grassland in Britain." Journ. Agric. Sci., vol. vi., 1914, pp. 1-17.

Tansley, A. G. (ed.): "Types of British Vegetation." By Members of the Central Committee for the Survey and Study of British Vegetation." Cambridge, 1911.

Watson, W.: "The Bryophytes and Lichens of Calcareous Soil." Joum. Ecol., vol. vi., 1918, pp. 189-198.

Watson, W. : "The Bryophytes and Lichens of Frosh Water." Journ. Ecol., vol. vii., 1919, pp. 71-83.

Yapp, R. H.: "Stratification in the Vegetation of a Marsh." Annals of Botany, vol. xxiii., 1909, p. 275.

Yapp, R. H. : "Spiraea Ulmaria, L., and its Bearing on the Problem of Xeromorphy in Marsh Plants." Ann. Bot., vol. Xxvi., 1912, pp. 815-872. 


\section{Plant Associations and Formations of Particular Regions of the British Isles.}

Adamson, R. S.: "An Ecological Study of a Cambridgeshire Woodland." Journ. Linn. Soc., Botany, vol. xl., 1912, pp. 339-384.

Adamson, R. S.: "On the Relationships of some Associations of the Southern Pennines." Journ. Ecol., vol. vi., 1918, pp. 97-109.

Armitage, E.: "Vegetation of the Wye Gorge'at Symonds Yat." Journ. Ecol., vol. ii., 1914, pp. 98-109.

Brown, G.: "Survey of the Vegetation of the Parish of Shotts, Lanarkshire." Trans. Bot. Soc. Edinb., vol. xxvi., 1913, pp. 101-118.

Cotton, A. D. : "Clare Island Survey, Part XV.: Marine Algæ." Proc. Roy. Irish Acad., vol. xxxi., 1912.

Crampton, C. B.: "The Vegetation of Caithness considered in relation to the Geology." Edinburgh, 1911.

Crampton, C. B., and Macgregor, M.: "The Plant Ecology of Ben Armine, Sutherlandshire." With Vegetation Map. Scot. Geogr. Journ., vol. xxix., 1913, pp. 169-192, 256-266.

Farrow, E. P.: "On the Ecology of the Vegetation of Breckland." Journ. Ecol., vol. iii., 1915, pp. 211-228; vol. iv., 1916, pp. 57-64; vol. v., 1917, pp. 1-18, 104-113, 155-172; vol. vi., 1918, pp. 144-152; vol. vii., 1919, pp. 55-64.

Fritsch, F. E., and Parker, W.: "The Heath Association on Hindhead Common." New Phyt., vol. xii., 1913, pp. 148-163.

Hardy, M. : "Esquisse de la Géographie et de la Végétation des Highlands d'Écosse." With Vegetation Map. Paris, 1905.

Hardy, M. : "Botanical Survey of Scotland. A General Map of the Highlands with a Sketch of the History and Methods." With Vegetation Map. Scot. Geogr. Mag., vol. xxii., 1906, pp. 229-241.

Harrison, J.W. Heslop: "A Survey of the Lower Tees Marshes and of the Reclaimed Areas adjoining them." Trans. Nat. Hist. Soc. Northumberland, Durham and Newcastle-on-Tyne, New Ser., vol. v., 1918, pp. 89-140.

Jeffreys, $H$. . " On the Vegetation of Four Durham Coal-Measure Fells." Journ. Ecol., vol. iv., 1916, pp. 174-195; vol. v., 1917, pp. 129-154.

Lewis, F. J.: "Geographical Distribution of Vegetation of the Basins of the Rivers Eden, Tees, Wear, and Tyne." With Vegetation Maps. Geogr. Journ., vol. xxiii., 1904, pp. 313-331; vol. xxiv. 1904, pp. 267-285.

Lewis, F. J.: "The History of the Scottish Peat Mosses and their Relation to the Glacial Period." Scot. Geogr. Mag., vol. xxii., 1906, pp. 241-252.

Marsh, A. S.: "The Maritime Ecology of Holme-next-the-Sea, Norfolk." Journ. Ecol., vol. iii., 1915, pp. 65-93.

Moss, C. F.: "Peat-Moors of the Pennines: Their Age, Origin, and Utilization." Geogr.Journ., vol. xxiii., 1904, pp. 660-671.

Moss, C. E. : "Geographical Distribution of Vegetation in Somerset." With Vegetation Map. London, 1907. 
Moss, C. E.: "Vegetation of the Peak District." With Vegetation Maps. Cambridge, 1913.

Newman, L. F., and Walworth, G. : "A Preliminary Note on the Ecology of Part of the South Lincolnshire Coast." Journ. Ecol., vol. vii., 1919, pp. 204-210.

Oliver, $F$. W., and Salisbury, E. J.: "Topography and Vegetation of Blakeney Point, Norfolk." London, 1913.

Pearsall, W. H.: "The Aquatio and Marsh Vegetation of Esthwaite Water." Journ. Ecol., vol. v., 1917, pp. 180-202; vol. vi., 1918, pp. 53-74.

Pethybridge, G. H., and Praeger, R. L'.: "The Vegetation of the District lying South of Dublin." With Vegetation Map. Proc. Roy. Irish Acad., vol. xxv., B., 1905, pp. 124-180.

Praeger, $R$. Ll. : "A Tourist's Flora of the West of Ireland." Dublin, 1909.

Praeger, $R$. Ll. : "Clare Island Survey, Part X.: Phanerogamia and Pteridophyta." With Vegetation Map. Proc. Roy. Irish Acad., vol. xxxi., 1911.

Salisbury, $E$. J.: "The Oaks-Hornbeam Woods of Hertfordshire." Journ. Ecol., vol. iv., 1916, pp. 83-117; vol. vi., 1918, pp. 1452.

Salisbury, E. J.: "The Ecology of Scrub in Hertfordshire: a Study in Colonisation." Trans. Herts. Nat. Hist. Soc., vol. xvii., 1918, pp. 53-64.

Smith, R.: "Plant Associations of the Tay Basin." Proc. Perthshire Soc. of Nat. Sci., vol. ii., 1898; vol. iii., 1900.

Smith, R.: "Botanical Survey of Scotland: I. Edinburgh District." With Vegetation Map. Scot. Geogr. Mag., vol. xvi., 1900, pp. 385-416.

Smith, R.: "Botanical Survey of Scotland: II. Northern Perthshire District." With Vegetation Map. Scot. Geogr. Mag., vol. zvi., 1900, pp. 441-467.

Smith, W. G. : "Botanical Survey of Scotland: III. and IV. Forfar, and Fife." With Vegetation Maps. Scot. Geogr. Mag., vol. xx., 1904; pp. 617-628; vol. xxi., 1905, pp. 4-23, pp. 57-83, pp. 117-126.

Smith, W. G. and Moss, C. E. : "Geographical Distribution of Vegetation in Yorkshire. Part I.: Leeds and Halifax District." With Vegetation Map. Geogr. Journ., vol. zxi., 1903, pp. 375-401.

Smith, W. G., and Rankin, W. M.: "Geographical Distribution of Vegetation in Yorkshire. Part II. : Harrogate and Skipton District." With Vegetation Map. Geogr. Journ., vol. xxii., 1903, pp. 149-178.

Stevenson, E.H.: "Notes on the Vegetation of Weston Bay, Somerset." Journ. Ecol., vol. i., 1913, pp. 162-166.

Tansley, A.G. (ed.): "Types of British Vegetation." By Members of the Central Committee for the Survey and Study of British Vegetation." Cambridge, 1911.

Tansley, A. G.: "The Vegetation of Hampstead Heath and the Neighbouring Woods," in "Hampstead Heath, its Geology and Natural History," prepared under the auspices of the Hampstead Scientifio Society. London, 1913. 
Tansley, A. G. and Adamson, R. G.: "Reconnaissance in the Cotteswolds and the Forest of Dean." Journ. Ecol., vol. i., 1913, pp. 81-89.

Watson, W.: "The Distribution of Bryophytes in the Woodlands of Somerset." New Phyt., vol. viii., 1909, p. 90.

Watson, W. : "Cryptogamic Vegetation of the Sand-dunes of the West Coast of England." Journ. Ecol., vol. vi., 1918, pp. 126-143.

West, George: "A Comparative Study of the dominant Phaneroganic and Higher Cryptogamic Flora of Aquatic Habit in Three Lake Areas of Scotland." Proc. Roy. Soc. Edinb., vol. Xxv., 1905, pp. 967-1023.

We:t, George: "A Further Contribution to a Comparative Study of the dominant Phanerogamic and Higher Cryptogamic Flora in Scottish Lakes." Proc. Roy. Soc. Edinb., vol. Xxx., 1910, pp. 65-182.

Woodhead, T. W. : "Ecology of Woodland Plants in the Neighbourhood of Huddersfield." Journ. Linn. Soc., Botany, vol. xxxvii., 1906, pp. 333.

Yapp, R. H. : "Wicken Fen." New Phyt., vol. vii., 1908, p. 61.

Yapp, R. H., Johns, D., and Jones, O.T.: "The Salt Marshes of the Dovey Estuary." Journ. Ecol., vol. iv., 1916, pp. 27-42; vol. v., 1917, pp. 65-103. 


\section{GENERAL INDEX}

Contractions employed : chars. = characters; fl. $=$ flower ; fr. = fruit ; infl. =inflorescence ; pl.=plant ; repr.=reproduction ; var. = variety ; veg. = vegetation.

Signs employed : * illustration; $\dagger$ derivation given.

Absorption of water: by roots, 25,33 , 74,91 ; causes reducing, 32,33 , 35 ; selective, 91 ; by soils, 87

Acacia, phyllodes, 44 ; cornigera, 133 ; false (seo Robinia pseudacacia)

Acelimatization of plants, 75

Achenes, $137, * \dagger 186, * 195, * 197$

Acids in plants, 143

Aconitin, 143

Aconitum Napellus, 143

Acorn : fr., *187; seod, 146 ; protection of fr., 136, *137

Actinic rays, 65, 67, 73

Adoxa, 62

Ágopodium Podagraria, 216

Aeration : of soil, 88 ; by earthworms, 96 ; of water, 52

Aërobic bacteria, 93

AEthusa cynapium, 216

Afforestation and climate, 13

Agave: source of alcohol, 151 ; americana, 113

Agriculture in British Isles, 19

Agrimony fr., 197

Air : chemical effects of, 6; in aquatics, 48,52 ; composition of, 6 ; dry, 34, 35 ; physical effects of, 8, 76 ; rarofied, 34,35

Aira flexuosa : habit, 115 ; procos, 60 Air-spaces: in aquatics, $47, * 48$; in leaves, $* 26, * 27$; in marsh-plants, 63 ; in zerophytes, 40

Albumin, 5

Albuminous seeds, *146, *147

Aicohol, 151

Alder, infl., 180

Alder-thickets, 229, 243, 269

Aleurone-grains, 146 ; -layer, 147

Alg $\oplus$, colour of, 53
Aliens, 215

Alisma Plantago, leaf-form, 50

Alkaloids, 143

Allium vineale, bulbils of, 160

Alluvium, 80

Almonds, bitter, seeds of, 138

Aloe, American. Seo Agave americana

Alopecurus agrestis, 216

Alpine : flora, 210; pasture, 230 , 251 ; plants, $36,37,38,72,74$, of Ireland, 286, 288, Scotland, 287, British Isles, 288 ; regions, 35 ; rocks, 286 ; vegetation : siummitheath, 251, vaccinium-moor, 255 , pasture, 259, rocks, 286

Altitude: influence on climate, 11 ; on veg., 21

Alumina, silicate of, 87

Ammonium compounds produced by bacteria, 95,124

Ampelopsis Veitchii tendrils, 118, *119

Amphibious plants, 28, 56

Anaerobic bacteria, $\uparrow 93$

Andrena, 171

Anemophilous fls., $\dagger 166$

Angiosperms, $\nmid 163,183$

Animals : food of, 5, 79; and plants, 79 ; and seeds, 196

Aniseed oil, 151

Annuals, 107, 145 ; aquatic, 54, 55, 236 ; autumn-, 59,107 ; garden-. 108 ; hygrophytic, 59 ; marsh-, 59,240 ; mesophytic, 60 ; seaside-, $58,59,277,280$; summer-, 107 ; tropophytic nature of, 59 ; weeds of eultivation, 108, 215

Anther, 162 
Ants and flowers, 172; symbiosis, 133

Apocarpous ovaries, $\uparrow 183$

Apple, 149 ; bud-scales, 61 ; pollination, 174 ; fr., 143, 184, 193 , 194 ; suckers, 155

Apricot suckers, 155

Aquatic associations : in slowlyflowing water, 235; standing water, 236 ; swiftly-flowing water, 234

Aquaties, $\nmid 28$; aeration of, 52 ; airspaces in, 47 ; annual, 55 ; broodbuds in, 54 ; chars. of, 47 ; chlorophyll in, 49 ; colour of, 53 ; cuticle in, 48 ; dangers to which exposed, 52 ; distribution, 233 ; free-floating, 237; leaf-form in, 50 ; in relation to light, 52; origin of, 55 ; pollination, 166 , 275 ; propagation, 53 ; respiration in, $48,50,52$; rooted, 237 ; roots, 49 ; soeding of, 54,275 ; transpiration of, 52 ; vascular system of, 49 ; zoning of, 236

Aquatic vegetation : fresh - water, $230,231,233$; maritime, 231, 275

Aqueous rocks, $\uparrow 82$

Arabis, 115

Arable land, 18, 19

Arbutus Unedo, 23, 211, 212, 213 ; berries, 149

Arctic plants, 72

Arenaria ciliata, 213; peploides, 218

Aril, 196, 197

Aristolochia (Birthwort or Dutchman's-pipe), fly-trap, 176

Arrack, I5I

Arrowhead. Seo Sagittaria sagittifolia

Arrowroot, 150

Artichoke, 150

Artifieial habitats, 16, 215, 216 ; manures, 97 ; pastures, 20,261 , 264

Arum maculatum berries, 149; pollination, *175

Ash, 22, 269 ; bud-scales, 61 ; fr., $186, * 187$; fruit-dispersal, 195 ; weeping, origin of, 154

Ash of plants, 80

Ash-oakwood association, 229, 272

Ashwood-association, 229, 272

Asparagus, 150

Aspidistra: leaf-typo, 42; pollination, 176
Assimilation, 4; in aquatics, 53 ; light-rays necessary for, 66 ; of nitrogen by bacteria, 95,99 ; in zerophytes, 38

Associations, 224, 227 ; alpine, 251. 255,259 ; aquatic, 234 ; bog-, 246 , $251,252,253$; classification of, 229 ; grassland-, 257 ; herbaceous, 230 ; influence of man on, 226 ; maritime, 275 ; marshland-, 241 , 244 ; methods of studying, 226 ; moorland-, 225, 248 ; strand-, 277 ; woodland-, 265

Atmosphere, 6, 34, 76

Atmospheric equilibrium, 77

Atriplex portulacoides, 218

Atropa Belladonna : poison, 136, 143; pollination, 174

Atropin, 143

Aucuba, 154

Autogamy, $\dagger 164$

Autotrophic pls., 6, 123

Avens Seo Geum; mountain., See Dryas octopetala

Awl-type of leaf in aquatics, 50

Awlwort. See Subularia

Bacteria : action on dead organic matter, 83 ; injurious, 61 ; nitrate, 95 ; nitrogen-, 95,99 ; parasitic, 125 ; saprophytic, 123 ; soil-, 83 , $93,95,96,97,123$

Ballota nigra, 216. See Horehound

Balsam. See Impatiens Noli-metangere

Bamboo, 212

Banana, 149. See Musa Sapientum

Barberry : honey, 172 ; root-suckers, 155; spines, $140, * 141$. See Berberis vulgaris

Barley : alcohol from, 151 ; crops, 98 ; cultivation of, 20 ; food, 147 ; starch, 146

Bartsia: parasitio nature of, 126 ; water-glands of, 127

Bastard - toadflax. See Thesium humifusum

Bay-laurel, 42

Beach, 16,58 ; veg. of pebbly beach, 283 ; of sandy beach, 279

Beachy Head, 77, 284

Bean : climbor, 116 ; protein of, 147 ; root-nodules, 95 ; seed, 146 ; dispersal of seed, 195

Bedstraw, 217. Seo Galium

Boech, 22 ; bud-soales, 61 ; fr., 187 ; inseots on leaves of, 144 ; 
pollination, 167 ; shade cast by, 272

Beechwood-association, 229, 272

Beer, 20, 151

Bees, $172,173,174$

Beot, fleshy root, 150; sugar in, 146

Beetles, pollination by, 172, 174

Begonia, vivipary, 160

Belladonnin, 143

Belt on myrmecophily, 133

Berberis vulgaris spines, 140, *141. See Barberry

Berry, 136, 192, 193, 196

Beverages, 151

Bibliography, 339

Bidens, 59 ; fr., *197

Biennials, 58, 60, 108 ; leaves, 115 ; tuberous roots, 111 ; xerophytic chars. of, 60

Bilberry, acids in, 143

Bindweed, 217

Biological classifications, 105 ; habitats, 223, 225

Biology, †I04, 184

Birch, 22 ; bud-scales, 61 ; competition with the oak, 270, 271; infl., 180 ; pollination, 167

Birchwood-association, 229, 271

Birds : migratory, 198; as pollinators, 176 ; as seed-distributors, 196, $198,209,211,213,233$; water-, 233

Bird's-loot treloil, 217 ; root-nodules, *95. See Lotus corniculatus

Bird's-nest orchid. See Neottia

Bird's-nest, yellow. See Monotropa Hypopitys

Birthwort, 218. See Aristolochia

Bitter principles in pls, 136,139 , 142

Blackberry : bud-scales, 61 ; fr., 192. See Rubus fruticosus and Bramble

Black bryony. Seo Tamus communis

Black horehound. See Ballota nigra

Black medick. See Medicago luprelina

Blackthorn. See Prunus spinosa

Bladderwort. See Utricularia

Bluebell, 228 ; fr., 187

Bog-associations, 246 ; Carex, 231 ; Juncus, 231; Molínia cærulea, 231, 250, 251; Myrica, 231, 250, 253 ; Sphagnum, 231, 250

Bog-moss. See Sphagnum
Bogs, 240, 246 ; insectivorous pls. in, 131 ; xerophytic factors of, 35

Boulder-clay, 80

Box, 39 ; leaf-form, 43 ; leaf-mosaic, 68 ; pollination, 176

Bracken, 89, 228

Bracts, 181, 194

Bramble, 220, 221; honey, I73; prickles, 141. See Rubus fruticosus and Blackberry

Brandy, 151

Brassica, 216

Brazil-nut, 146 ; oil in, 143

British Isles : agriculture, 19 ; climate, 12

Broccoli, 150

Bromus arvensis, 216 ; mollis, 60

Brood-buds, 161 ; in aquatics, 54

Broom, $44, * 45,89,152,220$; honey, 171 ; pollination, 169, 171. Seo Cytisus scoparius

Broomrape. Seo Orobanche

Brussels-sprouts, 150

Bryonia dioica, 214; berries, 149 ; pollen-flower, 171 ; tendrils, 119

Bryony : black (seo Tamus communis); white (see Bryonia dioica)

Buckthorn, 152

Bud-detachment, 161 ; -protection, 60 ; -scales, 61 ; -variation, 153 ; winter-buds, 60

Bulbils, 62 ; repr. by, 160

Bulbs, 62, 111, 115, 143, 161 ; multiplication by, 156

Bull's-horn acacia. See Acacia cornigera

Burdock, 60, 108 ; fr., 197

Bur-marigold. See Bidens

Bush-communities, 17 ; -swamp, 243

Butcher's-broom, 214 ; phylloclades, $44, * 45$

Buttercup, 218 ; fr., 187 ; honey, 172 ; hydathodes, 28 ; nectaries, 169 , * 170 ; seed, 146

Butterflies, 170, 173, 174

Caatinga forests, 10

Cabbage (Brassica oleracea), 150

Cacti, 9, 165

Cakile maritima, 59

Calcareous marl, 82 ; rocks, 82 ; soils : pastures on, 272 , woods on, 272

Calcedaria pollination, 171

Calciluges, 89, 260

Calciphilous pls., 89 ; list of, 260

Calcium oxalate, 142, 143 
Callitriche, 54

Calluna: relation to chalk, 89 ; distribution of, 224 ; honey, 173 ; leaf, 43. See Heather and Ling

Calluna-heath, 230, 249, 250, 252

Callus, 140

Calyx, 162

Cambium, *45

Campanula hybrida, 216

Camphor, 143

Campion, moss-. See silene acaulis

Canada, 12, 19

Canadian fleabane, 216; pondweed, 234 (see Elodea canadensis)

Canals, veg. of, 236

Canterbury-bell pollination, 173

Capers, 151

Capillarity, 86

Capillary water, 86

Capitulum, 178,*181

Capsella : autogamy, 165 ; fecundity of, 108 ; fr., 188. Sce Shepherd'spurse

Capsular fruits, 187

Capsules, 189

Caraway oil, 151

Carbohydrate, 5 ; in seeds, 146

Carbon-assimilation, 4. See Photosynthesis

Carbonate of lime, 89

Carbonic acid : agent of denudation, 80 ; gas, 4, 7, 50, 78

Cardamine pratensis: buds on loaves, *160; seeds, 196

Carex-bogs, 231, 247

Carlina spines, 140

Carnivorous pls., 246, 249. Seo Insectivorous pls.

Carpels, 183

Carrot, 60, 108 ; fleshy root, 108, 150

Caryopsis, 186

Caseades, veg. of, 234

Casein, 5

Castor-0il, 148; seeds, 143, 147

Casuals, 215

Catch-erops, 98

Cathin, 178, 180 ; pollination, 167

Cat's-tail grass, 217

Cattle, 20, 21

Cauliflower, 150

Cauline leaves, 114, 115

Celandine: greater (see Chelidonizum majus); lesser, tubors, 111. Sce Ranunculus Ficaria

Celery, 150

Cell-sap, 24, 92

Cellulose, 92 ; as food-reserve, 116
Cell-wall. 92

Centaurea Calcitrapa spines, 140; Cyanus, 216

Cerastium arvense. 216 ; semidecandrum, 60, 107

Ceratophyllum, 49, 54, 56

Cereal seeds, 146

Cetraria, 133

Chalk, 82 ; disintegration of, 81 ; effect on pls., 89; glands, 263; plants, 260

Chalk-downs : xerophy tic factors of, 35 ; xerophytic nature of pls. on, 89 ; veg. of, 258,259

Chalk-soil : meadows on, 264 ; physical properties of, 90

Chamærops, 23

Chamomile, 152, 216 ; oil, 151

Charlock, 216. See Sinapis arvensis

Chelidonium majus latex, 142

Chemical action of water, 80,81 ; properties of soils, 88

Chenopodium, 216. See Goosefoot

Cherry : bud-scales, 61 ; citric acid in, 143 ; -laurel, 152

Chervil, 62 ; root, 111

Chestnut, edible (sweet): bud-scales, 61 ; forests of, 23 ; fr., $136,{ }^{*} 137$, *187

Chestnut, horse : bud-scales, 61 ; fr., 190 ; infl., 179

Chicory, 216

Chickweed : fecundity of, 108, 165 ; pollination, 165 ; resistance to cold, 74. Seo Stellaria media

Chillies, 151

Chlorophyll : as energy-absorber, 66 ; effect of intense light on, 73 ; in mistletoe, 128

Chlorophyll-tissue : in aquatics, 49 ; in sun and shade leaves, *72, $* 73$; in zerophytes, *41, *45

Christmas-rose, 57, 177. Seo Helleborus

Chrysanthemum, 109 ; segetum, 216

Cichoriem latex, 142

Cinchona, 142, 152

Cinnamon, 151

Circcea fr., 197

Circumnutation, $† 116$

Citric acid, 143

Cladodes, $44, * 45,46$

Classifleation of plants, 217 ; artificial system, 219 ; natural systom, 219 ; biological, 105 ; climatic, 16 ; ecological, 223; physiognomic, 16; 
according to : frequency of seeding, 112, longevity. 107, mode of growth, 114, mode of nutrition, 123, water, 28,64

Clay, 82 ; absorptive power, 87 ; origin, 81 ; permoability, 87 ; physical properties of, 82, 90; relation to water, 02 ; water. capacity of, 87 ; water-retaining capacity of, 87

Clayey loam, 82

Claytonia, 215

C.eavers, 60, 197. See Galium Aparine

Cleistogamous fls., $\uparrow 165,275$

Clematis Vitalba, 214, 217 ; fr., *195; pollen-flower, 168 ; tondrils, 119

Clifis, veg. of, 283

Climate, 9 ; effect on veg., 15 ; types of, 12 ; relation of soil to, 84

Climatic factors, 9 ; types of veg, 16

Climbers, root-, 119; stem-, 114; tendril-, 120

Climbing habit, evolution of, 120

Climbing lily. See Gloriosa superba

Climbing plants, 115 ; habitat of, 119 ; leaf-mosaic, 68 ; of the hedgerow, 293 ; of woods, 267. See also Cuscuta, 128

Clouds, effect on climate, 13

Clover, 20 ; infi., 179 ; root-nodules, 95 ; sleep-movement of leaves, 70 ; white, insoct-visitor, 171, 174. See Trijolium repeno

Cloves, 151

Clubmoss, *46

Coal, 83

Coceus, 190

Cock's-loot, 217

Cocoa, 151

Coco-butter, 148

Coconut, source of alcohol, 151 ; oil, 147,148

Coffer, 151

Colchicum autumnale, 159

Cold : effect on absorption of water, 33 ; effect on pls., 73 ; effect on formation of humus, 83

Colonists, 215

Colonization : of islands, 208; of British Isles, 209 ; of Ireland, 214

Colour-adaptations, in algæ, 53

Colour of young leaves and shoots, 73

Coltsfoot, 62

Columbine, position of honey, 173

Colra-0il, 148
Combustion, 78

Commons, 271, 296 ; veg. of, 296

Competition among pls., 4, C5, 203, 208,210

Composita : infl,, 181 ; self-pollination in, 177 ; sleop-movements in flower-heads, 71; unisexual fls., 176 ; insect-visitors, 170

Concrescent type of leaf, $* 39,42$

Condiments, 151

Cones of pine, 184

Coniferous forest-belt, 22 ; woods, 250

Conifers: pollen, 167 ; seeds, 183; dispersal of seeds, 196

Continental climate, 12, 23 ; islands, 207

Convolvulus : nectaries, *169 ; sepium, climbing plant, 116, *117, insect-visitor, 171

Copper-beech, origin of, 205

Coppicing : effect on leaf-fall, 109 ; on veg. of woods, 268

Copses, 268

Corallorhiza innata, saprophyte, 124, *125

Coral-root orchid, 217. See Corallorhiza

Cork, $41,60,61,140$

Corms, 62, 63, 111 ; multiplication by, 161

Corn-bluebottle, 216 ; -buttercup. 60 ; -cockle, 216 ; -marigold, 216 ; -spurrey, 60

Corolla, 162

Cortex, *45

Corydalis claviculata, evolution of tendril, 120

Corymb, *179

Cotton-grass, 217. See Eriophorum

Cotton-grass association, 232

Cotton-grass (Eriophorum) moor, $231,250,251,252,253,254,255$

Cotton-seed oil, 148

Cotyledons, storage of food in, 146

Couch-grass, 62 ; rhizomes, *110, 154

Cow-wheat. See Melampyrum

Cranberry, citric acid in, 143

Crane's-bill. See Geranium

Cratagus Oxyacantha, thorns, 140. See Hawthorn

Creeping Jenny, 156 ; stems, 156

Crithmum maritimum, 59

Crocus, 62, 115, 215; structure of corm, *158; autumn- (see Colchicum autumnale) 
Crops : in Great Britain, 19 ; catch-, 98 ; root-, 98 ; rotation of, 97 ; variation in, 222

Cross-fertilization, 164, 165 ; -pollination, 164, 166

Cruciferæ (Crucifers), fr., 188 ; honey, 172 ; infl., 179

Cryptogams, $† 183$

Cuckoo-flower, 196 (see Cardamine pratensis); -pint, 175 (see Arum maculatum)

Cucumber (seo Cucumis) ; squirting, 196

Cucumis, tendrils, 119

Cucurbita, tendrils, 119

Cudweed, 39, 60

Cultivated fruits, 148, 149, 154; ground: weeds of, 296 (list), annuals of, 60,216 (list); land, 18,19

Cultivation : annual weeds of, 108 ; of food-products, 18

Cupule, *187

Currant, 61 ; acids in, 143. See Ribes

Current-leaves, 235

Cuscuta : twiner, 116, *128; germination of seed, 128 ; parasitic nature of, *128

Cushion-growth, 38 ; -plants, 114

Cutiele, *40,*45, 140; in aquaties, 48

Cutin, 40

Cyclamen, 215

Cymo, 178, 180,*181

Cypress, *39, 42

Cypsela, *186, *195,*197

Cytisus scoparius, 220. See Broom

Dabaccia, 213

Dahlia, tubers, 111

Dairy-farming, 20, 21

Daisy, 126, 217 ; rosette-habit, 115

Dandelion, 37, 126, 152 ; fr., 195 ; infl., 181 ; latex, 142 ; leaf-mosaic, 68 ; pollination, 170 ; rosettehabit, 115 ; root, 111 . See Taraxacum

Darkness, effect on growth, 71

Darwin : on climbing pls., 115 ; crossfertilization, 164; dispersal of seeds, 197 ; earthworms, 96 ; evolution, 202, 204 ; primrose, 177

Date, seed, 146

Deadly nightshade, 217. See Atropa Belladonna

Deadnettle, 30, 62, 216 ; honey, 173

Deal, 152
Deciduous trees and shrubs, 60,109 : woods, 265, 270 (mixed); wood. land, belt in Europe, 22

Decomposition, 78, 93

Defensive equipment of pls., 135

Dehiscence of fruits, 187

Denizens, 215

Denudation, agents of, 80

Deserts, 16, 17, 35, 86, 88, 281

De Vries, 204, 205, 221

Dhurra. See Sorghum vulgare

Dichogamy, +176

Dicotyledonous woodland, 16

Diffusion, 8, 25, 50, 92

Digitalin, 143

Digitalis purpurea, 143. See Foxglove

Dimorphism, +177

Dícecious fls., +176

Dionaa, 132

Disease-producing enemies of pls., 135

Dissected leaves in aquatics, 50

Dodder. See Cuscuta

Dog-rose. See Rosa canina

Dog's-mercury, 62 ; pollination, 176 ; rhizome, 154. Seo Mercurialis perennis

Dog's-tail grass, 217

Dominant pls., 227

Draba verna, 60, 107, 218

Drosera, 89 ; insectivorous pl., 129 , *130; See Sundew

Drought, effect on blooming of annuals, 107

Drugs, 152

Drupe: dispersal, 196 ; of holly, *147; protection by bloom, 136 ; structure, *192

Dryas octopetala, 114

Dryness, physiological, 34

Dry side of mountains, 12

Duckweed, 49. See Lemna

Dune-marsh, veg. of, 283

Dune-ridges, veg. of, 231,281

Dunes, 80 ; fixed, 230, 282 ; grey, 282 ; shifting, 281 ; white, 281

Dutchman's-pipe, 176, 217. See Aristolochia

Dwarting of plants, 36 ; by wind. $77,284,286$

Earth-acids, 83, 88, 94

Earthworms, 88, 96, 265

Ecological groupings : climatic, 16 ; physiognomic, 16 ; by habitat, 223 ; by plant-associations, 224 
Economic botany, 152

Edaphic factors, 8, 84

Eel-worm, 135

Egg-cell, 162

Elder : berries, 149 ; bud-protection, 61 ; bud-scales, 61

Elementary species, 205, 221

Elm : bud-scales, 61 ; pollination, 167 ; seed, 154 ; suckers, *155

Elodea, 56, 215, 234

Embryo-sac, *163

Embryo, storage of food in, 146

Empetrum, 43

Enchanter's-nightshade, 197. See Circea

Endemic, 208

Endocarp, 192

Endosperm, *146, *147

Enemies of plants, 135

Energy, 7 ; solar, 4, 65

Engler, 219

Entomophilous flowers, 167 ; classification of, 172

Environment : adaptation to, 3, 105, 203 ; factors of, 4

Epicarp, 192

Epidermis, *26, *27

Epiphytes, 121 ; seeds of, 122 ; of woods, 266 ; xerophytic nature of, 121

Epipogum aphyllum, eaprophyte, 124

Erica, 39, leaf, 43 ; stomata, 40, ciliaris, 213, cinerea, $*_{41}$; Mackayi, 213 ; mediterranea, 213 ; Tetralix, *43, pollination, 173 ; vagans, 213. See Heath

Erica Tetralix-moor, 231, 250, 252

Ericoid type of leaf, * 43

Erigeron canadense, 216

Eriacaulon, 214

Eriophorum. See Cotton-grass

Eriophorum (cotton-grass) moor, $231,250,251,253,254,255$

Erodium: dispersal of fr., 195; structure of fr., 190,*191

Eryngium maritimum, 59

Estuarine marshes, 231

Eucalyptus leaves, 46

Euphorbia, 105 ; latex, 142 ; hiberna, 213 : Peplis, 57

Euphrasia, 220; parasitic naturo, 126

Europe, climate and veg. of, 21

Evaporation, 34, 76

Evening-primrose: honey, 173 ; infl., 180 ; time of opening, 174
Evergreen coniferous woods, 22, 265, 273

Evergreen dicotyledonous woods, 16 , 23

Evergreen oak, 23, 212 ; perennials 109 ; plants, $10,16,29,30,31$; xerophytes, 39

Everlasting pea. See Làthyrus latifolia

Evolution, 201 ; theory, 202 ; of aquatios, 55 ; flowers, 168 ; thorns, 139

Eyobright, 220. See Euphrasia

False fruits, 193

False oat, swol len stem, 111, *113

Farming in British Isles, 19

Fats and oils, 5 ; storage in seeds, 147

Felspar, 81

Fennel, nectaries, $* 170$

Ferns, 62 ; Filmy, 29 ; Killarney, 29. 214

Fertilization, 164

Festuca - Agrostis - Anthoxanthum association, 250

Festuca ovina, viviparous, 160

Ficus. See Fig

Fig, 212 ; fr., 193, *194 ; symbiosis with insects, 133

Figwort: fls., 177 ; pollination, 174. See Scrophularia

Filament, 162

Fir, 22 ; resin of, 142

Flax, 152

Fleabane, 218

Fleshy roots, 150 ; of xerophytes, 41

Flies, visiting fls., 172, 173, 174

Floating leaves, 51 ; manna-grass (see Olyceria fluitans)

Flora, Alpine, 210 ; discontinuous, 211 ; of Great Britain, 209 ; Irish. 214 ; Lusitanian, 211 ; Pre-glacial, 212

Floras, list of, 342

Flour, 148

Flowers : anemophilous, 166 bee-, 174 ; butterfly-, 174 ; cleistogamous, $\nmid 165$; dimorphic, 177 ; entomophilous, 167 ; honey-, 169 ; and insects, 167, 178 ; moth-, 174 ; pollen-, 168; protandrous, 177 ; protogynous, 177 ; self-pollinated. 164, 165; sleep-movements in. 71 ; structure of, $162, * 163$; time of opening, 174 ; trap-, 175 ; trimorphic, 177 ; unisexual, 176 ; wasp-, 174 ; water-nollinated, 166 
Fluviatile deposits, 80

Fly-catchers, 132; -traps, 175, 177

Fodder, 21 ; -plants, 150

Follicle, 188, *189

Food, 24, 79, 145 ; -products, cultivation of, in British Isles, 18 ; -reserves, 62, 145, 161 ; -stuffs, 5

Fool's-parsley, 60, 216. See Aithusa cynapium

Forests : destruction of, 13, 22 ; maintenance of, 11, 17. Sce Woodland, Woods, Coniferous, Deciduous, Dicotyledonous, Evergreen, and Rain-forests

Forget-me-not, 2I7; early (see Myosotis collina)

Form : in relation to function, 103 ; to environment, 105

Formations, 225, 226, 227

Foxglove, 60, 108, 152; calcifuge, 89 ; inf., 179 ; pollination, 173 , 174. See Digitalis

Fox-tail grass (Alopecurus), 216

Freaks, origin of, 153

Frogbit. See Hydrocharis

Frost, 81

Fruits : achenial, 186 ; capsular, 187 ; classification of, 184, 194 ; cultivated, 148; propagation of, 149, 154; sterility of seeds in, 149 ; defensive equipment, 135,136 , * 137 ; development of, 183 ; dispersal of, 195, by animals, 196, birds, 196, 198, water, 197, wind, 196, 198; dry, 186; explosive, 196 ; false, 185, 193 ; feathered, 195 ; poisonous, 149 ; storage of food in, 148 ; succulent, 136,148 , 192 ; true, 185 ; winged, 195

Fumaria officinalis, tendrils, 120

Fumitory, 216. See Fumaria

Fungi, disease-producing, 61, 135, 138 ; parasitic, 125 ; saprophytic, 123 ; soil-, 96,133

Galium, 60; honey, 172; Aparine (cleavers), climbing habit, 116; fr., 197

Garden-annuals, 108

Geitonogamy, $\uparrow 166$

Gentian, 152

Genus, 218

Geophilous plants, $\uparrow 82$

Geophytes, 62, 74, 113, 115

Geranium: fr., 190; honey, 173 ; noctaries, $* 169$; seeds, 196 ; prosratum, 221 ; pusillum, 216; Robert- ianum, 60 ; sanguineum, 221; garden-, origin of vars., 154

Germination of seeds, 137, 138

Geum, fr., * 197

Ginger, 150, 151

Glacial Epoch, 209, 210, 212

Glaciers, 81

Gladiolus, 63

Glasswort. See Salicornia

Gloriosa superba, tendrils, 119

Glossopteris, 339

Glyceria fluitans, $\mathbf{5 1}$

Goat's-beard, 217. See Tragapogon

Gooseberry, 215 ; fr., * 193,195

Goosegrass. See Galium Aparine

Gorse: fl., 169 ; flowering of, 57 ; honey, 171 ; seeds, 196 ; thorns, 44, 139, 140. See Ulex

Goutweed, 216, 218. See ALgopodium

Granite, 80

Grape: fr., 136, 184, 193, 195 : source of alcohol, 151

Grasses: effect of shade on, 72 ; fls., 177 ; fr., 186; hay-producing, 262 ; hemi-parasites on, 126 ; infl., 179,180 ; pollination, 167

Grass-heath, 230, 249, 250; -land, $15,16,17,19,23,261$; - wrack (see Zostera) ; of Parnassis, mockglands, 171

Ground-ivy : creeping stems of, 156 ; leaf-mosaic, 68

Groundsel, 108. See Senecio vulgaris

Ground-water, 28, 85, 86

Growth : classification by mode of, 114 ; influenced by light, 71 : stunted, 36

Guano, 97

Guard-celis, *26, *27

Guilds, 122

Gulf Stream, 13

Gums, 142

Gymnosperms : pollinatıon, 163 seeds, 183

Habenaria intacta, 213

Habitat : biological, 223 ; closed, 16 ; open, 16

Hairs, 39, 6I, 136

Halophytes, $\uparrow 88,278,279$

Haptera, 235

Hart's-tongue, 217

Haustoria of parasites, 125, *129

Haw, 149, 184, 193

Hawkmoth, 170, 171, 174 
Hawkweed, 115, 220, 221. See Hieracium

Hawthorn : bud-scales, 61 ; fr., 193 ; suckers, 155; thorns, 140. See Cratogus Oxyacantha

Hay, 20, 262

Hazel : bud-scales, 61 ; fls., 176 ; fr., 187 ; infl., 180 ; oil of nut, 147 ; pollination, 167; -thickets, 269. See Corylus

Heartsease, 217

Heat : as a climatic factor, 9 ; effect on pls., 73 ; influence on vital functions, 6 ; rays, 65

Heath, 39 ; calcifuge, 89 ; mycorhiza of, 125 ; stomata, 40 ; type of leaf, 43. See Erica

Heath, 15, 16 ; Calluna-, 230, 249 , 250,252 ; grass-, $230,249,250$; summit-, 251

Heather. See Calluna

Heather-moor, 230, 250, 252, 253, 255

Hedera Helix, climbing roots, 119. $\mathrm{See}$ Iry

Hedge-mustard, honey, 172

Hedgerow plants : effect of weak light on, 72 ; list of, 292

Helianthemum Breweri, 209 ; guttatum, 213

Heliotropism, $\uparrow 68$; in the hedgerow, 292

Helleborus, honey-leaf, 172

Helminthia echioides, 60,115 . See Oxtongue

Hemi-parasites : of meadow-land, 263 ; of natural pasture, 257

Hemlock, 152

Henbane, fr., 187

Heracleum Sphondylium, pollination, 170. See Hogweed

Herbaceous perennials, $58,62,109$, $113,115,145$

Herbals, 217

Herb-Christopher, 217 ; -paris, 214 ; -Robert, 60, 217

Heterophylly, $\uparrow 51$

Heterotrophic plants, 6, 123

Hieracium, 220 ; latex, 142 ; iricum, 209

Highlands, 12, 17, 21

High-moor, 246

Hip, 149, 184, 195; citric acid in, 143

Hogweed : fls., 181"; hydathodes, 28; pollination, 170. See Herac'cum

Holcus lanatus, 115
Holly : bud-scales, 61 ; fr., *147 ; leaf, relation between form and function, 103 ; spines, 104, 139, 140 ; xerophytic chars. of, 30,39

Hollyhock, fr., 191

Honckenya peploides, 114

Honey: a source of alcohol, $15 \mathrm{l}$; con. cealment in fls., 170,172 ; position in fls., 172,173 ; protection of, 172

Honey-dew, 134; -fls., 169 ; -glands, $* 169, * 170$

Honeysuckle : bud-scales, 61 ; direction of climbing, 116 ; honey, 173 ; visits of insects to, 170. See Lonicera

Hook-climbers, 115

Hop, 214 ; climbing pl., 116, *117; fr., 194; pollination, 167. See Humulus

Hornbeam, fr., 194

Hornwort. See Ceratophyllum

Horse-chestnut : bud-scales, 61 ; fr., 190 ; infl., 179 ; leaf-mosaic, 68

Horse-radish, 151

Horse-tail, 44, 62

Hottonia, 56 ; brood-buds, 54 ; leafform, 50 ; stem-structure, *48. See Water-violet.

Houseleek, 155, *156

Humble bees, 171, 173

Humidity, 9, 11. See Moisture

Humous acids, 88, 94, 240, 244, 246 , 249

Humulus Lupulus, direction of twining, 116, *117

Humus, 19, 83, 93 ; " artificial," 83 ; mild, 94 ; of woods, 265 ; -soils, properties of, 93

Hyacinth, 63, 115 ; repr. by bulbs, 157 ; Roman, 143

Hybrids, 221

Hydathodes, $\uparrow 27,29,263$

Hydrocharis, 51, *54

Hygrophilous pls., $\uparrow 29$; tropophytes, 58, 62

Hydrophytes, $\uparrow 47$

Hygrophytic annuals, 59

Hygroscopic water, 86

Hymenoptera, 173

Hypocotyl, 146; swollen, 111

Ice Age, 22, 209, 210, 21:2, 213

Iceland moss. See Cetrariz

Igneous roeks, 82

Impatiens Yoli-me-tangere: fr., 189; seeds, 196; fulm, 215

In-breeding, 165 
Indian corn. See Zea Mais

Indigenous plants, 215

Inflorescences, 178

Insectivorous plants, 129, 131

Insect-pollination, 167

Insects, adaptation to fls., 168, 178

Integument, *163

Interdependence of $\mathrm{pl}$. and animal life, 79

Intoxicating drinks, 161

Inula salicina, 214

Ireland : alpine veg. of west of, 286 , 288 ; flora of, 213,214 ; pls. absent from, 214

Iris : aril (fotid iris), 196 ; fr., 187, *189; honey, 172; pollination, 177 ; rhizome, 154; seed, 146 ; mesophytic chars. of, 31 ; xerophytic chars. of, 31,46

Irrigation, 18

Islands : flora of, 207 ; origin of, 207

Isoëtes, 50

Ivy, 39 ; climbing pl., 119 ; honey, 172 ; leaf-mosaic, $68, * 69$. See Hedera Hetix

Ivy-leaved toadflax, 216

Jacob's-ladder, 217

Jasione montana, 60 ; insect-visitors, 170

Juncoid type of leaf, 43

Juncus-bog, 231, 246

Juncus bufonius, 59

Juniper, 36 ; leaf, 42 ; seeds, 196

Key, 186, 190

Killarney fern, 29, 214

Knight, Robert, on self-fertilization, 165

Kohlrabi, 111, *112

Labiatæ, fr., 191 ; honey, 173

Laburnum seeds, 138

Lactuca, latex, 142. See Lettuce

Lacustrine deposits, 80

Lady's-fingers, 217; -smock, 217 ; -tresses, 217

Lakes: veg. of highland-, 238 ; veg. of lowland.-, 236

Land-plants, 28 ; growth-forms of, 114

Larch, 22 ; -wood, 274

Larkspur : fr., 188, *189; pollination, 174

Latex, 142

Lathroa: parasitio habit of, 126 , * 127 ; water-glands of, 127
Lathyrus tendrils, $118, * 120$

Latitude, 10

Laurel, 23, 39, 212; bay-, 42; cherry-, extra-floral nectaries, 173

Lavender, essential oil, 143, 151

Law of heredity, 335

Leal : -fall, 60 , influenced by pruning. 109 , and coppicing, 109 ; erect-, 46 ; -modifications, 38 ; -mosaic, 45,68 ; position in xerophytes, 46 ; -scars, 62 ; shade-, 72, *72; -spines, 140, *141; sun-, *72; -types in aquatics, 50, in xerophytes, 42

Leaves : colour of young, 73 ; current-, 235 ; edible, 150 ; fixed light-position of, 69 ; floating-, 49, 51 ; heliotropism of, 68 ; sleep. movernents in, $70, * 71$

Legume, $188, * 189$

Leguminos : fr., 188 ; honey, 173

Leguminous crops, 98 ; pls. : protein of, 147 , root-nodules of, 95

Lemna, 55, 56 ; roots, 49

Lemon, 143, 151

Lenticels, 140

Lentils, 147

Lepidium ruderale, 60

Lepidoptera, 170, 174

Lepidopterous flowers, 170

Lettuce, 150. See Lactuca

Lianes, 121, 267

Lichen-flora, 22

Lichens : epiphytic, 121 ; habitat of. 133 ; symbiosis of, 132

Light: in relation to aquatics, 52 ; composition of, 66 ; source of energy, 4, 65 ; effect on growth, $36,71,72,115,120$; effect of intensity on veg. of woods, 266 , $269,270,272,274$; -position of leaves, fixed, 69, in xerophytes, 46 ; effect on transpiration, 34,45

Lignified tissue, 41

Lilae: bud-scales, 61 ; infl., 179 ; suckers, 155

Lily, 63,72 ; repr., 15 ; tiger-, repr. by bulbils, 160 ; of the Valley, 214

Lime-tree : bud-scales, 61 ; fr., 194 ; honey-dew, 134 ; insects on leaves of, 144 ; leaf, relation between form and function, 103

Lime: bicarbonate, 89 ; carbonate, 89 ; silicate, 81

Limestone, 82 ; disintegration of, 81 ; -hills, 81; -pasture, 230; 
-rocks, veg. of, 290; woods on, 272

Ling. See Calluna

Linseed oil, 143, 147, 148

Liquid-diffusion, 25,92

Liriodendron, 212

Littorella, 50

Loam, 82

Lobelia Dortmanna, 50, 56; urens, 213

Lochs, highland, veg. of, 238

Lomentum, 188, *189

London-pride, 213; offsets, 155 ; rosette-plant, *37. See Saxifraga umbrosa

Longevity : classification of pls. according to, 107; of leaves of xerophytes, 39

Lonicera. See Honeysuclde

Loosestrile: purple (see Lythrum Salicaria); yellow (see Lysimachia vulgaris)

Lousewort. See Pedicularis

Lowland-pastures, 230,258 ; -plants found in alpine regions, 289 ; -rocks, veg. of, 290

Low-moor, 246

Lung wort, 217

Lusitanian Flora, 211

Lychnis: fl., 174; fr., 187; honey, 173

Lycopsis arvensis, 216

Lysimachia vulgaris, insect-visitor, 171

Lythrum Salicaria, Als., 177

Macroxis, 171

Magnolia, 212

Maize, sugar of, 146. See Zea Mais

Malic acid, 143

Mallow, 216 ; fr., 191, *192

Malva sylvestris, 216

Man, influence on veg., $13,18,19$, 198, 227, 293

Mandioc (Manihot), tapioca from, 150

Mangold, 150

Manna-grass. See Glyceria fluitans

Manures, 96; artificial, 97; a source of humus, 83 ; living, 97 ; natural, 96; effect on veg. of meadows, 262

Maple : bud-scales, 61; fr., 190, 195; honey-dew, 134; leaf-mosaic, 68, $* 70, * 71$; origin of variegated vars., 154

Maqui, 23

Marigold, fr., 137
Marine deposits, 80

Maritime : aquatic veg., 275; as. sociations, 275 ; pls. growing in alpine regions, 288 , adaptations of, 281

Marl, 82

Marram-grass : leaf, $40, * 43$; association of, 281 ; binding power of, 281. See Psamma

Marsh : -annuals, 59, 240 ; dune-, 283 ; estuarine-, veg. of, 231,278 ; freshwater-, $230,240,283$; -marigold, 168 ; -plants : habit compared with bog pls., 245, chars. of, 240 , geophilous, 62, hygrophilous, 29,58 ; position of leaves with regard to light in, 46, tropophytes, 58 , xerophytic ohars. of, 58 ; salt-, veg. of, 231,278 ; true, 244,253

Mead, 151

Meadow-land, 261 ; weeds of, 263

Meadows, 15 ; on damp soils, 263 ; on dry chalk soils, 264 ; salt-, 279

Meadow-saxifrage, 62, 160 . See Saxifraga granulata

Meadow-sweet, 217

Mealies. See Zea Mais

Meat, 5 ; transformation of veg. into, 20

Medicago, 60 ; fr., 188 ; infl., 179

Medick. See Medicago

Meditorranean region, 16, 23

Melampyrum, parasitic nature, 126

Melilot, 216

Mericarp, +190

Mesocarp, 192

Mesophilous tropophyles, 58, 62

Mesophytes, $\uparrow 29,31$

Mesophytic annuals, 60

Mica, disintegration of, 81

Micropyle, 163

Mignonette, insect-visitor, 174

Millet, 147,148

Milk, 20, 21 ; -thistle, 216, 217

Mimiery, 137, 138

Mineral salts, $24,33,123$

Mint, 62 ; honey, 173 ; rhizome, *110; repr. by rhizomes, 154 ; volatile oil, 143

Mistletoe, 214 ; berries, 149 ; parasitic nature of, $128, * 129$

Mock - orange, suckers, 155

Moisture, 11, 34. See Humidity

Mole-heaps, 258

Molinia cærulea-bog, 231, 250, 251

Monkshood, 217 ; honey-leaf, * 171

Monoearpie plants, +112 
Moncecious flowers, $† 176$

Monotropa, saprophytic nature of, 124

Montbretia, 159

Moor: cotton-grass (Eriophorum), $231,250,251,252,253,254,255$; Erica Tetralix-, 231, 250, 252 ; heather-, 230, $250,252,253,254$; high-, 246 ; low-, 246 ; moss-, 225, 254 ; shooting-, 252 ; Vaccinium-, $231,249,251$

Moorland, 16, 19, 248 ; pls., ohars. of, 249

Morphia, 143, 152

Morphology, $+103,104,184$

Mosehatel. See Adoxa

Moss-campion (seo Silene acaulis) : -moor, 225, 254; -rose, prickles, 116

Mossy saxifrage. Seo Saxifraga hypnoides

Moths, 170, 173, 174

Mould, 94

Mountain-ash berries, 149; -avens (see Dryas octopetala)

Mountains : light, 35, 36; rainfall, 12,17 ; tempera ture, 11,17 ; veg., 22,36 ; lowland pls. growing on, 289

Mountain-torrents, veg. of, 234

Mouse-ear chickweed. See Ceras. tium

Mouse-tail. Seo Myosurus

Mucilage, *41

Mulberry, fr., 192,*193

Mullein, 39, 108

Musa Sapientum, 149

Mustard : fr., *190 ; source of, 148 , 151 ; and cress, 150

Mutation Theory, 204

Mycorhiza: of bog and moorland pls., 246,249 ; of forest-trees, 267 ; of partial saprophytes, 125 ; of saprophytes, *128; symbiosis, 133

Myosotis collina, 107

Myrica-bog, 231, 250, 253

Myriophyllum : brood-buds, 54 ; pollination, 167

Myrmecophily, $\dagger 133$

Myrtle, 23 ; leaf-type, 43

Narcissus, 62, 63 ; bulb, *157 ; fr., 186,189 ; infl., 181 ; nectaries, 169

Nardus stricta-association, 251

Nasturtium amphibium, 28 ; garden- : hydathodes, 28; tondrils, 119 ; fr. and seed, * 147
Natural manures, 96 ; Orders, 105 ; regions of dryness, 35 ; Selection, 139,203

Nectaries, 169; extra-floral, *118, 134, 173; sham, 171

Nectarine, origin of, 205

Needle-type of leaf, 42

Nepenthes, 132

Neottia, saprophytic nature, 124

Nettle, 152. See Urtica

Now Zealand flax, 42

Nightshade : common, 216; deadly (see Atropa Belladonna); enchanter's, 197 (see Circcea); woody. 152, sham-nectaries, 171

Nitrate-bacteria, 95

Nitrates produced by bacteria, 95

Nitrites produced by bacteria, 95

Nitrogen, 7 ; -bacteria, 95 ; circulation of, 99 ; fixation of, by bacteria, 99; losses of, in soil, 99 ; sources of, in soil, 99 ; utilization of, by pls., 95

Nitrogenous food-reserves, 146

Nomenelature of pls., 217

Norfolk Rotation, 97

Nuphar, 52

Nutmeg, 161

Nutrition : of green pls., 123 ; in sectivorous pls., 129; non-green pls., 123 ; parasites, 125 ; saprophytes, I23; effect of xerophytic conditions on, $36,38,139$

Nuts, ${ }^{*} 187$, 196; oil, 146; protection against animala, 136

Nux-vomica, 138

Nyctitropism, 70

Oak, 22 ; bud-scales, 61 ; competition with the birch, 270, 271; effect of coppicing, 109 ; enemies of, 138 ; galls, 138; pollination, 167 ; tannin of, 142

Oak-birch-heath association, 229 , 271,296

Oakwood-associations, 229

Oak-woods : damp, 269 ; dry, 270 ; lowland-, 269 ; upland-, 270

Oats, cultivation of, 20,98 ; food, 147

Ocean-currents, 13

Oceanic climate, $12,21,22$; islands, 207

Enanthe fuviatilis, 209; Phellandrium, 50

Atnotherabiennis (see Evening-primrose); Lamarckiana, 296

Ofisets, 155 
Oils, 5 ; antiseptic, 136 ; fixed, 142 ; as a food-reserve, 146 , in seods, 147 : volatile, 143,151 ; in xerophytes, 42

Oily seeds, 148

Old man's-beard, 217. See Clematis Vitalba

Olive, 23

Onion: bulb, 150 ; bulbils, 160 ; infl., 181 ; seeds, $* 146$; sugar, 146,150

Ononis arv'nsis, spines, 44

Open associations, 277 ; habitats, 16

Opium, 143, 152

Orange, 23

Orchid: bird's-nest (sce Neottia); coral-root (see Corallorhiza); fr., 189 ; honey, 173; infl., 180; pollination, 177; seed, 195; tubers, 111

Origin of species, 202

Orobanche, 127

Orobus, fr., *189

Osier-beds, 244

Osmosis, 25, 91

Ovary, 162, 183

Ovule, 162

Oxalis, 62 ; aril, 196 ; cleistogamous fls., 165 ; fr., 189 ; oxalic acid in, 143 ; rhizome, 154; seeds, 196 ; sleep-movements of leaves, 70 , *71. See Sorrel

Oxtongue, 60, 217. See Helminthia echioides

Oxygen, 6, 7; in air, 78, 79; in water, 48,50 ; in soil, 88

\section{Pmony, 168}

Palisade-tissue, 41, ₹72

Palm, 23 ; -oil, 148

Pampas, 20

Panicle, 178, 179

Papaver somniferum, alkaloid of, 143, 152

Paper-making materials, 152

Pappus, 195

Parasites, $6,+125,206$; partial, 126 ; total, 126 ; hemi-parasites of meadow-land, 263, of natural pasture, 257

Parallel development, 105

Parietaria officinalis, fls., 177

Paris quadrifolia, 214

Park-land, 17, 126

Parsley, 181

Parsnip, 150

Partial parasites, 126 ; saprophytes, 125
Passion-fiower, tendrils, *118

Pastures, 15, 18, 20; alpine, 230, 251,259 ; artificial, 20,261 , weeds of, 264 ; limestone-, 230, 259 ; lowland-, 230,258 ; natural, 257 ; sub-alpine, 230,258

Pea : fr., 188; pollination, 165 ; protein of, 147 ; root-nodules, 95 ; seeds, 146, 195; tendrils, 118. See Lathyrus

Peach : fr., * ${ }^{*} 192$; origin of, 205

Pear : bud-scales, 61 ; cultivation of, 149

Peat, 17, 83, 93, 94, 244, 248, 254; absorptive power of, 87 ; -bogs, 246,248 , xerophytic factors of, 35 ; moorland-, constitution of, 249 , comparison with marsh-peat, 249, conditions necessary for formation of, 248 ; water-capacity of, 87 . See Humus

Pedicularis, 59; parasitic nature, 126

Pelargonium : fr., 190, 195 ; infi., 181

Pellitory. See Parietaria officinalis

Pennyeress, 216

Pepper, 151 ; -mint, 151

Percolation in soils, 87

Perennating organs, 62, 109 ; structures, +62

Perennials, 108 ; evergreen, 109 ; herbaceous, 109, 115, 145; tropophytic, 59 ; xerophytic, 59

Perianth, $† 162$

Pericarp, 183

Permeability of soils, 87

Peruvian bark. See Cinchona

Petals, 162

Petioles : of A cacia, 43, *44 ; of floating aquatic leaves, 51

Phaseolus vulgaris, twiner, 116. See Scarlet runner.

Phleum arenarium, 60

Phloom, *45; in aquatics, 49

Phormium tenax, 42

Photosynthesis, $\uparrow 4,66,78$

Phragmites, 62 ; -associations, 242 , 245

Phylloclade, 44, *45

Phyllode, 43, *44, 46

Physical action of water on rocks, 81 ; properties of soil, 85

Physiognomic groups, 16

Physiological dryness, 34, 85

Physiology, $\dagger 103$

Pillwort. See Pilularia

Pilularia. 28, 50 
Fimpernel, fr., 187, *188

Pine, 22, 39, 272 ; leaf, 42 ; mycorhiza, 125; pollination, 163, 167; former range of, 273 ; resin, 142 ; seeds, 183, 195 ; shade cast by, 273 ; stomata, $* 40$

Pineapple, 194

Pin-eyed fls. of primrose, 177

Pine-woods, 273

Pinguicula: insectivorous pl., 130, * 131 ; grandiflora, 213 ; lusitanica, 213 ; vulgaris, 130

Pinks, infl., 180

Pistil, 162

Piteher-plants, 132

Pith, *45

Plains, 12

Plane, bud-protection, 61

Plantain, 37 ; fls., 177; fr, 187 ; infl., 180 ; pollination, 167

Plant-associations, 224

Plasmolysis, $\uparrow 92$

Plateaux : climate of, 12 ; growthform of pls. on, 36

Plum: bud-scales, 61 ; cultivation of, 149 ; fr., 184, 192, 194 ; extra. floral nectaries, 173 ; suckers, 155

Poa alpina: fecundity of, 108 ; vivipary, $160, * 161$; annua, 60

Pod, 188

Poisonous fruits, 149 ; pls., 162 ; seeds, 138

Polar regions : duration of sunlight, 67; growth-form in, 36 ; xerophytic factors of, 35

Polien, 162 ; -bread, 168 ; -fls., 168 ; -grains, 162, 163; -tube, *163; of wind-pollinated fls., 166 ; of Zostera, 166

Pollination, 163, 164 ; agents of, 166 ; by birds, 176 ; cross-, 164,166 ; by insects, 167 ; self-, 164 , effect on the stock, 165 ; prevention of, 176 ; by slugs, 176 ; a form of symbiosis, 133 ; by water, 166 ; by wind, 166

Polycarpie plants, +112

Polygonum amphibium, 28, 56 ; Convolvulus, direction of twining, 116 ; dumetorum, imperfect twiner, 117

Polypody, epiphytic, 121

Pome, 193

Ponds, lowland-, veg. of, 236

Pondweeds, 233. See Potamogeton

Pools, highland-, veg. of, 238

Poor man's weather-glass, 217. See Anagallis
Poplar: bud-scales, 61 ; fls., 176 pollination, 167, seeds, 195; suckers, 155

Poppy, 216 ; fr., 187 ; opium-, 152 ; seeds, $146, * 147,195$; summerannual, 107

Pore-space, 85

Potamogeton crispus, brood-buds, *51, 54 ; leaf-form, 50, *51

Potash, silicate of, 81

Potato, 62 ; a source of alcohol, 151 ; food-reserve in tubers, 150 ; "seed"-, 149; starch, 145; tubers, *111; repr. by tubers, 149,159

Potato, sweet, 150

Potentil, honey, 172

Poterium, pollination, 167

Prairies, 9, 15, 23, 35

Prickles, 139, 140

Primrose : dimorphism, 177; honey, 173

Privet : berries, 149 ; bud-scales, 61 : origin of variegated vars., 154 ; effect of pruning, 109

Prostrate stems, pls. with, 114

Protandrous flowers, $\nmid 177$

Protein, 5, 124; in seeds, 146, 147

Protogynous flowers, $\uparrow 177$

Protoplasm, 92, 93

Protozoa, soil, 96

Prunus spinosa, thorns, 140

Psamma, 62; -association, 281; leaf, $40, * 43$; binding power of, 281

Pseudocarp, 185, 193

Putrelaction, 78, 93

Puzstas, 20

Pyrus torminalis, 214

Quartz, 80

Quinine, 142, 152

Raceme, 178, *179

Radical and eauline leaves, pls. with, 115

Radish, 216; fr., 188 ; fleshy root, 150

Rainfall, 11

Rain-forests, 9, 16, 23, 27, 121 ; -shadow, 12

Ranunculaces, nectaries, 169

Ranunculus aquatilis, 56,220 , heterophylly, 5l, leaf-form, 50, 51 ; arvensis, 60 ; Ficaria, tubers, 154, 159 ; sceleratus, 59

Rapo:-oil, 148 ; -seod, 148 
Rare plants. See Aliens, Alpines, Discontinuous, and Lusitanian floras

Raspberry : fr., 192 ; acid in, 143; suckers, 155

Receptacle, *163

Reduction in structure, 206

Reed : common (see Phragmites); -mace (see Typha)

Reeds, 62; position of leaves in relation to light, 46 ; pollination, 167

Reed-swamp, 225, 230, 241 ; zoning of, 242

Reed-type of leaf, 43

Reindeer-moss, 22

Reproduction : of maritime aquatics, 275 ; by seed, 153, 162 ; vegetative, 153,154

Resin, 142

Respiration, 6, 7, 78; of aquatics, $48,50,52$; of roots, 88

Rest-harrow, thorns, 44

Retrogression, 206

Reversal-point in tendrils, 115

Rhinanthus, 60; parasitic nature, 126

Rhizomes, $62, * 110$; food-reserves in, 150 ; multiplication by, 161

Rhododendron, leaf-form, 43

Rhubarb, 152 ; calcium oxalate in, 143 ; culinary, 150

Ribbon-type of leaf in aquatics, 50, 51

Ribes, 215 ; bud-protection, 61

Rice: food, 147 ; -starch, 146

River-banks, veg. of, 243

Rivers, veg. of, 235

Robinia spines, 140,*141

Rock-cress (see Arabis); -rose, 169

Rocks : alpine, veg. of, 286 ; classification of, 82 ; denudation of, 80 ; limestone-, veg. of, 290 ; lowland-, veg. of, 290 ; maritime, 231, veg. of, 283 ; sub-alpine, veg. of, 290 ; xerophytic factors of, 35

Rocky summits, veg. of, 289

Rolled-leaves, $40, * 41, * 43$

Root-absorption, 25 ; -climbers, 119 ; -crops, 21, 98 ; -hairs, *25, 49, 91 ; -nodules, *44, *95, 97, 98, symbiosis, 133 ; -stock, 38, 62, 110 ; -tubers, 111

Rootless plants, $49,131, * 132$; Corallorhiza, 124

Roots: of aquatios, 49 ; clasping, 121 ; fleshy, 150
Rosa canina, climber, 116 ; spinosissima, prickles, 116

Rose, 220 ; bud-protaction, 61 ; bud. scales, 61 ; fl., 168 ; fr., 103 ; moss-, 116; prickles, 116, 141 ; suckers, 155

Rosemary oil, 42

Rosette-habit, *37, *62; pls., 60 , 115

Rotation : of crops, 97 ; -grasses, 20

Rubber, 142, 152

Rubus, 220; scramblor, 116. See Bramble

Rum, 151

Rumex, pollination, 167

Runners, 155, 161

Rupture-wort, 218

Russia, 12, 21, 22

Rye, 147

Sage oil, 42, 143

Sagittaria, heterophylly, 52 ; winterbuds, 64

Sago-palm, food, 150

Sainfoin, fr., 188, *189

St. Dabeoc's-heath, 213, 217

St. John's-wort, 217 ; fl., 169

Salicornia, $41,58,59,88,278$; -association, 277,278

Salix, 220. See Willow

Salsola Kali, 59

Salt : common, 88 ; effect on absorption, 33,88 ; -marsh, veg. of, 231 , 278 ; -meadow, 279 ; -swamps and marshes, zerophytic factors of, 35

Saltation, 204

Saltwort. See Salsola Kali

Salty seaside soils, 35

Samara, 186, *187, 190

Sand, 82 ; absorptive power, 87 ; origin from granite, 81 ; permeability, 87 ; physical properties, 81,90 ; water-capacity, 87 ; waterretaining capacity, 87

Sand-dunes, 16, 82, 90 ; formation of, 279 ; fixed, veg. of, 230 ; ridges, veg. of, 231 ; veg. of, $58,59,107$, 225

Sandstone-hills, veg. of, 257

Sandy loam, 82 ; soils, 35

Saprophytes, 6, *123, 206 ; partial, 125; total, 124; of woods, 266

Sarsaparilla. See Smilax

Savannah, 17. See Park-land

Saxitraga Geum, 213, 221 ; granu. lata, 62, bulbils, 160 ; hirsuta, 213 ; 
hypnoides, 38, 114 ; tridactylites, 60 ; umbrosa (London-pride), 37, $155,213,221$

Saxilrage: honey, 172 ; meadow- (see Saxifraga granulata); mossy (see S. hypnoides)

Seabious, 218 ; inf., 181 ; insectvisitors, 170

Scale-leaves of bulbs, 156

Scales, bud-, morphology of, 61

Scarlet runner, 116

Scar-woods, 269

Scent of pls., 143

Schizocarps, $\nmid 190$

Selerenchyma, $41, * 43$

Scotland : climate, 13 ; alpine veg. of Highlands, 287 ; veg. of mountains, 17,287

Scramblers, 115

Scrophularia, insect-visitor, 174

Scrophulariaceæ : hemi-parasites of, 126 ; honey, 173

Scrub-communities, 17

Seurvy-grass, 218

Sea-blite (see Sueda maritima); couch - grass association, 280; -holly (see Eryngium); -purslane, 218; -rocket (see Cakile maritima); -samphire (see Crithmum maritimum)

Seashore : condition of soil-water, 88 ; veg. of, 275

Seaside-annuais, 58, 59

Seasons, effect on veg.: summer and winter, $10,31,57$, wet and dry, 10

Seaweeds : colour of, 53 ; zoning of, 278,283

Sedges, 46, 62, 115 ; pollination, 167

Sedum acre, *39; Rhodiola, 62

Seedlings, *25; of Acacia, *44; protection of, 138

Seed-plants, 163, 183

Seeds : in aquatics, 54 ; albuminous, *146, *147; defensive equipment, 135, 137; dispersal: by animals, 196, birds, 196, man, 198 , water, 197, wind, 195; of epiphytes, 122 ; exalbuminous, 146, *147; explosive, 196 ; formation of, 162, 183 ; hairy, 195 ; oily, 148, 196 ; repr. by, 153, 162 ; resistance to cold, 74 ; starchy, 147 ; sterile, 149 ; storage of food in, 108, 146 ; winged, 195 ; zerophytic chars. of, $59,74,137$

Selective absorption, 91
Self-fertilization, 165; -pollination, 164 , effect on stock, 165 , prevention of, 176

Semi-deserts, $9,12,36$

Senecio, 105; Jacobcea, insect-visitors, 170 ; vulgaris, autogamy, 165

Sepals, 162

Service-tree. See Pyrus torminalis

Shade-plants, $72, * 73$

Sheep, 20 ; fat-tailed, 145; -runs, 257

Shepherd's-needle, 216, 217 ; -purse (see Capsella)

Shirley poppy, origin of, 153

Shoots : colour of young, 73 ; xerophytic forms of, 42

Shore, sandy, veg. of, 279

Shoreweed. See Littorella

Shrubs, deciduous, 60, 109

Silene: fr., 187, *188; honey, 173 ; acaulis, 38,114 ; nutans, 174

Siliea, 82,98

Silicate of alumina, 81 ; lime, 81 ; potash, 81

Silieula, 188

Siliqua, 188, *190

Silverweed, 217

Simethis, 214

Sinapis, 148 ; arvensis, 216

Sisyrinchium, 214

Sleep-movements: in fls., 71 ; in leaves, $70, * 71$

Sloe. See Prunus spinosa

Slopes, exposed maritime, veg. of, 284

Slugs, 176

Smitax, 212 ; tendrils, 119

Snapdragon : fr., 187, *188; honey, 171

Snowdrop, 57, 63, 214, 215

Societies, plant, 225

Soil, $8,14,80,91$; acids in, 88,94 ; aeration of, 87 ; aldehydes, 101 ; animals in, 96 ; -bacteria, 83,88 , $95,96,123$; biology of, 91 ; capillarity, 86 ; chemical properties, 80 , 88 ; and climate, 14, 84; dry, 85 , 87 ; -factors, $8,18,19$, influence on flora, 21, 84; forest-, 18; formation of, 80 ; -fungi, 96, 133; nutriment in, $24,33,83$, 90,93 ; percolation of, 87 ; permeability of, 87; living popula. tions of, 94; physical properties, $80,85,90$; protozoa, 95 ; salt-, 33 ; sour, $33,35,88,94$; and temperature, 87; influence on 
veg., 21, 84 ; warm, 87 ; water in, 28,84 ; water-capacity, 86 ; waterretaining capacity, 87 ; xerophytio factors of, 35

Solanum Dulcamara, inoipient climber, 116 ; nigrum, 216

Solar energy, 4, 9,65 ; spectrum, 66

Sonchus, latex, 216 ; arvensis, 216

Sorghum vulgare, 148

Sorrel, wood. See Oxalis

Sow-thistle. See Sonchus

Spadix, *175, 178

Sparganium natans, leaf, 51

Spathe, *175, 178

Species, 218, 219, 224 ; elementary, 205,221 ; origin of, 202

Spectrum, solar, 66

Spermaphytes, 183

Sphagnum, 89, 253

Sphagnum-bog, 231, 250, 252, 253

Spices, 150, 151

Spike, 178, *180

Spinach (Spinacea oleracea), 150

Spindle-treo : aril, 196 ; honey, 172 ; structure of seed, 146

Spines : of holly, 104 ; origin of, 139 ; as a protection, 136, 140, *141; in xerophytes, 44

Spirara, pollen-fl:, 169

Spiranthes Romanzoviana, 214

Spirits, 20, 151

Sports, horticultural, 153

Spurge, 216, 218 ; latex, 142

Stachys arvensis, 57,216

Stamen, 162

Starch: formation of, 5,66 ; reserve-, 145

Starchy seods, 147

Stellaria media, fertilization, 165

Stems : assimilating, $44, * 45$; edible, 150 ; stunted growth of, 36 ; -tubers, 111

Steppes, 19, 23, 35

Stigma, 162 ; of wind-pollinated fls., 167

Stinging hairs, *141; nettle, 167 , 216

Stipules : as bud-scales, 61 ; hollow, 133 ; as spines, $140, * 141$; as tendrils, *118

Stitchwort, 217 ; cleistogamous fls. 165

Stolons, 155

Stomata, *+26, *27; in aquatics, 49 ; regulating transpiration, 32 ; in xerophytes. $38,39,40, * 41$, *43
Stonecrop, *39, 41, 218; honey, 172

Stones, xerophytio factors of, 35

Storage of food-reserves, 145

Stork's-bill, 217. See Erodium

Strand-vegetation, 277, 279

Stratifeation of plants in woods, 228

Strawberry : acids in, 143 ; fr., 184 , $187, * 193$; stolons of, *155

Strawberry-tree. See Arbutus Unedo

Streams, veg. of, 235

Struggle for existence, 203, 208, 210

Strychnin, 143, 148

Strychnos Nux-vomica, 143, 148

Stunted growth of stems, 36

Style, 162

Sub-alpine pastures, 230 ; rocks, veg. of, 290

Subdominant plants, 227

Submerged leaves, 50

Subularia, 55

Succulent plants, $* 39, * 41, * 42,58,88$ (see Halophytes) ; fruits, 136, 192 Suckers, 155, 161

Sueda maritima, 58, 59

Sugar, 5, 146; -cane (Saccharum officinarum), 150, 151; -maple (Acer saccharum), 150

Sumach, 212

Summer-annuals, 107

Summit-heath, 251

Sun, the source of energy, 4, 65

Sundew, 89 . See Drosera

Sunflower: $\mathrm{fr}$., 187 ; seed, 146

Sunlight, 4, 65 ; duration of, 10,67 ; influence on veg., 67 ; intensity of, 67. See Light

Sun-plants, *72

Survey-maps, ecological, list of, 344

Surveys, ecological, 229

Survival of the fittest, 203

Swamp-eypress, 212

Swamps : bush-, 243 ; reed-, 241. See Boge and Marshes

Swede, 111, *112, 150

Sweet chestnut, $23,61,136, * 137$, * 187 ; cicely, 216 ; potato, 150

Switch-plants, $44, * 45$

Sycamore, fr., 190, *I91 ; dispersal of fr., 195

Symbiotic insects, 133, 144 ; pls., 132

Symbiosis, 132

Syncarpous ovaries, $\uparrow 183$

Tamus communis, 214 ; berries, 149 ; climbing pl., 116. See Black Bryony 
Tannin, 150

Tapioca, 150

Taraxacum. See Dandelion

Tares, 218

T'axodium, 212

Tea, 151

Telluric water, $\nmid 28,85,86$

Temperature, $6,10,11,18$; effect on pls., 74, rocks, 81 , soil, 87 ; effect on transpiration, 34, 74. See Heat and Cold

Tendril-climbers, 117

Tendrils : leaf-, 118; leaf-tip, 119 ; morphology of, 118; petiole-, 119 ; stipule-, 119; stem- or shoot., 118

Terrestrial plants, 28, 114

Thalictrum minus, pollination, 167

Thesium humifusum, parasitic nature of, 126

Thickets, 268; alder- and willow-, 229, 243, 269 ; hazel-, 269

Thistle, 198; fr., *195; prickles, 141

Thorny plants, $17,44,139$

Thorns : origin of, 139 ; as a protection, 140 ; in xerophytes, 17,44

Thrift, infl., 181

Thrum-eyed fls. of primrose, 177

Tiger-lily, bulbils, 160

Till, 80

Timber, 22, 152

Toadflax (Linaria), 62, honey, 170, pollination, 173; bastard- (see Thesium)

Tobacco, 152 ; -plant: fl, 174, honey, 173 , pollination, 173

Toddy, 151

Toothwort, 126, 217. See Lathraea

Touch-me-not, 217. See Impatiens Noli-me-tangere

Tragapogon, latex, 142

Transpiration, 26,32 ; in aquatics, 52 ; causes which increase, 34,35 ; regulated by stomata, 32 ; influenced by wind, 76 ; in winter, 60 ; in xerophytes, $32,34,35,36$, 40

Transpiration-current, 25,32 ; in hygrophytes, 29 ; in xerophytes, 32

Traveller's-joy, 214. See Clematis Vitalba

Treacle-mustard, 216

Tree-growth: limit of, in England, 270 ; effect of wind on, 77 ; effect of xerophytic conditions on, 36
Trees, deciduous, 60, 109

Trichomanes radicans. See Killarney fern

Trifolium arvense, 60 ; repens (white clover), 171,174

Trimorphic flowers, 177

Tropocolum majus: hydathodes, 28 ; tondrils, 119 ; fr. and seed, $* 147$

Tropical rain-forests, $9,16,23,27$, 121

Tropies: climate, 10; duration of sunlight, 67 ; veg., 10,23

Tropisms, 68

Tropophytes, 30, 31, 57; hygrophilous, 58; mesophilous, 58 ; xerophilous, 58

Tuberous roots, 111

Tubers, $60,62,110$; food-reserves in, 150 ; multiplication by, 159,161 ; root-, 111 ; stem-, 111

Tufted habit, 115

Tulip, 62,63 ; bulb, 156, *157

Tulip-tree, 212

Tundras, 21

Turgidity, 24

Turnip, 108, 111, 150

Turpentine, 142

Twiners, 116

Typha, 62

Ulex europoeus (see Gorse); minor, 214

Ultra-violet rays, 65

Umbel, 178, 181, *182

Umbellileræ : fls., 176 ; fr., 186, 191 , *192; honey, 172; infl., 181 ; insect-visitors, 170 ; nectaries, $169, * 170$; seed, 146

Uncultivated land, 18

Underground perennating organs, 109

Undergrowth of woods, 266

Units of classifleation. See Variety, Species, Genus, Association, Formation

Urtica: stinging hairs, *141 ; dioica, 216 ; urens, 216

Utricularia: brood-buds, 54 ; insectivorous habit, 131, *132; leaf-form, 50; pollination, 56 ; absence of roots, 49

Valerian, 152 ; infl., 180 ; pollination, 170

Vaccinium-moor, 231, 249, 251, 255

Vallisneria, 50

Variation, 210, 219, 220 ; bud-, 153 
Variegation in leaves, 154

Varieties, 219, 221

Vegetable-marrow, 119

Vegetables, culinary, 150

Vegetation: relation to climate, 9 , 15 ; climatic subdivisions of, 16 ; of Europe, 21; physiognomic divisions of, 16 ; relation to soil, $14,21,84,88,91$; types of, 15

Vegetative reproduction, 149, 153

Venus' fly-trap, 132

Verbena officinalis, 216

Vernal whitlow-grass. See Draba verna

Veronica: evergreen, 46 ; honey, 173 ; agrestis, 216 ; arvensis, 216

Vetch, 216, 218. See Vicia

$\nabla$ iburnum Lantana, 214

Vicia, tendrils, 118 ; sativa, 216

Victoria regia, 51

Vine, tendrils, 118, 119

Viola : cleistogamous fls., 165 ; fr., 187, *197; insect-visitors, 171, 174; nectaries, 169 ; seed-dispersal, 196

Violet, 218. See Viola

Virginia-creeper, tendrils, 118

Viscum album, parasitic nature of, $128, * 129$

Vitis, tendrils, $118, * 119$

Viviparous pls., $\nmid 160$

Wales, veg. of mountains, 17

Wallflower, 108 ; fr., 137, 187

Walls, veg. of, 290

Walnut, 212 ; oil, 143,147

Wasps, 172,174

Waste ground, veg. of, 295

Water : absorption of, by roots, 25, $33,35,74,91$; causes reducing absorption, $32,33,35$; effect of cold upon absorption, 74 ; amount available to pls., 85 ; amount entering the soil, 85 ; amount retained by the soil, 85 ; capacity for heat, 11 ; -capacity of soils, 86 ; capillary-, 86 ; chemical action on rocks, 80; classification of pls. according to, 64 ; as an agent of denudation, 80 ; evaporation of, 34,76 ; excretion of, $27,29,263$; -films, 85 ; -glands, 127 ; ground or telluric-, $28,85,86$; hygroscopic, 86 ; light in, 52 ; path of, in stems, 25; physical action on rocks, 81 ; percolation of, in soil, 87 : influence on pl. life, 24,32 ; rôle in pls., 24 ; an agent of pollination, 166 ; -retaining capacity of soils, 87 ; agent of seed dis. persal, 197 ; soil-, 28 ; stomata, 27 ; -storing tissue, 41 ; -supply. $18,19,28$; -vapour, 6,26

Water-buttercup (see Ranunculus aquatilis) ; -cress, 151 ; -dropwort (ses Qrnanthe); -lily: Ieaf, 51, seeds, 197, stomata, 49, wintorcondition, 54 ; -lobelia (see Lobelia Dortmanna); -plantain (see Alisma Plantago); -plants (see Aquatics); -starwort (see Callitriche); -violet (see Hottonia)

Waterfalls, veg. of, 234

Wax, 136

Waylaring - tree. See Viburnum Lantana

Weeds : of cultivated ground, 296 ; of cultivation, $60,108,215,216$ (list), 227, 297 (list); of the meadow, 263; of the natural pasture, 264

Weathering of rocks, 80

Woeping ash, 154 ; willow, 154

Weismann's law of heredity, 335

Wet meadow-plants, hygrophilous chars. of, 29

Wheat: albuminous seed of, 146; aleurone-layer of, 147; as a food, 147; -crops, 98; cultivation of, 18 , 19; flour of, 148

Whisky, 151

Willow, 220, 221 ; bud-protection, 61 ; bud-scales, 61 ; fls., 176 ; seeds, 195 ; -thiclwts, 229, 243, 269 ; weeping-, 154

Willowherb: fr., 187, 189 ; honey, 173 ; infl., 180 ; seeds, 195,197

Wind, 12 ; effect on pls., $36,37,76$, 284,286 ; agent of pollination, 166 ; effect on transpiration, 34 ; agent of seed-dispersal, 195, 198 ; forming sand-dunes, 279

Wine, 151

Winter, 10 ; -rest in aquatics, 54 ; -rest in tropophytes, 57

Winter-aconite, fl., 57

Wistaria : climbing pl., 116 ; spiny stipules, 116

Wolffia, absence of roots, 49

Woodland, 15, 16, 17, 265; belt of deciduous-, in Europe, 22 ; swamp-, 243, 269

Woods : artificial, 267 ; ash-, 229, 272 ; ash-oak, 229,272 ; beech-, 
229, 272 ; birch, 229, 271 ; deciduous, 265, 270 ; evergreen coniferous, $230,265,273$; groundveg. of, 266 ; larch-, 274 ; natural, 267 ; oak-, 229, 269 ; pine, 273 ; scar-, 269

Wood-sorrel. See Oxalis

Wormwood, 42

Wounds, 140

Xerophilous tropophytes, 58, 62

Xerophytes, 29, 30, 36, 74, 77, 89 ; air-spaces in, 40; palisade-tissue in, $41, * 72$; cuticle of, 40 ; development of hairs and scales in, 39, of sclerenchyma in, 41, *43; evergreen-, 39 ; mucilage in, *41; position of leaves in, 46 ; size of leaves in, *39; oil in, 42 ; water-storing tissue in, 41

Xerophytic annuals, 59 ; chars., 30 , $36,58,60,61$; conditions, 33 , effect on form of leaf, 38, of stem, 36 ; factors, 32,35 ; forms of leaf and shoot, 42 ; structures in leaves, 39,40 ; regions, $35,77,89$; tendencies, 39

Xylem, $* 45$; in aquatics, 49

Yellow bird's-nest (see Monotropa); rattle (see Rhinanthus); water-lily (see Nuphar)

Yew: leaf-mosaic, 68 ; succulent seeds, 196 ; Irish, origin of, 205

Yucca, 133

Zannichellia, 55

Zea Mais, 147, 148

Zones, 226

Zoning : of aquatics, 236 ; of the reed-swamp, 242 ; of seashore pls., 278,283 ; of seaweeds, 276

Zostera: leaf, 50 ; pollination, 166 , 276 


\title{
INDEX TO NAMES OF PLANTS IN PART III
}

\author{
For common names of grasses and ferns, see under these headings.
}

Abies (fir, spruce), 268, 273, 274

Acer campestre (maple), 270, 272, 273, 293; Pseudo-platanus (sycamore), 266,270

Aceras anthropophora (green manorchid), 260,264

Achillea Millefolium (milfoil, yarrow), 251, 258, 289, 293

Acorus Calamus (sweet sedge), 242

Adiantum Capillus-Veneris (maidenhair fern), 291

Adoxa Moschatellina (moschatel), 289,293

ALgopodium Podagraria (gout-weed), 216

Alsculus Hippocastanum (horsechestnut), 293

Athusa cynapium (fool's-parsley), 216

Agrimonia Eupatoria (common agrimony), 293

Agrimony, common - Agrimonia Eupatoria; hemp - Eupatorium cannabinum

Agropyron junceum (sea couchgrass), 280, 281, 282

Agrostis alba (white bent-grass), 263 ; canina (brown b.), 289; vulgar is (fine b.), 250, 251, 252, $258,260,295,296$

Aira caspitosa (tufted hair-grass), 244, 251; flexuosa (waved h.), $250,251,252,255,258,260,271$, 295,296 ; proecox (early h.), 296

Ajuga Chamapitys (ground-pine, yellow bugle), 261 ; reptans (common bugle), 270,293

Alchemilla alpina (alpine lady'smantle), 251, 255, 259, 288; arvensis, 298
Alder-buckthorn - Rhamnus Frangula ; common-Alnus glutinosa Algæ, marine, 275

Alisma Plantago (water-plantain), 242

Alkanet, field-Lycopsis arvensis

Alliaria offcinalis (Jack-by-thehedge, hedge-garlic), 293

Allium ursinum (ramsons), 293

Alnus glutinosa (alder), 243, 244, 269

Alopecurus agrestis (slender fox-tail), 216; alpinus (alpine f.), 287; geniculatus, 242 ; pratensis (meadow-f.), 263

Althae officinalis (marsh-mallow), 243

Anagallis arvensis (scarlet pimpernel), 282, 298; tenella (bog-p.), $245,247,253,254$

Andromeda polifolia, 247, 252

Anemone nemorosa (wood-anemone, wind-flower), $270,271, \quad 289$; Pulsatilla (pasque-flower), 260

Antennaria dioica (mountain cudweed), 251, 288

Anthemis nobilis (camomile), 216

Anthoxanthum odoratum (sweet ver. nal grass), 250, 258, 263

Anthyllis Vulneraria (lady's-fingers, kidney-vetch), 260, 264, 285

Antirrhinum majus (snapdragon), 291

Apium inundatum (least marshwort), 240, 242 ; nodiflorum (marshwort), 242

Arabis alpina (alpine rock-cress), 287; hirsuta (hairy r.), 290; stricta (Bristol r.), 290

Arbutus Unedo (strawberry-tree), $211,212,213$ 
Arctium Lappa (burdock), 293

Arctostaphylos alpina (alpine bearberry), 288 ; Uva-ursi (bearberry), 255

Arenaria ciliata (ciliated sandwort), 213,288 ; peploides (sea-purslane), $280,281,283$; rubella (mountain s.), 287 ; serpyllifolia (thymeleaved s.), 258, 282, 290, 291, 298 ; trinervia (three-nerved s.), 293 ; verna (spring s.), 288,290 , var. Gerardi, 289

Armeria maritima (thrift), 279, 284, 285,288

Arrhenatherum avenaceum (false oat. grass), 295

Arrow-grass-Triglochin spp.; -head-Sagittaria sagittifolia

Artemisia maritima (sea - wormwood), 279 ; vulgaris (mugwort), 293

Arum maculatum (cuckoo-pint), 294

Ascophyllum nodosum, 277

Ash-Fraxinus excelsior

Asperula cynanchica (squinancywort), 260 ; odorata (sweet woodruff), 269

Asphodel, bog - Narthecium ossifragum; Scottish-Tofieldia palustris

Aspidium aculeatum (prickly shieldfern), 295 ; Filix-mas (male fern), 270,295

Asplenium Adiantum-nigrum (black spleenwort), $290,291,295$; lanceolatum (lanceolate s.), 291 ; marinum (sea-s.), 284; Ruta-muraria (wall-rue), 290, 291 ; Trichomanes (maiden-hair s.), 290, 291 ; viride (green s.), 288

Aster Tripolium (sea-aster), 279

Astragalus alpinus (alpine milkvetch), 287

Athyrium alpestre, 288; Filix-foemina (lady-fern), 270, 295

Atriplex spp. (orachs), 281, 283 ; Babingtonii, 280; hastata, 280, 283 ; littoralis, 279 ; patula, 280 ; portulacoides (sea-purslane), 279

Atropa Belladonna (deadly night. shade), 273

Autumn crocus-Colchicum autumnale

Avena fatua (wild oat), 295 ; sativa (cultivated oat), 295

Avens, common-Geum urbanum ; mountein-Dryas octopetala
Awlwort-Subularia aquatica

Azalea procumbens (mountainazalea) 255, 288, 289

Azolla caroliniana 238

Ballota nigra (black horehound), 216, 294

Balsam, orange - flowered - Impatiens fulva

Barley-Hordeum spp.

Barren strawberry-Potentilla Fragariastrum

Bartsia Odontites, 263, 296 ; viscosa, 241

Basil, wild-Calamintha Clinopodium; -thyme-C. Acinos

Bastard toadfax-Thesium humifusum

Beak-rush-Rhynchospora alba

Bearberry-Arctostaphylos spp.

Bedstraw-Galium, spp.

Bee-orchid-Ophrys apıfera

Beech-Fagus sylvatica

Beet, sea-Bela maritima

Bell - flower - Campanula, spp.; -heather-Erica Tetralix

Bellis perennis (daisy), 264, 294

Beta maritima (sea-beet), 279, 283

Betony-Stachys, spp.

Betula alba (birch), 243, 265, 266. $269,270,271,274$; nana (dwarf b.), 255,288

Bidens cernua (nodding bur-marigold), 241 ; tripartita (tripartite b.), 241

Bilberry-Vaccinium Myrtillus

Bindweed - Convolvulus arvensis ; black-Polygonum Convolvulus

Birch-Betula, spp.

Bird's-foot trefoil-Lotus corniculatus

Bird's-nest, yellow-Monotropa $\mathrm{Hy}$ popitys; orchid-Necttia Nidusavis

Bittercress-Cardamine, spp.

Bittersweot-Solanum Dulcamara

Black-berry - Rubus fruticosus ; -bindweed-Polygonum Convolvu: lus; -bryony-Tamus communis; -horehound-Ballota nigra; -thorn - Prunus spinosa

Bladder - campion - Silene inflata (Cucubalus); - wort-Utricularia, spp. ; - wrack-Fucus vesiculosus

Blaeberry, mountain,-Vaccinium uliginosum

Blechnum Spicani (hard-fern), 295 
Blinks-Montia fontana

Blite, sea-Sueda maritima

Bluebell-Scilla nutans; of Scotland-Campanula rotundifolia

Bog-asphodel-Narthecium ossifragum; -bean-Menyanthes tritoliata ; -moss-Sphagnum; -myrtle -Myrica Gale; -pimpernel Anagallis tenella

Box-treo-Buxus sempervirens

Brachypodium pinnatum, 260, 296 ; sylvaticum (false brome), 270, 295

Bracken-Pteris aquilina

Bramble-Rubus fruticosus

Brassica, spp. (mustards), 216 ; oleracea (wild cabbage), 284

Briza media (quaking grass), 260, 295

Bromus arvensis (field-brome), 216 ; giganters, 270; mollis (soft b.), 295 ; sterilis (barren b.), 295

Brook-lime-Veronica Beccabunga; -weed-Samolus Valerandi

Broom, butcher's-Ruscus aculeatus; common-Cytisus scoparius ; hairy-Genista pilosa

Bryonia dioica (white bryony), 214, 293

Bryony, black-Tamus communis; white-Bryonia dioica

Buckthorn, alder-Rhamnus Frangula; common-R. catharticus; sea-Hippophaë rhamnoides

Bugle-Ajuga spp.

Bugloss, viper's-Echinm vulgare

Bulrush - Scirpus lacustris and Typha latifolia

Buniam flexuosum (pignut), 273

Burdock-Arctium Lappa

Bur-marigold-Bidens spp.

Burnet, lesser-Poterium Sanguisorba ; - saxifrage - Pimpinella Saxifraga

Bur-reed-Sparganium spp.

Butcher's-broom-Ruscus aculeatus

Butomus umbellatus (flowering rush), 242

Buttercup-Ranunculus spp.

Butterwort-Pinguicula spp.

Buxus sempervirens (box-tree), 260

Cabbage, wild-Brassica oleracea

Calkile maritima (sea-rocket), 280 , 281

Calamagrostis Epigeios (wood-reed), 244

Calamint-Calamintha officinalis
Calamintha Acinos (basil-thyme), 298; Clinopodium (wild basil), 294 ; offeinulis (oalamint), 294

Callitriche aquatica (water-starwort), 237

Calluna vulgaris (heather, ling), 250 , $251,252,253,255,259,270,271$, $274,285,291,296$

Caltha palustris (marsh-marigold), $244,245,289$

Camomilo-Anthemis nobitis

Campanula glomerata (clustered bell. flower), 260 ; hederacea (ivy-leaved b.), 245,254; hybrida (=Specularna hybrida, Venus' looking-glass). 216 ; rotundifolia (hair-bell, bluebell), 251, 259, 289, 296 ;) Trachelium (nettle-leaved b.), 272, 294

Campion, bladder-Silene inflata (=Cucubalus); moss-S. acaulis ; red-Lychnis dioisa (=diurna); sea-Silene naritima; whit6Lychnis alba (=vespertina)

Canadian pondweed-Elodea canadensis

Capsella Bursa-pastoris (shepherd'spurse), 216, 291, 294, 295

Cardamine flexuosa (wood bittercress), 289; hirsuta (hairy b.), $289,291,294,297$; pratensio (cuckoo - flower, lady's - smock). 244,263

Carduus acaulis (stemless thistle), $260,261,284,294$; arvensis (field-t.), 264, 298; eriophorus (woolly-headed t.), 272; lanceolatus (spear-t.), 264, 294, 298; Marianus (milk-t.), 216; palustris (marsh-t.), 263, 264; pycnocephalus (slender t.), 282

Carex spp. (sedges), 242, 245, 247. $251,253,254$; alpina, 287; arenaria (sand-s.), 280,282 ; atrofusca, 287 ; canescens, 255 ; flacca (glaucous 8.), 261 ; Goodenovii (common 8.), 251; rigida, 289 ; rupestris (rock-s.), 287 ; vaginata, 288

Carlina vulgaris (carline-thistle), 258, 282

Carpinus Betulus (hornbeam), 269 , 270,293

Carrot, wild-Daucus Carota

Castanea vesca (sweet chestnut), 268

Catabrosa aquatica (whorl-grass), 242

Catch-fly-Silene spp.

Cat-mint-Nepeta Cataria

Cat's-ear-Hypocharis radicala 
Caucalis Anthriscus (hedge-parsley), 294 ; nodosa, 298

Celandine, greater - Chelidonium majus; lesser-Ranunculus . Ficaria

Centaurea Calcitrapa (star-thistle), 260 ; Cyanus (cornflower), 216; nigra (bardhead, knapweed), 284 ; Scabiosa (great knapweed), 285

Centaury-Erythrcea Centaurium

Centranthus ruber (red valerian), 291

Cephalanthera pallens (large white helleborine), 273

Cerastium alpinum, 259, 288; ar. vense, 216 ; semidecandrum, 282 , 291 ; vulgatum (mouse-ear chickweed), 291, 294, 298

Ceratophyllum demersum (horn. wort), 237

Ceterach officinarum (scaly spleenwort), 291

Cetraria islandica (Iceland-moss), 289

Chorrophyllum sylvestre (wild chervil), 294 ; temulum (rough c.), 294

Chara (stonewort), 237, 239

Charlock-Sinapis arvensis

Cheddar-pink-Dianthus coesius

Cheiranthus Cheiri (wallflower), 291

Chelidonium majus (greater celan$\operatorname{din} \theta), 294$

Chenopodium spp. (goosefoots), 216, 296 ; album, 280 ; rubrum, 280

Cherleria sedoides (cyphel), 287

Cherry-laurel-Prunus Lauro-cera8us

Chervil-Chorophyllum spp.

Chestnut, horse-Assculus Hippocastanum; sweet-Castanea vesca

Chicory-Cichorium Intybus

Chickweed, common - Stellaria media ; mousse-ear - Cerastium spp.; winter-green-Trientalis europoea

Chlora perfoliata (yellow-wort), 261

Chorda filum, 276

Chrysanthemum Leucanthemum (oxoye daisy), 264; segetum (cornmarigold), 216

Chrysosplenium oppositifolium (golden saxifrage), 244, 289

Cicely, sweet-Myrrhis odorata

Cichorium Intybus (chicory), 216

Cinquefoil-Potentilla spp.; marsh -Comarum palustre

Circcea lutetiana (enchanter's-nightshade), 273, 294
Cladium Mariscus, 245

Cladonia, 289

Clary-Salvia Verbenaca

Claytonia alsinoides, 215 ; perfoliata, 215

Cleavers-Qalium A parine

Clematis Vitalba (traveller's-joy), $214,267,272,293$

Cloudberry-Rubus Chamomorus

Clover-Trifolium spp.

$\mathrm{Club}$ - moss - Lycopodium spp. ; -rush-Scirpus spp.

Cochlearia alpina, 288; anglica, 279 ; danica, 279, 284, 285; gronlandica, 288; officinalis (scurvy-grass), 279

Colchicum autumnale (autumn crocus), 263,272

Colt's-foot-Tussilago Frarfara

Comarum palustre (marsh-cinquefoil), 245,247

Comfrey-Symphytum officinale

Conium maculatum (hemlock), 294

Convallaria majalis (lily-of-thevalley), 214, 269

Convolvulus arvensis (bindweed), 298 ; sepium (hedge-b.), 293 ; Soldanella (sea-b.), 281, 282

Corallorhiza innata (coral-root orchid,) 274

Coral-root orchid-Corallorhiza innata

Corn-bluebottle-Centaurea Cyanus; -campanula-Campanula hybrida; -cockle-Lychnis Githago; -flower-Centaurea Cyanus; -marigold-Chrysanthemum segetum ; -salad-Valerianella olitoria

Cornish heath-Erica vagans

Cornus sanguinea (dogwood), 269 , $270,271,272,273,293$; suecica (dwarf d.), 255

Corydalis claviculata (climbing fumitory), 293

Corylus Avellana (hazel), 268, 270, $271,273,293$

Cotoneaster vulgaris, 284

Cotton-grass or sedge-Eriophorum spp.

Cotyledon Umbilicus (navelwort),291

Cowberry-Vaccinium Vitis-Idcea

Cow-parsnip-Heracleum Sphondylium

Cowslip-Primula veris

Crack-willow-Salix fragilis

Crambe maritima (sea-kalo), 283

Cranberry-Vaccinium Oxycoccus 


\section{INDEX TO NAMES OF PLANTS}

Cranesbill-Geranium spp.

Cratcegus Oxyacantha (hawthorn, whitethorn), 269, 270, 271, 272, $273,293,296$

Orepis spp. (hawk's-beard), 264

Cress, great water- - Nasturtium amphibium; hairy bitter-_Cardamine hirsuta; penny- -Thlaspi arvense; rook- -Arabis spp. and Draba spp.; thale- -Sisymbrium Thalianum; water- - Nasturtium officinale

Crithmum maritimum (samphire), 283,284

Crocus, autumn-Colchicum autumnale

Crocus vernus, 215, 263

Crosswort-Galium Cruciata

Crowberry-Empetrum nigrum

Crowfoot-Ranunculus spp.

Cuckoo-flower - Cardamine pratensis; pint-Arum maculatum

Cudweed, alpine-Gnaphalium norvegicum; dwarf-G. supinum; mountain-Antennaria dioica; upright-Filago germanica

Currant-Ribes spp.

Cuscuta spp. (dodder), 298

Cynoglossum officinale (hound'stongue), 282

Cynosurus cristatus (crested dog'stail), 260, 263

Cyphol-Cherleria sedoides

Cypripedium Calceolus (lady's-slipper orchid), 269

Cystopteris fragilis (brittle-fern), 288, 290

Cytisus scoparius (broom), 296

Dabacia polifolia (St. Dabeoo's heath), 213, 252

Dactylis glomerata (cock's-foot grass), 263

Daisy, common-Bellis perennis; ox-eye-Chrysanthemum Leucanthemum

Damasonium stellatum (star-fruit), 242

Dandelion-Taraxacum officinale

Daphne Laureola (spurge-laurel), 273

Daucus Carota (wild carrot), 260, 283,285

Dead-nettle—Lamium spp.

Devil's-bit scabious-Scabiosa Succisa

Dianthus caesius (Cheddar-pink), 290 ; prolifer, 283
Dicranum, 252

Digitalis purpurea (foxglove), 271, 294

Diplotaxis muralis (wall-rocket), 291

Dipsacus sylvestris (toazle), 294

Dock-Rumex spp.

Dodder-Cuscuta spp.

Dog-rose-Rosa canina; -violetViola canina and Riviniana; -wood-Cornus spp.

Dog's-meroury, Mercurialis per ennis

Dove's-foot crane's-bill-Geranium molle

Draba incana (hoary rock-cress), 288, 290 ; muralis (wall r.), 290; rupestris (rock-cress), 287 ; verna (whitlow-grass), 282, 290

Dropwort-Spircea Filipendula : water-OEnanthe fistulosa

Drosera spp. (sundews), 247, 253 ; rolundifolia (round-leaved s.), 253, 254,255

Dryas octopetala (mountain-avens), 286,288

Dryopteris montana (mountain-fern), 288

Duckweed-Lemna spp.

Dyer's-weed-Reseda Luteola

Earthnut-Bunium flexuosum

Echium vulgare (viper's-bugloss), 283,284

Elder —Sambucus nigra

Elm-Ulmus spp.

Elodea canadensis (Canadian pondweod), 215, 233, 237

Elymus arenarius (lyme-grass), 281, 282

Empetrum nigrum (orowberry), 251, $254,255,288,289$

Enchanter's - nightshade - Circcea lutetiana

Epilobium spp. (willowherbs), 243 , 245 ; alpinum (alpine w.), 288; alsinefolium (mountain w.), 288; angustifolium (rose-bay w.), 294 ; hirsutum (hairy w.), 244 ; lanceolatum (spear-leaved w.), 291; montanum (broad smooth-leaved w.), 270

Equiselum spp. (horsotails), 241, 245 ; limosum, 242

Erica ciliaris (ciliate heath), 213, 252,253 ; cinerea (common h.), $250,252,285,291,296$; Mackayi (Mackay's h.), 213, 253 ; mediterranea (Mediterranean h.), 213. 
253 ; Tetralix (cross-leaved h., bell-heather), 24.7, 251, 252, 253, 254, 255; vagans (Cornish h.), 213,252

Erigeron alpinum (alpine flea-bane), 287 ; canadense (Canadian f.), 216

Eriocaulon septangulare (pipewort), 214

Eriophorum spp. (cotton-grasses or sedges), 245, 251, 253, 254; angustifolium, 255; vaginatum, 251, 253, 254

Erodium cicutarium (stork's-bill), $282,291,296$

Eryngium maritimum (sea-holly, $281,282,283$

Erysimum cheiranthoides (treaclemustard), 216

Erythraa Centaurium (centaury), $261,282,284,285$

Euonymus europaus (spindle-tree), 272,273

Eupatorium cannabinum (hempagrimony, 243, 294

Euphorbia spp. (spurges), 216; amygdaloides (wood-s.), 270 ; hiberna (lrish s.), 213; Paralias (sea-s.), 281, 282; portlandica (Portland s.), 282, 285

Euphrasia officinalis (eyebright), $251,257,260,284,287,289,296$

Eyobright-Euphrasia officinalis

Fagus sylvatica (beech), 265, 266, $268,270,293$

Fern, brake-Pteris aquilina; brittlo - Cystopteris fragilis; filmy-Trichomanes radicans; hard-Blechnum Spicant; hart'stongue-Scolopendrium vilgare; Killarney-Trichonuanes radicans; lady-Athyrium Filix-fomina; maiden-hair-Adiantum Capillus-Veneris; male-Aspidium Filix-mas; prickly shieldA. aculeatum; royal-Osmunda regalis

Festuca Myuros (mouse-tail grass), 295 ; ovina (sheep's-fescue), 250 , $251,252,255,258,259,260,263$, $289,290,296$; pratensis (meadow f.), 263 ; rubra (red f.), 298, var. arenaria, 282

Field-madder-Sherardia arvensis

Figwort-Scrophularia spp.

Filago germanica (upright cud weed), $282,291,296$
Fir, Douglas-Abies Douglasit: Scotch-Pinus sylvestris

Flag, yellow-Iris Pseudacorus

Flax-Linum spp.; toad-Linaria spp.

Flea-bane-Erigeron spp. ; common - Inula dysenterica

Flowering rush-Butomus umbellatus

Fly-orchid-Ophrys muscifera

Fontinalis antipyretica, 234

Fool's-parlsey - Atthusa cynapium

Forget-me-not-Myosotis palustris

Foxglove-Digitalis purpurea

Fragaria vesca (strawberry), 294

Fraxinus excelsior (ash), 244, 263, $266,268,269,272,293$

Fritillaria Meleayris (snake's-head fritillary), 263

Fritillary, snake's-head-Fritillaria Meleagris

Frog-bit-Hydrocharis Morsus-ranae

Fucus platycarpus, 277 ; serratus, 277 ; vesiculosus (bladder-wrack), 277

Fumavia spp. (fumitory), 216

Fumitory-Fumaria spp. ; climbing -Corydalis claviculata

Furze-Ulex spp.

Gatanthus nivalis (snowdrop), 214, 215

Gale, sweet-Myrica Gale

Galeopsis Ladanum (red hemp. nettle), 298, var. canescens, 283 ; Tetraht (common hemp-nettle), 298

Galium Aparine (cleavers, goose. grass), 283, 293 ; boreale (northern bedstraw), 288 ; Cruciaia (crosswort), 293 ; Mollugo (great hedgeb.), 283, 293 ; saxatile (heath-b.), $251,258,259,271,274,289,296$; verum (yellow or lady's-b.), 259, 282

Garlic, bear's-Allium ursinum; hedge-Alliaria officinalis

Genista pilosa (hairy broom), 291

Gentiana nivalis (small mountain. gentian), 259,257

Geranium dissectum (cut-leaved crane's-bill), 298 ; lucidum (shining c.), 290, 291; molle (dove'sfoot c.), $291,294,298$; pratense (meadow c.), 263 ; pusillum (small c.), 216; Robertianum (herb. Robert), 270, 294, var. purpu. 
reum, 283 ; rotundifolium (roundleaved c.), 294; sanguineum (bloody c.), 285,290

Germander - speedwell - Veronica Chamedrys

Geum urbanum (avens), 294

Gipsy-wort-Lycopus europaus

Glasswort-Salicornia herbacea

Glaucium luleum (sea or horned poppy), 281, 282, 28.3

Glaux maritima (sea-milkwort), 279

Glyceria aquatica (reed mannagrass), 237,242 ; maritima, 278 , 279

Gnaphatium norvegicum (alpino cud. woed), 287 ; supinum (dwarf c.), 288,289

Goat's-beard-Tragapogon pratensis

Golden-rod-Solidago Virgaurea ; saxifiage-Chrysosplenium oppositifolium; samphire - Inula crithnoides

Goldilocks-Ranunculus auricomus

Goose - foot - Chenopodium spp.; -grass-Galium Aparine

Gorse-Ulex spp.

Gont - weed - Asgopodium Podagraria.

Grass, arrow - Triglochin spp. ; bent-Agrostis vulgaris; bromeBromus spp.; cat's-tail-Phleum pratense; cock's-foot-Dactylis glomerata; cotton-Eriophorum spp. ; couch-Triticum repens; crested dog's-tail-Cynosurus cristatus; false brome-Brachypodium spp.; false oat-Arrhenatherum avenaceum; fescueFestuca spp.; fox-tail-Alopecurus pratensis; goose-Galium Aparine; hair-Aira spp.; heath -Triodia decumbens; linotPolygonum avicillare; lymoElymus arenarius; marram$P$ samma arenaria; melick-Melica unifiora; millet-Milium effusum ; moor-Sesieria carulea; mouse-tail-Festuca Myuros; of Parnassus-Parnassia palustin; purple moor-Molinia carulea; qualing-Briza media; reedPhragmites vulgaris ; rye-Lolium. perenne; scorpion-Myosotis spp.; scurvy-Cochlearia spp.; seacouch - Agroxyron junceum; sheep's fescue-Festuca ovina : soft-Holcus mollis ; sweet vernal
-Anthoxanthum odoratum; Timothy-Phleum pratense; tus. sock - Aira caspitosa; whitlow -Draba verna; whorl-Catabrosa aquatica; wild oat-Avena fatua ; Yorkshire-fog-Holcus lanatus

Grass-wrack-Zostera spp.

Green man-orchid-Aceras anthropophora

Gromwell-Lithospermum officinale

Ground - ivy - Nepeta Glechoma ; -pine-Ajuga Chamaepitys

Groundsel-Senecio vulgaris

Guelder-rose-Viburmum Opulus

Habenaria conopsea (fragrant orchid), 261, 264 ; intacta, 213

Hair-bell-Campanula rotundifolia

Halidrys siliquosa, 277

Hardhead-Centaurea nigra

Hare's-foot trefoil-Trifolium arvense

Hawk's-beard-Crepis spp. ; -bitLeontodon spp.

Hawkweed-Hieracium spp.

Hawthorn-Cratogus Oxyacantha.

Hazel-Corylus Avellana

Heath-Erica spp. ; St. Dabeoc'sDabocia polifolia

Heather-Calluna vulgaris; bellErica Tetralix

Hedera Helix (ivy), 267, 293

Hedge-parsley-Caucalis Anthriscus

Helianthemum Breweri, 209 ; Cham. acistus (rock-rose), 259, 260, 290; guttatum, 213

Hellebore, green-Helleborus viride

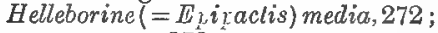
purpurata, 272

Helloborine, white-Cephalanthera pallens

Helleborus viride (green hellebore), 273

Helminthia echioides (oxtongne), 283, 294

Hemlock-Conium maculatum

Hemp-agrimony-Dupalcrium can. nabinum; -nettle-Galeopsis spp.

Henbano-Hyoscyamus niger

Heracleum Sphondylium (hogweed, cow-parsnip), 289, 294

Herb-paris - Paris quadrifolia; -Robert-Geranium Robrianum

Hieracium spp. (hawkwee]s), 261, 271, 285; Iricum, 209 ; Pilocella (mouse-ear h.), 251, 258, 282, 290, 291, 296 


\section{BRITISH PLANTS} Hippocrepis comosa (horso-shoe
vetch), 260

Hippophaë rhamnoides (sea-buckthorn), 281, 282

Hippuris vulgaris (mare's-tail), 237 , 239

Hogweed-Heracleum Sphondylium

Holcus lanatus (Yorkshiro fog), 263 ; mollis (soft grass), 271

Holly-Ilex Aquifolium

Honeysuckle-Lonicera Periclymenum

Hop-Humulus Lupulus

Hor'deum maritimum (sea-barley), 279 ; murinum (wall-b.), 295

Horehound, black-Ballota nigra

Hornbeam-Carpinus Betala

Horned pondweed--Kannichellia spp.; poppy-Glaucium luteum

Hornwort - Ceratophyllum demersum

Horse-chestnut-AEsculus Hippocastanum; -shoe vetch-Hippocrepis comosa; -tail-Eqursefum spp.

Hottonia palustris (water-violet), 237,239

Hound's-tongue-Cynoglossum officinale

Houseleek-Sempervivun tęctorum

Hunulus Lupulus (hop), 214, 293

Hutchinsia petroea, 290

Hyacinth, wild-Scilla nutans

Hydrocharis Morsus-rance (froglit), 237

Hydrocotyle vulgaris (marsh-pennywort), $245,247,251$

Hyoscyamus niger (henbane), 282

IIypericum Elodes (marsh St. John's. wort), 242 ; perforatum (ccmmon St. J.). 294; pulchrum (upright St. J.), 296 ; quadrangulum, 245 ; tetrapterum (St. Peter's-wort), 245

Hypochoris radicata (cat's-ear), 204

Icoland-moss-Cetraria islandica

Ilex Aquifolium (holly), $269,270,271$

Impatiens fulva (orange-flowered balsam), 215, 241

Inulk Conyza (1)Ioughman's-spikenard), 261, 272, 282; crithmoides (golden samphire), 284, 285; dysenterica (common flea-bane), 294 ; salicina, 214

Iris foetidissima (fotid iris), 272, 28:; Pseudacorus (yellow flag), 242,245

Isoëtes lacustris (quillwort), 238
Ivy, common-Hedera Helix; ground - Nepeta Glechoma

Jack-by-the-hedge--Alliaria offcinalis

Jacob's-ladder-Polemonium caruleum

Jasione montana (sheep's-bit scabious), 291

Juncus spp. (rushes), 253, 254; articulatus, 246 ; biglumis, 287; bufonius, 241 ; conglomeratus, 246, 251 ; effusus, 251 ; Gerardi, 279 ; obtusiflorus, 245, 247 ; squarrosus, 251 ; supinus, 246 ; trifidus, 288 , 289

Juniper-Juniperus communis

Juniperus communis (juniper), 261, 271,273 , var. nana, 288

Kale, sea-Crambe maritima

Kidney-vateh-Anthyllis Vulnerar ia

Knapweed-Centaurea spp.

Knautia arvensis (field-scabious), 298

Knot-grass-Polygonum aviculare

Kobresia caricina, 259

Kelcria cristata, 260

Lactuca alpina (alpine sowthistle), 287 ; muralis (wall-lettuce), 290 , 291

Lady's - bedstraw-Galium verum ; fingers - Anthyllis Vulneraria; slipper-orchid-cypripedium Calceolus; smock-Cardamins pratensis; tresses-Spiranthes spp.

Lamb's - lettuce - Valerianella olitoria

Laminaria, 277

Lanium album (white deadnottle), 216, 294; Galeobdolon (yellow d., archangel), 270,294 ; purpurcum (red d.), 294

Lapsana communis (nipplewort), $216,263,294$

Larch-Larix

Larix (larch), 273, 274

Lathroea squamaria (toothwort), 269 , 294

Lathyrus pratensis (meadow-pea), 263,293

Laurel, cherry-Prunus Lauro-cerasus ; spurge-Daphne Laureola

Lavatera arborea (treo-mallow), 284

Lemna gibba (thick-leared duckweed), 237 ; minor (small d.), 233, 237 ; trisulca (ivy-leaved d.), 237 
Leontodon spp. (hawlk's-bit), 264, 285 ; hirtus, 282, 283

Lepidium Smithii, 291

Lottuce-Lactuca spp.; lamb'sI'alerianella olitoria

Leucobryum, 272

Ligusticum scoticum (lovage), 284

Ligustrum vulgare (privet), 244, 209 , 272,293

Lily-of-the-valley-Convallaria majalis

Lily, white water-Nymphoea alba; yellow water- $N$ uphar luteum.

Lime-tree-Tilia spp.

Linaria Cymbalaria (ivy-leaved toadflax), 216, 291 ; minor (small t.), 298 ; vulgar is (yellow t.), 294

Ling-Calluna vulgaris

Linnoea borealis, 274, 288

Linseed-Linum usitatissimum

Linum catharticum (purging flax), 258, 259, 260: perenne (poronnial f.), 260 ; usitatissimum (common f., linseed), 260

Listera cordata (lesser twayblado), 274 ; ovata (common t.), 201

Lithospermum officinale (gromwell), 294

Littorella lacustris (shoreweed), 237

Live-long-Sedum Telephium

Lizard-orchid-Orehis hircina

Lloydia serotina, 288

Lobelia Dortmanna (water-lobalia), 238 ; urens, 213

Lolium perenne (perennial rye-grass), 263

London pride-Saxifraga umbrosa

Lonicera Periclymenum (honcysuckle, woodbine), $267,270,271$, 293

Loosestrife, common-Lysimachia vulgaris; purple-Lythrum Salicaria

Lotus corniculatus (bird's-foot trefoil), $259,264,282,284,285,294$, 296

Lousewort-Pedicularis spp.

Lovage-Ligusticum scoticum

Lungwort-Pulmonaria officinalis

Luzula arcuaba (alpine wood-rush), 287 ; campestris (field w. r.), 251, 258

Lychnis alba (=vespertina, white campion), 216, 294; dioica (=diurna, red c.), 270, 289, 294; diurna, see dioica; Flos-cuculi (ragged Robin), 294; Githago (corn-cocklo), 216 ; vespertina, see alba

Lycopodium spp. (clubmosses), 255 : alpinum (alpine c.), 259; clavatum (common c.), 251, 259; Selago (fir c.), 251, 255, 259. 289

Lycopsis arvensis (field-alkanet), 216, 282

Lycopus europaus (gipsy-wort), 243

Lysimachia nemorum (yellow pimpernel), 270; vulgaris (common loosestrife), 243

Lythrum Salicaria (purplo looso. strife), 243

Madder, field-Sherardia arvensis

Mallow-Malva spp.; trce- - Lavatera arboren; marsh-Althoed offcinalis

Malva rotundifolia (dwarf mallow), 296 ; sylvestris (common m.), 216, 294

Man-orchid-Aceras anthropophora

Maple-Acer campestre

Mare's-tail-IIip puris vuigaris

Marigold, bur-Bidens sup. ; corn-Chrysanthemum Lencinthemum ; marsh-Caltha palis stris

Marjoram-Orizanum vulgare

Marsh-cinquefoil--Comarum pahustre; figwort-Scrophularia cuquatica; lousewort - Pedicularia palustris; mallow-Althcea offcinalis ; marigold-Caltha palustris; orchid-Orchis lasifolin; pennywort - Hydrocotyle vulgaris; ragwort-Senecio aquatica ; St. John's-wort--Hypericum Elodes; speedwell- T'eronica scutellata; stitchwort-Stellaria uitginosa; valerian - Valeriana dioica; violet-Viola palustris; -wort-A pium spp.; woundwort -Stachys palustris

Matricaria inodora (scentless may. weed), 296, 298, var. salina, '253

Matthiola incana (wild stock), 284

Mayweed, scentless - Matricaria inodora

Meadow-cranesbill-Geranium pratense; pea-Lathyrus pratensis; rue-Thalictrum flavum; saffron -Colchicum autumnale; saxifrage -Saxifraga granulata; -sweet - Spircea Ulmaria

Medicago lupulina (black medick, nonsuch, shamrock), 291, 295, 298 
Medick, black-NIedicago lupulina

Melica uniflora (wood melick), 270

Mclilot-Melilotus officinalis

Melilotus officinalis (melilot), 216, 295

Mentha spp. (mints), 243 ; aquatica, 243

Menyanthes trifoliata (bog-bean), 245,247

Menziesia ccerulea, 287

Mercurialis perennis (dog's-mercury), $269,270,273,290,294$

Mercury, dog's-Mercurialis perennis

Mignonette, wild-Reseda lutea

Milfoil - Achillea Millefolium; water-Myriophyllum spp.

Milium effusum (millet-grass), 270

Milk-thistle-Carduus Marianus: -wort-Polygala spp., sea-Glaux maritima

Mint-Hentha spp.; cat-Nepeta Calaria

Mistletoo-Viscum album

Molinia carulea (purple moor-grass), $244,245,247$

Monotropa Hypopitys (yellow bird'snest), 266, 273, 274

Mosehatel - Adoxa Mosehatellina

Moss, bog-Sphagnum; clubLycopodium spp.; hair-Poly-

Morichum; Iceland - Cetraria

Mostandica

tso-campion-Silene acaulis

issy saxifrage-saxifraga hyp. noides

Mountain-ash-Pyrus Aucuparia; avens-Dryas octopetala; azalea - Azalea procumbens; blaeberry -Vaccinium uliginosum ; sorrelOxyria reniformis

Mouse-ear chickweed-Cerastium spp.

Mouse-tail-Myosurus minimus

Mudwort-A pirum inundatum

Mugwort-Artemisia spp.

Mullein-Verbascum spp.

Mustard-Brassica spp.; garlicAlliaria officinalis; treaclo-Erysimum cheiranthoides

Myosotis arvensis (field scorpiongrass), 298 ; collina (early forget. me-not), 282, 290, 291 ; palustris (marsh f.), 243, 244 ; pyrenaica, 287.

Myosurus minimus (mouse-tail), 214, 297
Myrica Gale (sweet gale, bogmyrtle), 253

Myriophyllum spp. (water-milfoils), 237, 239; spicatum, 235, 239

Myrrhis odoralum (sweet cicely), 216

Myrtle, bog-Myrica Gale

Nardus stricta (mat-grøss), 251, 255, $258,259,260,296^{\circ}$

Narthecium ossifragum (bog-asphodel), 247, 251,253, 254, 255

Nasturtium amphibium (watercress), 242 ; officinale, 242

Navelwort-Cotyledon Umbilicus

Needle, shepherd's-Scandix Pecten-Veneris

Neottia Nidus-avis (bird's-nest orchid), 266,273

Nepeta Cataria (cat-mint), 294; Glechomo (ground-ivy), 270, 294

Nettle-Urtica spp. ; dead-Lamirm spp. ; hemp-Galeopsis spp.

Nightshade, common or gardenSolanum nigrum ; deadly-Atropa Belladonna; enchanter's - C'irceEa lutetiana; woody-Solanum Dulcamara

Nipplewort-Lapsana communis

Nitella, 237

Nonsuch-Medicago lupuline

Nuphar luteum (yellow water-lily), 237,239

Nymphcea alba (white water-lily). 237

Oak-Quercus spp.

Oat-Avena spp.; false-Arrhenatherum avenaceum

Enanthe fistulosa (water-dropwort), 242; fluviatilis, 209; Phellan. drium, 209, 242

Onobrychis sativa (sainfoin), 264

Ononis arvensis (rest-harrow), 281, 282,296

Ophrys apifera (bee-orchid), 261 ; Arachnites (late spider-o.), 261 ; aranifera (spider-o.), 261 ; muscifera (Hy-o.), 260, 264

Orach-Atriplex spp.

Orchid, bee-Ophrys apifera : bird's-nest-Neottia Nidus-avis: coral-root-Corallorhiza innata; early purple-Orchis mascula: fly-Ophrys muscifera; fragrant - Habenaria conopsea ; green man - Aceras anthropophora; lady'sslipper-Cypripedium Calceolus ; 


\section{INDEX TO NAMES OF PLANTS}

lizard-Orchis hircina; marshOrchis latifolia; pyramidal-Orchis pyramidalis; spider-Ophrys aranifera; late spider-Ophrys Arachnites ; spotted-Orchis maculata

Orchis hircina (lizard-orchid), 261 ; latifolia (marsh-0.), 245, 247; maculata (spotted o.), 264 ; mascula (early purple o.), 263 ; pyramidalis (pyramidal o.), 261,264 ; ustulata, 261

Origanum vulgare (marjoram), 272

Orpine-Sedum Telephium

Osier-Salix viminalis

Osmunda regalis (royal forn), 245, 295

Oxalis Acetosella (wood-sorrel), 270. 274,289

Ox-eye daisy-Chrysanthemum Leucanthemum

Oxtongue-Helminthia echioides

Oxyria reniformis (mountain-sorrel), 288

Oxylropis campestris, 287 ; uralensis, 259,288

Paonia corallina (pæony), 284

Pæony-Paonia corallina

Papaver spp. (poppy), 216

Parietaria officinalis (pellitory-ofthe-wall), 290, 291

Paris quadrifolia (herb-paris), 214, 269, 272

Parnassia palustris (grass of Par. nassus), 245, 247

Parsley, fool's-Athusa cynapium : hedge-Caucalis Anthriscus

Parsnip-Pastinaca sativa; cowHeracleum Sphondylium; water -Sium spp.

Pastinaca sativa (parsnip), 294

Pasque-flower-Anemone Pulsatilla

Pea, meadow-Lathyrus pratensis

Pear-Pyrus communis

Pearlwort-Sagina spp.

Pedicularis palustris (marsh-lousewort), 241,245 ; sylvatica (common 1., red rattle), 251

Pellitory - of - the - wall - Parietaria officinalis

Pelvetia caniculata, 277

Penny - cress - Thlaspi arvense; -wort, marsh-Hydrocotyle vulgaris, wall-Cotyledon Umbiticus

Peplis Portula (water-purslane), 240
Pepper, water-Polygonum Hydropiper

Phalaris arundinacea, 242

Phleum alpina (alpine cat's-tail grass), 255,287 ; pratense (cat'stail grass, Timothy grass), 263

Phragmites communis (common reed), $242,245,278$

Phyteuma orbiculare (rampion), 261, 284

Picris hieracioides, 261

Pignut-Bunium flexuosum

Pillwort-Pilularia globulifera.

Pilularia globulifera (pillwort), 237. 239

Pimpernel, bog-Anagallis tenella; scarlet-Anagallis arvensis; yel. low-Lysimachia nemorum

Pimpinella Saxifraga (burnot-saxi. frage), 259

Pine, ground-Ajuga Chamcepitys ; Scots-Pinus sylvestris

Pinguicula spp. (butterwort), 247. 253,254 ; grandiflora, 213 ; lusi. tanica, 213 ; vulgaris, 253

Pink, Cheddar-Dianthus coesius

Pinus sylvestris (Scots pine), 268, 273

Pipowort-Eriocaulon septangulare

Plantago Coronopus (buok's-horn plantain), 282, 284, 285 ; lanceolata (ribwort p.), 263, 294, 298 ; major (greater p.), 295, 298; maritima (sea-p.), 279, 284, 285, 288 ; media (hoary p.), 261,264

Plantain-Plantago spp.; waterAlisma Plantago

Ploughman's - spikenard - Inula Conyza

Plum, wild-Prunus domestica

Poa alpina (alpine meadow-grass), 259,288 ; annua (annual m. g.) $287,289,291,295$; laxa, 287; pratensis (smooth m. g.), 258,260 , 263 ; trivialis (rough $\mathrm{m}$. g.), 263

Polemoninm coeruleum (Jacob'sladder), 269

Polygala calcarea (chalk-milkwort), 260 ; serpyllacea (heath-m.), 251 ; vulgaris (common m.), 259, 260, 285

Polygonatum officinale (Solomon'sseal), 269

Polygonum amphibium, 237, 240, 243 ; aviculare (common knotgrass), 296; Convolvulus (black bindweed), 298; Hydropiper 
(water-pepper), 240, 243 ; viviparum, 288

Polypodium vulgare (common poly. pody), 267, 291, 295

Polypody-Polypodium vulgare

Polyirichum (hair-moss), 252

Pondweed-Potamogeton spp. ; Canadian-Elodea canadensis ; horned -Zannichellia spp.; tasselRuppia maritima

Poplar-Populus

Poppy-Papaver spp.; horned or sea-Glaucium luteum

Poputus (poplar), 270, 293

Potamogeton spp. (pondweeds), 233, 236, 237 ; lucens (shining p.), 238 ; natans (broad-leaved p.), 235, 239 ; pectinatus (fennel-leaved p.), 235

Potentilla alpestris (alpine cinquefoil), 259 ; anserina (silver-weed), 260, 294 ; Crantzii (alpine cinquefoil), 259 ; Fragariastrum (barren strawberry), 294 ; reptans (сreеping c.), 296; Sibbaldi, 288, 289; Tormentilla (tormentil), 251, 271, $274,285,289,296$

Poterium Sanguisorba (lesser-burnet), 260, 264

Primrose-Primula vulgaris

Primula veris (ćowslip), 264 ; vulgaris (primrose), 270, 294

Privet-Ligustrum vulgare

Prunella vulgaris (self-heal), 263, 270

Prunus domestuca (wild plum), 293 ; Lauro - cerasus (cherry - laurel), 293 ; spinosa (sloe, blackthorn), $269,270,271,272,273,293,296$

Psamma arenaria (marram-grass), 281,282

Pteris aquilina (bracken-fern), 251, 259,270

Purslane, sea-Arenaria peploides and Atriplex portulacoides; water - Peplis Portula

Pyrola media, minor, rotundifolia, secunda, uniflora (wintergreens), 274

Pyrus Aria (whitebeam), 271, 272, 273, 293 ; Aucuparia (mountain. ash, rowan-tree), 269, 271, 274 ; communis (pear), 293 ; torminalis (wild service-tree), 214

Quercus spp. (oak), 244, 265, 266, 268, $269,270,272,293$; pedunculata, 270 ; robur, 270 ; sessiliflora, 270

Quillwort-Isoètes lacustris
Ragged Robin-Lychnis Flos-cuculi Raphanus Raphanistrum (wild radish), 216

Rattle, red-Pedicularis oylvatica; yellow-Rhinanthus Crista-galli

Reed, common-Phragmites communis ; -mace-Typha latifolia

Reseda lutea (wild mignonette), $261^{\prime}$; Luteola (dyer's-weed), 261

Rest-harrow-Ononis arvensis

Rhacomitrium lanuginosum, 289

Rhamnus spp., 269, 273 ; catharticus (common buckthorn), 241, 293 ; Frangula (alder b.), 244, 271

Rhinarthus Crista-galli (yellow rattle), 263

Rhynchospora alba (beak-rush), 251

Kibes 8 pp., 244 ; Grossularia (gooseberry), 215 ; nigrum (black currant), 215 ; rubrum (red c.), 215

Rock-cress-Arabis spp. and Draba spp. : -rose-Helianthemum spp.

Rocket, sea-Cakile maritima; wall -Diplotaxis muralis

Rosa spp. (rose), 270, 271, 293

Rose-Rosa spp.; -bay-Epilobium angustifolium; guelderViburnum Opulus; rock-Helianthemum spp.; -root-Sedum Rhodiola

Rowan-tree-Pyrus Aucuparia

Rubus Chamcemorus (cloudberry), $251,253,254,255$; fruticosus (bramble, blackberry), 251, 270, $271,274,293$

Rue, meadow-Thalictrum flavum ; wall-Asplenium Ruta-muraria

Rumex spp. (dock), 298; Acetosa (sorrel), 263, 288; Acetosella (sheep's-sorrel), 251, 258, 271, $289,291,296$; crispus (curled dock), 263, 283, 295 ; Hydrolapathum (water d.), 243; obtusifolius (broad-leaved d.), 295

Ruppia naritima (tassel-pondweed), 276

Ruscus aculeatus (butcher's-broom), 214,273

Rush-Juncus spp.; beakRhynchospora alba; bul- -Scirpus lacustris and Typha latifolia; club-Scirpus spp.; floweringButomus umbellatus; woodLuzula spp.

Sage, wild-Salvia Verbenaca; wood. - Teucrium Scorodonia 
Sagina Boydii, 287 ; Linnai (mountain pearlwort), 259, 287 ; maritima (sea-p.), 284, var. alpina, 288 ; procumbens (common p.), $289,290,295,298$

Sagittaria sagutitifolia (arrow-head). 235,242

Sainfoin-Onobrychis sativa

St. Dabeoo's heath-Dabrecia polifolia

St. John's-wort-Hypericum spp.

St. Peter's-wort-Hypericum tetrapterum

Salicornia herbacea (annual glasswort), 277, 278, 279 ; radicans, 278

Salix spp., 293; Arbuscula, 287 ; Caprea (goat-sallow), 244, 269, 270,271 ; cinerea (grey s.), 244, 269 ; fragilis (craok-willow), 244 ; herbacea (dwarf w.), 288, 289; lanata (woolly w.), 287 ; Lapponum (downy w.), 288 ; Myrsinites (whortle-w.), 288; repens (creeping w.), 247, 251, 253, 283 ; reticulata. 288

Sallow-Salix spp.

Salsola Kali (saltwort), 280

Saltwort-Salscla Kali

Salvia Verbenaca (wild sage, clary), 261

Sambucus nigra (elder), 269, 270, 273,293

Samolus Valerandi (brook-weed), 245

Samphire-Crithmum maritimum : golden-Inula crithmoides

Sandwort-Arenaria spp.

Sanicle, wood-Sanicula europoea

Saussurea alpina (alpine saw-wort), 288

Saw-wort, alpine-Saussurea alpina Saxifraga aizoides (yellow mountain saxifrage), 286, 288 ; caspitosa (tufted s.), 288 ; cermua (drooping s.), 287 ; decipiens, 288 ; elegans. 288; Geum, 213, 288 ; granulata (meadow s.), 263; hirsuta, 213, 288 ; hyproides (mossy 8.), 288 ; oppositifolia (purple 8. ), 288; rivularis (alpine $\mathrm{s}$ ), 287 ; stellaris (starry 8.), 288 ; tridactylites (ruoleaved s.), 290, 291 ; umbrosa (London-pride), 213, 288

Saxifrage-Saxifraga spp.; burnet-Pimpinella Saxifraga; goldenChrysosplenium oppositifolium

Scabiosa Columbaria (small acabi- ous), 261, 264, 272, 284 ; Succisa (devil's-bit 8.), 258

Scabious-Scabiosa spp.; fieldKnautia arvensis; sheop's-bitJasione montana

Scandix Pecten-Veneris (shepherd'sneedle), 216

Scapania undulata, 234

Scilla nutans (wild hyacinth, bluebell), $269,270,271$

Scirpus caspitosus (tufted clubrush), 255; fluitans (floating c.), 239 ; lacustris (bulrush), 242; maritimus, 279; rufus (sea-c.), 279 ; sylvaticus (wood c.), 244; triqueter, 279

Scolopendrium vulgare (hart's. tongue fern), 295

Scorpion-grass-Myosotis spp.

Scrophularia aquatica (marsh-figwort), 243 ; nodosa (knotted f.), 295

Scurvy-grass-Cochlearia spp.

Scutellaria galericulata (common skull-cap), 243

Sea arrow-grass-Triglochin maritimum; -beet-Beta marilima; -bindweed-Convolvulus Soldanella; -blite-Sueda maritima; buckthorn - Hippophaë rhamnoides; -campion-Silene maritima; club-rush-Scirpus rufus; -holly-Eryngium maritimum; -kale-Crambe maritima; -lavender-Statice spp.; -milkwortGlaux maritima; -pearlwortSagina maritima; -pink-Armeria maritima; -plantain-Plantago maritıma; -poppy-Qlaucium luteum; -purslano-Arenaria peploides and Atriplex portulacoides;-rocket-Cakile maritima; -spurge - Euphorbia Paralias; -starwort-Aster Tripolium

Seaweeds (algce), 275

Sedge-Carex spp.; beak-Rhynchospora alba; cotton-Eriophosum spp.

Sedum spp., 291 ; acre (biting stonecrop), 282, 290, 291 ; album (white B.), 290 ; anglicum (English s.). $282,284,290$; reflexum (large yellow s.), 290 ; Rhodiola (rose-root), 280,288 ; rupestre (yellow s.), 290 ; Telephium (orpine, livelong). 290,295

Selaginella spinosa, 247, 254, 255 
Self-heal-Prunella vulgaris

Sempervivum tectorum (houseleek), 291

Senecio aqualicus (marsh-ragwort), 243 ; erucifolius (hoary r.), 295 ; Jacobaza (common r.), 263, 282, 285,295 ; vulgaris (groundsel), $263,295,298$

Service-tree, wild-Pyrus torminalis Sesleria ceerulea (moor-grass), 260

Shamrock-Trifolium repens, $T$ minor and Medicago lupulina

Sheep's-bit scabious-Jasione montana; -sorrel-Rumex Acetosella.

Shepherd's-needle-Scandix PectenVeneris; -purse-Capsella Bursapastoris

Sherardia arvensis (field-madder), 282

Silene acaulis (moss-campion), 288 ; Cucubalus (bladder-c.), 264, 298; maritima (sea-c.), 283, 288

Silver-weed-Potentilla anserina

Simethis bicolor, 214

Sinapis arvensis (charlock), 216

Sisymbrium Thalianum (thalecress), 297

Sisyrinchium angustifolium, 214

Sium angustifolium and latifolium (water-parsnips), 243

Skull-cap, common-Seutellaria galerzculata

Slipper, lady's-Cypripedium Calceolus

Sloo-Prunus spinosa

Snapdragon-Antirrhinum majus

Snowdrop-Galanthus nivalis

Solanum Dulcamara (bittersweet, woody nightshade), 293, var. marinum, 283 ; nigrum (common n.), 216

Solidago Virgaurea (golden-rod), 271,289

Solomon's-seal - Polygonatum officinale

Sonchus arvensis (corn-sowthistle), 216,295 ; oleraceus (common s.), 282

Sorrel-Rumex Acetosa; mountain -Oxyria reniformis; sheep'sRumex Acetosella; wood-Oxalis Acetosella

Sowthistle-Sonchus spp.; alpine-Lactuca alpina

Sparganium natans (floating burreed), 238 ; ramosum (branched b.-r.), 242
Spearwort, greater, Ranunculus Lingua ; lesser-R. Flammula

Speedwell-Veronica spp.

Spergula arvensis (corn-spurrey), 298

Spergularia marina (sea-spurrey), 283 ; rupestris, 284, 285 ; salina, 279

Sphagnum (bog-moss), 246, 251. 253,255

Spikenard, ploughman's - Inula Conyza

Spindle-tree-Euonymus europaus

Spircea Filipendula (dropwort), 261 ; Ulmaria (meadow-sweet), 243 , $244,263,295$

Spiranthes autumnalis (lady's tresses), 261; Romanzoviana, 214

Spleenwort-Asplenium spp.

Spruce-Abies excelsa

Spurge-Euphorbia spp.; -laurelDaphne Laureola

Spurrey, corn-Spergula arvensis; sea-Spergularia spp.

Squinancy-wort-Asperula cynanchica

Stachys arvensis (field-betony), 216. 298 ; palustris (marsh-woundwort), 243

Star-fruit-Damasonium stellatum

Starwort-Stellaria spp.; seaAster Tripolium; water-Callitriche aquatica

Statice auriculcefolia, 284, 285 ; Limonium (sea-lavender), 279

Stellaria graminea (lesser stitchwort or starwort), 295, 296; Holostea (greater s.), 270, 295; media (chickweed), 295, 298; uliginosa (bog-s.) , 245, 247, 289

Stock-Matthiola incana

Stonecrop-Sedum spp.

Stonewort-Chara

Stork's-bill-Erodium cicutarium

Strawberry-Fragaria vesca; barren -Potentilla Fragariastrum ; -tree - Arbutus Unedo

Sueda maritima (sea-blite), 279

Subularia aquatica (awlwort), 238

Sundew-Drosera spp.

Sweet-chestnut-Castanea vesca; cicely-Myrrhis odorata; galeMyrica Gale; sedge-Acorus Ca. lamus

Sycamore-Acer Pseudo-platanus Symphytum officinale (comfrey), 243, 295 
Tamus communis (black bryony), 214,293

Taraxacum officinale (dandelion), 264,289

Tassel-pond weed-Ruppia maritima

Taxus baccata (yew), 272, 273

Teazle-Dipsccus sylvestris

Teucrium Scorodonia (wood-sage), $251,271,283,296$

'Ihale-cress - Sisymbrium Thalianum

Thalictrum alpinum, 288; favrum (meadow-rue), 243; minus var. calcareum, 290

Thesium humifusum (bastard toadflax), 258, 261

Thistle-Carduus spp; carlineCarlina vulgaris; sow-Sonchus spp. ; star-Centaurea Calcitrapa

Thlaspi alpestre, 288, 290; arvense (penny-cress), 216

Thorn, black- -Prunus spinosa; buck- - Rhamnus spp.; haw-, or whito-Cratcegus Oxyacantha; sea buck- - Hippophaë rhamnoides

Thrift-Armeria maritima

Thyme, basil-Calamintha Acinos; wild-Thymus Serpyllum

Thymus Serpyllum (wild thymo), $251,257,259,282,285,289,291$, 296

Tilia spp., 270 ; europcea (lime-tree), 268,293

Toadflax-Linaria spp.; bastardThesium humifusum

Tofeldia palustris (Scotch asphodel), 255

Toothwort-Lathroea squamaria

Tormentil-Potentilla Tormentilla

Touch-me-not-Impatiens Noli-metangere

Tragapogon pratensis (goat's-beard), 263

Traveller's joy-Clematis Vitalba

Trichomanes radicans (Killarney fern), 214

Treacle-mustard-Erysimum cheiranthoides

Tree-mallow-Lavatera arborea

Trefoil-Trifolium spp.; bird's-foot -Lotus corniculatus

Trientalis europoea (chickweed winter-green), 255, 274

Trifolium spp. (clover), 263, 295; arvense (hare's-foot trefoil), 283 ; dubium (small yellow t.), 259; pratense (clover), 298; procum- bens (hop t.), 298 ; repens (Dutch c.), 259,298

Triglochin maritimum (sea arrowgrass), 278, 279; pa'lustre (marsh a.), 242,245

Triodia decumbens (heath-grass), 258 Triticum repens (couch-grass), 295

Tussilaga Farfara (coltsfoot), 289

Twayblade-Listera spp.

T'ypha latifolia (bulrugh, reed-mace), 242

Ulex europous (furze, gorse, or whin), $250,252,259,270,271,283,285$, 293 ; minor (dwarf gorse), 214

Ulmus spp. (elm), 268, 270, 293; montana (wych-elm), 272

Urtica dioica (nettle), 216, 295 ; urens, 216

Utricularia spp. (bladderwort), 237

Vaccinium Myrtillus (bilberry, whortleberry), 250, 251, 255, $259,271,274,289$; Охусоссив (cranberry), 247, 251, 253, 254; uliginosum (mountain blaeberry), 251 ; Vitis-idaea (cowberry), 251

Valerian-Valeriana spp.; redCentranthus ruber

Valeriana dioica (marsh-valerian), 244,245 ; officinalis (common v.), 243

Valerianella olitoria (lamb's-lettuce, corn-salad), 291, 298 .

Venus' looking - glass - Campanula hybrida

Verbascum nigrum (mullein), 261 ; Thapsus, 261

Verbena officinalis (vervain), 216

Veronica agrestis (field-speedwell), 216, 291 ; alpina (alpine s.), 288; Anagallis (water-s.), 243 ; arvensis (wall-s.), 216, 291; Beccabunga (brook-lime), 243 ; Chamodrys (germander-s.), 274, 295; fruticans (blue rock-s.), 287; officinalis (common 8.), 251, 260, 295, 296; seutellata (marsh-s.). 243 ; serpyllifolia (thyme-leaved s.), 289,291

Vetch-Vicia spp.; norse-shoeHippocrepis comosa; kidneyAnthyllis Vulneraria; milk-, alpine-Astragalus alpinus

Viburnum Lantana (wayfaring-treo), $214,244,269,272,273,293$; Opulus (guelder-rose), 244,270,271 
Dicia Cracea (tufted vetch), 293 ; sativa (common v.), 216 ; sepium (bush-v.), 293

Viola cunina (dog-violet), 270; hirta (hairy v.), 259, 260; lutea (mountain จ.), 289; odorata (sweet จ.), 295 ; palustris (marshv.), 245, 253, 289; Riviniana (dog v.), 289 ; sylvatica (wood-v.), $273,295,296$

Violet-Viola spp.; water-Hottonia palustris

Viper's-bugloss-Echium vulgare

Viscum album (mistletoe), 214

Wallflower-Cheiranthus cheiri

Wall-rue-Asplenium Ruta-muraria Water-blinks - Montia fontana ; -cress-Nasturtium spp.; -crowfoot-Ranunculus spp.; -doclsRumex Hydrolapathum ; -dropwort-G Enanthe fistulosa; -fennel -OE. Phellandrium ; -lily, whiteNymphoea alba, yellow-Nuphar luteum ; -milfoil-Myriophyllum spp.; -parsnip - Sium spp.; - pepper-Polygonum Hydropiper; - plantain - Alisma Plantago; -purslane - Peplis Portula; -speedwell-Veronica Anagallis; -starwort-Callitriche aquatica; - violet-Hottonia palustris

Wayfaring-tree-Viburnum Lantana
Whin-Ulex europceus

Whitebeam-Pyrus Aria

Whitethorn-Cratcegies Oxyacantha

Whitlow-grass - Lraba verna

Whortleberry-Vaccinium Myrtillus

Willow-Salix spp.; -herb-Epilo. bium spp.

Windflower-Anemone nemorosa

Winter-green-Pyrola spp.; chickweed - Trientalis europcea

Woodbine-Lonicera Periclymenum

Wondruff, sweet-Asperula odorata

Wood-rush-Luzula spp.; -sageTeucrium Scorodonia; -sorrelOxalis Acetosella

Wormwood-Arlemisia spp.

Woundwort--Stachys spp.

Wrack, bladder-Fucus vesiculosus ; grass-Zostera marina

Yarrow-Achillea Millefolium

Yellow archangel-Lamium Galeob. dolon; bird's-nest - Monotropa Hypopitys ; loosestrife-Lysimachia vulgaris; rattle-Rhinanthus Crista-galli; water-lily-Nuphar luteum; wort-Chlora perfoliata Yew-Taxus baccata

Zannichellia palustris (horned pondweed), 237; pedunculata, 276

Zostera marina (grass-wrack), 276 , 278 ; nana, 276 

PRINTED IN GREAT BLITAIN BF

BILLING AND SONS, LIBITED, GUILIFORD AND JSHLR 


\section{A SELECTION FROM MESSRS. METHUEN'S PUBLICATIONS}

This Catalogue contains only a selection of the more important books published by Messrs. Methuen. A complete catalogue of their publications may be obtained on application.

Bain (R. W.)-

A Digit of The Moon: A Hindoo Love Story. The Descent of THE SUN: A Cycle of Birth. A HeIfer or THE DAwn. in THE Great God's Hair. A Draught OF THE BLUE. AN ESSENCE OF THE DUSK. An Incarnation of the Snow. A Mune of Faults. The Ashes of a God. BUbBles OF THE FoAM. A SYRUP OF THE Bees. The Livery of Eve. Thr SubSTANCE OF A DREam. All Fcap. 8vo. $5 s$. net. AN Echo OF THE SPHERES. Wide Demy. 125. 6d. net.

Balfour (Graham) 'THE' LIFE OF ROBERT LOUIS STEVENSON. Fifteenth Edition. Ith one Volume. Cr. S20. Buckram, 7s. 6d. met.

Belloc (B.)-

Paris, 8s. 6d. net. Hills and The Sea, 6s. net. ON NOTHING AND KINDReD SUBJECTs, 6s. net. ON EVERYThing, 6s. net. ON SOMETHING, 6s. net. FIRST AND LAST, 6s. net. This and That and THE OTHER, 6 s. net. Marie Antoinet te, i8s. net. The PyreNEES, ros. $6 d$. net.

Bloemiontein (Bishop of. ARA CCELI : an Essay in Mystical Theology. Secunth Edition. Cr. 8zo. 5s. net.

FAITH AND EXPERIENCE. Third Edition. Cr. 800. 5s. net.

THE CULT OF THE PASSING MOMENT. Fourth Edition. C\%. 800 . $5 . s$ met.

THE FNGLISH CHURCH AND RE. UNION. Cr. 8שo. 5s. met.

SCALA MUNDI. Cr. 8zo. 4s.6d. net.

\section{Ohesterton (G. K.)-}

The Ballad of the White Horse. All Things Comsidered. Tremendous Trifles. Alarms and Discursions. A Miscellany of Men. All facas, 8vo. 6s. ret. WINE, WATER, AND SoNG. Fcap. 8vo. ss. $6 d$ net.

Clutton-Brook (A.). WHAT IS THE KINGDOM OF HEAVEN? Fourth Edition. $F_{c a p}$. 800. 5s. net.

ESSAYS ON ART. Second Edition. Fcap. 800. 5s. net.

Gole (G. D. H.). SOCIAL THEORY. Cr. 8vo. 5s. Het.

Conrad (Joseph). THE MIRROR OF THE SEA: Memories and Impressions. Fourth Edition. Fcap. 8vo. 6s. net.
Binstein (A.), RELATIVITY : THE SPECIAL AND THE GENERAL THEORY. Translated by RoBerT $W$. LAwsun. Cr. 820. 5s. net.

Fyleman (Rose.). FAIRIES AND CHIMNEYS. Fcap. 8vo. Sixth Eitition. 35. 6d. net.

THE FAIRY GREEN. Third Edition. Fcap. 8vo. 3s. 6d. net.

Glbbins (H, de B.). INDUSTRY IN ENGLAND: HISTORICAL OUT. LINES. With Maps and Plans. Tenth Edition. Demy 8vo. 12s. 6d. net.

THE I N DUSTR I AL HISTORY OF ENGLAND. With 5 Maps and a Plan. Tuenty-sevesth Edition. Cr. 8vo. 5.5 .

Glbbon (Rdyard). THE DECLINE AND FALL OF THE ROMAN EMPIRE Edited, with Notes, Appendices, and Maps, by J. B. Bury. Illustrated. Seven Volumes. Demy Bzo. Illustrated. Each 12s. 6d. net. Also in Saven Volumes. Cr. 8vo. Each 75. 6r. net.

Glozer (T. R.). THE CONFLICT OH RELIGIONS IN THE EARLY ROMAN EMPIRE. Eighth Edition. Deny 8vo. Ios. $6 d$. net.

POETS AND PURITANS. Second Edition. Demy 800. IOs. 6d. net.

FROM PERICLES TO PHILIP. Third Edicion. Deny 8vo, ros. 6d. net.

VIRGIL. Fourth Edition. Demy 800. 10s. $6 d$. net.

THE CHRISTIAN TRADITION AND ITS VERIFICATION. (The Angus Lecture for 19I2.) Second Edition Cr. 8vo. 6.5. net.

Grahame (Kenneth), THE WIND IN THE WILLOWS. Terth Edition. Cr. 8vo. 75. 6d. net.

Hall (H. R.). THE ANCIENT HISTORY OF THE NEAR EAST FROM THE EARLIEST' TIMES TO THE BATTLE OF SALAMIS. Illustrated. Fourth Edition. Demy 80o. I6s. net.

Hobson (J. A.). INTERNATIONAL TRADE: AN APPLICATION OF ECONOMIC THEORY. Cr. 8vo. 5s. net.

PROBLEMS OF POVERTY: AN INOUIRY into THE INDUSTRIAL Condition OF THE Poor. Eighth Edition. Cr. 800 . 5s. net.

THE PROBLEM OF THE UN. EMPLOYED: AN INQUIRY AND AN Economic Policy. Sizth Edition. Cr. 8vo. 5s. net. 
Tlleaton (Mary W.). DAILY STRENGTH FOR DAILY NEEDS. Twenty-sixth Edition. Medium r6mo. 3s. 6d. net.

Underhill (Evelyn). MYSTICISM. A Study in the Nature and Development of Man's Spiritual Consciousness. Eighth Edition. Demy 8vo. r5s. net.

Yardon (Harry), HOW TO PLAY GOLF. Illustrated. Thirteenth Edition. Cr. 8zo. 5s, net.

Waterhouse (Elizabeth), A LITTLE BOOK OF LIFE AND DEATH. Twentieth Editions Small Pott 8vo. Cloth, 2s. 6d. net.

Wells (J.). A SHORT HISTORY OF ROME. Seventeenth Edition. With 3 Maps. Cr. 8vo. $6 s$.

Wilde (0eoar). THE WORKS OF OSCAR WILDE. Fcap. 8vo. Each 6s. 6d. net.

I. Lord Arthur Savile's Crime and THE Portrait of Mr. W. H. II. The Duchess of Padua. III. Pozms, iv. LADY WINDERMERE'S FAN. v. A WOMAN OF No IMPORTANCE. vI. AN IDEAL HUS-
Band. VII. The Importance of Being EARnest. vili. A House OF POMEgranates. IX. InTENTIONS. $x$. DE ProFUNDIS AND PRISON LETTERS. XI. ESSAYS. xiI. Salomé, a Florentine Tragedy, and LA Sainte Courtisane. xili. A Critic in Pall Mall. xiv. Selected Prose of Oscar Wilde. XV. ART and DeCORATION.

A HOUSE OF POMEGRANATES. Illustrated. Cr. 4 to. 21s. met.

Wood (Lleut. W. B. ) and Edmonds (Gol. J. E.) A HISTORY OF THE CIVIL WAR IN THE UNITED STATES $\left(186 \mathrm{r}-6_{5}\right)$. With an Introduction by SPENSER Wilkrinson. With 24 Maps and Plans. Third Edition. Demy 8vo. I 5s. net.

Wordsworth (W.). POEMS. With an Introduction and Notes by Nowell C. Smith. Three Volumes. Demy 8vo. 18s. net.

Yeats (W. B.). A BOOK OF IRISH VERSE. Fourth Edition. Cr. 8vo. 7s. net.

\title{
Part II.-A Selection of Series
}

\section{Ancient Cities}

\author{
General Editor, SIR B. C. A. WINDLE
}

Cr. 8vo. 6s. net each volume

With Illustrations by E. H. New, and other Artists

Bristol, Canterbury. Chester. Dub-| Eminburgh. Lincoln. Shrewseury. LIN.

\section{The Antiquary's Books}

\section{General Editor, J. CHARLES COX \\ Demy 8zo. Ios. 6d. net each volume \\ With Numerous Illustrations}

ancient Painted Glass in England. ARCh mology and False antiguities. The Bells of England. The Brasses of England. The Castles and Walled Towns of England. Celtic art in Pagan and Christian Times. ChurchWARDENS' ACCOUNTS. THE DOMESDAY Inouest, English Church Furniture. English Costume. English Monastic Life. English Seals. Folk-Lore as an Historical Science. The Gilds and Companies of LoNDON. The Hermits AND ANCHORITES OF ENGLAND. THE
Manor and Manorial Rrcords. The MEDIEYAL Hospitals of ENGLAND. Old English Instruments of Music. Old English Librarias. Old Service Books of the English Church. Parish Life in Medifval England. The Parish Registers of ENGland. REMAINS OF THE PREHISTORIC AGE IN ENGland. The Roman ERa in Britain. Romano-British Buildings and EarthwORKS. THE ROYAL Forests of ENGLand. The Schools of Medieval ENGLand. Shrintes of British Saints. 


\section{Messrs. Methuen's Publications}

\section{The Arden Shakespeare}

General Editor, R. H. CASE

Denty 8vo. 6s. net each volume

An edition of Shakespeare in Single Plays; each edited with a full Introduction,

Textual Notes, and a Commentary at the foot of the page.

\section{Classics of Art}

Edited by DR. J. H. W. LAING

With numerous Illustrations. Wide Royal 8vo

Thr ART of The Grieks, I5s. net. The ART of the Romans, i6s. net. CHaRdin, 15s. net. Donatello, I6s, net. GeorGe ROMNEY, I5s. net. GHIRLANDA10, I5s, net. LAWrEncE, 25s. net. MichelangeLo, Iss. net. RapHaEL, I5s. net. REMBRandT's ETChINGs, Two Vols., 25s, net. TintorETTO, I6s. net. Titian, r6s. net. TURNER's Sketches and Drawings, 15 . net. VELAZQUEZ, I5s. net.

\section{The 'Complete' Series \\ Fully Illustrated. Demy 8vo}

The Complete Amateur Boxer, ios. $6 d$. net. The Complete Association FootBALler, 1os. 6d. net. ThE COMPLETE Athletic Trainer, ras. $6 d$. net. The Complate Billiard Player, izs. $6 d$. net. The Complete Cook, ios. 6d. net. The Complate Cricketer, ios. $6 d$. net. The Complete Foxhonter, r6s, net. The COMPLETE Golfer, 12s. 6d. net. The Complete Hocket-Player, ios. $6 d$. net. The Complete Horseman, izs. $6 d$. net. The CoMplete Jujrisoan, 5s. net. The Complete Lawn Tennis Player, 12s. 6d. net. The CoMplete Motorist, Ios. $6 d$. net. The Complete MountaineER, I6s. net. The Complete OARsman, I5s. net. The Complete Photographer, 15. net. The CoMplete RUGBY Foot: BALlER, ON THE NEW ZEALAND SYSTEM, I2s. 6d. net. The Complete Shot, i6s. net. ThE COMPLETE SWIMMER, Ios, 6d. net. The Complets Y YchTSMan, r6s. net.

\section{The Connoisseur's Library}

With numerous Illustrations. Wide Royal 8vo. 25s. net each volume

English Colourkd Books. English FurNitUre. ETChings. European Enamels. Fine Books. Glass. Goldsmiths' and SILVERSMITHS' WORK. IllUMYNATED

MANUSCRIPTS. IVORIES. JEWELLERY. Mezzotints. Miniatures. Porcelark. Seals. WoOd Sculfture.

\section{Handbooks of Theology Demy 8vo}

The Doctrine of the InCARNation, I5s. net. A History of EARLY Christian DOCTRINE, I6s. net. INTRODUCTION TO THE History of RELIGION, 12s. $6 d$. net. AN INTRODUCTION TO THE History OF the Criends, 12s. 6d. net. The Philosophy of Religion in England and America, I2s. 6d. net. THE XXXIX ARTICLBs of THE CHURCh OF ENGLAND, I5s. net.

\section{Health Series}

Fcap. 8vo.

The Baby. The Care of the Body. The Care of the Teeth. The Eyes of OUR Children. Health for the MiddleAgrd. The Health of a Woman. The Health of the Skin. How to Live

\section{2s. $6 d$. net}

Long. The Prevention of the Common Cold. Staying the Plague. Throat and Ear Troubles. Tuberculosis. The Health of THe Child, 2s. net. 


\section{Leaders of Religion}

Edited by H. C. BEECHING. With Portraits

Crown 8vo. 3s. net each volume

\section{The Library of Dexotion}

Handy Editions of the great Devotional Books, well edited.

With Introductions and (where necessary) Notes

Small Pott 8vo, cloth, 3s. net and $3^{5.6}$. . net

\section{Little Books on Art}

\section{With many Illustrations. Demy I6mo. 5s. net each volume}

Each volume consists of about 200 pages, and contains from 30 to 40 Illustrations, including a Frontispiece in Photogravure

Albrecht DÚRer. The ARts of Japan.

Bookplates. BotTicelli. Burne-Jonks.

Cellini. Christian Symbolism. Christ
in Art. Claude. Constable. Corot.

Earty English Water-Colour. ENa-

mels. Frederic Leighton. George

RoMrey, GreEk ARt. GReuze AND

BOUCHER. HOLBEIN. ILLUMINATED MANuSCRIPTS. JEWELlery. JOHN HOPP* NeR. Sir Joshua Reynolds. Millet. Miniatures. Our Lady in ARt. Raphael. Rodin. TuRngr. Vandyck. Velazodrz. WATTS.

\section{The Little Guides}

With many Illustrations by E. H. New and other artists, and from photographs Small Pott 8vo. 4s. net and 6s. net

Guides to the English and Welsh Counties, and some well-known districts

The main features of these Guides are (I) a handy and charming form ; (2) illustrations from photographs and by well-known artists; (3) good plans and maps ; (4) an adequate but compact presentation of everything that is interesting in the natural features, history, archæology, and architecture of the town or district treated.

\section{The Little Quarto Shakespeare}

Edited by W. J. CRAIG. With Introductions and Notes Pott 16 mo. 40 Volumes. Leather, price Is. 9d. net each volume Cloth, is. $6 d$.

\section{Nine Plays}

\section{Fcap. 8vo. 35. 6d. net}

Across ThE Border. Beulah Marie Dix. Cr. 8 vo.

Honzymoon, The. A Comedy in Three Acts. Arnold Bennett. Third Edition.

Great Adventure, The. A Play of Fancy in Four Acts. Arnold Bennett. Fifth Edition. Milestones. Arnold Bennett and Edward Knoblock. Ninth Edition.

Ideal Husband, AN. Oscar Wilde. Acting Edition.

Kismet. Edward Knoblock. Fourth Edztion.

Typroon. A Play in Four Acts. Melchior Lengyel. English Version by Laurence Irving. Second Edition.

Ware Case, Thr. George Pleydell.

Gengral Post. J. E. Harold Terry. Second Edition. 


\section{Messrs. Methuen's Publications}

\section{Sports Series}

Illustrated. Fiap. 8v0. 2s. net and 3s. net

All About Flying, 3s. net. Golf Do's and Don T's. The Golming Swing. How to Swim. Lawn Tennis, 3s. net. Skat.

ING, 3s. net. Cross-Country SkI-ING, gs. net. WRestling, 2s. net. Quick CuTs To GOOD GOLF, 2s. 6d, net.

\section{The Westminster Commentaries}

\section{General Editor, WALTER LOCK}

\section{Demy 8vo}

ThE ACTS of THz Apostles, r6s. net. Amos, 8s. 6d. net. I. Corintrians, 8s. 6d. ret. EXodus, I5s. net. EzEKIEL, r2s. 6d. net. GEN ESIs, 16s. net, HEBREw's, 8s. 6d. net. IsAiah, i6s, net. Jeremiah,

I6s. net. JoB, 8s. 6d. net. The PAstoral Eipistles, $8 s .6 d$. net. The Philippians, 8s. 6d. net. ST. JAMES, 8s. 6d. thet. ST, MatThew, I5s, net.

\section{Methuen's Two-Shilling Library}

Cheap Editions of many Popular Books Fcap. 8 8vo

\section{Part III.-A Selection of Works of Fiction}

\section{Bennett (Arnold)-}

Clayhanger, 8s. net. Hilda Lessways, 8s. 6d. net. These Twain. The Card. THE Regent: A Five Towns Story of Adventure in London. THE PrICE oF Love. BurIed Alive. A MAN FroM THE NoRTH. THE MATADOR OF THE FrVE Towns. WhOM GoD hath JoINed. A Great MaN: A Frolic. All $7 s$. $6 d$. net.

\section{Birmingham (George A.)-}

Spanistr Gold. The Search Party. Ialage's Lovers. The Bad Times. UP, THE REBELS. All 7s. $6 d$, nat.

\section{Burroughs (Edgar Rice)-}

Tarzan of the Apes, 6s. net. The Return of Tarzan, 6s. net. The Beasts of TARzan, 6s. net. The Son of Tarzan, 6s. net. Jungle Tales of Tarzan, 6s. met. TARzan and THE JEWELS OF OPAR, 6s. net. 'TARZAN THE UNTAMED, 7s. 6d, net. A Princess of Mars, 6s. net. The Gods OF MARS, 6s, net. THE WARLORD OF Mars, 6s. net.

Conrad (Joseph). A SET OF SIX. Fourth Edition. Cr. 8vo. 7s. 6d. net.

VICTORY: AN IsLand Tale. Sixth Edition. Cr. Bvo. gs. net.

\section{Corelll (Marib)-}

A Romance of Two Worlds, 7s, $6 d$, net. VendetTa: or, The Story of Ore Forgotten, 8s. net. Thelma: A Norvegian Princess, $8 s .6 d$. net. A of a Dead Self, $7 s$, 6d. net. THE Soul or LiliTH, 7s, 6d. net. WoRmwood : A Drama of Paris, 8s. net. BarabBas: A Dream of the World's Tragedy, 8s. net. THE Sorrows or Satan, 7s. 6d. net. The MasterChristian, 8s. 6d. net. Temporal Power: A Study in Supremacy, 6s, net. God's GOOD Man : A Simple Love Story, 8s. 6d. net. HOLY ORDERs: The Tragedy of a Quiet Life, 8s. 6d. net. The Mighry AToM, 7s. 6d. net. Boy: A Sketch, 7s. 6d. net. Cameos, Gs. net. ThE LIFE EverLastiNG, 8s. $6 d$. net.

Doyle (Sir A. Conan). ROUND THE RED LAMP. Twelfih Edition. Cr. 8vo. 7s. 6d. net.

\section{Hichens (Robert)-}

Tongues of Conscrence, 7s. 6d. net. FELIX : Three Years in a Life, 7s. 6d. net. ThE WOMAN WITH The Fan, $\eta^{s}$. $6 d$. net. Bveways, 7s. 6d. net. The GaRDeN of Allah, 8s, 6d. net. The CALL of the Blood, 8s. 6d. net. Barbary Sheep, 6s. net. THE DWELlers ON THE THRESHOLD, 75. 6d. net. THE WAY of AMBITION, 7s. 6d. net. IN THE WILDERNESS, 7s. 6d. net. 


\section{Hope (Anthong)-}

A Change of Air. A Man of Mark The Chronicles of Count Antonio. Simon Dale. THE King's MirRor Ouisante. The Dolly Dialogues. Tales of Two People. A Servant of the Public. Mrs. Maxon Protests. A Young Man's Year. Beaumaror HOME FROM THE WARS. All 7s. 6d. net.

Jacobs (W. W.)

Many Cargoes, 5s. net and 2s. 6d. met. SEA URCHINS, $5 s$. net and $3 s$. $6 d$. net. A Master of CRAFT, 5s, net. Light Freights, 5s. met. The SkipPer's WoOING, 5s. net. AT SuNwich PORT, 5s. net. Dialstone Lane, 5s. net. OdD Craft 5s. net. The Lady of The Barge, 5s, net. Salthaven, 5s, net. Sallors' KNots, 5s. net. SHORT CruISES, 5s. net.

London (Jack), WHITE FANG. Ninth Edition. Cr. 8zo. 7s, 6d. net.

\section{MoKenna (Stephen)-}

SonIA : Between Two Worids, 8s, net. Ninety-Six Hours' Leave, 7s. 6d. net. The Sixth Sense, 6s. met. Midas \& Son, 8s. net.

\section{Malet (Lucas)-}

The Histogy of Sir Richard Calmady: A Romance. The Wages of Sin. ThE Carissima, The Gateless Barrier. DEADHAM HARD. All $7 s .6 d$. net.

Mason (A. E. W.). CLEMENTINA. Illustrated. Ninth Edition. Cr. 800. 75. $6 d$. net.

\section{Maxwell (W. B.) -}

Vivien. The Guarded Flame. OdD lengths, Hill Rise. The Rest Cure. All 7s. 6d. net.

\section{Oxenham (John)-}

A Weayer of Webs. Profit and Loss. The Song of Hyacinth, and Other Stories. Lauristons. The CoIl of Carne. The Quest of The Golden Rose. Mary All-Alone. Broken Shackles. "1914." All 75. 6d. net.

\section{Parker (Gilbert)-}

Pierre anc hie Phople. Mrs. Falchion. The Translation of a Savage. When Valmond came to Pontiac: The Story of a Lost Napoleon. AN ADventurer of THE North: The Last Adventures of "Pretty Pierre.' The Seats of the Mighty. The Battle of the Strong: A Romance of Twe Kingdoms. THE PoMp of THE LAVILETTES. NORTHERN Lights. $A 2$ 75. 6d. net.

\section{Phillpotts (Rden)-}

ChILDREN OF THE Mist. Sons of THE Morning. The River. The AMerican Prisoner. Demeter's Daughter. 'The Human Boy aND THE WAR. $A l l{ }_{7} s, 6 d$. net.

\section{Ridge (W. Pett)-}

A SoN of the State, 75. 6d. net. The ReMINGTON SENTRNCE, 7s. 6d. net. Madame Prince, 7s. 6d. net. Top SpeEd, 7s. $6 d$. net. Special Performances, $6 s$. net. The Bustling Hours, 7s, 6d. net.

\section{Rohmer (Sax)-}

The Devil Doctor. The St-Fan. MYsteries. Tales of Secret EgYPT. The Orchard of Tears. The Golden SCORPION. All 7s. 6d. net.

Bwinnerton (E.). SHOPS AND HOUSES. Third Edition. Cr. 8vo. 7s.6d. net.

SEPTEMBER. Third Edition. Cr, 800. 75. 6d. net.

Wells (H. G.). BEALBY. Fourth Edition. Cr. 8vo. 75. 6.t. net.

Williamson (C. N. and R. M.) -

The Lightning Conductor: The Strange Adventures of a Motor Car. LADY BETTY ACROSS THE WATER. SCARLET RUNNER. LORD LOVELAND DISCOVERS AMERICA. The Guests of Hercules. It Happened IN EgYPT. A Soldier of THE LEgION. The Shop Girl. The Lightning ConDUCTRRSS. Secret History. The Love Pirate. $A l l$ 7s. 6d. net. Crucifix Corner. 6s. net.

\section{Methuen's Two-Shilling Noyels}

Cheap Editions of many of the most Popular Novels of the day Write for Complete List 



